\title{
Arctic climate change and decadal variability
}

\author{
Eveline C. van der Linden
}




\section{Thesis committee}

\section{Promotor}

Prof. Dr W. Hazeleger

Professor of Climate Dynamics

Wageningen University

\section{Co-promotor}

Dr R. Bintanja

Senior scientist

Royal Netherlands Meteorological Institute (KNMI), De Bilt

\section{Other members}

Prof. Dr R. Caballero, Stockholm University, Sweden

Dr A. S. von der Heydt, Utrecht University

Prof. Dr H. Renssen, University College of Southeast Norway, Bø, Norway

Prof. Dr A. H. Weerts, Wageningen University

This research was conducted under the auspices of the Graduate School for Socio-Economic and Natural Sciences of the Environment (SENSE). 


\title{
Arctic climate change and decadal variability
}

\author{
Eveline C. van der Linden
}

Thesis

submitted in fulfilment of the requirements for the degree of doctor at Wageningen University by the authority of the Rector Magnificus

Prof. Dr A. P. J. Mol, in the presence of the Thesis Committee appointed by the Academic Board to be defended in public on Wednesday 21 December 2016 at 1:30 p.m. in the Aula. 
Eveline C. van der Linden

Arctic climate change and decadal variability, $x x+200$ pages.

$\mathrm{PhD}$ thesis, Wageningen University, Wageningen, NL (2016)

With references, with summaries in Dutch and English

ISBN: 978-94-6257-945-3

DOI: $10.18174 / 391406$ 
"As if some little Arctic flower, Upon the polar hem, Went wandering down the latitudes, Until it puzzled came To continents of summer, To firmaments of sun, To strange, bright crowds of flowers, And birds of foreign tongue! I say, as if this little flower To Eden wandered in What then? Why, nothing, Only, your inference therefrom!"

Emily Dickinson 



\section{Contents}

Summary $\quad$ xi

Samenvatting $\quad$ Xv

1 General introduction 1

1.1 Current changes in the Arctic . . . . . . . . . . . 1

1.1 .1 Arctic amplification .............. 1

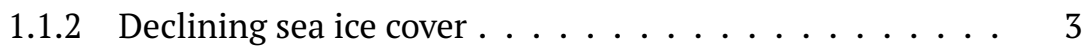

1.1.3 Environmental impacts ............. 4

1.2 The Arctic climate system . . . . . . . . . . . . 6

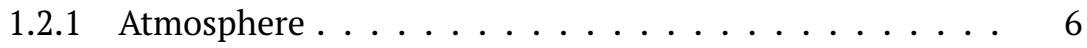

1.2 .2 Ocean ....................... 9

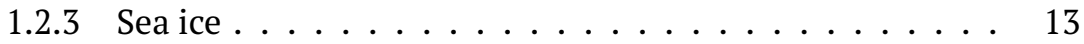

1.2.4 Feedback mechanisms .............. 16

1.3 Long-term climate variability and change . . . . . . . . . . . 19

1.3.1 Past: paleoclimates ............. 20

1.3.2 Present: the instrumental record . . . . . . . . 23

1.3.3 Future: climate model projections . . . . . . . . 27

1.4 Aims and outline .................. 30

2 The role of the mean state of Arctic sea ice on near-surface tempe$\begin{array}{ll}\text { rature trends } & 35\end{array}$

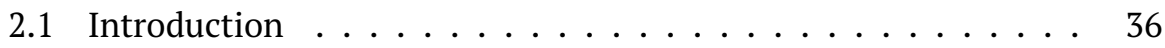

2.2 Data and methods . . . . . . . . . . . . . . . . 40

2.3 Temperature trends and control sea ice state . . . . . . . . 43 
2.3.1 Surface air temperature trends . . . . . . . . . . 43

2.3 .2 Sea ice control state . . . . . . . . . . . . . 47

2.4 Local sea ice-temperature response $\ldots \ldots \ldots \ldots \ldots$

2.4.1 Concentration-warming relation . . . . . . . . . 53

2.4.2 Thickness-warming relation . . . . . . . . . . . 59

2.5 Arctic mean sea ice-temperature response . . . . . . . . . . 61

2.5.1 Control climate volume and area . . . . . . . . . . 62

2.5.2 Trends in volume and area . . . . . . . . . . 63

2.6 Discussion and conclusions . . . . . . . . . . . . . 65

3 Oceanic heat transport towards the Arctic under high and low $\mathrm{CO}_{2}$ $\begin{array}{ll}\text { forcing } & 69\end{array}$

3.1 Introduction $\ldots \ldots \ldots \ldots \ldots \ldots \ldots \ldots \ldots \ldots$

3.2 Model and simulations . . . . . . . . . . . . . . . . 72

3.2 .1 Model description . . . . . . . . . . . . . 72

3.2 .2 Simulations . . . . . . . . . . . . . . . 73

3.3 Global characteristics . . . . . . . . . . . . . . 73

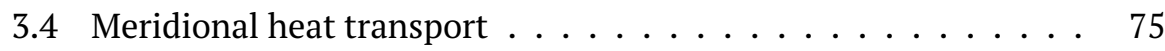

3.5 Atlantic ocean heat transport . . . . . . . . . . . 78

3.5.1 The Atlantic meridional overturning circulation $\ldots . .78$

3.5.2 The Atlantic subpolar gyre . . . . . . . . . . 81

3.5.3 The overturning and gyre ocean heat transport . . . . . . . 89

3.6 Summary and conclusions . . . . . . . . . . . . . . . . 93

4 Low-frequency variability of surface air temperature over the Ba$\begin{array}{ll}\text { rents Sea: causes and mechanisms } & 97\end{array}$

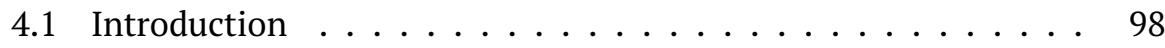

4.2 Data and methods . . . . . . . . . . . . . . 100

4.3 Barents Sea variability characteristics . . . . . . . . . . . . 102

4.4 Energy budget analysis of the Barents Sea . . . . . . . . . . . . 104

4.4 .1 Leads and lags . . . . . . . . . . . . . . . . 106

4.5 Seasonal cycle in variability . . . . . . . . . . . . . . . . . 109

4.6 Local characteristics . . . . . . . . . . . . . . . . 110

4.6.1 Surface energy balance . . . . . . . . . . . . . . . . . . . . . . 112

4.7 Summary and conclusions . . . . . . . . . . . . . . . . . . 119 
5 Arctic decadal variability in a warming world 121

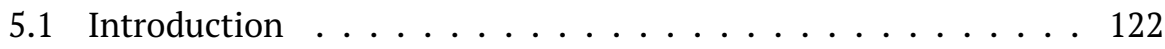

5.2 Model and simulations . . . . . . . . . . . . . . . 124

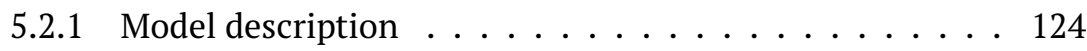

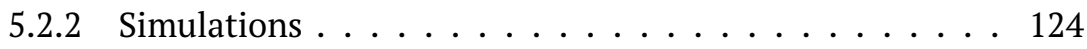

5.3 Temperature and sea ice . . . . . . . . . . . . . . . . 125

5.3 .1 Mean state . . . . . . . . . . . . 125

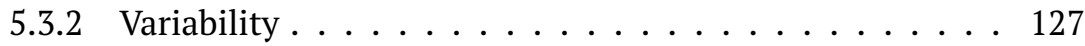

5.4 Changes in the atmospheric circulation . . . . . . . . . . 134

5.4 .1 Mean state . . . . . . . . . . . . . . . . 134

5.4 .2 Leading modes ................. 136

5.5 Patterns of temperature variability and heat transports . . . . 141

5.5 .1 Winter patterns ...................... 142

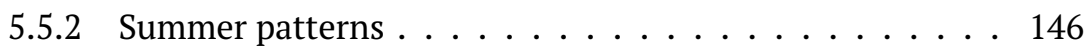

5.5 .3 Seasonal cycle ................ . . 147

5.6 Summary and conclusions . . . . . . . . . . . . 148

6 Synthesis and outlook 153

6.1 Overview of the present research . . . . . . . . . . . 153

6.2 Changes in the Arctic mean climate state . . . . . . . . . . . 154

6.3 Low-frequency Arctic climate variability . . . . . . . . . . . 158

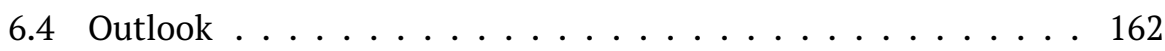

$\begin{array}{ll}\text { Bibliography } & 169\end{array}$

$\begin{array}{lr}\text { Dankwoord } & 191\end{array}$

$\begin{array}{ll}\text { About the author } & 193\end{array}$

$\begin{array}{ll}\text { List of journal publications } & 195\end{array}$

$\begin{array}{lr}\text { Graduate school certificate } & 197\end{array}$ 



\section{Summary}

The Arctic is one of the most barren regions on Earth. At first sight it may seem as if nothing ever changes in its frozen landscape. Climate change, however, proceeds much faster in this part of the world than anywhere else on the planet. Over the last thirty years the temperature in the North Polar region has increased by about $2^{\circ} \mathrm{C}$. This is about three times as large as the worldwide average rise in temperature. Arctic warming goes hand in hand with a strong retreat in sea ice extent, and also with thinning of the sea ice cover. The Arctic will likely become ice-free in late summer before the end of the century.

The amplified warming in high northern latitudes is also evident by the large-scale melting of glaciers, thawing of permafrost, and an increase in precipitation. The impact of these Arctic changes is visible through the subsidence of buildings and roads, coastal erosion and endangered wildlife. But also outside the Arctic the impacts do not pass unnoticed. Meltwater from the Greenland ice sheet and glaciers contributes to global sea level rise. Also, the salinity of the Arctic Ocean decreases through the additional meltwater runoff and precipitation, thereby potentially affecting global ocean currents. Arctic warming being larger than that in lower latitudes impacts the atmospheric circulation, as weather patterns depend strongly on the temperature gradient between high and low latitudes. In the midlatitudes, where the majority of the world population lives, these changes could lead to more extreme weather, such as heat and cold waves, droughts, and floods. Climate change in the North Polar region is thus also relevant for the rest of the world. It is therefore crucial to understand the past and current Arctic changes, and to assess how the Arctic climate will develop in the future. 
This thesis deepens our understanding of the Arctic climate system by investigating the various relevant climate components and their mutual interactions. This is achieved by studying the physical mechanisms underlying climate changes, covering the respective roles of sea ice, ocean heat transport, and the large-scale atmospheric circulation. At the same time, it addresses both externally forced changes (by atmospheric $\mathrm{CO}_{2}$, aerosols, and solar insolation) including long-term trends as well as equilibrium climate states - and natural climate fluctuations on time scales of decades (decadal variability). Due to the remote location and prevailing extreme weather conditions in the Arctic there are not many in situ measurements available. Many processes in the Arctic climate system need therefore be addressed using global climate models, in particular when studying the future evolution of the climate system. Therefore, throughout this thesis the results are primarily based on simulations of global climate models, whereby climate changes are enforced by regulating the atmospheric $\mathrm{CO}_{2}$ level.

Although global climate models become more and more complex and simulate the climate system quite realistically, projections for the future climate diverge substantially among the various models. These intermodel differences peak in the high northern latitudes, pointing at large uncertainties in the simulated Arctic climate compared to that in other parts of the planet. Chapter 2 investigates the possible causes of this large spread between climate models. By studying the relation between sea ice and temperature trends at several spatial scales, it is found that especially the effect of sea ice on local variations in warming is important. This means that the pattern of the simulated increase in temperature is related to the spatial distribution of sea ice.

As stated before, the Arctic is more sensitive to climate change than other parts of the globe. This is due to a variety of positive feedback mechanisms that amplify small perturbations - either warm or cold - in the Arctic climate system. Besides these local processes within the Arctic, interactions with lower latitudes through the ocean and the atmosphere may also influence high-latitude warming. Chapter 3 focuses on the contribution of oceanic energy transports to the amplified warming in the North Polar region. Most model simulations show increasing heat transports toward the Arctic in a warming climate, but the underlying physical mechanisms are not yet understood. This chapter investigates in detail the governing mechanisms in the Atlantic Ocean using a series of five climate model sensitivity simulations, each with a length of five hundred and fifty years, in which the atmospheric $\mathrm{CO}_{2}$ concentration is abruptly set at one quarter to four times the current level. It is found that the increase in north- 
ward heat transport toward the Arctic in warmer climates is caused by a combination of higher temperatures of the ocean and an enhanced northward volume transport. The model results also demonstrate that sea ice plays a key role in the changing ocean transport by affecting the density of seawater as well as the stress that surface winds exert on the ocean surface.

The climate on Earth is always subject to changes, due to external forcings either human-induced or natural - or internal fluctuations within the system at a wide range of time scales. The main cause of the global average temperature rise over the past decades is undisputed, namely the amplification of the greenhouse effect by anthropogenic emission of $\mathrm{CO}_{2}$ and other greenhouse gases. However, internal decadal variability in the climate system has the potential to temporarily dampen or amplify long-term trends. This effect is not only dependent on time but is also location specific. It is especially relevant in the Arctic, where decadal variability currently exhibits a relatively large amplitude compared to other regions. Chapter 4 investigates the physical mechanisms related to Arctic decadal variability. The spatial pattern of temperature variability shows a maximum over the Barents Sea, where the current sea ice edge is located. The ocean plays a key role in the timing of the variability by transporting heat northward and by warming the atmosphere through infrared radiation and turbulent heat fluxes. Sea ice modulates the temperature changes, because it controls the interaction between the ocean and the atmosphere through its insulating properties and hence governs the location of maximum variability. Moreover, sea ice reinforces the variability through various feedback processes.

As the climate warms, and sea ice retreats or even disappears, this could affect the characteristics of decadal fluctuations in the Arctic. Chapter 5 therefore focuses on how decadal variability changes in a warming world. The climate model simulations clearly show that the amplitude of the variability in temperature increases when $\mathrm{CO}_{2}$ levels double compared to today, but decreases again when the climate continues to warm. The region in which decadal variability is maximum, currently over the Barents Sea, shifts northward to the central Arctic in warmer climates, along with the sea ice margin. Again, sea ice plays a major role through sea ice-related feedback processes. As the sea ice edge is located more northerly in warmer climates, the sea ice extent can more easily fluctuate because the surrounding continents can no longer limit the lateral expansion. The variability of the large-scale atmospheric circulation also changes in warmer climates. Its effect on decadal temperature variability also alters, which is partly related to the changes in sea ice. It is therefore vital to consider (changes in) decadal variability when addressing future Arctic climate change. 



\section{Samenvatting}

Het Noordpoolgebied is één van de meest onherbergzame plekken op aarde. Op het eerste gezicht lijkt het een totaal bevroren gebied waar nooit iets verandert. Klimaatverandering verloopt in deze regio echter veel sneller dan elders in de wereld. Over de afgelopen dertig jaar is de temperatuur in het Noordpoolgebied met ongeveer $2^{\circ} \mathrm{C}$ gestegen. Dat is een drie keer zo grote verandering vergeleken met de wereldgemiddelde temperatuurstijging over diezelfde periode. De opwarming gaat hand in hand met een sterke afname in zee-ijs, niet alleen qua oppervlakte maar het zee-ijs wordt ook steeds dunner. De kans is groot dat het zee-ijs in het Arctische gebied voor het eind van deze eeuw in de nazomer volledig zal verdwijnen.

De versterkte opwarming in het hoge noorden gaat naast de genoemde afname in zee-ijs ook gepaard met het afsmelten van gletsjers en ijskappen, het ontdooien van permafrost, en een toename in neerslag. De impact van deze veranderingen is al duidelijk merkbaar: verzakkingen van gebouwen en wegen, kusterosie, en met uitsterven bedreigde dier- en plantensoorten. Maar ook buiten het Arctisch gebied zijn de gevolgen van de opwarming voelbaar. De toename van smeltwater van de Groenlandse ijskap en andere gletsjers in het hoge noorden draagt bij aan zeespiegelstijging. Ook neemt het zoutgehalte van de Arctische Oceaan af, vanwege het extra smeltwater en de toegenomen neerslag, wat gevolgen kan hebben voor mondiale oceaanstromingen. Een Noordpoolgebied dat sneller opwarmt dan de tropen beïnvloedt bovendien de circulatie van de atmosfeer, waardoor weerspatronen zich zullen gaan aanpassen aan de veranderende temperatuurverschillen tussen hoge en lage breedtegraden. In gematigde breedten, waar het grootste deel van de wereldbevolking leeft, kan dit 
leiden tot extremer weer, zoals hitte- en koudegolven, droogte, en overstromingen. Arctische klimaatveranderingen zijn derhalve niet alleen relevant voor het gebied zelf, maar ook voor de rest van de wereld. Het is daarom cruciaal om de huidige veranderingen te begrijpen en om te bestuderen hoe het Noordpoolklimaat zich in de toekomst zal ontwikkelen.

Dit proefschrift vergroot ons inzicht in het Arctische klimaatsysteem door de verschillende componenten en hun onderlinge interacties te onderzoeken. Dit gebeurt door de fysische mechanismen achter klimaatveranderingen te bestuderen. Veranderingen in onder andere zee-ijs, de warmtetransporten in de oceaan, en de grootschalige atmosferische circulatie komen aan bod. Tegelijkertijd wordt gekeken naar extern geforceerde veranderingen (door $\mathrm{CO}_{2}$ in de atmosfeer, aerosolen en zonnestraling) - waarbij zowel langetermijntrends als evenwichtsklimaten aan bod komen - en naar natuurlijke klimaatschommelingen op tijdschalen van enkele tientallen jaren (decadale variabiliteit). Vanwege de afgelegen ligging en extreme weerscondities zijn er maar weinig metingen van het Noordpoolklimaat beschikbaar. Veel processen in het Arctische klimaatsysteem hebben we daarom bekeken met behulp van mondiale klimaatmodellen. Ook voor het bestuderen van veranderingen in het toekomstige klimaat zijn modelsimulaties onmisbaar. De resultaten in dit proefschrift zijn daarom voornamelijk op simulaties van mondiale klimaatmodellen gebaseerd, waarbij klimaatveranderingen in gang zijn gezet door de $\mathrm{CO}_{2}$-concentratie van de atmosfeer aan te passen.

Hoewel mondiale klimaatmodellen nog altijd complexer worden en steeds beter het werkelijke klimaatsysteem kunnen nabootsen, lopen de projecties van verschillende modellen voor het toekomstige klimaat sterk uiteen. De verschillen zijn het grootst in de hoge noordelijke breedtegraden, duidend op grote onzekerheden in het gesimuleerde Arctische klimaat ten opzichte van dat van de rest van de planeet. Hoofdstuk 2 onderzoekt de mogelijke oorzaken van de grote spreiding tussen klimaatmodellen. Hierbij ligt de focus op de rol van zeeijs, omdat klimaatmodellen de hoeveelheid zee-ijs in het huidige klimaat zeer verschillend simuleren. Door op diverse ruimtelijke schalen de relatie tussen zee-ijs en temperatuurtrends te bestuderen, wordt duidelijk dat de invloed van zee-ijs op de verschillen in opwarming vooral lokaal belangrijk is. Dit betekent dat het patroon van de gesimuleerde toename in temperatuur samenhangt met de ruimtelijke verdeling van zee-ijs.

Zoals eerder opgemerkt, is het Arctisch gebied gevoeliger voor temperatuurveranderingen dan andere delen van de wereld. Dit wordt veroorzaakt door diverse positieve terugkoppelingen die kleine temperatuurveranderingen - zo- 
wel warm als koud - in het Arctische klimaatsysteem versterken. Naast deze lokale Arctische processen kunnen ook interacties met lagere breedtegraden via zowel de oceaan als de atmosfeer de opwarming in het hoge noorden beïnvloeden. Hoofdstuk 3 richt zich op de bijdrage van oceanische energietransporten aan de versterkte opwarming van het Noordpoolgebied. De meeste modelsimulaties laten zien dat oceanische warmtetransporten naar het Arctisch gebied in een opwarmend klimaat zullen toenemen, maar de fysische mechanismen die hierbij een rol spelen worden nog niet goed begrepen. Dit hoofdstuk onderzoekt in detail de onderliggende processen in de Atlantische Oceaan door middel van een serie van vijf gevoeligheidsexperimenten van elk vijfhonderdvijftig jaar lang, waarin de $\mathrm{CO}_{2}$-concentratie in de atmosfeer abrupt op een kwart tot vier maal de huidige waarde wordt gezet. De toename van de noordwaartse warmtetransporten naar het Arctische gebied in warmere klimaten wordt, zo blijkt uit deze simulaties, veroorzaakt door een combinatie van hogere temperaturen van het zeewater en een toegenomen noordwaarts volumetransport. De modelresultaten laten ook zien dat zee-ijs een sleutelrol speelt ten aanzien van de veranderende oceaantransporten, omdat het zowel de dichtheid van het zeewater als het effect van de wind op oceaanstromingen beïnvloedt.

Het klimaat op aarde is altijd aan veranderingen onderhevig geweest, hetzij veroorzaakt door externe forceringen - door de natuur of door de mens - of door interne fluctuaties binnen het systeem (op allerlei tijdschalen). De hoofdoorzaak van de wereldgemiddelde temperatuurstijging over de afgelopen decennia is duidelijk gelegen in de versterking van het broeikaseffect door antropogene emissies van $\mathrm{CO}_{2}$ en andere broeikasgassen. Interne decadale variabiliteit in het klimaatsysteem kan temperatuurtrends echter voor perioden van meer dan tien jaar tijdelijk versterken of afzwakken. Dit effect is behalve tijdsafhankelijk ook locatiespecifiek, en is bijzonder relevant voor het Arctisch gebied, waar de decadale variabiliteit in het huidige klimaat een grotere amplitude heeft dan in de rest van de wereld. Hoofdstuk 4 onderzoekt de fysische mechanismen die samenhangen met Arctische decadale cycli. Het ruimtelijke patroon van temperatuurvariabiliteit vertoont een maximum in de Barentszee, waar in het huidige klimaat de zee-ijsrand ligt. De oceaan speelt een leidende rol in de timing van de variabiliteit door warmte noordwaarts te transporteren en de atmosfeer te verwarmen via infrarode straling en turbulente warmtefluxen. Zee-ijs moduleert de temperatuurveranderingen omdat het door zijn sterk isolerende eigenschappen bepaalt waar de interactie tussen de oceaan en atmosfeer plaatsvindt en de decadale variabiliteit maximaal is. Bovendien versterkt zee-ijs de variabiliteit door diverse terugkoppelingen. 
Als het klimaat opwarmt en zee-ijs afneemt of zelfs verdwijnt, zou dat gevolgen kunnen hebben voor de decadale klimaatschommelingen in het Arctisch gebied. Hoofdstuk 5 richt zich daarom op de veranderingen in Arctische decadale variabiliteit in warmere klimaten. De modelsimulaties laten zien dat de amplitude van de temperatuurvariabiliteit toeneemt wanneer het $\mathrm{CO}_{2}$-gehalte verdubbelt, maar weer afneemt (zelfs tot onder het huidige niveau) bij een verdere stijging in $\mathrm{CO}_{2}$-concentratie. Het gebied waar de variabiliteit maximaal is, in het huidige klimaat gesitueerd in de Barentszee, schuift in de warmere klimaten noordwaarts richting het centrale deel van het Arctisch gebied, net als de zee-ijsrand. Wederom speelt zee-ijs hierin een belangrijke rol vanwege de vele versterkende terugkoppelingen. Doordat de zee-ijsrand in een warmer klimaat noordelijker ligt heeft het zee-ijs meer ruimte om qua oppervlakte te fluctueren. Dit komt omdat de omliggende continenten dan geen barrière meer vormen. De variabiliteit van de grootschalige atmosferische Arctische circulatie verandert ook als het klimaat opwarmt. Tevens beïnvloedt de circulatie de decadale variabiliteit in temperatuur in het Noordpoolgebied, onder meer door veranderingen in zee-ijs. Het is dus van belang om de rol van (veranderende) decadale variabiliteit mee te nemen bij het bestuderen van toekomstige klimaatveranderingen in het Arctisch gebied. 



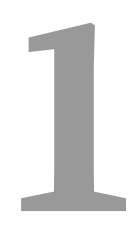

\section{General introduction}

\subsection{Current changes in the Arctic}

\subsubsection{Arctic amplification}

Over the past few decades, climate changes in the Arctic have been large and rapid compared to those in the global mean. The observed rate of Arctic warming between 1981 and 2012 was $\sim 0.60^{\circ} \mathrm{C}$ per decade, compared to $\sim 0.17^{\circ} \mathrm{C}$ per decade globally (Comiso and Hall, 2014), representing a threefold amplification of the global temperature trend. The warming was largest over the Arctic Ocean, strongest near the surface, and most prominent in autumn, winter, and spring, as shown in Figure 1.1 (Screen and Simmonds, 2010; Serreze and Barry, 2011; Johannessen et al., 2016). Melting of glaciers, retreat of sea ice, and increases in precipitation accompany this enhanced warming (Comiso and Hall, 2014). These changes are, at least partly, attributable to the intensified global greenhouse effect through human activities (Gillett et al., 2008; Min et al., 2008a,b; Najafi et al., 2015; Notz and Marotzke, 2012). However, long-term natural fluctuations in the climate system, such as the North Atlantic Oscillation, modulate Arctic climate changes (Delworth et al., 2016). The high sensitivity of the Arctic region to climate change (compared to that of the lower latitudes) can be ascribed to internal climate processes that amplify the initial response.

The enhanced Arctic surface temperature response to increasing greenhouse 

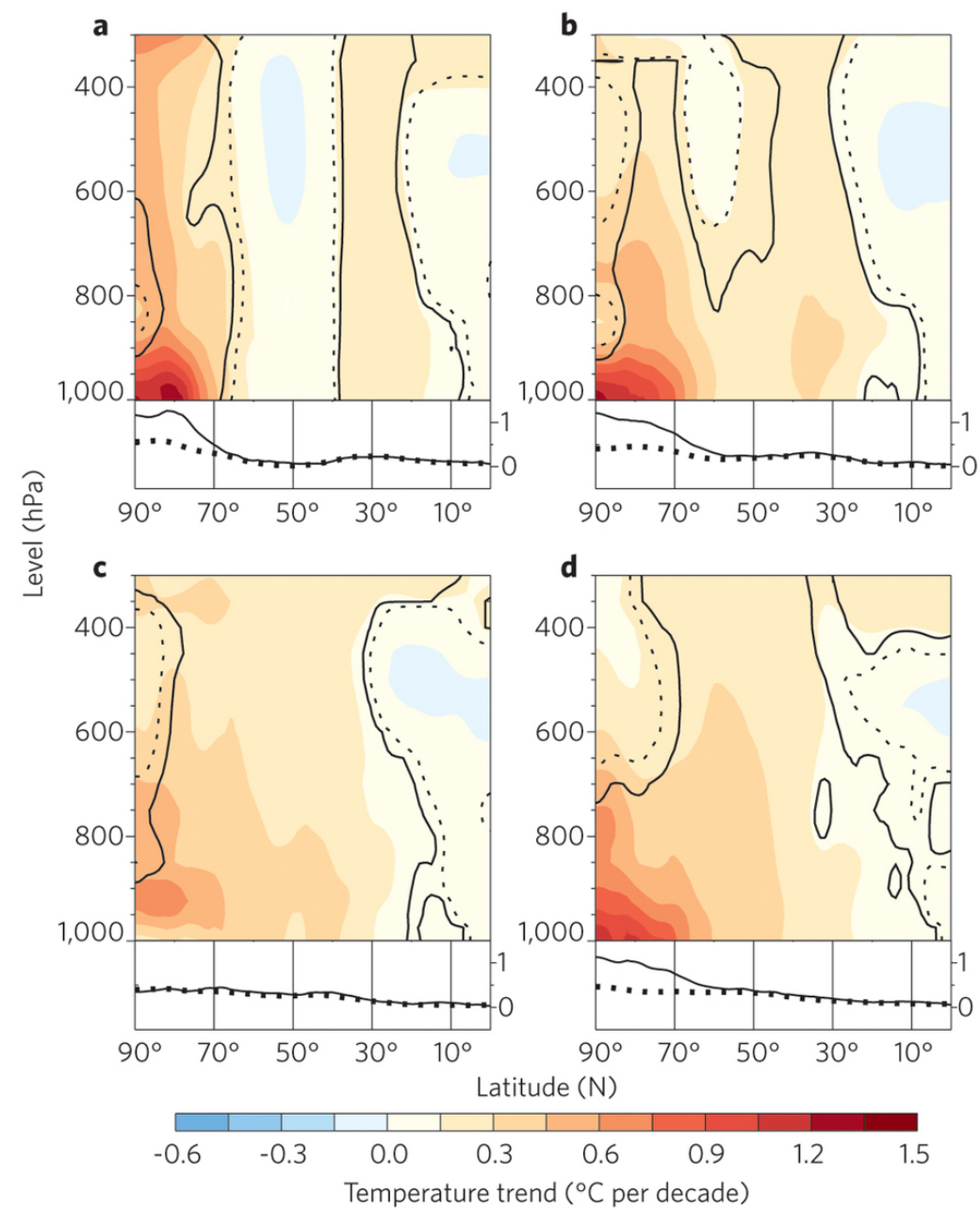

Figure 1.1 | Temperature trends averaged around circles of latitude for (a) winter (December-February), (b) spring (March-May), (c) summer (June-August) and (d) autumn (September-November). Trends are based on ERA-Interim reanalysis data (Dee et al., 2011) from March 1979 to February 2014. The black contours indicate where trends differ significantly from zero at the $99 \%$ (solid lines) and $95 \%$ (dotted lines) confidence levels. The line graphs show trends (same units as in color plots) averaged over the lower part of the atmosphere (950-1,000 hPa; solid lines) and over the entire atmospheric column (300-1,000 hPa; dotted lines) (from Cohen et al., 2014). 
gases in the atmosphere - a phenomenon coined Arctic amplification - was already predicted more than a century ago by the Swedish scientist Svante Arrhenius (Arrhenius, 1896). Although Arctic amplification is often mentioned in the context of global warming, it is not limited to periods of warming, but also applies to times of cooling (Masson-Delmotte et al., 2006; Otto-Bliesner et al., 2006). A general definition of Arctic amplification can be formulated as: trends and variability of surface air temperature in the Arctic - whether increasing or decreasing - tend to be larger in magnitude than in other regions (Serreze and Barry, 2011). Evidence from the instrumental record, paleoclimate reconstructions from proxy data, and simulations with global climate models has demonstrated that Arctic amplification is an inherent feature of the climate system (see, e.g., Manabe and Stouffer, 1980; Holland and Bitz, 2003; Miller et al., 2010).

\subsubsection{Declining sea ice cover}

One of the most prominent changes related to Arctic warming is the rapidly diminishing Arctic sea ice cover (Stroeve et al., 2007). The nine lowest September sea ice extents over the satellite period (since 1979) have all occurred in the last nine years, of which the most recent years are depicted in Figure 1.2. In the twenty-first century, a new record low extent at the end of summer was reached four times (in 2002, 2005, 2007, and 2012) and several other years saw near-record lows (Stroeve et al., 2012b). At the date of writing, Arctic sea ice extent is approaching its minimum value and is tracking third-lowest in the satellite record. Whether the record low of 2012 will be surpassed or not, the data show no sign of recovery of the ice extent. A comparison of recent sea ice extent minima with the 1981-2010 values shows that sea ice did not return to the long-term climatology.

Highly variable summer circulation patterns in the atmosphere play a significant role in the minimum ice extent (including its year-to-year variability) and its spatial distribution (Lynch et al., 2016). For example, in 2007, surface wind conditions were favorable for strong ice retreat (Lindsay et al., 2009). In 2012, a persistent cyclone in early August helped to break up the ice and enhance melt (Parkinson and Comiso, 2013). Also, summertime warming of the upper ocean by ocean surface fluxes and ocean currents that transport warm water northward contributes to summer ice melt (Steele et al., 2010). Regardless of considerable year-to-year variations, the Arctic September sea ice extent exhibits a consistent downward trend over the period 1979 to 2012 of $\sim 11.5 \%$ 


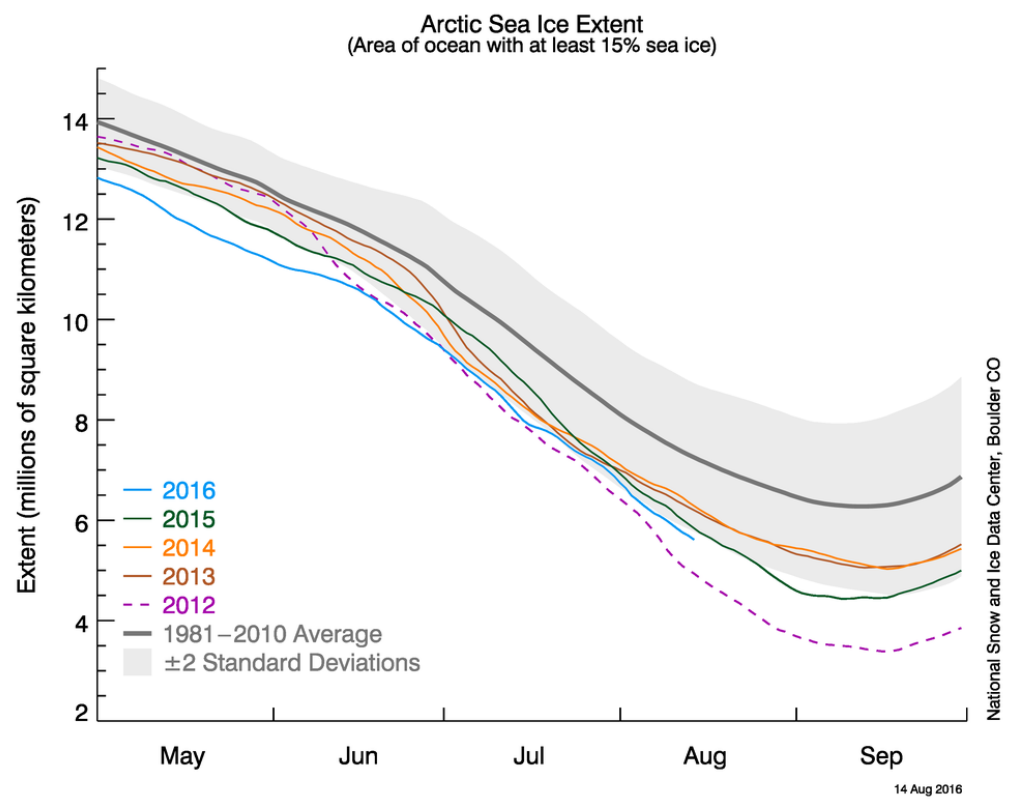

Figure 1.2 | Arctic sea ice extent in recent years compared to the long-term average (1981-2010). Image courtesy of the National Snow and Ice Data Center, University of Colorado, Boulder.

per decade (Comiso and Hall, 2014). The average decline in sea ice extent is most pronounced in summer and autumn, but the extent decreases in every season (Cavalieri and Parkinson, 2012). As an example, in 2015 and 2016, two new record-low extents for the winter maximum were set (Fetterer et al., 2016). At the same time, sea ice is thinning at a considerable rate (Kwok and Untersteiner, 2011). Annual mean ice thickness over the central Arctic Ocean has decreased from an average of $3.59 \mathrm{~m}$ in 1975 to only $1.25 \mathrm{~m}$ in 2012, a 65\% reduction (Lindsay and Schweiger, 2015). These sea ice trends go hand in hand with Arctic warming.

\subsubsection{Environmental impacts}

Impacts of recent Arctic warming also extend beyond the Arctic. Changes in snow and sea ice affect the Earth's energy balance as well as the large-scale circulation of the oceans and atmosphere. Accelerated Arctic warming results 
in increased precipitation (Bintanja and Selten, 2014) which, in combination with meltwater from sea ice and the Greenland ice sheet, has reduced the Arctic ocean salinity (Giles et al., 2012; Morison et al., 2012; Mauritzen, 2012). This freshening, in turn, might affect oceanic deep water formation in the Arctic and thereby the global ocean circulation (Stommel and Arons, 1959; Cheng et al., 2007; Yang et al., 2016). In addition, melting of the Greenland ice sheet and smaller ice caps and glaciers will increase the ocean water volume, thereby affecting eustatic sea level (Jacob et al., 2012). This is especially relevant for lowlying coastal areas such as the Netherlands, where the rise in regional sea level may be as high as $40 \mathrm{~cm}$ in 2050 (Klein Tank et al., 2015). Strong warming in the Arctic also potentially impacts the large-scale atmospheric circulation, thereby affecting the frequency, duration, and severity of extreme events in the midlatitudes, such as winter cold spells, and summer droughts and heatwaves (Francis and Vavrus, 2012; Tang et al., 2013; Cohen et al., 2014; Coumou et al., 2014; Ayarzagüena and Screen, 2016). Furthermore, current climate change is associated with lower temperatures in the Arctic stratosphere, which likely increases the frequency and severity of ozone-depletion episodes (Manney et al., 2011).

The recent changes in the Arctic climate have already led to major impacts beyond the climate system itself. Besides the decline in sea ice extent, direct effects within the Arctic include unusual thawing of permafrost, melting of glaciers, shifts in patterns of rain and snowfall, freshwater run-off, and forest/tundra growth (ACIA, 2005). Thawing of permafrost brings widespread changes in ecosystems (Post et al., 2013), and damage to infrastructures, such as buildings, roads, and pipelines (Nelson et al., 2001). Furthermore, permafrost melt potentially enhances the microbial breakdown of organic carbon and the release of considerable amounts of greenhouse gases (carbon dioxide and methane) into the atmosphere, which could accelerate climate change (Schuur et al., 2015). Sea ice retreat allows larger storm surges to develop in the increased open-water areas (Thomson and Rogers, 2014), increasing erosion, sedimentation, and the risk of inundation of coastal regions (Forbes et al., 2004). Moreover, coastlines where permafrost has thawed are more vulnerable, which in combination with increased wave action can lead to enhanced erosion (Overeem et al., 2011; Barnhart et al., 2014). In the longer term, prolonged icefree seasons are likely to provide substantial benefits to marine transport and offshore operations in the petroleum industry (Stephenson et al., 2013), which will likely have significant implications for trade and defense and affect geopolitical issues within the Arctic region (Blunden, 2012). Changes in sea ice also affect the habitats of marine life, such as algae, plankton, fish, and seabirds, 
as well as marine mammals (polar bears, seals, walruses) that hunt, feed, and breed on the ice (Laidre et al., 2008; Hollowed et al., 2013). This, in turn, threatens indigenous human populations that strongly rely on ice-dependent wildlife for their survival, social identity, and cultural life (Ford, 2009).

Evidently, the Arctic is an important actor in the global climate system. Indirectly, Arctic climate change significantly affects communities as well as ecosystems across the Arctic and the globe. With the research presented in this thesis, we aim to obtain better insight into the processes responsible for (accelerating) Arctic climate change, which contributes to improved climate projections for the coming century. To understand the possible causes of Arctic amplification and the rapid loss of sea ice in recent decades, fundamental knowledge about the Arctic climate system is required.

\subsection{The Arctic climate system}

The present section provides an overview of the main Arctic climate components that will be assessed throughout this thesis: the atmosphere, the ocean, and sea ice. Climate change in the Arctic is the result of a number of interactions between these climate components (and some others as well). Therefore this section also addresses the interplay between the various components, as well as feedback mechanisms through which Arctic amplification could be affected.

\subsubsection{Atmosphere}

The Arctic has no formal boundaries but is mostly defined as the region north of the Arctic Circle $\left(66.5^{\circ} \mathrm{N}\right)$. When defined in this way, long hours of daylight in summer and long hours of darkness during winter are fundamental characteristics. These extreme variations in the amount of solar radiation received by the Arctic strongly affect the mean seasonal cycle of surface air temperature. The winters are frigid with January mean values as low as $-38^{\circ} \mathrm{C}$ over parts of Siberia (Johannessen et al., 2016). Over the Arctic Ocean, January mean values are typical $-24^{\circ} \mathrm{C}$ to $-32^{\circ} \mathrm{C}$, owing to moderating ocean heat fluxes through the ice cover. In July, average temperatures of $+10^{\circ} \mathrm{C}$ to $+20^{\circ} \mathrm{C}$ are typical over snowfree land surfaces. Over the sea-ice-covered areas in the central Arctic Ocean, melting ice keeps the surface air temperature close to $0^{\circ} \mathrm{C}$ during the summer. Temperature inversions, with a lighter and warmer air mass overlying a denser 
and colder layer, are very common in the Arctic (Hansen et al., 1997), especially in winter. These are the result of the surface cooling more rapidly than the air above through outgoing longwave radiative fluxes.

Essentially, all energy that enters Earth's climate system originates from the Sun (Pierrehumbert, 2011). Part of the incoming solar (shortwave) radiation is reflected back to space by the surface $(7 \%)$ or clouds $(22 \%)$, while the atmosphere (23\%) and the surface (47\%) absorb the rest (Wild et al., 2013). The heated surface warms the atmosphere from below through turbulent fluxes (sensible and latent heating) and longwave (infrared) radiation exchanges. Fluxes of sensible heat lead to direct temperature changes, while latent heat fluxes affect temperature through phase changes of water such as evaporation and sublimation. Longwave radiation emitted by the surface is a function of surface temperature and is partly absorbed by the gases and clouds in the atmosphere (mostly in the warm and moist boundary layer), which re-emit radiation both up- and downward. The longwave radiation emitted to space originates primarily from the atmosphere, except for a small fraction that is transmitted in the so-called 'atmospheric window', a spectral section where absorption by atmospheric gases is relatively low. Eventually, the outgoing longwave radiation restores Earth's energy balance.

As the Earth is a sphere and tilted on its axis of rotation, the amount of solar radiation that the top of the atmosphere receives is unevenly distributed over the globe. The equatorial region receives more radiative energy than both poles. The resulting differential heating of the atmosphere causes a temperature gradient between the poles and the equator, which, in turn, induces a north-south pressure gradient. The atmosphere and ocean act to reduce this gradient by transporting energy poleward, with the atmospheric transport in the northern hemisphere being dominant north of about $20^{\circ} \mathrm{N}$ as shown in Figure 1.3 (Fasullo and Trenberth, 2008). The Hadley circulation, which is characterized by rising motions of warm and moist air near the equator and subsidence at about $30^{\circ} \mathrm{N}$, is the primary energy transporting structure in the tropics. In middle to higher latitudes, the time-mean flow is primarily westerly (west to east) due to an approximate balance between the north-south pressure gradient and Coriolis force that is induced by the rotation of the Earth. The poleward atmospheric energy transport occurs mainly through quasi-stationary planetary waves that are related to disturbances in the westerly flow, and smaller scale baroclinic eddies (associated with surface cyclones and anticyclones) that intimately interact with the large scale waves. The baroclinic eddies in the Northern Hemisphere transport most of the energy along two major storm tracks in the western North 

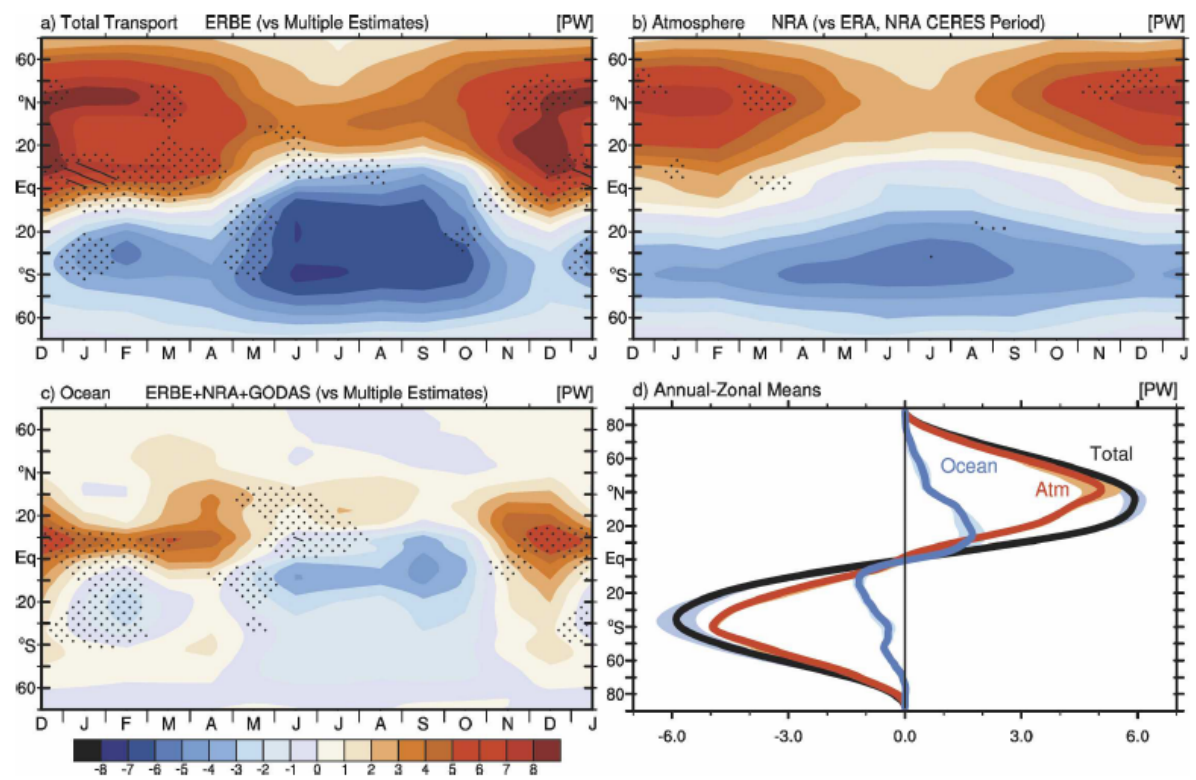

Figure 1.3 | The annual cycle of the meridional (in north-south direction) energy transport in PW $\left(10^{15} \mathrm{~W}\right)$ averaged around circles of latitude over the period February 1985 to April 1989 by (a) the atmosphere and ocean; (b) the atmosphere; and (c) by the ocean. (d) The median annual mean transport by latitude for the total (black), atmosphere (red), and ocean (blue) accompanied with the associated range of two standard deviations (shaded) (from Fasullo and Trenberth, 2008).

Atlantic and North Pacific. The atmospheric transport of energy is largest in winter when the latitudinal temperature and humidity gradients are most pronounced (Trenberth and Stepaniak, 2003).

An important feature of the upper atmospheric circulation is the polar vortex, which is a permanent low-pressure zone centered over the Arctic. The polar vortex interacts with lower latitudes through teleconnections in the stratosphere. Variations in its strength have been linked to e.g. El Niño (Hu et al., 2016) and volcanic eruptions (Toohey et al., 2014). However, the polar vortex is also dynamically coupled to the surface climate in the Arctic region (Kim et al., 2014; Kidston et al., 2015). For instance, it closely interacts with the Arctic Oscillation (AO) (Thompson and Wallace, 1998) or Northern Annular Mode (NAM), which is the dominant pattern of variability in the sea level pressure north of $20^{\circ} \mathrm{N}$. Basically, it represents an oscillation of atmospheric mass between the 
Arctic latitudes and midlatitudes. When the AO is in its positive phase, the surface pressure is below average in the Arctic region, and relatively high over the Atlantic and Pacific Oceans. During winter, the AO signature extends upward in both the troposphere and stratosphere. A positive $\mathrm{AO}$ is associated with strong westerly winds in the upper atmosphere that tend to keep cold polar air in the north, and cause a northward shift in cyclone activity. Furthermore, the colder-than-average Arctic surface temperatures contribute to an extended sea ice cover. The North Atlantic Oscillation (NAO), which describes co-variability in sea level pressure between the Icelandic Low and the Azores High, is the more regional expression of the hemispheric $\mathrm{AO}$ and has a very similar impact on Arctic climate. The AO exhibits variability on a broad range of timescales, varying from months to tens of years.

\subsubsection{Ocean}

North of $70^{\circ} \mathrm{N}$, the Arctic consists mainly of ocean, which is surrounded almost entirely by the mainlands of Eurasia and North America (Fig. 1.4). The submerged Lomonosov Ridge subdivides the central Arctic Ocean in two basins, the Eurasian and Amerasian basin, which are both more than $3000 \mathrm{~m}$ deep (Jakobsson et al., 2012). The ocean boundary of the Arctic Ocean runs along the Barents Sea Opening from Norway to Svalbard, across Fram Strait, along the western margin of the Canadian Archipelago and across Bering Strait. Defined in this way, the Arctic Ocean covers an area of about 11.5 million $\mathrm{km}^{2}$, of which $60 \%$ is continental shelf. The continental shelf varies in width from only $100 \mathrm{~km}$ in the Beaufort Sea to more than $1000 \mathrm{~km}$ in the Barents Sea and the Canadian Archipelago. The depth of the shelf seas is typically 50 to $100 \mathrm{~m}$ off the coasts of Alaska and Siberia, whereas the shelf areas in the Barents Sea, East Greenland, and northern Canada are 200 to $500 \mathrm{~m}$ deep.

The Arctic Ocean is only in a limited way connected to the rest of the other world oceans. The main route is the sector between $20^{\circ} \mathrm{E}$ and $20^{\circ} \mathrm{W}$, where the Nordic Seas (Greenland, Iceland, and Norwegian Seas) make the connection between the Arctic and the Atlantic Ocean through the Barents Sea Opening $(220 \mathrm{~m})$ and the much deeper Fram Strait $(2600 \mathrm{~m})$. Furthermore, shallow passages with sills of 85-140 m deep prevail between the islands of the Canadian Archipelago, connecting the Arctic Ocean to Baffin Bay, Davis Strait, and the Labrador Sea. The very shallow and narrow Bering Strait between Alaska and Russia (45 m deep), links the Arctic Ocean to the Pacific. 


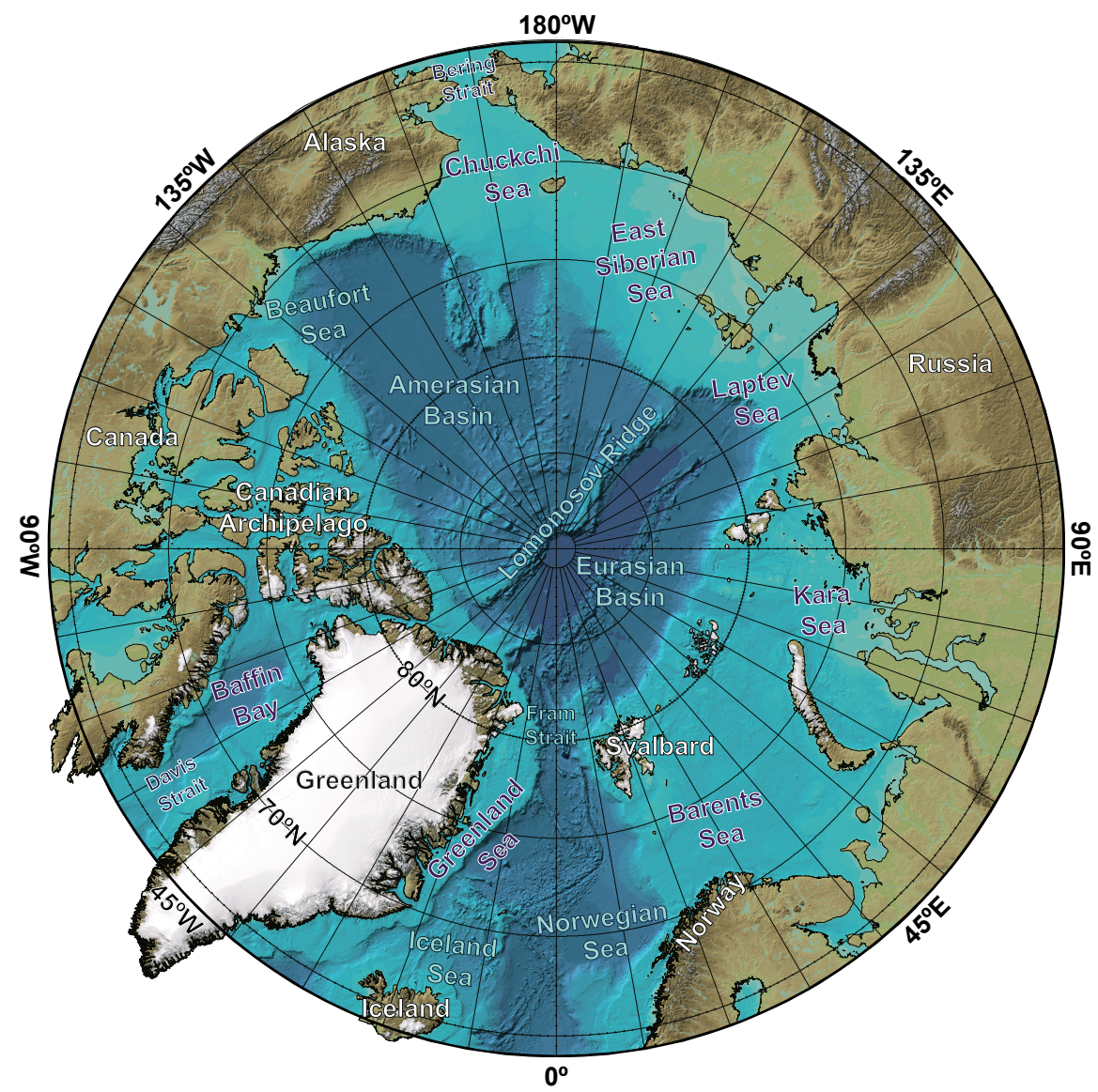

\section{Bathymetry and topography}

100000

Figure 1.4 | Map showing bathymetry of the Arctic Ocean from the International Bathymetric Chart of the Arctic Ocean (Jakobsson et al., 2012) and place names of the major basins, shelf seas, ridges, and gateway straits. 
Figure 1.5 shows the flows of water in and out of the Arctic Ocean. Relatively warm waters from the North Atlantic flow through the Nordic Seas to the Arctic Ocean via the Barents Sea and Fram Strait (Weaver et al., 1999). The inflow of Atlantic water to the Nordic Seas occurs across the shallow sill between Greenland, Iceland, and Scotland (the Greenland-Scotland Ridge) and becomes warmer and more saline towards the southeast. The volume inflow of Atlantic water is about ten times larger than the Pacific inflow, which enters the Arctic through Bering Strait. Two main features characterize the surface circulation within the Arctic Oceans: the clockwise Beaufort Gyre north of Alaska, and the Transpolar Drift Stream that flows from the Siberian shelf seas across the pole towards Fram Strait. Both systems are governed by wind forcing.

Several processes affect the temperature and salinity of the waters in the Arctic Ocean, including the Pacific and Atlantic inflow, heat exchange with the atmosphere, precipitation, river runoff, and melting and freezing of sea ice. The sea surface temperature is generally near the (salinity-adjusted) freezing point at the surface, owing to the presence of sea ice. Temperatures increase to maximum values around 300-500 $\mathrm{m}$ depth, below which the temperatures decline towards the bottom. Surface salinity fluctuates through the seasonal cycles of sea ice melt and expansion, river runoff, and precipitation (Carmack et al., 2016). Down to about $300 \mathrm{~m}$ depth, the subsurface layer is characterized by a rapid increase in salinity, termed the halocline, below which salinity does not vary much (Aagaard et al., 1981). The characteristics of the halocline are mainly determined by the relatively fresh water from the Pacific, whereas Atlantic-derived waters characterize the warm salty layers below the halocline. The vertical distribution of salinity controls the vertical density stratification, owing to the low temperatures in the Arctic Ocean. Due to the sharp increase in salinity with depth, the upper Arctic Ocean is very stably stratified, which inhibits vertical mixing. In combination with the cold surface waters, the strong density gradient is a governing factor for the presence of year-round sea ice in the current climate.

The outflow of Arctic Ocean water mainly occurs through Fram Strait and the Canadian Archipelago. The waters that exit through Fram Strait are transported southward east of Greenland, and around the Labrador Sea and the Baffin Bay, where they merge with the outflowing waters from the Canadian Archipelago. There this flow joins the southward flowing Labrador Current, which forms the western boundary of the North Atlantic subpolar gyre. This cyclonic (counterclockwise) cell is governed by currents south of Greenland and in the Labrador Sea, and is a dominant circulation feature of the time-mean ocean currents in 


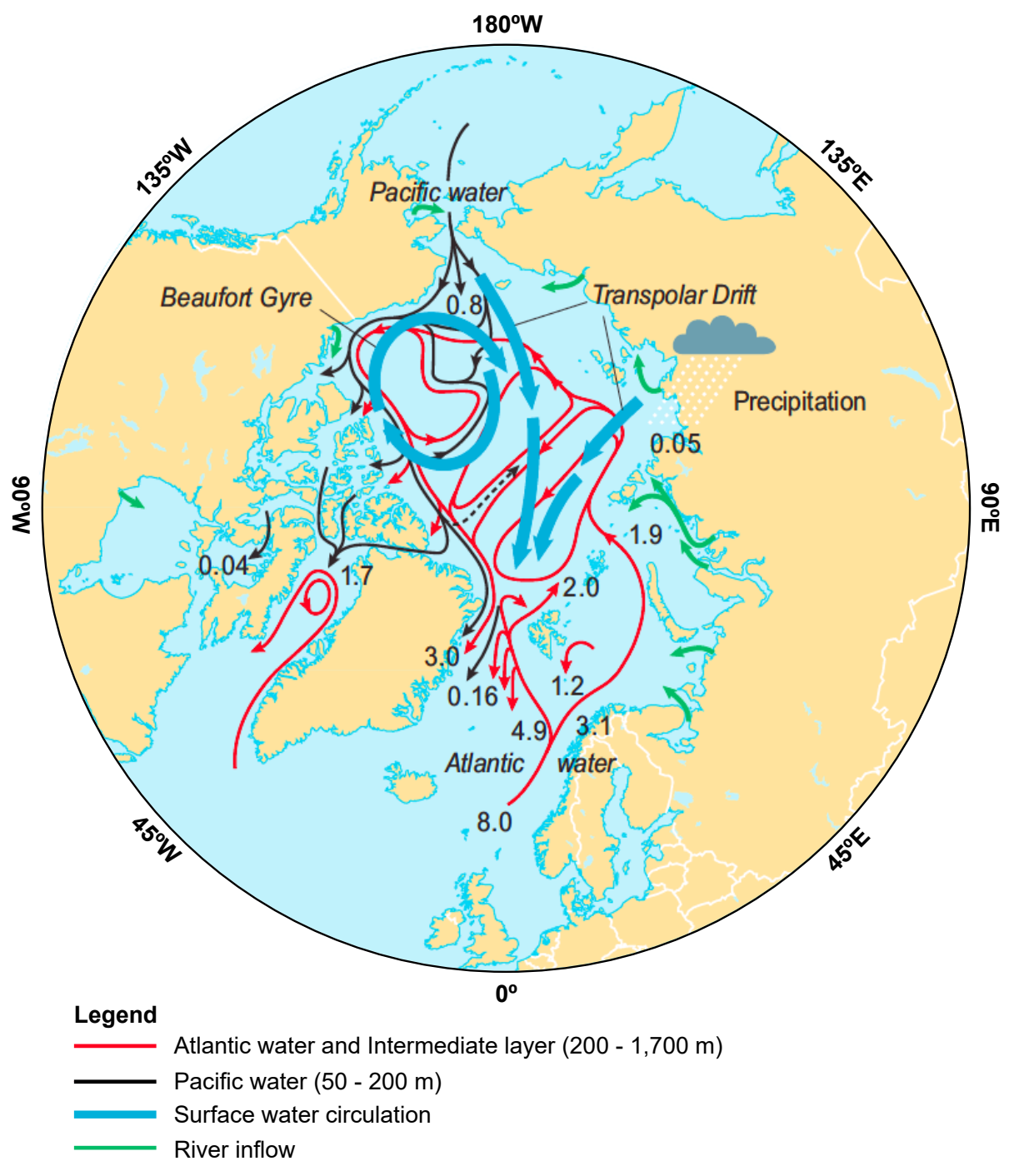

Figure 1.5 | The Arctic ocean circulation, including pathways of Pacific water inflow from 50 to $200 \mathrm{~m}$ depth (black lines), pathways of Atlantic water and intermediate water masses into the Arctic (red lines), surface water circulation (blue arrows), and major river inflow (green arrows). Values are estimated inflows or outflows in Sverdrups (million $\mathrm{m}^{3}$ per second). Figure from the Arctic Monitoring and Assessment Program (AMAP, 1998; adapted from Miller et al., 2010). 
the northern North Atlantic. The subpolar gyre is driven by wind stress and horizontal density differences.

The most northerly margins of the subpolar gyre in the North Atlantic Ocean - the Labrador and Greenland Sea - are locations where deep ocean convection occurs, which is a crucial part of the global ocean circulation (Aagaard et al., 1985; Meincke, 1997). In early winter, surface waters become denser by atmospheric cooling and ejection of salt during sea ice growth. Once the water is sufficiently dense, it mixes vertically and forms deep water. This process, called deep convective mixing, can reach depths of about $2000 \mathrm{~m}$. The freshly formed deep water in the Greenland Sea flows over the Greenland-Scotland Ridge, after which it merges with the Labrador deep water and forms the North Atlantic Deep Water (NADW). NADW is one of the main branches of the global-scale Atlantic Meridional Overturning Circulation (AMOC), which is of primary importance for global ocean heat transport. Both the volume flux and the density of the Arctic water outflow are thus critical to the Arctic influence on the global climate through the AMOC.

\subsubsection{Sea ice}

Currently, a large fraction of the Arctic Ocean is covered by sea ice. Arctic sea ice extent is typically about 15.5 million $\mathrm{km}^{2}$ in late winter, and approximately 7 million $\mathrm{km}^{2}$ at the end of summer (Vaughan et al., 2013). Summer sea ice covers the central Arctic Ocean basin and the Canadian Archipelago, whereas winter sea ice extends further southwards into the peripheral seas. The southern sea ice margin consists mainly of seasonal (or first-year) ice, which melts away in summer and starts to (re)grow next winter. Typical winter sea ice concentrations (area fractions) over the central Arctic Ocean are 98-99\%, compared to $85-95 \%$ in late summer, and decrease towards the margin between sea ice and open ocean (marginal ice zone). Sea ice thickness varies from a few decimeters where it borders the ocean up to $2 \mathrm{~m}$ in the central Arctic at the end of winter. When sea ice survives the summer, it becomes perennial (or multi-year) ice. The distribution of ice thickness and concentration is due to both thermodynamic (melting and freezing) and dynamic (deformation and motion) forces (Carmack et al., 2015). In the present climate, perennial ice can thermally grow up to about $3 \mathrm{~m}$ thick. Sea ice can become even thicker in response to winds and currents when slabs of thick ice bend or fracture and pile on top of itself, forming ridges on the surface which can become up to tens of meters thick. 


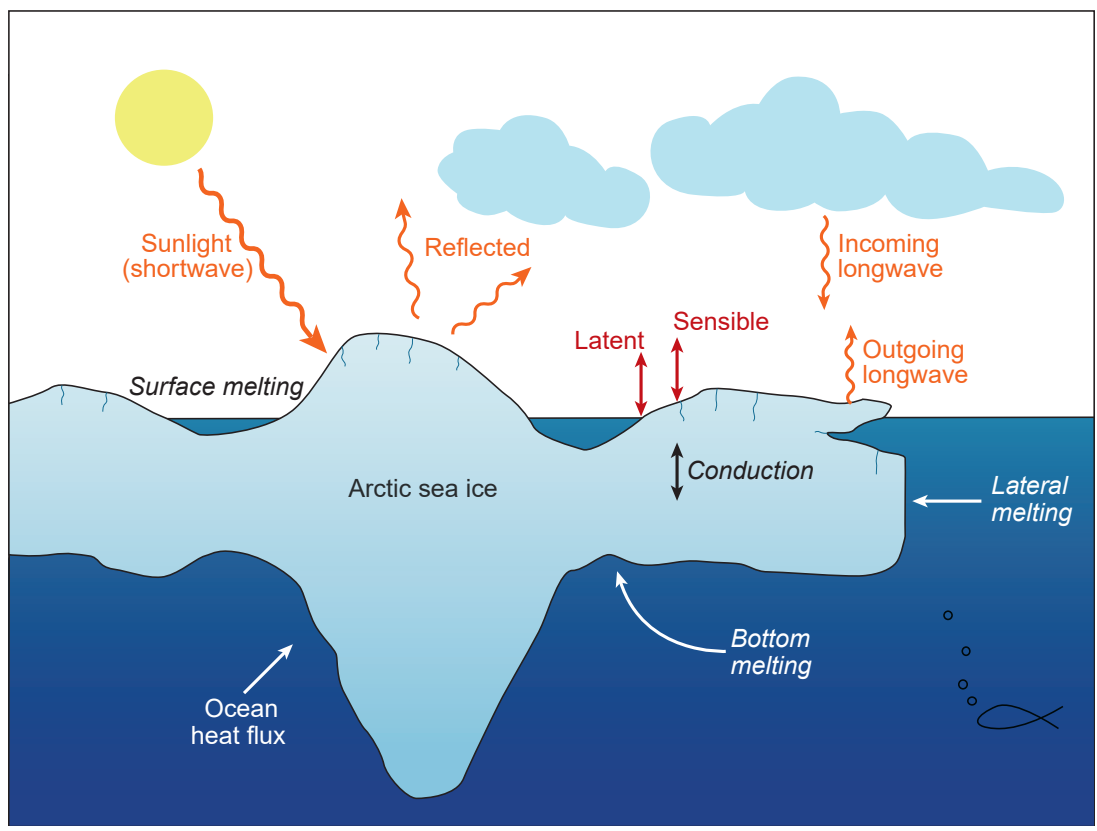

Figure 1.6 | Schematic of the energy budget of sea ice, including radiative fluxes (orange), turbulent fluxes (red), heat conduction (black), and ocean heat fluxes (white) (adapted from Perovich and Richter-Menge, 2009).

Sea ice growth or melt depends on the way energy is exchanged with its surroundings and distributed within the ice (Fig. 1.6). Before ice can form, the ocean surface should cool down to the freezing point. When cold air and outgoing radiative fluxes cool the ocean surface, it results in dense surface water that destabilizes the (upper) water column. This unstable stratification induces mixing that replaces the surface water by warmer water that must be cooled as well. So the water underneath the surface layer also needs to reach the freezing point before sea ice can form. The depth to which the water must be cooled is typically 10-40 m (i.e. the mixed layer). Once sea ice begins to form, it progressively insulates the relatively warm ocean from the cold atmosphere. This insulation slows down the growth rate since it takes longer to cool the water below the ice to the freezing point. Thick ice, therefore, grows slower than thin ice. A snow layer on the ice limits the growth rate even further, due to the effective insulation properties of snow.

In summer, sea ice melts at the surface, the bottom and the lateral edges of 
the ice, and also internally. Melting initiates when the sum of all the energy fluxes entering the ice becomes positive and when the temperature reaches the melting point of ice. Solar and longwave radiative fluxes dominate the energy budget of the sea ice, but the turbulent fluxes of latent and sensible heat and heat conduction through the ice also contribute. The amount of solar radiation that is absorbed depends on the albedo, defined as the ratio of reflected and incoming solar radiation. The typical surface albedo varies from 0.07 for open water and deep, dark melt ponds to 0.6 for bare, white sea ice. The albedo increases even further to 0.85 when fresh snow covers the ice (Perovich and Polashenski, 2012). A reduction of sea ice and snow acts to increase surface temperatures as relatively dark land and water surfaces replace the highly reflective ice and snow surfaces. Bottom and lateral melting are mainly determined by the heat flux from the ocean to the ice. For instance, during winter, the ice extent is constrained by relatively warm ocean waters in the Greenland, Norwegian, and Barents Seas.

Sea ice does not grow and melt in one location, however. The sea ice cover is in a state of constant motion, except in coastal regions where it is attached to the shore. Sea ice motion can cause rapid changes in the ice cover. A divergence of the ice cover creates open water, whereas convergence causes ridging which increases the ice thickness. The large-scale annual mean circulation of sea ice consists mainly of the Beaufort Gyre and the Transpolar Drift Stream (Perovich and Richter-Menge, 2009). This mean pattern is primarily caused by wind stress acting on the upper surface of the ice cover, and water stress (ocean currents) dragging on the ice base. The clockwise circulating Beaufort Gyre is induced by a persistent high-pressure system over the Beaufort Sea. As a result, the thickest ice in the Arctic is found along the shores of northern Canada and Greenland, where the Beaufort Gyre pushes ice against the coasts, thereby compressing and deforming the ice into ridges. The circular rotation also promotes deformation of sea ice due to internal ice stresses, creating thicker and more ridged ice than in other regions. The Transpolar Drift Stream transports sea ice from the Siberian shelves across the Arctic basin towards Fram Strait where it exits the Arctic basin. Due to the prevailing winds over the Siberian shelf seas, newly formed ice is continuously transported offshore, enabling thin ice to form along the coast in open water areas. 


\subsubsection{Feedback mechanisms}

Now that physical aspects of the Arctic climate system have been introduced, we return to the issue of Arctic amplification. As mentioned before, the warming trend in the Arctic is larger than the global average. Why is this? Several climate feedbacks contribute to Arctic amplification. The basic concept of a climate feedback is that an initial perturbation to the climate system is amplified (positive feedback) or suppressed (negative feedback) through interactions with other climate variables. Sea ice plays a central role in Arctic amplification processes, but other feedbacks contribute to Arctic amplification as well. Alternative potential mechanisms are changes in water vapor content and cloud cover, and poleward heat advection by the atmospheric and oceanic circulation. Here, we examine all relevant processes in more detail.

The current warming of the Arctic is part of a global warming trend. At least half of the recent global warming trend has been attributed to the rise in anthropogenic greenhouse gases that absorb longwave radiation (Bindoff et al., 2013), whereby those gases reduce the amount of longwave radiation that is radiated out to space. The reduction in outgoing longwave radiation disturbs the topof-the-atmosphere radiation balance, leading to an increase in global (surface) temperature through which the climate system tries to restore the balance. The impact of rising temperatures on the outgoing longwave radiation to space is the main negative feedback that acts to stabilize the climate system at a new equilibrium temperature (temperature feedback).

It is useful to decompose this temperature feedback into the Planck feedback, which is the rate at which a black body radiates away energy while warming, and the lapse-rate feedback, which takes into account deviations from vertically uniform warming (Pithan and Mauritsen, 2014). We already noted that rising temperatures itself have a direct effect on outgoing longwave radiation at the top of the atmosphere. However, this contribution is unevenly distributed over the Earth. In colder regions, a larger warming is required for a given increase in longwave radiation, meaning that warming in the Arctic would have to be enhanced compared to the tropics to balance a particular radiative flux change (Planck feedback). Furthermore, the vertical structure of warming is strongly latitude-dependent. In the tropics, warming in the upper troposphere is larger than at the surface due to deep convection processes and latent heat release. Therefore the tropical system can radiate more effectively to space, meaning that only a relatively small increase in surface temperature is required to offset the radiation imbalance at the top of the atmosphere. In the Arctic, 
where warming is mainly confined to the lower troposphere owing to weak vertical atmospheric mixing, a relatively large increase in surface temperature is required to offset this imbalance (lapse-rate feedback). Both the lapse-rate and Planck feedbacks are directly related to the temperature distribution in the atmosphere, which spatial variations contribute to Arctic amplification.

Furthermore, enhanced Arctic warming is accompanied by relatively high concentrations of water vapor in the Arctic atmosphere, as observed by satellites (Boisvert and Stroeve, 2015). The changes in atmospheric humidity are caused by increased evaporation and enhanced northward atmospheric moisture transport. Since water vapor is an efficient greenhouse gas, Arctic moisture will contribute to enhanced surface warming by trapping longwave radiation in the atmosphere. This water-vapor feedback interacts closely with the lapse-rate feedback and cloud formation (Mauritsen et al., 2013).

An increase in water vapor into the atmosphere could reinforce the Arctic cloud fraction (Vavrus et al., 2009). Arctic clouds are a potential contributor to Arctic surface warming, because of their downward emission of longwave radiation. The longwave emission partially depends on the vertical distribution of clouds (Palm et al., 2010). Low-level clouds, such as Arctic stratus, emit more longwave radiation than high-level clouds due to their higher temperatures. More Arctic stratus is thus expected to lead to enhanced surface warming. However, the effect of clouds is more complicated because of their differential reflectivity of solar radiation. Like sea ice, clouds reduce the shortwave radiative flux reaching the surface by reflecting solar radiation, a cooling effect that is only active during the short summer season. Observations suggest that the greenhouse warming effect of clouds dominates during most of the year, except for a short period in summer (Shupe and Intrieri, 2004; Kay and L'Ecuyer, 2013). The representation of clouds is, generally speaking, not yet well simulated in climate models (Flato et al., 2013), especially in the Arctic (Wyser et al., 2008).

The best-known contributor to Arctic amplification is the ice-albedo feedback (e.g., Curry et al., 1995; Hall, 2004; Winton, 2006a; Graversen and Wang, 2009; Kumar et al., 2010), even though Arctic amplification is also found in model simulations with a fixed sea ice cover (Fig. 1.7) (Graversen and Wang, 2009). Nevertheless, its contribution is of significant importance. Over land, warming leads to earlier melt of snow which exposes the dark surface underneath, resulting in a stronger absorption of solar radiation. The heated surface warms the overlying atmosphere by the emission of longwave radiation and stronger turbulent fluxes. In turn, the warmer air emits more longwave ra- 


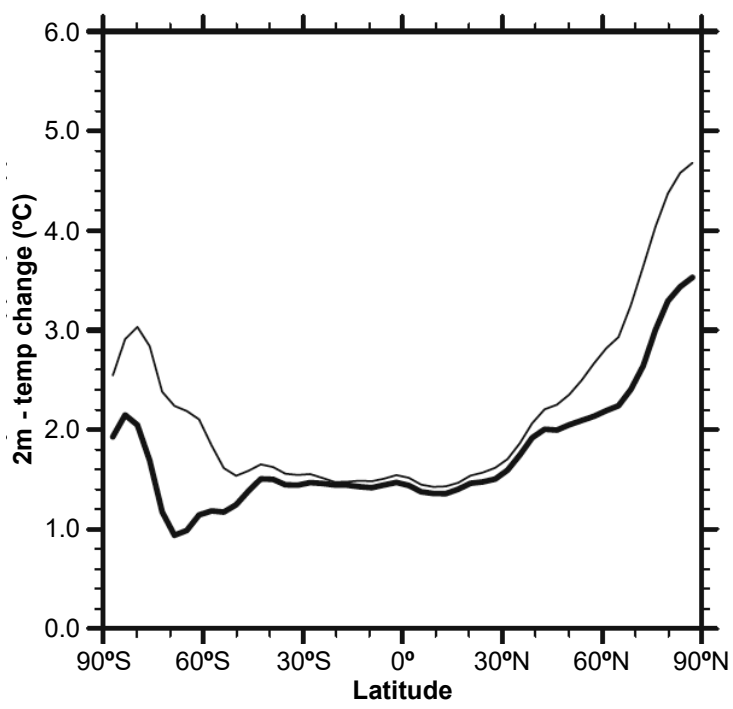

Figure 1.7 | Surface air temperature change averaged around latitude circles with doubled atmospheric $\mathrm{CO}_{2}$ concentration for experiments with locked albedo (thick line) and variable albedo (thin line) (adapted from Graversen and Wang, 2009).

diation back to the surface. Over the ocean, warming will lengthen the melt season, resulting in more open water and enhanced absorption of solar radiation due to its lower albedo, which leads to warming and increased ice melt. This constitutes the direct ice-albedo feedback. However, the ice-albedo feedback also exerts a delayed seasonal response over the ocean. The absorption of solar radiation adds sensible heat to the upper ocean, which is mainly used to melt ice. The reduced sea ice cover 'survives' to the subsequent autumn and winter, reinforcing ocean heat release to the atmosphere and causing intense warming of the near-surface air. This indirect ice-albedo feedback consists of a seasonal link between the atmospheric and oceanic response.

Changes in the atmospheric or oceanic energy transports into the Arctic region can affect Arctic amplification as well (Yang et al., 2010). Considering the Arctic as a whole, there is a net convergence of atmospheric and oceanic energy transport (see Fig. 1.3). This convergence is balanced mainly by a longwave radiative loss to space. In the atmosphere, enhanced northward advection of heat and moisture from lower to higher latitudes will contribute to Arctic warming (Cai, 2006; Graversen et al., 2008). In turn, this might alter the atmospheric wa- 
ter vapor content and cloud cover in the Arctic, and modulate related feedback processes. Changes in poleward ocean heat transport could also impact Arctic warming through water inflow from the Atlantic and Pacific Oceans (Chylek et al., 2009). Besides, the prevailing wind patterns might drive the changes in the ocean currents. As the water temperature and/or the volume flux of the inflowing water increases, more heat is brought to the Arctic region, reinforcing Arctic warming.

Sea ice loss somehow modulates most of the feedbacks that are related to Arctic amplification. A reduction of the sea ice cover induces an increased ocean-to-atmosphere moisture flux through evaporation, which leads to enhanced atmospheric humidity and clouds, thereby strengthening the cloud and water-vapor feedbacks (Francis and Hunter, 2006). Furthermore, sea ice is intimately connected to the energy budget and circulation of the ocean and atmosphere, since changes in sea ice strongly influence the air-ocean heat exchanges (Maykut, 1978). The sea-ice-related heat and radiation exchanges largely regulate the pronounced seasonal response of Arctic warming, which in winter is three to four times larger than in summer (Bintanja and van der Linden, 2013). Also, sea ice modulates the effect of wind stresses on the ocean surface, and thereby the wind-driven ocean circulation.

Feedback mechanisms other than those previously discussed, such as those related to changes in river discharge (Ogi et al., 2001), permafrost melt (Schuur et al., 2015), black carbon (Sand et al., 2013), and vegetation changes (Pearson et al., 2013), are likely to affect Arctic warming as well. Although this is not a complete overview of Arctic feedback mechanisms, it is clear that many feedback mechanisms act in concert to amplify the Arctic climate response. It is important to realize that while most processes can increase the warming, some negative feedbacks damp the response. Due to the tight coupling between local feedbacks and poleward energy transports, attempts to quantify each individual contribution to recent Arctic amplification (e.g., Crook et al., 2011) have yielded diverging results. In any case, the net effect of all relevant feedback processes turns out to be more positive in the Arctic than for the globe as a whole, resulting in Arctic amplification.

\subsection{Long-term climate variability and change}

How out of the ordinary are the recent climate changes in the Arctic? Earth's climate has always fluctuated, and will continue to do so in the future. It has 


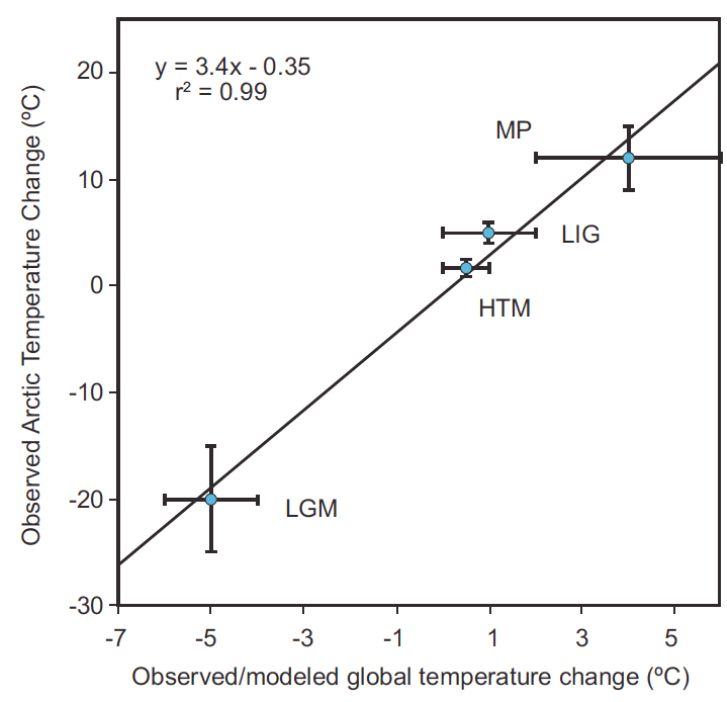

Figure 1.8 Quantification of the magnitude of Arctic amplification with paleoclimate data. Plotted are paleoclimate proxy estimates of Arctic summer temperature anomalies relative to the current climate state, and the associated Northern Hemisphere or global summer temperature anomalies, together with their uncertainties, for the Last Glacial Maximum (LGM; 21 kyr ago), Holocene Thermal Maximum (HTM; 8 kyr ago), Last Interglaciation (LIG; 130-125 kyr ago) and middle Pliocene ( 3.5 Myr ago). The trend line suggests that summer temperature changes are amplified 3-4 times in the Arctic (from Miller et al., 2010).

done so for many different reasons, including natural forcings external to the climate system, human-induced external forcings, and internal variability climate fluctuations not associated with external forcing. Natural variability might sometimes reinforce and sometimes dampen long-term trends. These internal climate fluctuations also vary considerably, and over a wide range of timescales. It is, therefore, imperative to examine the record of past climate change in the Arctic to provide a context in evaluations of recent climate change and also with respect to possible impacts of future climate change.

\subsubsection{Past: paleoclimates}

Global and Arctic climates have varied considerably in the past. Over geological time periods, Earth's climate has been forced by a number of natural forcings external to the climate system. These include tectonic processes that af- 
fect the location and topography of the continents (millions of years or longer), changes in the orbit of the Earth around the Sun that modulates the amount of solar radiation received by latitude and by season (tens to hundreds of thousands of years), and changes in the emissivity of the sun (decades, centuries, millennia). Although instrumental observations of Arctic climate changes before the 20th century are very scarce or absent, indirect paleoclimate proxy indicators do yield information on long-ago climatic changes. Sources of paleoclimate information on Arctic climate include ice cores, marine sediment cores, tree rings, lake sediments, and geomorphological features (e.g., Overpeck et al., 1997). Proxy data from these sources provide the necessary perspective on the sensitivity of the Arctic climate system, and at the same time provide a testing ground for climate model verification (Braconnot et al., 2012).

Current climate change is largely driven by atmospheric $\mathrm{CO}_{2}$ concentrations (Myhre et al., 2013). Therefore, it is informative to study periods of Earth's history when atmospheric concentrations of $\mathrm{CO}_{2}$ were very different than today. In this introduction, we highlight two geological time periods that will be referred to later in this thesis, namely the early Eocene climate as an analog for high $\mathrm{CO}_{2}$ conditions (Lowenstein and Demicco, 2006) and the Last Glacial Maximum as a low- $\mathrm{CO}_{2}$-climate case. Furthermore, we will examine the main climate variations during the Holocene.

Warm, past, 'greenhouse' climates are intriguing analogs in the perspective of recent climate warming. One such warm period concerns the Early Eocene Climatic Optimum (EECO, 54 to $48 \mathrm{Ma}$, where Ma is million years before present). During this time interval, both low- and high-latitude temperatures were much higher than today. Proxy estimates indicate that enhanced atmospheric $\mathrm{CO}_{2}$ concentrations of 1000 to 2000 ppm (Beerling and Royer, 2011) were, at least partly, responsible for these high temperatures. Superimposed on the already warm background climate, a geologically short period of extreme warming occurred, lasting about $~ 170,000$ years (170 kyr) (Röhl et al., 2007): the Paleocene-Eocene Thermal Maximum (PETM; 55 Ma). During the PETM, $\mathrm{CO}_{2}$-release to the atmosphere was a magnitude similar to that projected for the 21st century (Bowen et al., 2006). During this event, Arctic continental air temperatures increased from $\sim 17$ to about $25^{\circ} \mathrm{C}$ (Weijers et al., 2007), and sea surface temperatures from $\sim 18$ to $23^{\circ} \mathrm{C}$ (Sluijs et al., 2006). The PETM warming has been found to be stronger in the Arctic than in the tropics, providing one of the earliest estimates of Arctic amplification (Zachos et al., 2005). Hence, even under tropical high-latitude conditions, Arctic amplification was a feature of exceptional warming. This dramatic warming event coincided with the widespread 
extinction of deep-sea benthic foraminiferal species, which was associated with a decline in ocean ventilation (Winguth et al., 2012).

In contrast, as recently as $\sim 21 \mathrm{kyr}$ before present (ka), the Arctic was very cold and ice sheets reached their greatest extension during the last glacial period. Immense ice sheets covered much of North America, northern Europe, and northeast Asia. This glacial period, termed the Last Glacial Maximum (LGM), was the latest in a series of repeated glaciations, which in combination with intervening brief warm periods characterized the Pleistocene epoch $(\sim 2.6 \mathrm{Ma}-$ $11.5 \mathrm{ka}$ ). Pleistocene climate fluctuations were forced by variations in Earth's orbital parameters (Hays et al., 1976) in combination with reduced atmospheric $\mathrm{CO}_{2}$ levels (Ganopolski and Calov, 2011). During the LGM, $\mathrm{CO}_{2}$ concentrations dropped to around $200 \mathrm{ppm}$ (Anklin et al., 1997). High-latitude processes, such as the ice-albedo feedback and deep water formation in the North Atlantic, likely contributed to the climate changes as well. Due to the significant amount of ice on land, LGM sea level was about 120-135 m lower than today (Clark et al., 2002). During the LGM cold climate, Arctic temperatures were approximately $18^{\circ} \mathrm{C}$ lower than at present, compared to a global temperature decrease of 'only' $\sim 5^{\circ} \mathrm{C}$ (Miller et al., 2010), showing that Arctic amplification also occurred during past cold periods (Fig. 1.8).

The rate of temperature increase following the LGM was about $2^{\circ} \mathrm{C}$ per millennium between 20 and $10 \mathrm{ka}$ in Greenland, with smaller trends in other regions. Superimposed on these long-term temperature trends were abrupt high amplitude millennial-scale oscillations between warm and cold conditions known as Dansgaard-Oeschger (D-O) cycles (Dansgaard et al., 1993) as seen in Greenland ice cores. The sudden warmings associated with $\mathrm{D}-\mathrm{O}$ cycles were typical $\sim 10^{\circ} \mathrm{C}$ and occurred within a few decades, and may even have been as large as $16^{\circ} \mathrm{C}$ (Lang, 1999; Huber et al., 2006). Marine sediment cores show that these high latitude warmings were accompanied by synchronous temperature trends of $2-3^{\circ} \mathrm{C}$ in tropical Atlantic surface waters (Curry and Oppo, 1997), again indicating an amplified Arctic response. Incidentally, the origin of the internally-forced D-O cycles remains under debate (e.g., Dokken et al., 2013; Petersen et al., 2013; Peltier and Vettoretti, 2014).

The gradual warming that followed the LGM was interrupted by a sudden cooling event, the Younger Dryas (YD; 12.9-11.6 ka). The YD is often attributed to a freshwater pulse induced weakening of the Atlantic meridional overturning circulation, but the underlying climate mechanism was likely more complex (Renssen et al., 2015). Following the abrupt end of Younger Dryas, the Arctic appears to have been comparatively warm due to enhanced solar insola- 
tion. During this unusually warm period, known as the Holocene Thermal Maximum (Renssen et al., 2012), summer temperatures in the Arctic were $\sim 1.7^{\circ} \mathrm{C}$ above present-day values, much higher than the average summer temperature anomaly of $\sim 0.5^{\circ} \mathrm{C}$ for the entire Northern Hemisphere (Fig. 1.8) (Miller et al., 2010). At that time, treelines extended above their present limits and glaciers were greatly reduced. Around $5 \mathrm{kyr}$ ago, this warm phase was followed by a general cooling during which sea ice cover expanded southward again and glacier lengths increased. The most notable cold 'spell' during this period was the Little Ice Age (LIA) (Mann et al., 2009), which occurred between 1450 and 1850 as revealed by Greenland ice cores (Dahl-Jensen et al., 1998). Causes of the LIA are likely a combination of increased aerosols from volcanic eruptions, solar variability, a minor drop in greenhouse gases, and internal climate variability, but their relative contributions are still uncertain (Masson-Delmotte et al., 2013). The LIA has been followed by an overall warming, which extends to the present.

\subsubsection{Present: the instrumental record}

This section focuses on the observed variability and long-term changes in the Arctic since the beginning of the twentieth century. Performing in situ measurements in the Arctic is very challenging due to the extremely low temperatures, variable sea ice cover, prevailing winter darkness, and the remoteness. Over land, Arctic surface station temperature data extend back to the beginning of the 20th century, with spatial coverage before 1930 being very poor (Jones and Moberg, 2003). Over the Arctic Ocean, 20th-century temperature data are even scarcer and are mostly based on one or two manned Russian camps drifting on ice floes between 1950 and 1991 (Martin et al., 1997). After 1979, autonomous buoy data were continuously employed, but temperature measurements are of uncertain quality (Rigor et al., 2000). Beginning in the late 1970s to early 1980 s, clear-sky temperature retrievals from satellites with excellent spatial and temporal coverage became available (Comiso, 2003). All these data have been compiled into zonally averaged annual temperatures by e.g. Johannessen et al. (2004). However, due to uncertainties related with the retrieval of surface temperature from satellite data, gridded datasets, such as the widely used Hadley Centre-Climate Research Unit Version 4 (HadCRUT4) (Morice et al., 2012), only include in situ measurements to reconstruct surface temperature fields. Because of the undersampling of those measurements over the (high) Arctic, these datasets should be treated with caution. The Arctic coverage bias 
might even have contributed to an underestimation of the recent global warming trend (Cowtan and Way, 2014; Marvel et al., 2015).

Due to its continuously changing edges and immense size, it is virtually impossible to determine sea ice extent from direct observations accurately. The first systematic observations of Arctic ice extent with sufficient spatial and temporal coverage began in late 1978 by polar orbiting satellites using multichannel microwave radiometers (Gloersen et al., 1993). Arctic-wide sea ice thickness estimates from above-water height measurements of sea ice started as recently as 2003, within the first Ice, Clouds, and Land Elevation Satellite (ICESat) mission (Kwok and Rothrock, 2009), and are currently being continued with other satellites. To validate the indirect ice thickness estimates, observational campaigns remain invaluable.

Although satellites now provide much better and more sophisticated observational information on Arctic climate, not all quantities can be directly measured or derived. An alternative method to obtain observation-based information on these 'hard-to-measure' climate variables, is to use forecast models and data assimilation systems to 'reanalyze' archived observations. Even in observations-sparse regions such as the Arctic, the resulting atmospheric reanalysis products provide climate information that extends back as far as a century or more (Poli et al., 2013). In areas with low data coverage, however, the reanalysis product is more dependent on the model structure, modeling assumptions, and data assimilation methods compared to observation-rich regions. One should thus be carefull with using these products in undersampled regions such as the Arctic, and verify their reliability before usage (Screen and Simmonds, 2011; Simmons and Poli, 2015).

Some quantities can only be derived from a combination of in situ observations, satellite retrievals, and reanalysis products. For instance, the annual cycle of meridional energy transports in the ocean and atmosphere that is shown in Figure 1.3 (Fasullo and Trenberth, 2008) cannot be quantified with any single dataset. The computation of the transports includes energy budgets from satellite retrievals of top-of-the-atmosphere radiative fluxes, in situ ocean temperature measurements, and global atmospheric temperature and moisture reanalysis fields.

Figure 1.9 shows the time series of Arctic surface air temperature over the instrumental record from land stations. The time series clearly reveals an isolated Arctic warming in the 1930s and 1940s and the recent Arctic warming that is clearly part of global warming but amplified. In between these periods a pronounced cooling occurred during the 1960s-1970s. This warming-cooling- 


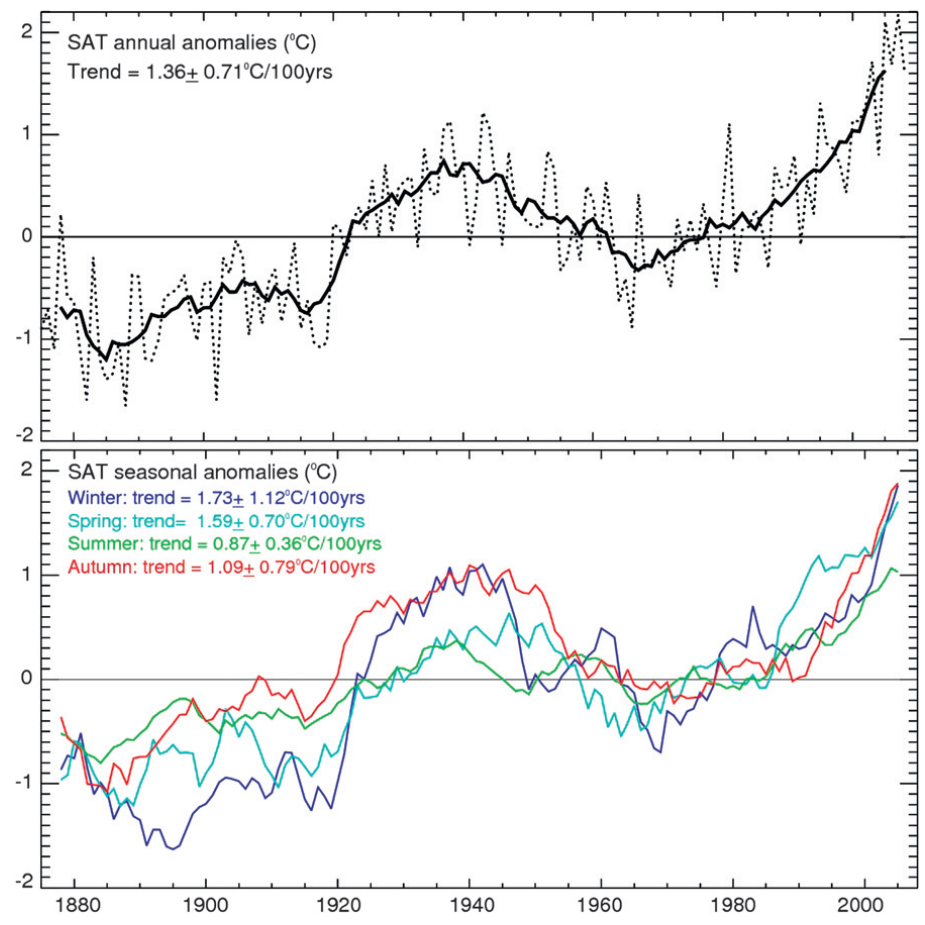

Figure 1.9 | Composite time series of the (top) annual and (bottom) seasonal surface air temperature $(\mathrm{SAT})$ anomalies $\left({ }^{\circ} \mathrm{C}\right)$ from high-latitude (poleward of $59^{\circ} \mathrm{N}$ ) meteorological land stations. Dotted lines show unsmoothed values; solid lines 7-yr running means. In the legend, trends are for 1900-2008 (from Bekryaev et al., 2010).

warming sequence in the Arctic time series is generally similar to the global time series, but decadal changes and interannual variability are much larger in the Arctic. The surface air temperature anomalies (deviations from the long-term mean) during each of these periods are largest in winter, and smallest in summer. The largest observed positive temperature trends over the 20th century are found in the Arctic in winter during the Early Twentieth Century Warming (ETCW; $3.8^{\circ} \mathrm{C} / 30 \mathrm{yr}$ ). On the other hand, the largest negative trends occurred in the Arctic in winter as well, during the cooling period in the middle of the 20 th century $\left(-2.7^{\circ} \mathrm{C} / 30 \mathrm{yr}\right)$. In the most recent warming period, Arctic surface air temperature trends reached over $\sim 3^{\circ} \mathrm{C} / 30 \mathrm{yr}$ in winter, autumn, and spring (Johannessen et al., 2016).

The ETCW is intriguing since it shares some characteristics with the present 
temperature trend, including an amplified Arctic response, but the human impact through enhanced greenhouse gas emissions was still small. This triggers the idea that the current warming might, at least partially, be due to natural multidecadal fluctuations of the climate system. However, the ETCW differs from the present warming in its geographical distribution. The ETCW occurred exclusively in the Arctic, in contrast to the recent warming which was a worldwide phenomenon (Yamanouchi, 2011), meaning that Arctic amplification during the ETCW was stronger than in recent years. Several views exist on how the ETCW evolved. External forcing from solar and volcanic activity alone seem insufficient to explain the observed warming (Bengtsson et al., 2004). Other studies suggest that internal variability can explain the ETCW (Beitsch et al., 2014). The pronounced warming pattern suggests that atmospheric circulation changes have contributed significantly (Wood and Overland, 2010). Also, a link between ocean heat transport and sea ice reductions has been proposed to have played a role (Semenov and Bengtsson, 2003). Either way, the respective roles of internal variability and external forcing on Arctic warming remains unclear, mainly due to limited data coverage and uncertainties about cause and effect. However, the answer involves most likely a combination of natural internal variability and positive feedbacks that amplified the warming, superimposed on a gradual background warming due to external forcing (Yamanouchi, 2011).

The most recent Arctic warming is well observed (see Section 1.1), and at least partly associated with anthropogenic forcing due to human-induced enhanced concentrations of greenhouse gases. However, it has proven difficult to quantify the contributions of external (natural and anthropogenic) forcings and natural internal variability to the recent warming, since the Arctic signal resulting from greenhouse gas forcing is considerable, but the variability (noise) is also significant. Hence, the signal-to-noise ratio may be lower than in other regions. Moreover, the paucity of observational data hampers analyses to determine the cause of Arctic warming. Whatever the driving mechanism is, polar amplification acts to enhance Arctic warming through several feedback mechanisms, including those related to sea ice loss, changes in the oceanic and atmospheric circulation, water vapor, cloud cover, and other processes (see Section 1.2.4). All feedbacks can interact mutually, thereby promoting an amplified Arctic response for which it is complicated to separate and quantify their individual contributions using only observations. Climate models are the most promising way to obtain a better understanding of the changes in Arctic climate. 


\subsubsection{Future: climate model projections}

The primary tools for understanding and projecting Arctic climate change are global climate models, or General Circulation Models (GCMs). These mathematical representations of the climate system are based on the fundamental laws of physics, including conservation of mass, energy, and momentum, and reproduce many important aspects of Earth's climate (Flato et al., 2013). GCMs are intimately related to models used for day-to-day weather prediction. The most extensively used GCMs are coupled Atmosphere-Ocean General Circulation Models (AOGCMs). They contain essential components of the climate system, including the atmosphere, oceans, land surface, and sea ice, and some GCMs have even incorporated an ice sheet model for Greenland. Over the past decade, many models have been extended into Earth System Models by including the representations of physical and biogeochemical cycles that simulate Earth's cycles of carbon and aerosols (Flato, 2011).

The atmosphere and the ocean are represented on three-dimensional (latitude-longitude-height) grids. Grids of the climate models that are used within this thesis have a typical horizontal resolution of one to two degrees, with about 50 layers in the vertical for both the atmosphere and the ocean. Contemporary climate models explicitly resolve large-scale oceanic currents and the overturning circulation, and synoptic features in the atmosphere, such as the progression of high- and low-pressure systems. For all small-scale ('subgrid') processes that cannot be resolved by this resolution, parameterizations have to be used in all model components, the effects of which are expressed in an approximate form on the coarser model grid. For instance, small-scale processes associated with cloud formation, oceanic and atmospheric turbulence, and radiation, have to be parameterized.

Sea ice is generally represented by multiple layers in the vertical with one layer of snow on top. Equations specify processes such as internal ice stress, horizontal transport, and thermodynamics. Sea ice melt or growth is computed from energy budgets at the top and bottom surfaces of the snow-ice cover. The multi-layer structure accounts for storage of sensible heat and vertical heat conduction. Further, most sea ice models incorporate latent heat storage in brine pockets and represent the formation of leads (open water) in the ice cover. An effective thermal conductivity implicitly implements the effect of a subgrid scale thickness distribution. Most sea ice models have a fairly straightforward albedo scheme that accounts for the state of the surface (frozen or melting) and the presence of snow on the ice (snow-covered or bare ice). The most widely 
used method to represent melt ponds is to decrease the surface albedo under melting conditions (Hunke et al., 2011). However, more advanced parameterizations, such as a multiple-scattering radiation scheme, the evolution of salinity inside the ice, and a multi-category ice thickness distribution, are making their way into the sea ice components of global climate models (Bitz et al., 2012).

On finer model grids, more small-scale processes can be resolved explicitly, but then the simulations become computationally much more expensive since the number of grid cells increases and the time step has to be smaller. Due to the ongoing expansion of computing and storage capacity, the next generation of GCMs runs at resolutions of $50 \mathrm{~km}$ or finer in the atmosphere, and $0.25^{\circ}$ or less in the ocean. At this resolution, more 'mesoscale' processes can be explicitly resolved, such as mixing due to oceanic eddies and extratropical cyclones in the atmosphere (e.g., Delworth et al., 2012; Kirtman et al., 2012; Haarsma et al., 2013). Depending on the aim of the experiment, one should consider the benefits of resolving small-scale processes in simulating climate mechanisms as realistic as possible against computational and storage costs, as well as the duration of the simulation.

Much of our current knowledge of the Arctic climate system is derived from climate model simulations. To have confidence in the information provided by these models, it is imperative to evaluate the climate model performance against observations. Aspects that should be assessed include observed trends, mean seasonal cycles, spatial and temporal variability patterns, responses to perturbations, and mutual interactions between relevant variables (Gleckler et al., 2008; Pincus et al., 2008; Reichler and Kim, 2008). As mentioned before, validation is complicated due to the lack of observations in the Arctic, especially over the Arctic Ocean. Reanalysis data are therefore useful to assess model performance in the Arctic region. Also, paleoclimate proxy data can serve to verify the ability of models to simulate climate conditions that are different from today's.

Climate models are vital to understanding processes and feedbacks between variables and components that are difficult, or even impossible, to examine using observations alone. A standard way to do this is a sensitivity test. In the real climate system, many aspects vary simultaneously and can hardly be controlled or analyzed in isolation (i.e. without changing many other variables). In a sensitivity test, only one boundary condition or physical description is altered in the present-day configuration of the model. For instance, the atmospheric $\mathrm{CO}_{2}$ concentration can be doubled instantaneously. By comparing the output of such a sensitivity simulation with the present-day control case, the importance of the 


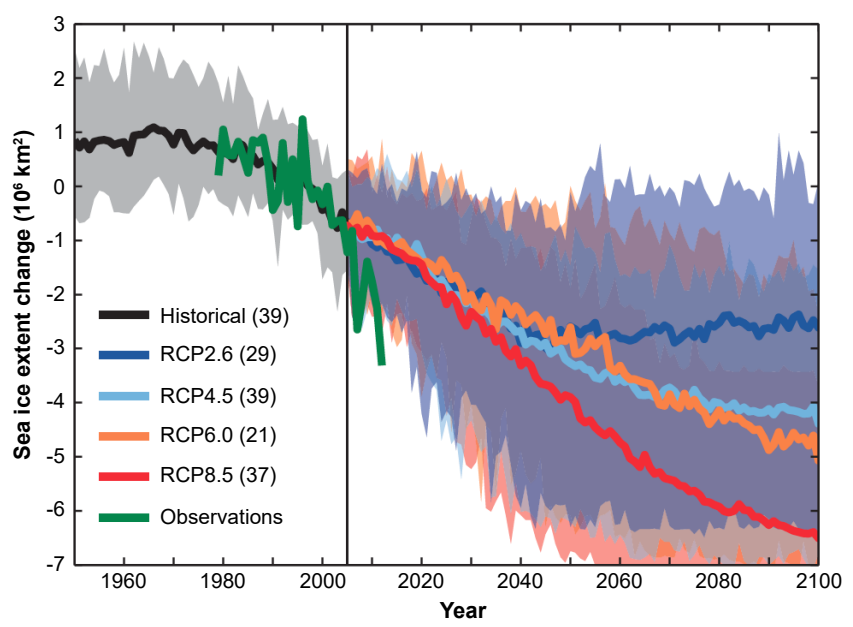

Figure 1.10 | Changes in Northern Hemisphere sea ice extent as simulated by CMIP5 models over the period 1950 to 2100 under a wide range of possible future forcing scenarios (RCP2.6, RCP4.5, RCP6.0, and RCP8.5) for September. The solid curves show the multimodel mean values, and the shading represents the 5 to $95 \%$ range of the associated models. The number of models in each ensemble is indicated in the legend. Changes are relative to the period 1986-2005. Also, satellite data of (Comiso and Nishio, 2008) are plotted over 1979-2012 (green solid curves). As a reference, September sea ice extent averaged over 1986-2005 is about 7 million km² (from Collins et al., 2013).

perturbation in the modeled system is isolated, allowing a better understanding of the relevant climate mechanisms. A disadvantage of using only one model to do so is that the results may be model dependent.

Furthermore, climate models can be used to make projections of climate over the coming century and beyond (Fig. 1.10). However, projections of future climate cannot be simply extrapolated from the past climate owing to several sources of uncertainty (Hawkins and Sutton, 2009). Part of the uncertainty arises from unknown future concentrations of greenhouse gases and other anthropogenic and natural forcing agents. Therefore, a range of plausible future greenhouse gas and aerosol concentration pathways or emission scenarios has to be taken into account. However, even with the same external forcing conditions, there is considerable scatter between projections of individual models, including the rate of warming, as well as the geographical patterns of the changes and the temporal evolution of temperature and other climate indices. Not unexpectedly, these intermodel differences are largest in the high northern 
latitudes (Holland and Bitz, 2003). Reasons for the intermodel scatter include incomplete understanding of climate mechanisms and differences in parameterizations of small-scale processes. However, in each model simulation a part of the intermodel scatter will remain irreducible since the effects of greenhouse gases will be superimposed on low-frequency natural climate variability that is inherently unpredictable owing to the chaotic nature of the climate system (Knutti and Sedláček, 2012). For any moment in time, the real and simulated climates may be in different phases of low-frequency variability. Multicentury long simulations from climate models are required to assess the influence of natural variability on decadal to multidecadal timescales, in part because the current observational record is too short, and also in part because observations are not free from external influences (Stott et al., 2010).

To assess and characterize intermodel differences, future model projections are generally carried out using a coordinated set of experiments, in which many climate models are run with the same external forcing conditions. The Coupled Model Intercomparison Project Phase 5 (CMIP5) (Taylor et al., 2012) is the most recent coordinated set of simulations. Without exception, CMIP5 climate models project a continuation of the strong warming trend of the recent decades, with the largest warming in the Arctic. Furthermore, year-round reductions in Arctic sea ice extent are simulated (see Fig. 1.10), with the Arctic becoming ice-free in summer before the end of the 21st century in the highest emission scenario for $90 \%$ of the models (Collins et al., 2013).

\subsection{Aims and outline}

In the previous sections, it was shown that the strongest warming on Earth in recent decades occurred in the Arctic, a process that is still ongoing. This regional climate change can in part be attributed to a global warming signal caused by increased greenhouse gas concentrations, but is locally amplified by various feedback processes. It is important to know how Arctic warming will develop in the future. For this reason, projections of Arctic and global climate change are made with global climate models. This type of projections are subject to various types of uncertainties, which are partly related to an incomplete knowledge of the climate system, but also to internal climate variability which in the Arctic is relatively large.

The primary objective of this thesis is to understand how anthropogenic forcing by greenhouse gases and aerosols and natural decadal to multi- 
decadal variability affect the Arctic climate system, in order to improve our understanding of observed Arctic climate changes and to better forecast future Arctic climate changes. The underlying hypotheses are: 1) simulated anthropogenically-forced decade-to-century-scale Arctic climate changes depend on the representation of the mean state of the Arctic climate system in global climate models; and 2) natural decadal to multidecadal climate variability substantially contributed to Arctic climate change over the past century, and has the potential to dampen or amplify anthropogenically-forced changes in future Arctic climate.

Climate models have become more and more complex as our understanding of the climate system improved, leading to better parameterizations of small-scale processes and feedbacks, and thereby to a more realistic representation of the real climate system (Flato et al., 2013). Nevertheless, there are large intermodel differences in future climate projections, which peak in the Arctic region, indicating significant uncertainties in the simulated climate response in the Arctic compared to other parts of the globe. The large intermodel scatter poses the question:

Q1 What causes the intermodel spread in future climate model simulations of Arctic warming?

Chapter 2 addresses this question and focuses specifically on the role of the mean state of Arctic sea ice since there is considerable uncertainty in how well current sea ice cover is simulated by climate models. For this purpose, a multimodel assessment of standardized scenario simulations is used to investigate the role of the large-scale mean state of the sea ice cover, i.e. its extent and volume, but also to study in more detail how the spatial distribution of ice concentration and thickness contributes to Arctic warming. This multi-scale approach provides new insights into the relation between the simulated mean state of Arctic sea ice and long-term surface temperature trends.

Physical processes that cause the intermodel spread are not necessarily the same physical processes that contribute most to Arctic warming. However, the physical mechanisms that enhance Arctic warming might amplify the intermodel spread. Chapter 3 therefore concentrates on the question:

Q2 What feedback mechanisms contribute to Arctic amplification, and to what extent? 
We focus on the dynamical feedback mechanisms that contribute to Arctic warming, while the contribution of ocean heat transport is investigated in detail. We carried out sensitivity simulations with a fully coupled oceanatmosphere global climate model, in which both high- $\mathrm{CO}_{2}$ and low- $\mathrm{CO}_{2}$ forcing conditions were applied. In this way, ocean processes in both warmer and colder climates than the present-day climate can be assessed. The principal regions of investigation are the subpolar North Atlantic, where the dominant oceanic mechanisms that influence the Arctic are most likely located, and the Nordic Seas, where in the present climate the greatest poleward heat transport into the Arctic occurs.

On all timescales, surface temperature changes tend to be larger in the Arctic than anywhere else on Earth (Serreze and Barry, 2011). This applies to equilibrium changes, but also to changes that are related to decadal variability. The driving mechanisms of natural decadal variability in the Arctic region are, however, not yet well understood. Chapter 4 investigates these processes, addressing the question:

Q3 What are the causes and governing mechanisms of Arctic low-frequency climate variability?

This chapter concentrates on the long-term climate fluctuations over the Barents Sea, where the variability in the Arctic is greatest. We describe the mechanisms driving surface temperatures and energy fluxes in the Barents Sea, based primarily on analyses of a multicentury preindustrial climate simulation of one coupled climate model. For this purpose an energy budget approach is used, in which the Barents Sea is treated as a box with in- and outflow of energy fluxes. Leads and lags, as well as monthly differences between climate variables, are investigated to obtain a better understanding of the seasonally-varying climate mechanisms of low-frequency variability.

In Chapter 4, we studied mechanisms underlying natural climate variability in one climate state. However, the Arctic is warming at a relatively fast rate, and sea ice is rapidly diminishing. This means that the background climate on which natural variability is superimposed is changing, raising the question:

\section{Q4 How does Arctic low-frequency climate variability change in a warming world?}

Chapter 5 uses the high- $\mathrm{CO}_{2}$ sensitivity experiments of Chapter 3 to address this question. Our approach concentrates on large-scale coupled mechanisms that are involved in atmosphere-ice-ocean interactions. Changing relationships between the three leading modes of atmospheric variability and Arctic climate 
characteristics are assessed. For a better process understanding, oceanic and atmospheric energy transports toward the Arctic are also taken into account.

Finally, in Chapter 6 we summarize and reflect on the results of the previous chapters, and put them in a broader context. Furthermore, we provide recommendations for future research. 



\title{
2
}

\section{The role of the mean state of Arctic sea ice on near-surface temperature trends}

\author{
E. C. van der Linden, R. Bintanja, W. Hazeleger, and C. A. Katsman
}

Journal of Climate, 2014, 27 (8), 2819-2841

Century-scale global near-surface temperature trends in response to rising greenhouse gas concentrations in climate models vary by almost a factor two, with greatest intermodel spread in the Arctic region, where sea ice is a key climate component. Three factors contribute to the intermodel spread: (1) model formulation, (2) control climate state, and (3) internal climate variability. This study focuses on the influence of Arctic sea ice in the control climate on the intermodel spread in warming, using idealized $1 \%$ per year $\mathrm{CO}_{2}$ increase simulations of 33 state-of-theart global climate models, and combining sea ice-temperature relations on local to large spatial scales. On the Arctic mean scale, the spread in temperature trends is only weakly related to ice volume or area in the control climate, and is probably not dominated by internal variability. This suggests that other processes, such as ocean heat transport and meteorological conditions, play a more important role in the spread of long-term warming than control sea ice conditions. However, on a local scale, sea ice-warming relations show that in regions with more sea ice, models generally simulate more warming in winter and less warming in summer. The 
local winter warming is clearly related to control sea ice and universal among models, whereas summer sea ice-warming relations are more diverse, and are probably dominated by differences in model formulation. To obtain a more realistic representation of Arctic warming it is recommended to simulate control sea ice conditions in climate models so that the spatial pattern is correct.

\subsection{Introduction}

High northern latitudes exhibit more warming in a climate with increasing greenhouse gas concentrations than other regions, indicating an amplified climate response in the Arctic. The amplified Arctic warming is visible in both observations and climate model simulations (Johannessen et al., 2004; Manabe and Stouffer, 1980; Miller et al., 2010; Serreze and Barry, 2011). In coupled models, the rate of Arctic annual mean warming (based on $1 \%$ per year increase in atmospheric $\mathrm{CO}_{2}$ concentration) is projected to be roughly two to four times larger than the global mean response (Holland and Bitz, 2003; Winton, 2006a) (Table 2.1). The intermodel spread in projected warming is also greatest in the Arctic, indicating a large uncertainty in the simulated climate response in the Arctic compared to any other region of the globe. Shortwave feedbacks (Hall, 2004; Winton, 2006a), longwave feedbacks (Boé et al., 2009; Bintanja et al., 2011), and northward heat transport (Holland and Bitz, 2003; Cai, 2006; Ridley et al., 2007; Mahlstein and Knutti, 2011) have all been shown to contribute to Arctic warming, but there is no consensus on their relative magnitude (Kay et al., 2012). The physical processes that contribute most to Arctic warming are not necessarily the same that cause the intermodel spread. In high northern latitudes, sea ice is thought to play a crucial role in amplifying local temperature changes (Screen and Simmonds, 2010). Global climate models underestimate the trend in the annual minimum sea ice extent in the Arctic over the past decades (Stroeve et al., 2007; Winton, 2011), although the newest generation of climate models seems to perform somewhat better on this point (Stroeve et al., 2012a). Mahlstein and Knutti (2012) found that Arctic temperature and sea ice area are nearly linearly related, which can be used to estimate at what global temperature increase the Arctic will be ice-free in September. It is therefore imperative to elucidate the reasons behind the spread in both the temperature and sea ice trends in the Arctic. 
Three important aspects determine the climate pathway, and thus temperature and sea ice trends, of a single model simulation in response to (changes in) radiative forcing: (1) model formulation of physics and dynamics (including parameterizations), (2) control climate state, and (3) internal climate variability (Kattsov et al., 2010). If we want to understand the cause of the spread in climate response, the uncertainty that is related to all these three aspects should be analyzed.

Uncertainty related to the model formulation of physics and dynamics is largest at high latitudes (Hawkins and Sutton, 2009). Being a key component of the Arctic climate system, sea ice is expected to be an important actor in the temperature response in the Arctic through various feedback mechanisms. Intermodel differences in representations of the various sea ice-related feedbacks in climate models can significantly contribute to divergence of the projected temperature responses. Model features responsible of different climate responses are, however, not the focus of this study.

The second major factor that governs the response of climate models is the mean climate state from which a climate simulation is started, termed the control climate. The control climate is usually obtained from a reference model integration, in which the forcing is kept constant over hundreds of years or longer. Each global climate model will simulate its own unique control climate conditions due to a combination of internal model physics and tuning. These conditions include the state of the atmosphere, ocean, sea ice, and land. Even though climate models are mostly tuned so that control conditions best match observational constraints, fundamental laws of nature (e.g. conservation of energy, mass and momentum) must be obeyed. As a consequence, control climate conditions of Arctic sea ice vary considerably between global climate models (Flato, 2004; Arzel et al., 2006). If the climate system is very sensitive to these control conditions, then projections of climate will exhibit an uncertainty associated with the varying control state.

The third source of spread in climate response is internal climate variability. Deser et al. (2012) show that besides variability on interannual to decadal timescales, in some regions even trends over 50 years are subject to substantial uncertainty related to internal variability. Therefore, the influence of internal variability should be evaluated when externally forced climate change signals are assessed (Tebaldi et al., 2011). This applies especially for regions where natural variability is high, such as the Arctic. However, the relative importance of internal variability compared to model physics and dynamics in the spread of climate projections decreases over longer time scales (Hawkins and Sutton, 
2009).

As the largest intermodel spread in temperature response is in the Arctic, where sea ice is the key component, one would expect that sea ice is at least partially responsible for the modeled spread in warming and Arctic amplification. The role of the mean control climate state of Northern Hemispheric sea ice on the spread in simulated temperature response was examined in various modeling studies. For instance, Rind et al. (1995) found that global climate sensitivity is greater for more extensive or thinner sea ice cover. This finding was based on one particular model with a mixed-layer ocean coupled to an atmospheric general circulation model. In a subsequent study, Rind et al. (1997) found that Northern Hemisphere sea ice thickness affects global climate sensitivity more than its extent. Holland and Bitz (2003) expanded upon this by making an intermodel comparison between atmosphere-ocean general circulation models, and focused on Arctic temperature amplification instead of global warming. They found enhanced Arctic amplification in models with thinner sea ice, which typically exhibit larger ice extent loss, suggesting a stronger ice-albedo feedback. Flato (2004) confirmed that models with thick ice in their control climate tend to produce less Arctic warming than models with thin ice. Mahlstein and Knutti (2011) also found an intermodel relation between Arctic warming and sea ice extent, linked by ocean heat transport differences between models. However, all the above studies dealt mainly with the large-scale mean state of Arctic sea ice: its mean thickness and extent. The large-scale state of sea ice, however, does not give information about its spatial distribution, which may be relevant to explain different patterns of simulated warming, through local sea ice feedbacks. Also, differences in model physics might be more pronounced on smaller scales, because these might be overwhelmed by large-scale processes if averaged over a large geographic region.

Our aim is to obtain a better understanding of the relation between control climate sea ice conditions and surface air temperature trends, by expanding upon previous studies with a multiscale analysis: varying from a classification based on local sea ice conditions to the entire Arctic. For the former, the sea ice cover is spatially divided into several sea ice classes, based on its local sea ice thickness or concentration. On this scale, correlation analyses are applied to each model separately, and provide more insight into local model physical processes that are related to spatial differences in near-surface warming. On the Arctic scale the focus is on the influence of differences in control climate sea ice on the intermodel spread in surface air temperature trends. On this spatial scale, the hemispherically integrated quantities of thickness and concen- 
Table 2.1 | Model name, modeling center and institution of the models used in this study.

\begin{tabular}{|c|c|c|c|}
\hline \# & Model & Modeling Center & Institution \\
\hline 1 & ACCESS1.0* & CSIRO-BOM & $\begin{array}{l}\text { CSIRO (Commonwealth Scientific and Industrial Re- } \\
\text { search Organisation, Australia), and BOM (Bureau of } \\
\text { Meteorology, Australia) }\end{array}$ \\
\hline 2 & ACCESS1.3* & ” & 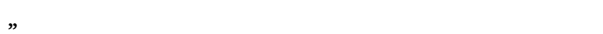 \\
\hline 3 & BCC-CSM1.1* & $\mathrm{BCC}$ & $\begin{array}{l}\text { Beijing Climate Center, China Meteorological Adminis- } \\
\text { tration }\end{array}$ \\
\hline 4 & BCC-CSM1.1(m)* & $”$ & 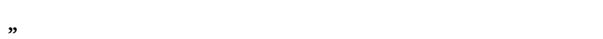 \\
\hline 5 & BNU-ESM* & GCESS & $\begin{array}{l}\text { College of Global Change and Earth System Science, } \\
\text { Beijing Normal University }\end{array}$ \\
\hline 6 & CanESM2* & CCCMA & Canadian Centre for Climate Modelling and Analysis \\
\hline 7 & CCSM $4 * *$ & NCAR & National Center for Atmospheric Research \\
\hline 8 & CESM1(BGC) $)^{* * *}$ & NSF-DOE-NCAR & $\begin{array}{l}\text { National Science Foundation, Department of Energy, } \\
\text { National Center for Atmospheric Research }\end{array}$ \\
\hline 9 & CESM1(CAM5) $* * *$ & $»$ & 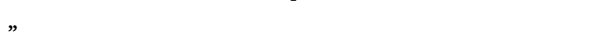 \\
\hline 10 & CMCC-CM ${ }^{* * * *}$ & CMCC & Centro Euro-Mediterraneo per I Cambiamenti Climatici \\
\hline 11 & CNRM-CM5* & CNRM-CERFACS & $\begin{array}{l}\text { Centre National de Recherches Meteorologiques / Cen- } \\
\text { tre Europeen de Recherche et Formation Avancees en } \\
\text { Calcul Scientifique }\end{array}$ \\
\hline 12 & CSIRO-Mk3.6 & CSIRO-QCCCE & $\begin{array}{l}\text { Commonwealth Scientific and Industrial Research Or- } \\
\text { ganization in collaboration with Queensland Climate } \\
\text { Change Centre of Excellence }\end{array}$ \\
\hline 13 & EC-EARTH* & EC-EARTH & EC-EARTH consortium \\
\hline 14 & FGOALS-g2 & LASG-CESS & $\begin{array}{l}\text { LASG, Institute of Atmospheric Physics, Chinese } \\
\text { Academy of Sciences; and CESS, Tsinghua University }\end{array}$ \\
\hline 15 & FGOALS-s2 & LASG-IAP & $\begin{array}{l}\text { LASG, Institute of Atmospheric Physics, Chinese } \\
\text { Academy of Sciences }\end{array}$ \\
\hline 16 & GFDL-CM3* & NOAA GFDL & Geophysical Fluid Dynamics Laboratory \\
\hline 17 & GFDL-ESM2G & 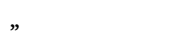 & $"$ \\
\hline 18 & GFDL-ESM2M & ” & ” \\
\hline 19 & GISS-E2-H** & NASA GISS & NASA Goddard Institute for Space Studies \\
\hline 20 & GISS-E2-R* & $"$ & $"$ \\
\hline 21 & HadGEM2-ES* & MOHC & Met Office Hadley Centre \\
\hline 22 & INM-CM4* & INM & Institute for Numerical Mathematics \\
\hline 23 & IPSL-CM5A-LR & IPSL & Institut Pierre-Simon Laplace \\
\hline 24 & IPSL-CM5A-MR* & $”$ & 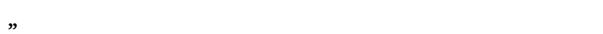 \\
\hline 25 & IPSL-CM5B-LR & $”$ & 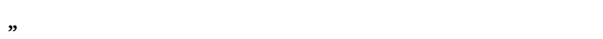 \\
\hline 26 & MIROC5* & MIROC & $\begin{array}{l}\text { Atmosphere and Ocean Research Institute (The Uni- } \\
\text { versity of Tokyo), National Institute for Environmental } \\
\text { Studies, and Japan Agency for Marine-Earth Science and } \\
\text { Technology }\end{array}$ \\
\hline 27 & MIROC-ESM**** & 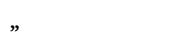 & 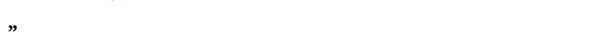 \\
\hline 28 & MPI-ESM-LR* & MPI-M & Max Planck Institute for Meteorology \\
\hline 29 & MPI-ESM-MR* & $”$ & 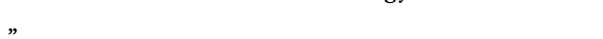 \\
\hline 30 & MPI-ESM-P* & $"$ & $"$ \\
\hline 31 & MRI-CGCM3* & MRI & Meteorological Research Institute \\
\hline 32 & NorESM1-M** & NCC & Norwegian Climate Centre \\
\hline 33 & NorESM1-ME ${ }^{* * *}$ & $”$ & 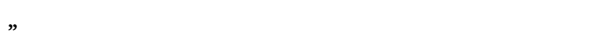 \\
\hline
\end{tabular}

* Arctic nearly free of September sea ice (less than 1.0 million $\mathrm{km}^{2}$ ) before end of 1pctCO2 simulation (140 yr). ** Unknown year of initialization of 1pctCO2 simulation, the piControl climate is defined as the first 80-year interval of the piControl simulation.

***: Sea ice trends of 1 pctCO2 simulation are missing. 
tration, i.e. volume and area, are studied. Correlation analysis is applied to the multimodel ensemble to get a better understanding of the cause of intermodel differences in Arctic near-surface warming.

\subsection{Data and methods}

Global and Arctic surface air warming (at 2 meters) and their relation to the control climate mean sea ice state and evolution are assessed, based on simulations of a multimodel ensemble of 33 Atmosphere-Ocean General Circulation and Earth System Models (AOGCMs and ESMs). All of the included simulations contribute to the fifth phase of the Coupled Model Intercomparison Project (CMIP5) (Taylor et al., 2012). The CMIP5 models and modeling groups that provided the data are listed in Table 2.1. For each of the models a set of two simulations with different forcing conditions was used: a control simulation with constant pre-industrial (1850) $\mathrm{CO}_{2}$ concentration (piControl), and an idealized simulation with increasing $\mathrm{CO}_{2}$ concentration (1pctCO2). In the $1 \mathrm{pctCO} 2$ scenario, $\mathrm{CO}_{2}$ in the atmosphere was increased at a rate of $1 \%$ per year from piControl $\mathrm{CO}_{2}$ concentration to about four times its control value at 140 years. Only the first ensemble member of each model was included in the analysis. The 1 pctCO2 scenario with a well-defined and large external forcing ('academic climate sensitivity experiment') was chosen over more realistic future scenarios involving various forcing agents, as our aim is to better understand why climate models differ in their temperature response.

Each CMIP5 model provides output on its native grid with its original landsea mask, which quantifies the portion of the surface covered by land and by sea. To facilitate the grid-point-wise intercomparison of models with output on a different grid, prior to analysis, all data sets were interpolated to a common $1^{\circ} \times 1^{\circ}$ latitude/longitude grid, using bilinear interpolation. By interpolating to a typical grid resolution of the ocean grid (on which sea ice output is stored) of CMIP5 models, i.e. $1^{\circ}$ (Taylor et al., 2012), we try to minimize uncertainties that are associated with the interpolation. We did not apply a common land-sea mask for sea ice computations because this has a potentially large effect on the total computed sea ice volume or area (Massonnet et al., 2012).

We consider four characteristics of Arctic sea ice cover: thickness, concentration, volume and area. Ice thickness is equal to the total ice volume in a grid cell distributed equally over the cell area, and Arctic ice volume is the integrated sea ice thickness across all grid cells in the Northern Hemisphere. Simi- 

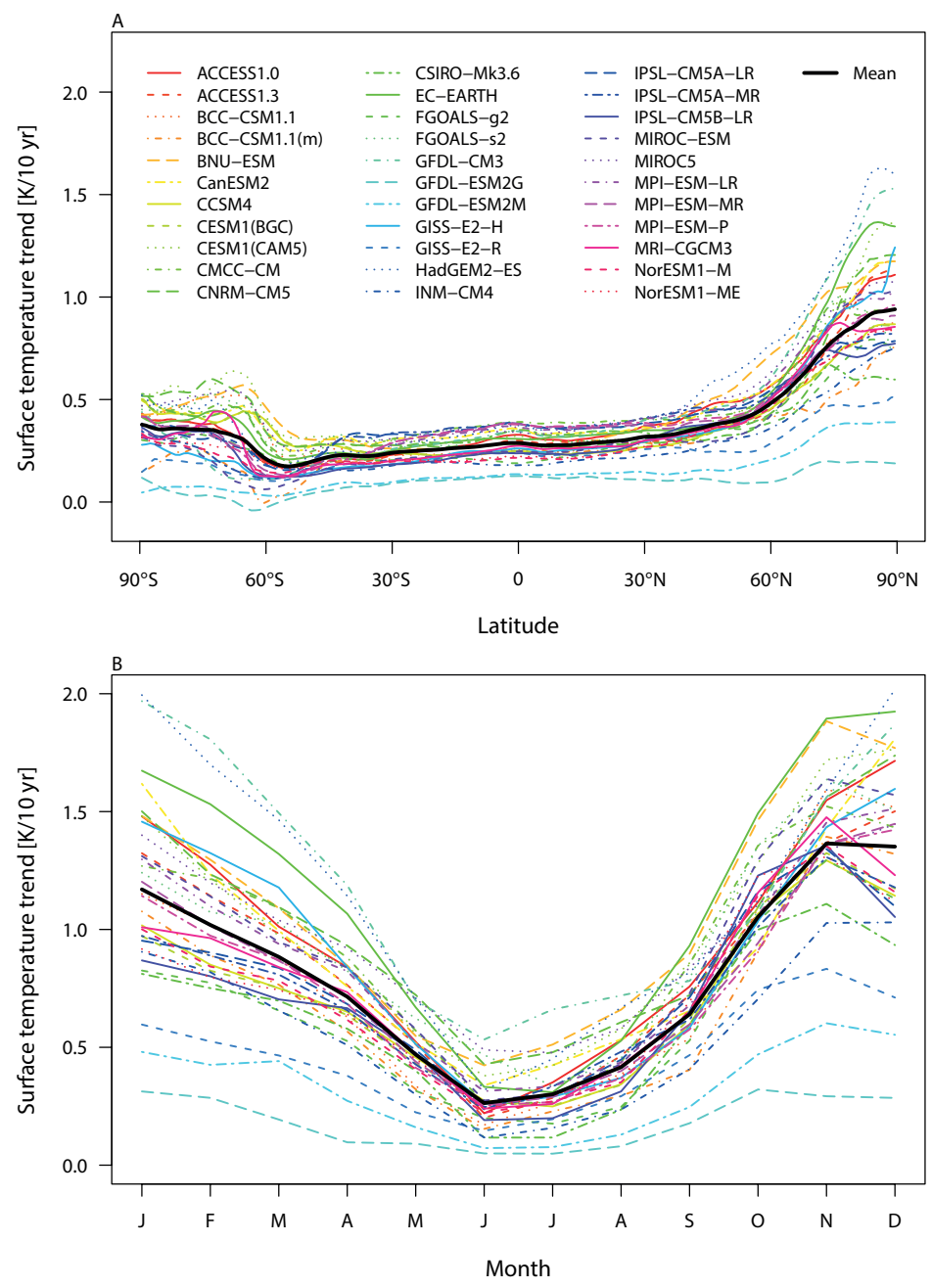

Figure 2.1 | (a) Zonal mean surface air temperature trends over 140 years in the $1 p c t C O 2$ simulation for the 33 global climate models, and the multimodel mean (black line). (b) Seasonal cycle of Arctic $\left(70-90^{\circ} \mathrm{N}\right)$ surface air temperature trends. Models GFDLESM2G and GFDL-ESM2M did not continue with increasing $\mathrm{CO}_{2}$ after reaching twice the piControl concentration (Caldeira and Myhrvold, 2013), and are not included in the multimodel mean. 

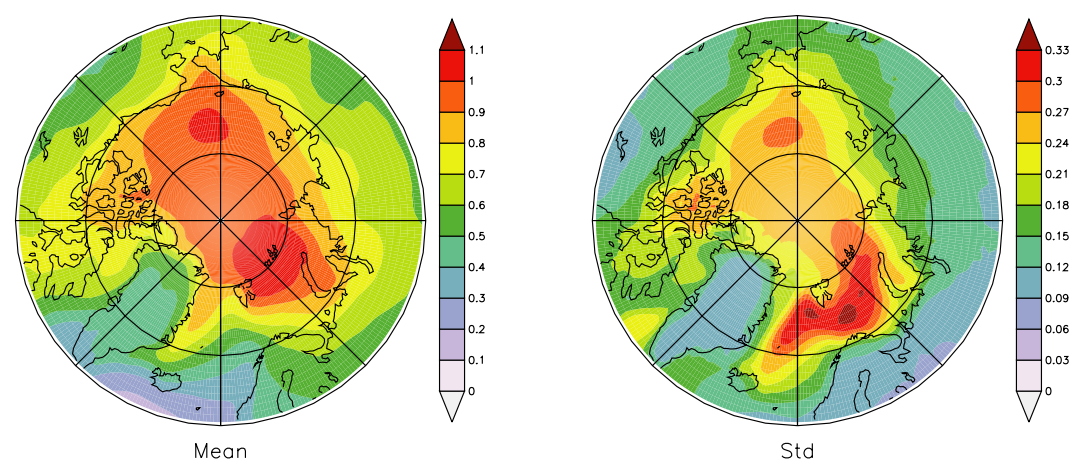

Figure 2.2 | Multimodel mean of surface air temperature trends (in $\mathrm{K} / 10 \mathrm{yr}$ ) in the 1 pctCO2 simulation, and its standard deviation. Note the differences in color scale. Models GFDL-ESM2G and GFDL-ESM2M are excluded.

larly, sea ice concentration is the fraction of the grid cell covered by sea ice, and sea ice area is the integrated sea ice concentration across the Northern Hemisphere. Mean thickness or concentration of a geographical region is computed by excluding grid cells which consist of only open ocean. We use sea ice area instead of extent, because sea ice extent is generally based on a binary term which marks each grid cell as either 'ice-covered' or 'not ice-covered' defined by a cutoff concentration to mark the ice edge (typically 15\%), and does not give information about the real surface area that is actually covered with ice (Chevallier and Salas-Mélia, 2012). Arguably, in studies that focus on sea ice-related warming feedbacks, total area is more relevant than extent (Blanchard-Wrigglesworth et al., 2011). Arctic surface air temperature is defined as the average surface air temperature over the region north of $70^{\circ} \mathrm{N}$.

The piControl mean climate is defined as the 80 -year mean value of the piControl simulation. From the 1pctCO2 simulation, linear trends of the four sea ice components and surface air temperature are computed by Ordinary Least Squares (OLS) regression. The linear regression over 140 years reveals the longterm systematic climate trend, and reduces the effect of low-frequency natural climate fluctuations over (multi-)decadal timescales (Vinnikov et al., 1999). Before computing the trends, each dataset was corrected for drift using the piControl simulation (Table 2.1). 


\subsection{Temperature trends and control sea ice state}

In this section, we examine the surface air temperature trends and sea ice state of the set of models that we use in our analyses. First, we examine the nearsurface temperature trends in the 1 pctCO2 simulation, to get a clear picture of model similarities and differences therein. Next, the piControl Arctic sea ice cover is explored, both its multimodel mean state and individual model spatial characteristics.

\subsubsection{Surface air temperature trends}

Figure 2.1a shows the zonal annual-mean temperature trend near the surface in the 1pctCO2 simulation for the various CMIP5 models. The temperature trend in models GFDL-ESM2G and GFDL-ESM2M is small relative to other models, because $\mathrm{CO}_{2}$ concentration was held constant after doubling its piControl value (Caldeira and Myhrvold, 2013). Globally averaged, the annual-mean warming to a transient $\mathrm{CO}_{2}$ quadrupling ranges from 3.15 to $5.71 \mathrm{~K}$ across the remaining 31 global climate models used in this study, with a multimodel mean $( \pm 1$ standard deviation) of $4.50 \pm 0.73 \mathrm{~K}$, and the magnitude of annual-mean Arctic warming is $11.69 \pm 2.48 \mathrm{~K}$ (Table 2.2). The Arctic warming is amplified relative to the global warming by a factor ranging from 1.94 to 3.40 , with a mean value of $2.59 \pm 0.38$ (Table 2.2). The spread (defined as the standard deviation) in the annual-mean Arctic temperature trend is more than three times larger than the global mean value.

We use a 36-member multimodel ensemble of the 95-yr RCP8.5 scenario (Taylor et al., 2012) to estimate the effect of internal variability on intermodel spread in century-scale surface air temperature trends. Note that this is a different model ensemble than the one used in the rest of the paper. RCP8.5 is chosen over 1pctCO2, because it includes more members per individual model than 1pctCO2, and because the surface air temperature trend in RCP8.5 is of similar magnitude as in 1pctCO2. Spread in a multimodel ensemble is due to model formulation, control climate and internal variability, whereas in an ensemble of an individual model spread is due to internal variability alone. By computing the ratio of the spread in a multimodel ensemble to the spread in an individual model's ensemble with an equal number of members, an estimation of the signal-to-noise ratio of model formulation-plus-control climate relative to internal variability is obtained. If the signal-to-noise ratio is less than 0.5 , internal variability has a smaller contribution to the intermodel spread than 
Table 2.2 | Annual-mean global warming $\left(\Delta \mathrm{T}_{\text {global }}\right)$ and Arctic warming $\left(\Delta \mathrm{T}_{\text {arctic }}\right)$ to a transient $\mathrm{CO}_{2}$ quadrupling (at $140 \mathrm{yr}$ ), as computed from the temperature trends in the 1 pctCO2 simulations. Arctic amplification (AA) is estimated by OLS linear regression of annual-mean Arctic temperature on global mean temperature, where the magnitude of Arctic amplification is then equal to the regression slope.

\begin{tabular}{lrrr}
\hline Model & $\Delta \mathrm{T}_{\text {global }}(\mathrm{K})$ & $\Delta \mathrm{T}_{\text {arctic }}(\mathrm{K})$ & $\mathrm{AA}$ \\
\hline ACCESS1.0 & 4.76 & 12.71 & 2.68 \\
ACCESS1.3 & 4.23 & 11.92 & 2.80 \\
BCC-CSM1.1 & 4.34 & 11.02 & 2.61 \\
BCC-CSM1.1(m) & 3.51 & 7.53 & 2.41 \\
BNU-ESM & 5.32 & 14.54 & 2.74 \\
CanESM2 & 5.32 & 13.04 & 2.45 \\
CCSM4 & 4.16 & 10.09 & 2.44 \\
CESM1(BGC) & 4.19 & 10.09 & 2.42 \\
CESM1(CAM5) & 5.14 & 14.02 & 2.72 \\
CMCC-CM & 5.50 & 12.95 & 2.36 \\
CNRM-CM5 & 4.63 & 13.10 & 2.93 \\
CSIRO-Mk3.6 & 4.49 & 8.72 & 1.94 \\
EC-EARTH & 4.88 & 15.38 & 3.25 \\
FGOALS-g2 & 3.72 & 9.22 & 2.42 \\
FGOALS-S2 & 4.79 & 12.90 & 2.76 \\
GFDL-CM3 & 4.94 & 16.61 & 3.26 \\
GFDL-ESM2G* & 1.35 & 2.71 & 2.14 \\
GFDL-ESM2M* & 1.82 & 5.13 & 2.47 \\
GISS-E2-H & 3.86 & 12.60 & 3.18 \\
GISS-E2-R & 3.15 & 6.48 & 2.05 \\
HadGEM2-ES & 5.71 & 17.35 & 2.89 \\
INM-CM4 & 3.20 & 8.25 & 2.58 \\
IPSL-CM5A-LR & 5.16 & 10.45 & 2.08 \\
IPSL-CM5A-MR & 5.14 & 10.36 & 1.98 \\
IPSL-CM5B-LR & 3.81 & 10.13 & 2.51 \\
MIROC5 & 3.73 & 12.65 & 3.40 \\
MIROC-ESM & 5.65 & 13.39 & 2.35 \\
MPI-ESM-LR & 5.07 & 12.64 & 2.35 \\
MPI-ESM-MR & 4.92 & 11.17 & 2.23 \\
MPI-ESM-P & 4.94 & 11.24 & 2.19 \\
MRI-CGCM3 & 4.04 & 11.60 & 2.72 \\
NorESM1-M & 3.61 & 10.23 & 2.83 \\
NorESM1-ME & 3.73 & 10.22 & 2.75 \\
\hline Mean & 4.50 & 11.69 & 2.59 \\
Standard deviation & 0.73 & 2.48 & 0.38 \\
\hline CO Concentatin & & \\
\hline
\end{tabular}

* $\mathrm{CO}_{2}$ concentration is held constant after year 70 , and therefore not included in the multimodel mean and standard deviation. 

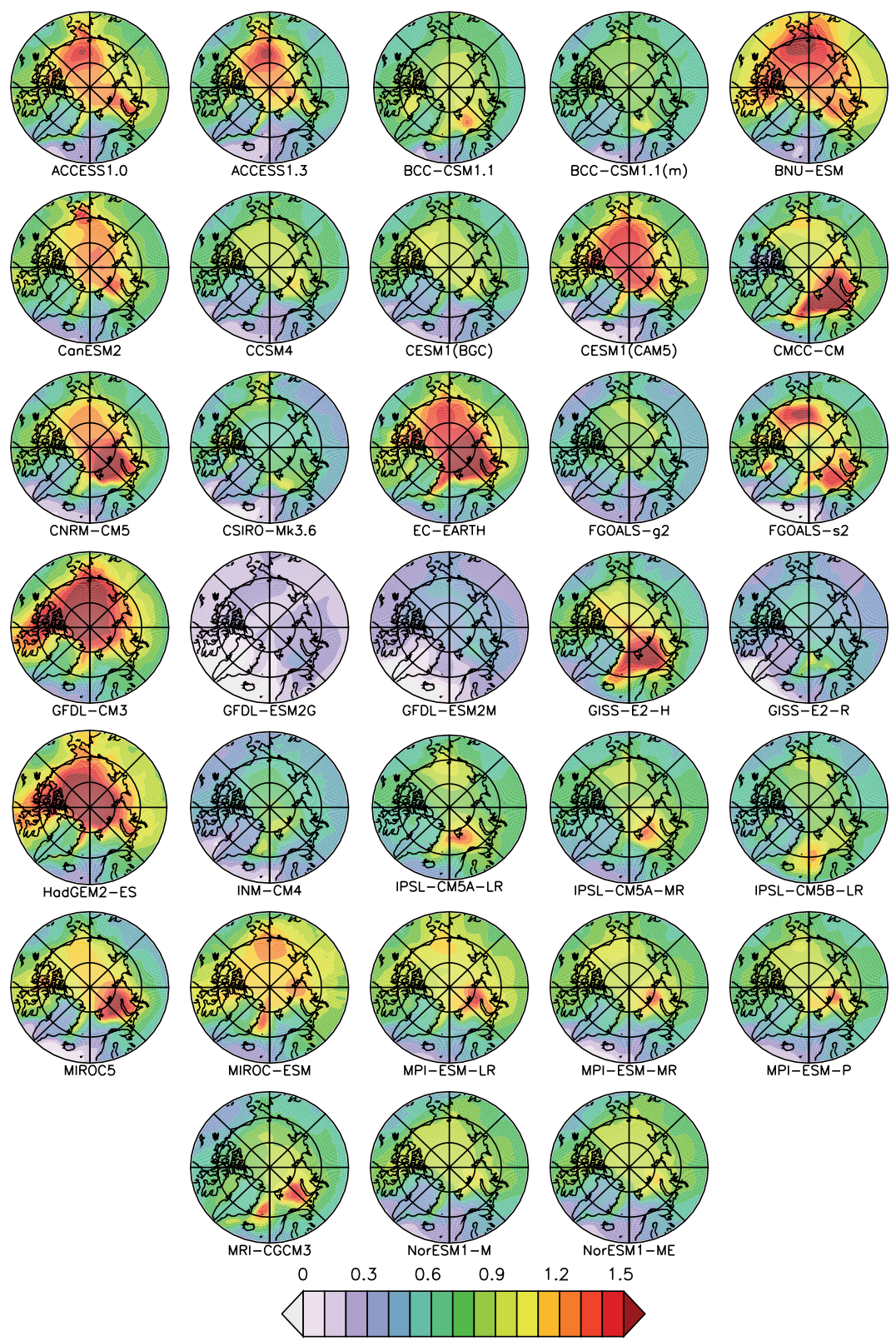

Figure 2.3 Maps of surface air temperature trends (in $\mathrm{K} / 10 \mathrm{yr}$ ) in the 1 pctCO2 simulation, for each model separately. Models GFDL-ESM2G and GFDL-ESM2M did not continue with increasing $\mathrm{CO}_{2}$ after reaching twice the piControl concentration (Caldeira and Myhrvold, 2013). 

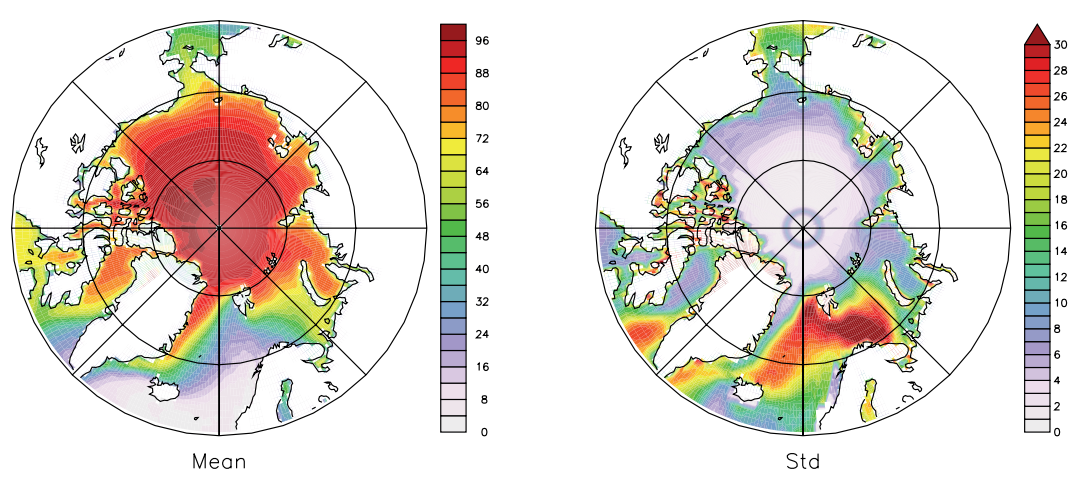

Figure 2.4 | Multimodel mean of sea ice concentration (in \%) in the piControl climate (80-yr mean value), and its standard deviation. Note the differences in color scale.

model formulation and control climate. The ensemble spread in four individual model ensembles with 5 to 10 members is compared with the mean spread of 1000 randomly chosen multimodel ensembles of the same size, with members selected from the 36-member multimodel ensemble. In this comparison the signal-to-noise ratio of the four individual model ensembles varies between 0.11 and 0.32 , suggesting that intermodel variability does not dominate the intermodel spread in temperature trends. By taking a large multimodel ensemble (33 models) for our analyses, and computing trends over 140 years, we expect that the chance that the internal variability of an individual model influences our results is small.

Multimodel mean warming is larger over the ocean than over land, and is strongest near Franz Josef Land (Fig. 2.2). The intermodel spread is also larger over the ocean than over land, and the largest intermodel spread is found over the Barents Sea. This is an indication that sea ice presumably plays a role in the spread of near-surface temperature trends. The intermodel spread is greater in particular regions, because the spatial pattern of annual mean surface air temperature trends in the Arctic varies considerably from model to model (Fig. 2.3). All models agree on strongest warming being located over the ocean. Although the majority of the models show peak warming concentrated near Franz Josef Land or over the Barents Sea, their exact location of maximum warming varies. Other models show peak warming on the opposite side of the Arctic near the Chukchi and/or Beaufort Sea (ACCESS1.0, ACCESS1.3, BNU-ESM, CanESM2, and FGOALS-s2). A few models typically have more northerly located maximum temperature trends over the central Arctic Ocean (CESM1(CAM5), FGOALS-g2, 

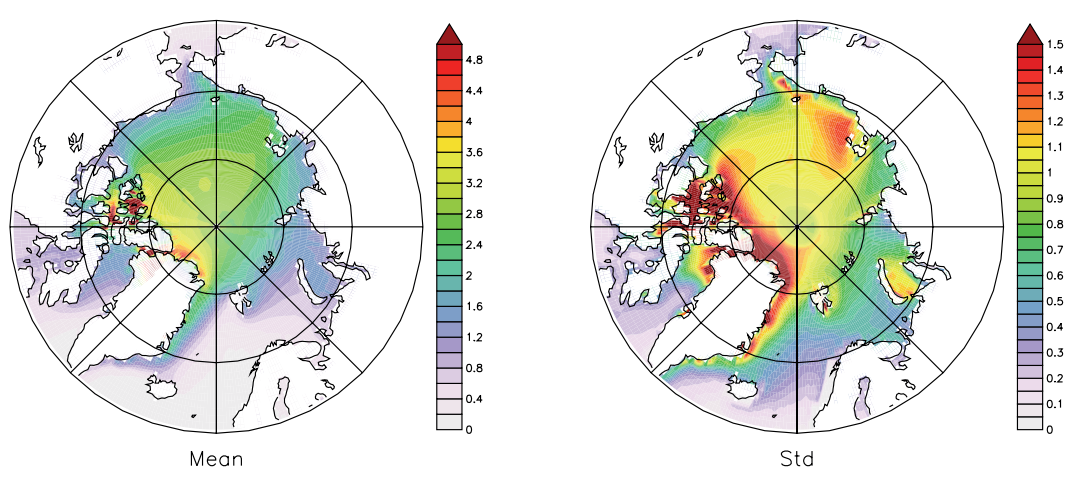

Figure 2.5 | Multimodel mean of sea ice thickness (in $\mathrm{m}$ ) in the piControl climate (80-yr mean value), and its standard deviation. Note the differences in color scale.

GFDL-CM3, and HadGEM2-ES), whereas others have more southerly located maximum warming over the Norwegian or Greenland Sea (IPSL-CM5B-LR, and MIROC-ESM). The seasonal cycle of surface air temperature trends (Fig. 2.1b) shows that annual mean warming is dominated by the winter season, because the temperature trends in winter are larger than in summer. The intermodel spread in surface air warming is also largest in winter. In summer, all models simulate greatest warming over land, with minor warming over the central Arctic Ocean. Averaged over the Arctic, we found no intermodel relation between annual mean control climate temperature and temperature trends $(r=0.03$, $p=0.87$ ), neither for winter or summer. This indicates that the intermodel spread in century-scale Arctic surface air temperature trends is not sensitive to differences in the Arctic mean temperature of the control climate, and the feedbacks related to rising $\mathrm{CO}_{2}$ concentrations govern the differences in the response.

\subsubsection{Sea ice control state}

Next we examine the sea ice state in the piControl climate. The multimodel mean sea ice state is characterised by high sea ice concentrations over the central Arctic Ocean (Fig. 2.4), and thick ice near the coasts of Greenland and the Canadian Archipelago (Fig. 2.5). The intermodel spread in sea ice concentration is largest in the Barents Sea, and is related to the varying location of the ice edge in different models (Fig. 2.6). In some models the Barents Sea is annually averaged nearly ice free (e.g., ACCESS1.3, INM-CM4, and MIROC-ESM), 

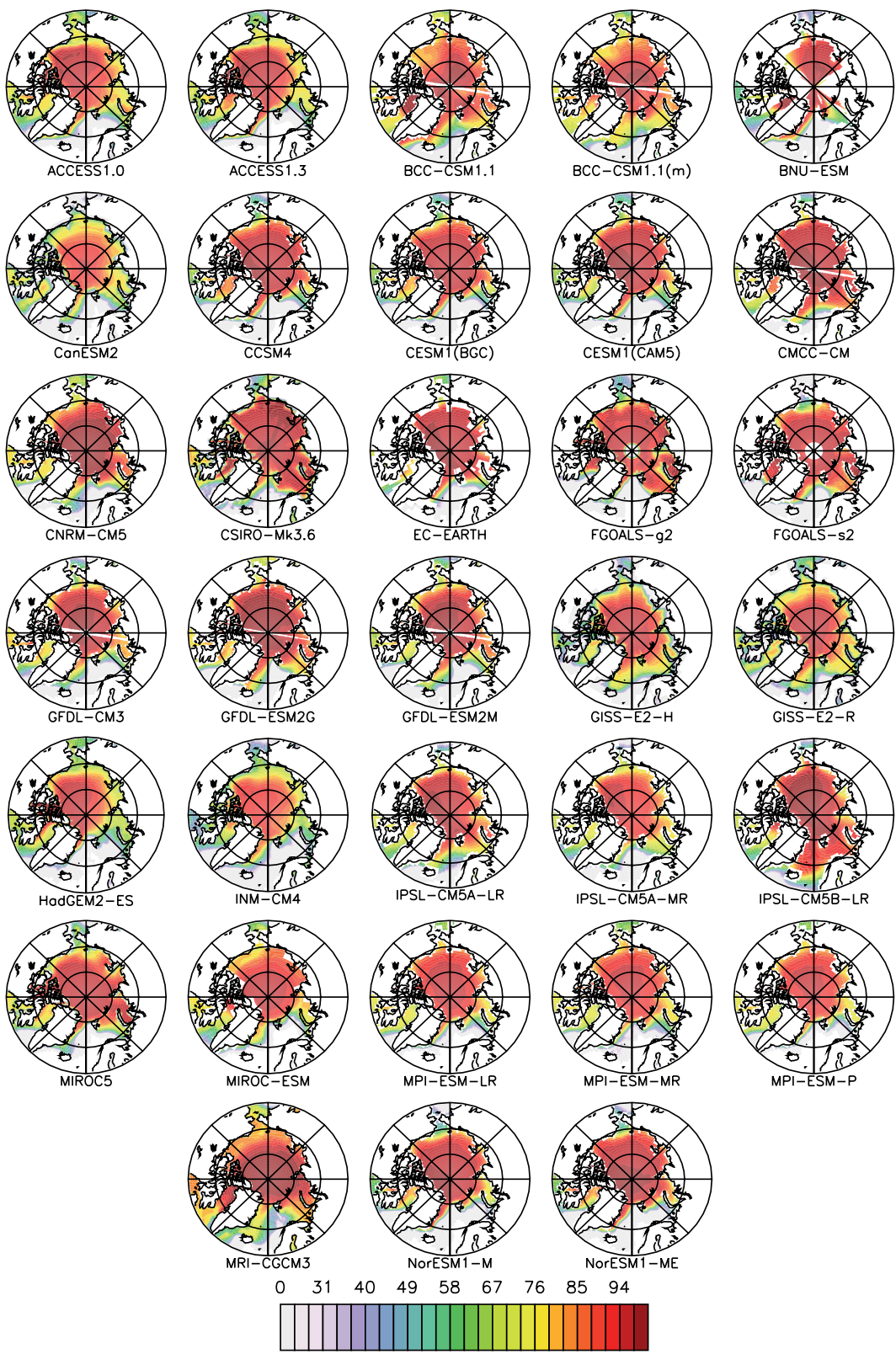

Figure 2.6 | Maps of mean sea ice concentration (in \%) in the piControl climate (80-yr mean value), for each model separately. Note that model BNU-ESM has in two quadrants of the Arctic almost no sea ice output. 


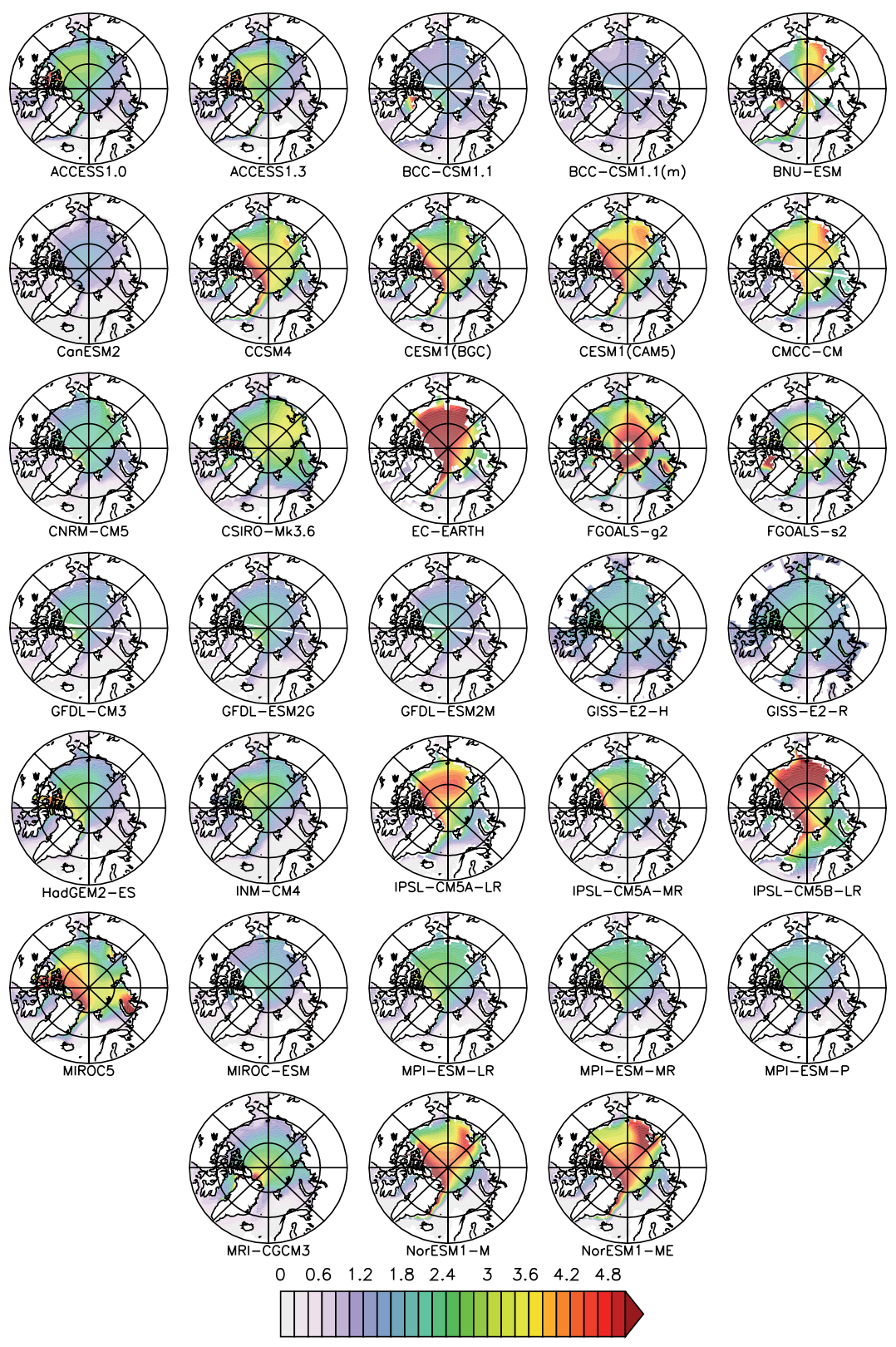

Figure 2.7 | Maps of mean sea ice thickness (in m) in the piControl climate (80-yr mean value), for each model separately. Note that model BNU-ESM has in two quadrants of the Arctic almost no sea ice output. 


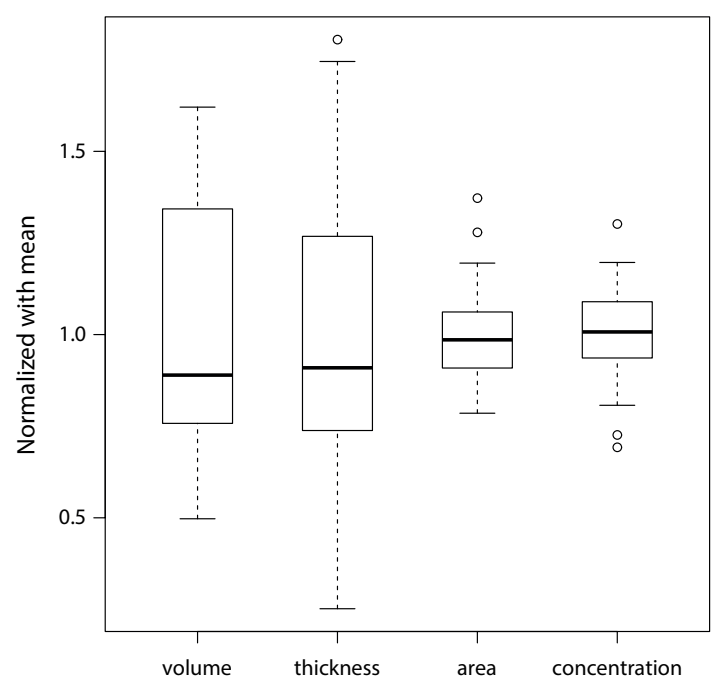

Figure 2.8 | The normalized intermodel spread of the Arctic sea ice state across the 33 global climate models in the piControl climate, averaged over 80 years. Arctic mean sea ice volume, thickness, area, and concentration are depicted, normalized by their multimodel mean value. The box-and-whisker plots show the maximum and the minimum values among the models as well as the 25 th and 75 th percentile and the median. Models that deviate more than two intermodel standard deviations from the multimodel mean, are depicted as outliers (open circles). The thickness outlier is EC-EARTH (thick ice). The area outliers are CSIRO-Mk3.6 (large area), and MRI-CGCM3 (large area). The concentration outliers are MIROC5 (high concentration), BNU-ESM (low concentration), and INM-CM4 (low concentration).

whereas in other models sea ice extends into the Norwegian and/or Greenland sea (e.g., BCC-CSM1.1, BCC-CSM1.1(M), GISS-E2-H, GISS-E2-R, IPSL-CM5ALR, IPSL-CM5B-LR, and MRI-CGCM3). The models generally agree more on the spatial distribution of sea ice concentration, than on the distribution of sea ice thickness (Fig. 2.7). The spread in thickness is largest in the regions with thick ice, and in the East Siberian Sea. The latter intermodel spread is caused by several models that simulate a second sea ice thickness maximum in the East Siberian Sea near the New Siberian Islands (e.g., BNU-ESM, CCSM4, CESM1(BGC), CESM1(CAM5), CNRM-CM5, CSIRO-Mk3.6, MIROC5, NorESM1$\mathrm{M}$, and NorESM1-ME), whereas others only simulate thin ice at this location. In a lot of models thick ice extends from the Canadian Archipelago into the Arctic Ocean north of the Beaufort Sea (e.g., ACCESS1.0, ACCESS1.3, HadGEM2-ES, INM-CM4, IPSL-CM5A-MR, MPI-ESM-LR, MPI-ESM-MR, and MPI-ESM-P). 
Figure 2.8 shows the normalized intermodel spread in Northern Hemisphere control sea ice conditions for volume, thickness, area, and concentration, across the 33 global climate models. The average sea ice state in the piControl climate varies widely between models, as was also found for the historical simulation of CMIP5 models (Stroeve et al., 2012a). Not surprisingly, models with a warmer Arctic control climate typically have a smaller sea ice area $(r=-0.40$, $\mathrm{p}=0.02)$ and volume $(\mathrm{r}=-0.54, \mathrm{p}=0.01)$. A larger range in thickness and volume is found, compared to area and concentration. The ensemble mean Northern Hemisphere sea ice volume is $25.2 \pm 8.1$ thousand $\mathrm{km}^{3}$, and the mean sea ice area is $10.4 \pm 1.4$ million $\mathrm{km}^{2}$. The relative magnitude of the intermodel standard deviation compared to the mean value (normalized standard deviation $s$ ) confirms that models tend to agree more on control surface area covered with sea ice $(s=13 \%)$, than on ice volume $(s=32 \%)$. This might be partly due to the land-locked Arctic Ocean, for which the adjacent continents act as a natural boundary to the extent of sea ice cover beyond which sea ice cannot expand (Bitz et al., 2005). The comparable large spread in Arctic mean thickness and volume illustrates that intermodel differences in piControl sea ice volume are governed by ice thickness rather than by ice area or concentration. Indeed, the intermodel correlation between volume and thickness is strong $(\mathrm{r}=0.80, \mathrm{p}<0.01)$, whereas volume and area are not notably related $(\mathrm{r}=0.12, \mathrm{p}=0.52)$.

Figure 2.9 depicts the seasonal cycle in control ice area and ice volume for each model. Most models agree on the month of maximum and minimum sea ice conditions. Generally, ice area reaches its maximum in March, and ice volume reaches its maximum in April. Minimum sea ice conditions are in August/September. The intermodel spread in control sea ice conditions is largest in winter for sea ice area. For sea ice volume, the intermodel spread is equally distributed throughout the year.

\subsection{Local sea ice-temperature response}

Now that we have established that the intermodel spread in surface air temperature trend is largest over the Arctic Ocean, and piControl sea ice conditions vary widely between models, we study the local temperature response over icecovered regions in the Arctic. We choose to study a summer and winter season separately, because the Arctic has a large seasonal cycle in piControl sea ice cover (Fig. 2.9) and in 1pctCO2 temperature trends (Fig. 2.1). The summer season is defined as June, July, August, September (JJAS) and the winter season as 

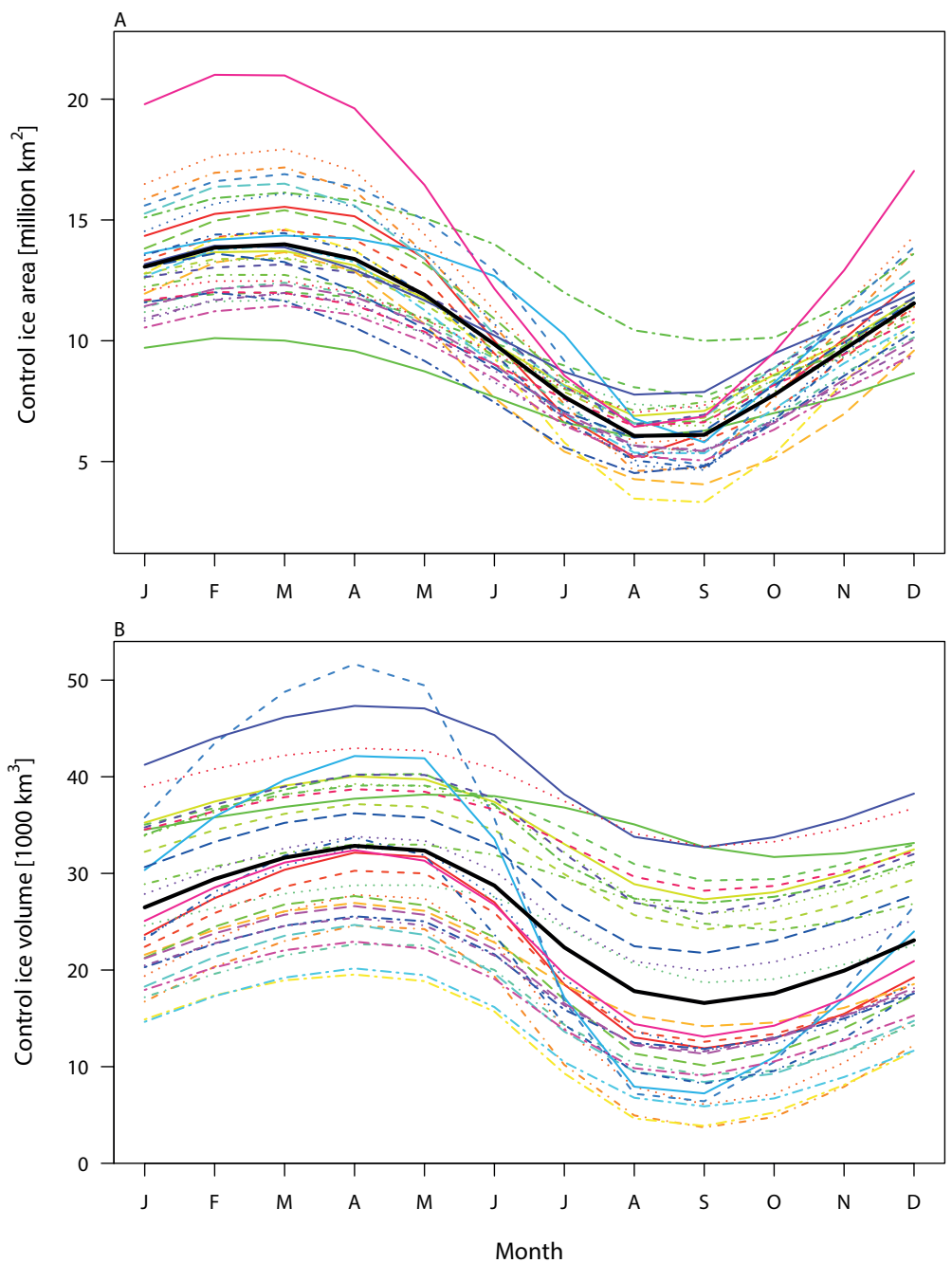

Figure 2.9 | Seasonal cycle of (a) sea ice area and (b) sea ice volume in the piControl climate for the 33 global climate models, averaged over 80 years. The colors for the models correspond with Figure 2.1. The black line represents the multimodel mean. 
December, January, February, March (DJFM) so that the extreme control sea ice conditions (Fig. 2.9) are included in the analysis.

To study the sea ice conditions and temperature trends locally, for each model, control sea ice cover was divided into ten thickness or concentration classes. Figure 2.10 shows the distributions of sea ice concentration and thickness in the CMIP5 models, for maximal sea ice conditions in March and minimal sea ice conditions in September. There is a much larger proportion of area with concentration lower than $10 \%$ and higher than $90 \%$ than in the other concentration classes. There is also a much larger proportion of area in the thinnest ice bin $(0-0.5 \mathrm{~m})$ compared to thicker ice classes. Over each class and for each month, the field mean surface air temperature trend was computed over 140 years.

\subsubsection{Concentration-warming relation}

First, we study the local relation between concentration and warming. Figure 2.11a and $2.11 \mathrm{~b}$ depict for each model the field mean surface air temperature trend over each concentration class, for winter and summer. The annual mean correlation coefficient for the linear regressions between the concentration bins $(5,15,25 \%$, etc. $)$ and field mean temperature trends over these bins averaged over all models is $0.97 \pm 0.02(\mathrm{p}<0.01)$, indicating that fields with a high ice concentration in the control climate typically warm more. The strength of the annual correlation between control concentration and warming is dominated by the winter season $(r=0.97 \pm 0.04, p<0.01)$, because the temperature trends during winter are much larger than during summer. The signs of the summer correlations are on average opposite to the winter correlations $(r=-0.26 \pm 0.61$, $\mathrm{p}=0.12 \pm 0.20$ ), with smaller temperature trends over bins with higher ice concentration. This is in agreement with largest warming being found over the ocean in winter, where ice concentration is higher, and over the subpolar seas and land in summer, where ice concentration is lower or absent. The large intermodel spread in summer is caused by oppositely signed relations of different models, with a distinction between models having a positive concentrationwarming correlation ( $\mathrm{r}=0.67, \mathrm{p}=0.11 \pm 0.20,9$ models) and models having a negative correlation $(\mathrm{r}=-0.61, \mathrm{p}=0.13 \pm 0.21,24$ models $)$.

We checked whether the unequal bin areas (Fig. 2.10) affected the spread in temperature trends around the bin averages of each model, i.e. the spread between different grid cells belonging to a particular ice class. The multimodel mean spread around the bin average was not larger in bins with more grid area 

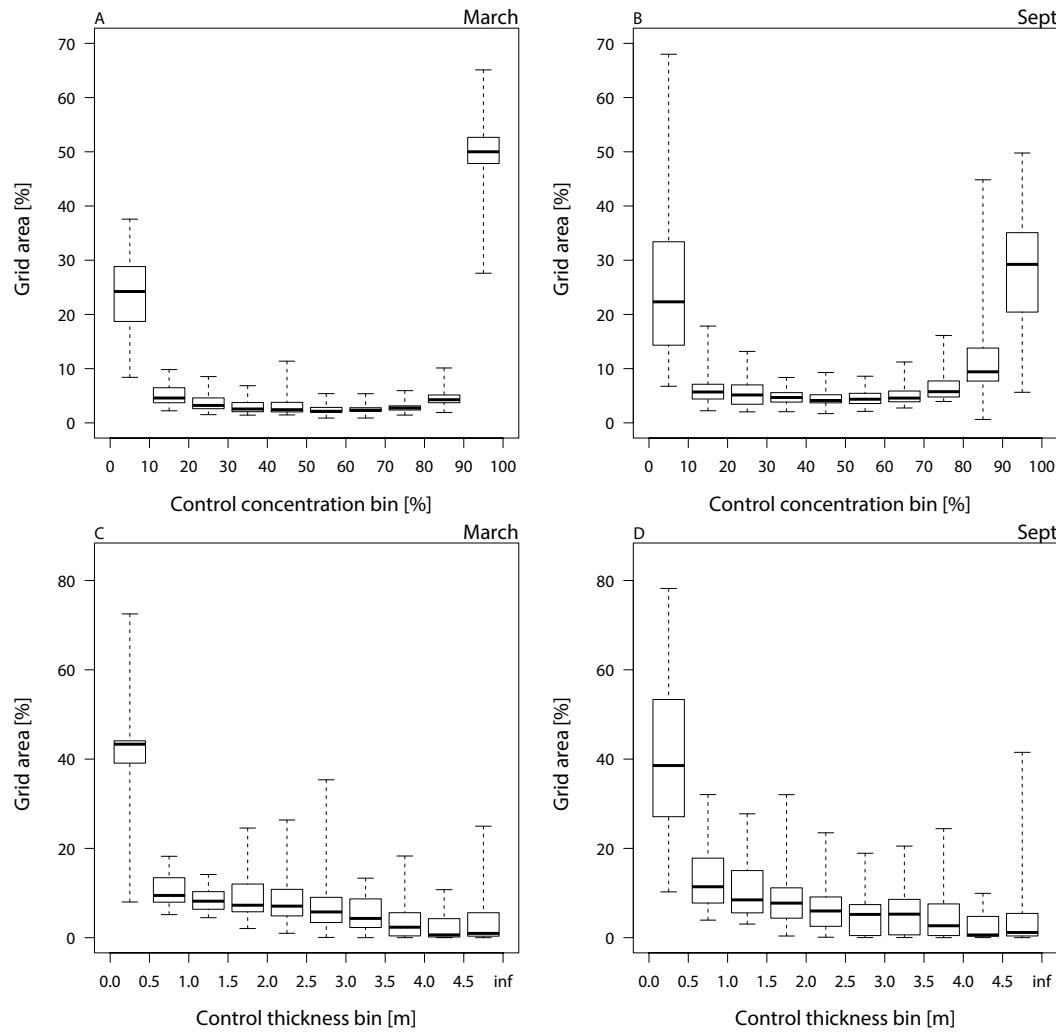

Figure 2.10 | Distribution of sea ice grid area over ten sea ice bins across the 33 global climate models. The plots show the proportion of sea ice grid area per concentration class in (a) March and (b) September, and per thickness class in (c) March and (d) September. We only consider the area of grid cells with a mean concentration or thickness greater than zero. The last thickness bin contains all thicknesses of $4.5 \mathrm{~m}$ and more, without an upper thickness limit. In bins with ice thicker than $2.0 \mathrm{~m}$ fewer models are considered, because not all models simulate ice in all ten thickness classes.

than in other ice bins, from which we conclude that bin area does not have a large effect on the bin spread of near-surface temperature trends.

Figure 2.12a shows the multimodel mean surface air temperature trends per concentration bin, split by month. Temperature trends are approximately linearly related to concentration classes, with increasing trends over higher concentration in winter, and decreasing trends over higher concentration in summer months. The largest seasonal amplitude in surface air temperature trends is thus over ice with the highest concentration. 

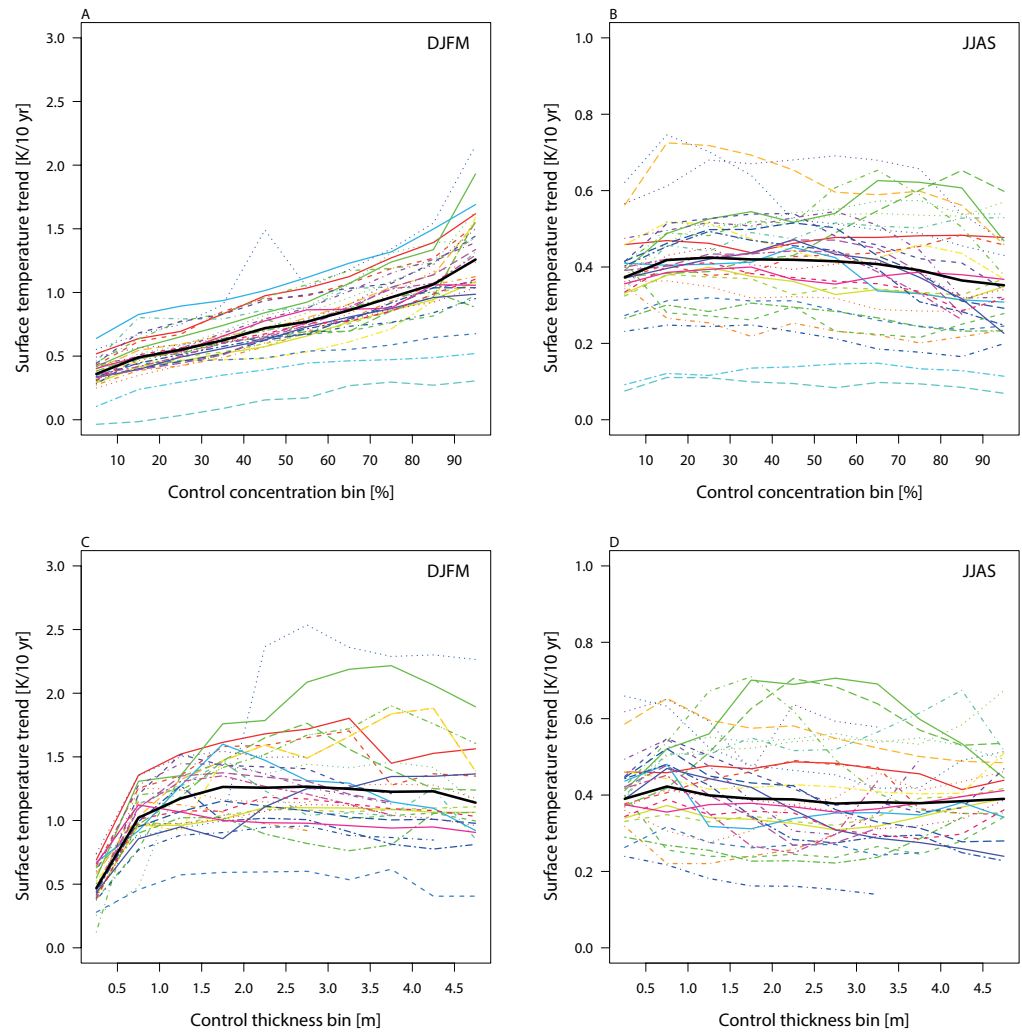

Figure 2.11 | Relation between surface air temperature trends in the 1pctCO2 simulation and piControl climate ice concentration bins averaged over (a) winter and (b) summer, and ice thickness bins averaged over (c) winter and (d) summer, for the 33 global climate models. The colors for the models correspond with Figure 2.1. The black line represents the multimodel mean. The peak in the $40-50 \%$ concentration bin belongs to the HadGEM2-ES model.

Now that we have an indication that control sea ice concentration relates to local near-surface temperature trends, we examine how sea ice concentration in a given class varies with near-surface temperature during the entire $140 \mathrm{yr}$ simulation. Figure 2.13a shows the relation between $2 \mathrm{~m}$ temperature and sea ice concentration over time series of $140 \mathrm{yr}$ for winter and summer, averaged over all models. Each line (10 per season) represents the average of all time series in one ice class, starting with the control mean ice concentration in one given bin at the start of the $140 \mathrm{yr}$ model run (black crosses). As time evolves, grid points are defined to stay in the class from which they started, even though their ice 
concentration changes. The concentration-temperature curves of the different bins overlap and have similar shapes, showing that ice concentration relates nonlinearly with surface air temperature during climate change in a generic way. The strength of the local interaction between surface air temperature and concentration might be represented by the tangent line to each curve, which is basically the change in sea ice per degree Arctic warming. It appears that both in winter and summer, ice concentration is most sensitive to temperature perturbations between $50-60 \%$ ice concentration, suggesting that ice adjusts most to a certain temperature perturbation in this ice concentration range. Above the melting point of sea ice, ice concentration and temperature are almost not related, because there is almost no ice left $(<10 \%)$. For high ice concentrations (> 80\%), the sensitivity of sea ice concentration to temperature also becomes weaker, but is still present. Probably, the relatively thick ice in high ice concentration classes delays the loss of concentration.

In summer months, we found that regions with a higher control climate ice concentration, undergo less warming (Fig. 2.11a and 2.12a). Melting of sea ice in summer keeps the near-surface temperature near the melting point temperature of sea ice. This is clearly visible in Figure 2.13a (red lines), which depicts the steepest slopes in ice concentration in summer near the melting point. As a consequence, in summer, surface air temperatures over melting sea ice hardly increase as long as sea ice is present, which is most effective in high concentration bins in the control climate, where sea ice takes longer to disappear. Temperatures stagnate near the melting point temperature while the ice melts, and increase at a much faster rate after most ice has disappeared. In low control ice concentration bins, melting leads faster to open water areas that absorb more energy and cause more near-surface warming. In higher ice concentration classes, the summer sea ice does not disappear after $140 \mathrm{yr}$ (Fig. 2.13a) so that the temperatures do not exceed the ice melting point, and temperature trends are therefore small. This might explain why there is less warming in higher concentration classes. This is illustrated in Figure 2.13a by the flattening of the concentration-temperature curve above the sea ice melting point: at low ice concentration hardly any additional ice can melt to keep the surface air temperature near the melting point, so that surface air temperature goes up in each ice class where ice disappears. An additional effect that can explain the relation between control concentration and warming in summer, is advection of warm surface air from the surrounding warmer land to the ocean. In summer, warming is larger over land, and this land-to-sea advection might be responsible for the peak warming near the ice periphery, where most models simulate a 

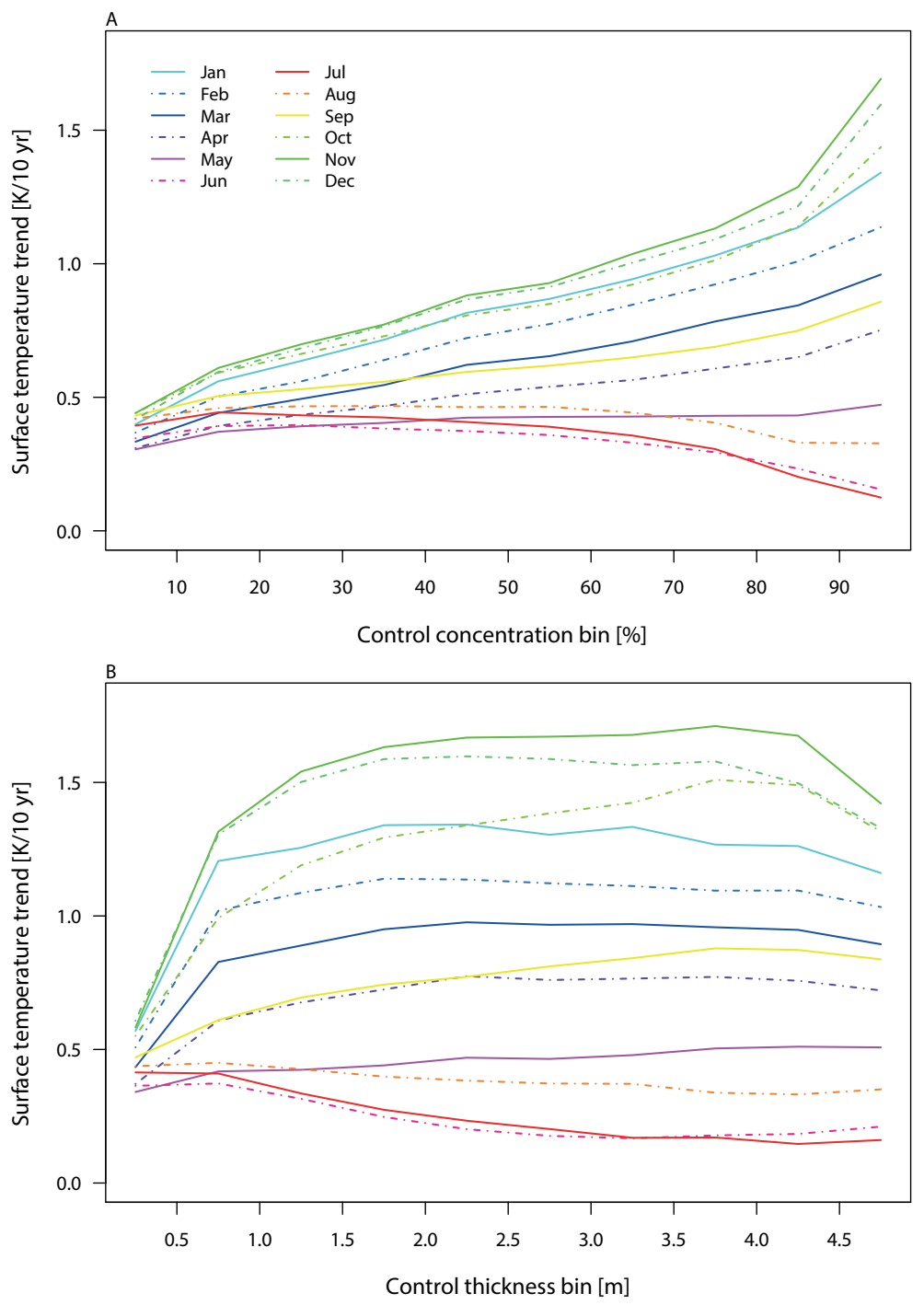

Figure 2.12 | Relation between surface air temperature trends in the 1pctCO2 simulation, and piControl climate sea ice bins for each month for (a) concentration and (b) thickness, averaged over all models. 
low control ice concentration.

In contrast to summer, in winter months, there is more warming over higher ice concentration fields (Fig. 2.11a and and 2.12a). Although one could think that the positive control concentration-warming relations only reflect latitudedependent warming, and thus visualize indirectly Arctic amplification, the overlap between the concentration-temperature curves is an indication that the relation between concentration and warming is more than just a latitudinal dependence of both concentration and warming; The temperature-concentration pathway is almost independent of the control concentration. There will be more transfer of heat from the ocean to the atmosphere if more open ocean is exposed, because sea ice acts as an insulator between ocean and atmosphere. We thus expect that in areas where more ice disappears, more ocean heat will be released to the atmosphere, thereby creating a larger surface air temperature trend. Figure 2.13a (blue lines) illustrates that high ice concentration classes have a larger decrease in ice concentration compared to lower concentration classes, and thus a larger increase in open ocean area. In addition, sea ice fields starting in a higher concentration class, start with a lower near-surface temperature, and keep a lower surface air temperature than lower concentration classes during the entire 140-yr simulation, but also have a larger change in surface air temperature and thus a larger temperature trend (Fig. 2.13a; blue lines). Most warming in winter thus occurs over regions with higher ice concentration, which can be explained by a larger decrease in ice concentration and thus a larger change in the amount of heat that can be transferred to the atmosphere, warming the surface air. The potential warming by this mechanism, if all ice would disappear in those regions, would be even larger, because high ice concentration classes have more ice to melt.

In summary, it appears that sea ice concentration and surface air temperature interact during climate warming, but the type of interaction does not depend on the control ice concentration class from which the curve started, because nearly all curves overlap and have a similar shape, which is nonlinear. The interaction does depend on season, because there is an opposite relation between concentration and warming for summer and winter. An explanation for the negative concentration-warming relation in summer months, is that melting prevents the near-surface air from warming, a mechanism that is effective longer over higher ice concentration classes because they exhibit more years of melting. In winter, the positive concentration-warming relation might be related to the insulating role of sea ice for the heat fluxes between ocean and atmosphere. However, both these hypotheses should be tested in further research 
before a definitive conclusion can be drawn.

Despite the fact that the intermodel spread in Arctic mean sea ice concentration is small (Fig. 2.8), there are large intermodel differences in the temperature response within each single ice concentration class (Fig. 2.11). In both summer and winter, models with a relatively high temperature trend over low ice concentration, typically also have a relatively high temperature trend over high ice concentration. In winter, the intermodel spread in the temperature trend increases with larger control climate ice concentration (Fig 2.11a), while in summer, the spread is about equal for all ice concentration classes (Fig. 2.11b). The greater spread in winter over higher ice concentrations means that most uncertainty in winter is over the central Arctic. In summer, the equally distributed intermodel spread in temperature response over each ice concentration class suggests that there is a common cause.

We compared the spread around the bin average with the intermodel spread, to check if a regression through the bin averages is meaningful. This comparison shows that the multimodel mean spread around the bin average is of about the same size as the intermodel spread between the bin averages of the models, which implies that the relation between control concentration bins and surface air temperature trends of each individual model is not very robust. However, in winter, all models agree on the sign of the control concentration-warming relations, which is a strong indication that the control concentration-warming relations are more than just a coincidence. In addition the clear seasonal cycle in control concentration-warming relations (Fig. 2.12a) corroborates these results.

\subsubsection{Thickness-warming relation}

The same analysis is repeated replacing concentration with thickness. Figures $2.11 \mathrm{c}$ and $2.11 \mathrm{~d}$ depict the spread in the local temperature trend for ten thickness classes in $0.5 \mathrm{~m}$ bins, for winter and summer. Averaged over all models, the correlation coefficient for the linear regressions between the centers of the thickness bins and the field mean surface air temperature trend is $0.58 \pm 0.26$ $(p=0.19 \pm 0.27)(0.59 \pm 0.27$ when the eight models that do not have ice in all thickness bins are excluded). Like for sea ice concentration, the relation between sea ice thickness and temperature trends varies by season. In winter, a clear distinction is visible in the temperature trends between regions with thin $(<1.0 \mathrm{~m})$ and thick $(>1.0 \mathrm{~m})$ sea ice, with smaller trends in temperature in the two thin ice classes (Fig. 2.11c). This result agrees well with our finding 

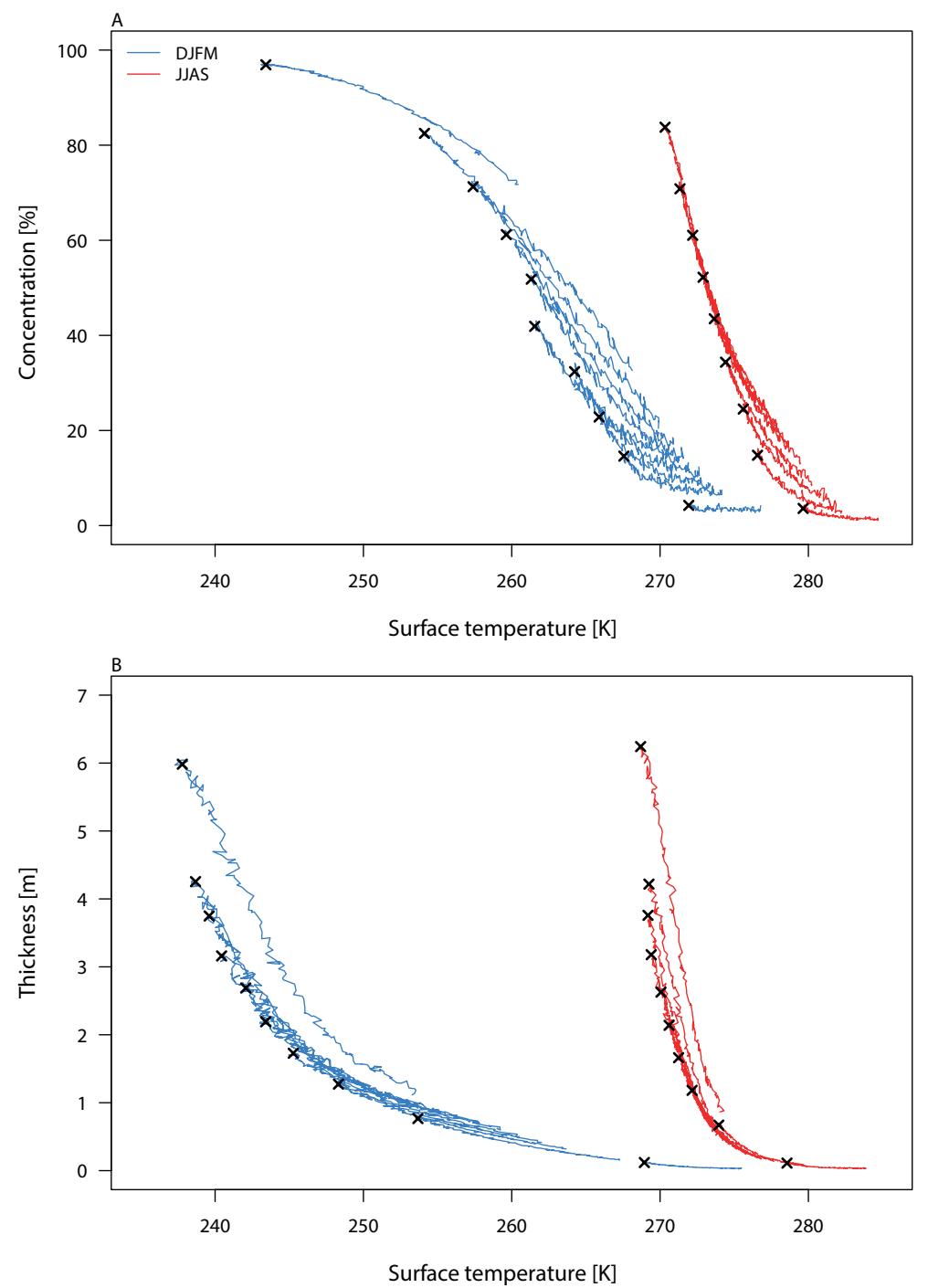

Figure 2.13 | (a) Multimodel mean relations between surface air temperature and sea ice concentration during the 140-year 1pctCO2 simulation. Each line represents the multimodel average of all 33 time series starting in one given bin (10 in total). Winter (blue lines) and summer (red lines) are plotted separately. The starting point of each ice class is labeled by a black cross. (b) The same, but for sea ice thickness. 
that regions with low ice concentration in winter have a relatively small temperature response, because regions with thinner ice generally have a lower ice concentration. The winter mean correlation between the thickness classes and field mean temperature trends is $0.42 \pm 0.37$ ( $\mathrm{p}=0.27 \pm 0.30$ ), and positive for 28 models out of 33. In summer, similar as for concentration, temperature trends are almost independent of ice class (Fig. 2.11d). The summer mean correlation between thickness classes and field mean temperature is $-0.13 \pm 0.60$ ( $p=0.23 \pm 0.29$ ), and more or less equally distributed between positive and negative values with 18 out of 33 models having a negative correlation. Figure $2.12 \mathrm{~b}$ depicts the monthly dependence of the control thickness-warming relation. For ice thinner than $1 \mathrm{~m}$ temperature trends do not exhibit a seasonal cycle; temperature trends of different months converge to one value. For ice thicker than $1 \mathrm{~m}$ trends do have a monthly dependence, but there is hardly any difference in the seasonal cycle of temperature trends for ice classes thicker than $1 \mathrm{~m}$.

The relation between near-surface temperature and thickness during the 140 -yr simulation is visible in Figure 2.13b. Like for ice concentration, all thickness-temperature curves overlap and have a similar shape. In classes with thick ice in the control climate, more ice melt takes place for a certain increase in temperature than over thin ice. This relation is termed the growth-thickness feedback by Bitz and Roe (2004). Thin ice need not thin much to adjust to a certain temperature perturbation, whereas thicker ice, which is generally over the central Arctic (Fig. 2.7), must adjust more.

Although the monthly control thickness-warming curves differ from the control concentration-warming relations (Fig. 2.12), their general behavior is the same. They exhibit more warming in winter over higher ice concentration/thicker ice and slightly less warming in summer over higher ice concentration/thicker ice. Also they have a stronger seasonal dependence over thick ice classes/classes with a higher concentration. So the thickness results correspond roughly with the results for ice concentration, and the possible explanation is the same.

\subsection{Arctic mean sea ice-temperature response}

So far the analysis has focused on local sea ice-temperature relations at the sea ice-class scale. Now we analyze if relations at the sea ice-class scale are also recognizable at the Arctic mean scale. At the Arctic mean scale, spatial variations in concentration and thickness are averaged out, and their integrated 

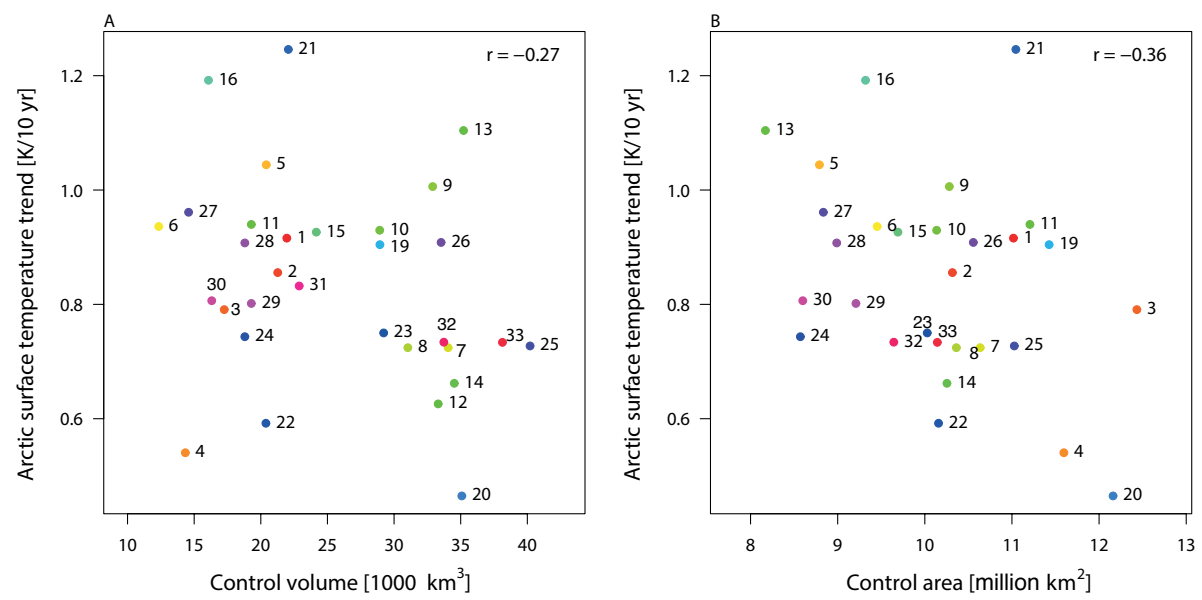

Figure 2.14 | Arctic near-surface temperature trends in the 1pctCO2 simulation versus (a) ice volume and (b) ice area in the piControl climate for the models, excluding models GFDL-ESM2G and GFDL-ESM2M, and models that deviate more than two intermodel standard deviations from the multimodel mean (see Figure 2.8). The numbers for the models correspond with Table 2.1.

quantities, area and volume, remain. We start by looking at the relation between control sea ice and near-surface temperature trends on the Arctic mean scale. Then the trends in volume and area, and their relation with surface air temperature trends are assessed. In addition, we examine whether there exist connections between the sea ice-class scale and Arctic mean scale.

In this section models are defined as outliers and excluded from the analyses when they deviate more than two intermodel standard deviations from the multimodel mean.

\subsubsection{Control climate volume and area}

First we examine the large-scale relation between control sea ice and Arctic warming (Fig. 2.14). The intermodel correlation between Northern Hemisphere control sea ice volume and Arctic warming is $-0.27(p=0.15)$ (Fig. 2.14a), showing that there is no clear relation between ice volume in the control climate and Arctic warming. On the other hand, models with a larger control climate ice area tend to have smaller trends in Arctic surface air temperature $(r=-0.36$, $\mathrm{p}=0.06$ ) (Fig. 2.14b). On the local scale, warming is larger over ice with a higher ice concentration. Based on the local-scale results we would expect that if sea 
ice physical processes play a dominant role in intermodel differences of Arctic warming, models with a larger sea ice area should warm more. The opposite seems to be the case, but the correlation is quite small. Also, this indicates that other processes, such as poleward ocean heat transport, play a more prominent role in intermodel differences of Arctic warming, while the physical processes of sea ice account for spatial differences within each single model. For example, enhanced ocean heat transport can lead to less sea ice, and therefore more energy can be absorbed during summer and radiated back during winter.

We find essentially no correlation between relative Arctic warming (Arctic amplification) and either control climate ice volume $(r=0.01, p=0.94)$, or ice area $(r=0.04, p=0.83)$. Holland and Bitz (2003) found a somewhat stronger relation between control climate ice thickness and Arctic amplification.

These weak correlations suggest that differences in the mean control sea ice state do not drive the intermodel spread in the Arctic warming or amplification signal. For winter and summer, none of the correlations of the control climate sea ice state with the Arctic temperature trend, or with Arctic amplification, is much different than its annual mean value.

\subsubsection{Trends in volume and area}

The relations between trends in sea ice and control climate sea ice conditions might provide more insight in the feedback mechanisms underlying the relation between control sea ice conditions and temperature trends. The intermodel correlation between control climate ice volume and trends in ice volume is strong and negative $(\mathrm{r}=-0.82, \mathrm{p}<0.01)$ (Fig. $2.15 \mathrm{a})$, showing that models with more ice volume in piControl conditions exhibit a larger decline in ice volume, which is not surprising because a model cannot lose any additional ice in summer if the ice disappears earlier in one simulation compared to another. At the end of the 140 year simulation, the Arctic Ocean is nearly free of summer sea ice in 20 models out of 32 (less than 1 million $\mathrm{km}^{2}$; Table 2.1). This is related to the growth-thickness feedback of sea ice discussed earlier; Most ice disappears over initially thick ice, which results in most thinning in bins with thick ice, and hence in models with a larger control climate ice volume.

The intermodel correlation of control climate ice area and trends in ice area is negligibly small ( $r=0.01, p=0.97$ ) (Fig. 2.15b), and comparably small for the winter and summer season, implying that there is no tendency for models with a larger control area to decline faster in area. We find, however, a strong positive correlation between control climate ice volume and trends in ice area $(r=0.53$, 

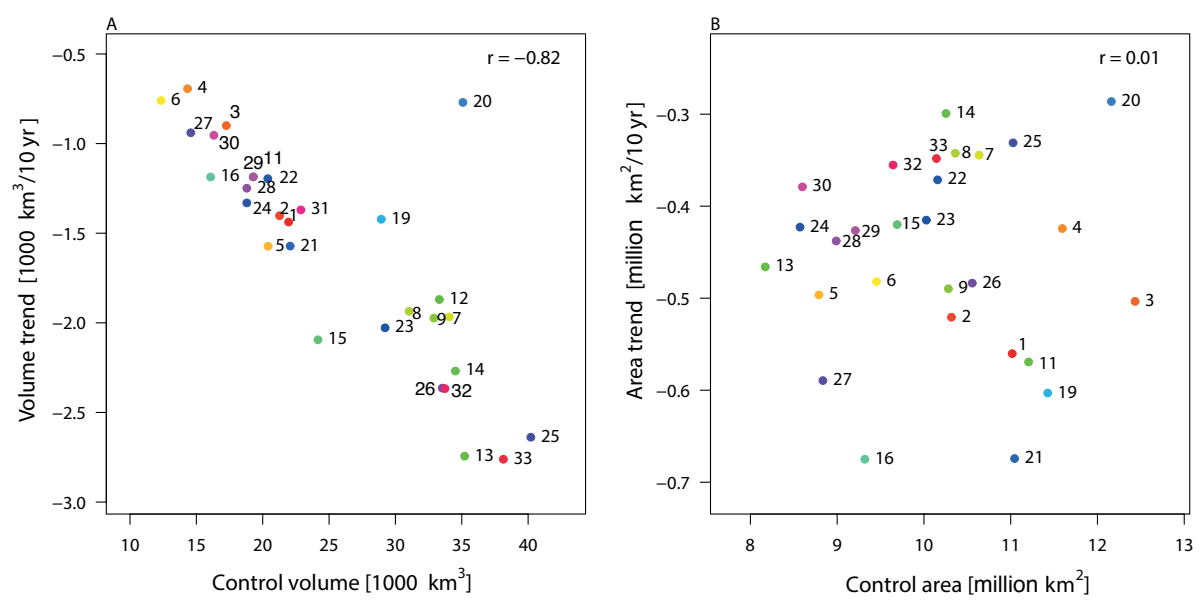

Figure 2.15 | Sea ice volume trends in the $1 \mathrm{pctCO} 2$ simulation versus (a) ice volume and (b) ice area in the piControl climate for the models, excluding models GFDL-ESM2G and GFDL-ESM2M, and models that deviate more than two intermodel standard deviations from the multimodel mean (see Figure 2.8). The numbers for the models correspond with Table 2.1.

$\mathrm{p}<0.01$ ), indicating that models with more piControl ice volume have smaller ice area trends. This relation probably shows that sea ice in models with more ice volume first has to thin before its concentration, and thus its area, decreases.

As a next step the intermodel relation between trends in sea ice and temperature trends is explored. Annually averaged, Arctic surface air temperature trend is not related to ice volume trends $(r=-0.07, p=0.73)$ (Fig. 2.16a), and hence mean thickness trends. The correlation is very weak, also for summer and winter.

Arctic warming is strongly negatively related to ice area change $(\mathrm{r}=-0.79$, $\mathrm{p}<0.01$ ) (Fig. 2.16b), indicating that models with more near-surface warming tend to have a larger decline in ice area. In those models with a larger decline in ice area, it is likely that more heat is absorbed during summer and radiated back during winter, thereby warming the surface air. This correlation is only slightly stronger in winter than in summer. 

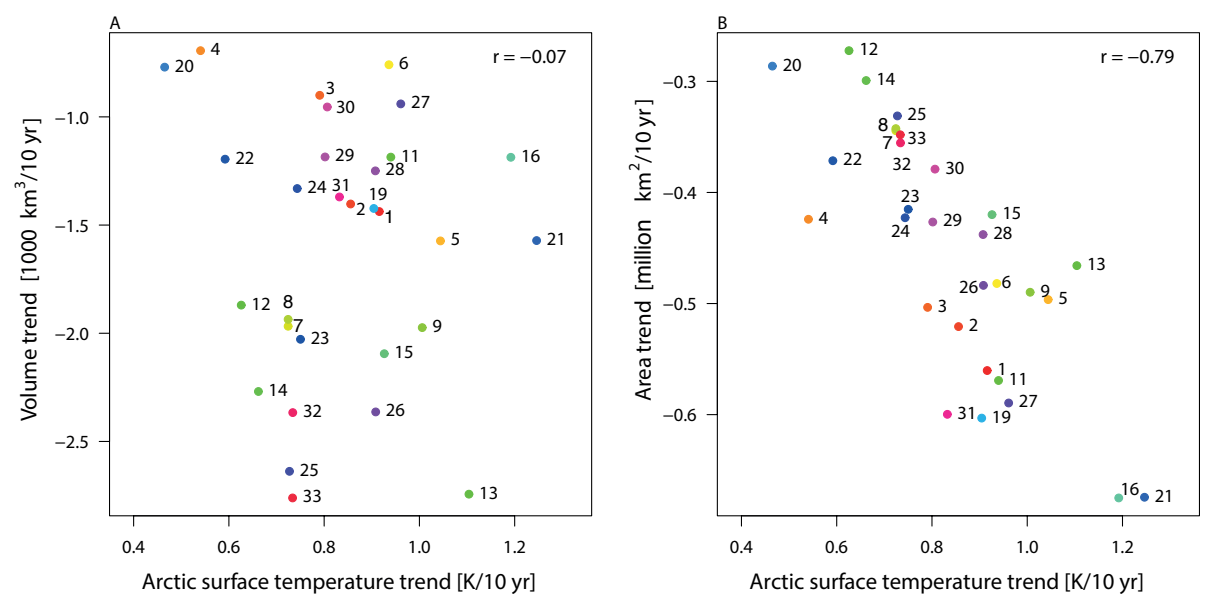

Figure 2.16 | (a) Sea ice volume trends and (b) sea ice area trends, versus Arctic neartemperature trends, in the $1 \mathrm{pctCO} 2$ simulation for the models, excluding models GFDLESM2G and GFDL-ESM2M, and models that deviate more than two intermodel standard deviations from the multimodel mean (see Figure 2.8). The numbers for the models correspond with Table 2.1.

\subsection{Discussion and conclusions}

The aim of this study is to elucidate whether the projected ranges in centuryscale Arctic temperature trends in transient climate change simulations are influenced by sea ice conditions in the control climate from which the simulations were initiated. Arctic warming is part of global warming, and although the Arctic region covers only a small part of the globe, it has a relatively large influence on the global-mean temperature response, as the magnitude of Arctic warming is about three times as large as global warming. This study uses the $1 \%$ per year $\mathrm{CO}_{2}$ increase simulation of an ensemble of 33 state-of-the-art global climate models, all part of CMIP5 (Taylor et al., 2012). The greatest intermodel spread in the temperature response to increasing $\mathrm{CO}_{2}$ levels for the global climate models is located in the Arctic, in accordance with Holland and Bitz (2003) and Winton (2006b). Understanding this spread is important for more reliable climate change projections. The main explanation for the spread is probably related to model formulation of physics and dynamics, or control climate conditions, because we estimated that natural variability is not the dominant cause of intermodel spread in century-scale projections. However, we recommend that the influence of natural variability on climate change projections is ana- 
lyzed more extensively in further research. We search for processes that explain geographical patterns of long-term Arctic warming in transient climate model simulations, and which of these processes can explain the intermodel spread on the Arctic mean scale, keeping in mind that the main cause of model-to-model differences in projections of Arctic warming can in principle be different from the main cause of Arctic warming itself. For this purpose, we combine physical understanding of surface air temperature trends on local and large scales into a consistent picture, using correlation analyses. Correlations may occur by chance, or may reflect common model deficiencies, but by attempting to explain them in terms of known physical processes they can give us more insight into underlying mechanisms related to Arctic warming.

To study the local sea ice-temperature response, for each model, control sea ice cover was divided into ten thickness or concentration classes. On the sea ice class scale, for each model, the temperature trends and ice loss patterns depend on the control climate ice thickness and concentration distribution. Generally speaking, annually averaged, in high-ice regions, there is more ice loss, and more warming. Bitz and Roe (2004) gave an explanation for the larger ice loss in high-ice regions in terms of the negative growth-thickness feedback, which states that the growth rate of ice is inversely proportional to ice thickness. We found that the spatial concentration/thickness-warming relations are dominated by the winter season, because winter warming exceeds summer warming, and summer has an oppositely signed concentration/thickness-warming relation with a much larger intermodel spread. A physical explanation for the enhanced warming in high-ice regions in winter is related to the insulating capacity of sea ice. When sea ice retreats, the relatively warm ocean releases heat to the atmosphere, thereby warming the surface air. This mechanism is expected to be more effective in regions with more ice loss. Also, inversion strength can strengthen the positive spatial relations between control climate sea ice concentration and near-surface warming in winter. In a spatial comparison, Pavelsky et al. (2011) show that wintertime sea ice concentration and inversion strength are positively correlated. Bintanja et al. (2011) show that the wintertime temperature inversion in the Arctic amplifies near-surface warming. Combining these two findings supports that inversion strength can enhance local amplification of near-surface warming over high ice concentrations in winter.

In summer, melting of sea ice keeps the near-surface temperature close to its melting point temperature, which prevents the surface air from warming as long as the ocean is ice-covered. This might explain why summer warming is 
smaller over high-ice regions, whereas regions near the ice periphery exhibit more warming. Atmospheric advection of warm air from the surrounding land could also be the main cause of more warming over thinner ice (which is generally located near the ice edge), because summer temperature trends over the continents are larger than over the ocean.

The spatial distribution of the control climate ice concentration/thickness thus relates to the distribution of the local temperature response within each individual model in a seasonally dependent way. However, models do not agree on the magnitude of the temperature response for one particular control sea ice concentration or thickness class. In summer, a large part of the substantial spread in local sea ice-warming relations can likely be attributed to the formulation of the individual sea ice models. Although we did not look into details of sea ice models, this should be the focus of future studies. In winter, the relations are more universal among models, suggesting that the distribution of sea ice in the control climate plays a role in century-scale surface air temperature trends. However, it is complicated to separate the influence of control conditions from the influence of model formulations within a multimodel ensemble.

Remarkably, in contrast to control sea ice, control climate near-surface temperature has essentially no correlation with temperature trends in transient climate change. One should thus be careful with using model results in the present climate to inform future climate projections.

The largest intermodel spread in Arctic mean sea ice conditions in piControl climate is in sea ice thickness, which mainly determines sea ice volume, whereas models tend to agree better with respect to control sea ice area and concentration. Sea ice volume trends are strongly linked to ice volume in the control climate state, which can be understood from the spatial thickness-warming relation on local scales. This result is also found by Gregory et al. (2002), who showed that sea ice declined more rapidly in a global climate model when it was initially thicker and more extensive, and by Bitz (2008), who showed that intermodel spread in sea ice thickness-decline in a CMIP3 model ensemble can be explained by spread in control climate thickness. A large intermodel spread in control climate sea ice volume can result in large intermodel differences in ice volume trends. To improve projections of sea ice volume loss, it is thus necessary to reduce spread in simulated sea ice volume in the control climate.

The intermodel spread in Arctic mean temperature trends is only weakly related to ice volume or area in the control climate. The weak correlation suggests that on the large scale other processes, such as ocean heat transport and meteorological conditions play a more important role in the spread of century- 
scale warming than local sea-ice processes. In addition, the intermodel spread in Arctic amplification is not correlated at all with control climate ice volume or ice area. Related to this, Holland and Bitz (2003) also found no significant correlation between control climate ice extent and Arctic amplification.

In conclusion, although there is no clear relation between control climate sea ice and temperature trends at the Arctic mean scale, there is a subtle dependency of surface air temperature trends on control sea ice conditions at the sea ice class scale. This means that it is important to simulate control sea ice conditions in a realistic way, not only at the Arctic mean scale, but also at the spatial scale, because this can lead to constraints for the climate response. 


\title{
Oceanic heat transport towards the Arctic under high and low $\mathrm{CO}_{2}$ forcing
}

\author{
E. C. van der Linden, R. Bintanja, and W. Hazeleger
}

Climate Dynamics, under review

Enhanced ocean heat transport toward the Arctic is linked to stronger future Arctic warming and polar amplification. To quantify the impact of ocean heat transport on Arctic climate it is imperative to understand how its magnitude and the associated mechanisms change in other climate states. This paper therefore assesses the ocean heat transport toward the Arctic for climates forced with a broad range of carbon dioxide $\left(\mathrm{CO}_{2}\right)$ concentration levels, ranging from one-fourth to four times modern values. We find that poleward Atlantic ocean heat transport through $70^{\circ} \mathrm{N}$ increases from $0.03 \mathrm{PW}$ in the coldest climate to $0.2 \mathrm{PW}$ in the warmest climate. This is primarily caused by changes in the horizontal currents owing to anomalous wind responses to changes in sea ice, to changes in the sea ice cover itself, and to differential advection of thermal anomalies. Surprisingly, at subpolar latitudes, the subpolar gyre weakens towards both warmer and colder climates. This can be attributed to a combination of the near-surface wind response to sea ice changes and changes in the density-driven circulation. The Atlantic meridional overturning and its associated heat transport play a more modest role, and even oppose the total ocean heat transport into the Arctic in the warmest climate. Evidently, 
the net ocean heat transport toward the Arctic depends on an interplay between various (remote) coupled ocean-atmosphere-sea ice mechanisms that respond in a nonlinear way to climate change.

\subsection{Introduction}

Future climate projections with increasing atmospheric $\mathrm{CO}_{2}$ concentrations (and other greenhouse gases) provide a range of global and regional climate change. Although $\mathrm{CO}_{2}$ is well-mixed in the atmosphere, its influence on surface warming is non-uniform. Arctic amplification, a stronger Arctic than global mean surface temperature trend, is one of the primary elements of climate change as simulated by climate models (e.g., Manabe and Stouffer, 1980; Holland and Bitz, 2003). Also, variability and trends in surface air temperature as seen in recent observations (Johannessen et al., 2004; Chylek et al., 2009; Bekryaev et al., 2010) and in paleoclimate records (Brigham-Grette, 2009; Miller et al., 2010) show that the stronger warming or cooling in high-latitude regions is an intrinsic part of the response of the climate system to external forcing.

Enhanced oceanic heat transport (OHT) towards the Arctic is one of the many factors that is related to stronger future Arctic warming and polar amplification (Holland and Bitz, 2003; Bitz et al., 2006; Mahlstein and Knutti, 2011). In simulations of the twenty-first-century climate, most models project a decrease in poleward OHT in midlatitudes and an increase in higher latitudes (Hwang et al., 2011). The decrease in the midlatitudes is mainly associated with a weakening of the Atlantic meridional overturning circulation (AMOC) (Cheng et al., 2013), which plays a key role in the Atlantic ocean heat redistribution by transporting heat northwards from the tropics and subtropics. This concurs with a paleoclimate model simulation of the Eocene climate $(\sim 50 \mathrm{Ma})-$ with about four times modern $\mathrm{CO}_{2}$ values - in which the North Atlantic overturning reduced in intensity and depth relative to present-day values (Huber and Sloan, 2001). Despite the consensus about the slowdown of the AMOC under climate warming, it is still not clear what mechanisms explain the projected increase in OHT in higher latitudes.

The simulated high-latitude increase in OHT is found to be primarily caused by increased temperatures of the incoming Atlantic water (Koenigk and Brodeau, 2014; Jungclaus et al., 2014), which is consistent with a 2000-year record of ocean temperature variations derived from marine sediments (Spiel- 
hagen et al., 2011). The warming of the Atlantic water as it flows towards the Arctic is linked to changes in ocean dynamics in the North Atlantic, where the subpolar gyre (SPG) and subtropical gyre are located. It is, however, not fully understood how the North Atlantic ocean processes influence the OHT toward the Arctic. Jungclaus et al. (2014) find that a spin-up and cooling of the SPG, which in this study is associated with a weakening AMOC, may increase the total heat transport at the entrance to the Arctic. In contrast, Hátún et al. (2005) find that a weaker SPG may enhance the transport of warm and saline waters toward the Arctic. While the SPG thus seems to play a prominent role in enhanced northward heat transport toward the Arctic, the associated mechanisms are still unclear.

Poleward OHT in colder-than-present climates is less extensively analyzed than in warmer climates. Coupled model simulations of the Last Glacial Maximum (LGM; $\sim 21$ kyr before present) - when $\mathrm{CO}_{2}$ values dropped to $\sim 50 \%$ of present-day concentrations - vary widely in their responses of the Atlantic meridional overturning (Otto-Bliesner et al., 2007). Some models show a stronger AMOC, whereas others exhibit a weaker or negligible change in strength in the Atlantic overturning cell. In some models the ocean response was linked to sea ice, which in this cold climate covers a much larger area and on average is thicker. In any case, the heat transport toward the Arctic in colderthan-present climates, and in particular the changes in the SPG, have not been extensively studied thus far.

In this study we investigate differences in OHT to the Arctic in quasiequilibrium climate states with a broad range of atmospheric $\mathrm{CO}_{2}$ concentrations varying from one-fourth to four times modern levels. In contrast to most previous sensitivity studies of the OHT in which transient and/or future experiments are investigated the climate states in the present study are all in quasi-equilibrium. In this way we can test the sensitivity of the OHT for equilibrium changes to constant $\mathrm{CO}_{2}$ forcings. To our knowledge, this is the first time that the OHT to the Arctic under both very high and very low $\mathrm{CO}_{2}$ conditions is systematically analyzed with a state-of-the-art global coupled climate model. Moreover, the $\mathrm{CO}_{2}$ concentrations in the extreme climate states are similar to typical values in paleoclimate model studies (e.g., $\mathrm{CO}_{2}$ levels in the LGM are about $\sim 50 \%$ and in the Eocene $\sim 400 \%$ modern values). In this way, climate states with $\mathrm{CO}_{2}$ levels similar to modern, Eocene and LGM values are all included, and the sensitivity of ocean processes to $\mathrm{CO}_{2}$ concentration can be properly analyzed. In the present paper we focus on the differences in Atlantic OHT toward the Arctic and the mechanisms behind these differences. There- 
fore, our main study area is the subpolar North Atlantic, where the dominant mechanisms influencing Arctic heat transport are most likely located, and the Nordic Seas, where in the current climate the largest heat inflow toward the Arctic occurs.

This paper is organized as follows. The model and simulations are presented in Section 3.2. Section 3.3 describes some general characteristics of the climate states, including climate sensitivity and Arctic amplification. The northern hemisphere meridional oceanic and atmospheric heat transports are presented in Section 3.4. The North Atlantic OHT and its overturning and gyre components are examined in detail in Section 3.5. Finally, Section 3.6 contains a summary and conclusions.

\subsection{Model and simulations}

\subsubsection{Model description}

The experiments in this study are performed with EC-Earth (Hazeleger et al., 2012). Here we use version 2.3, which has also been used for the Coupled Model Intercomparison Project phase 5 (CMIP5) (Taylor et al., 2012). EC-Earth is a fully coupled ocean-atmosphere global climate model. The atmospheric component is the Integrated Forecast System (IFS) of the European Center for Medium-range Weather Forecasts (ECMWF). It runs at T159 spectral resolution with 62 vertical levels. The ocean component is the Nucleus for European Modelling of the Ocean (NEMO) model (Madec, 2008), developed by the Institute Pierre Simon Laplace (IPSL). NEMO uses a horizontal grid configuration which has a resolution of about 1 degree and 42 vertical levels. NEMO incorporates the Louvain la Neuve sea ice model version 2 (LIM2) (Fichefet and Morales Maqueda, 1997; Bouillon et al., 2009), which is a dynamic-thermodynamic sea ice model. The atmosphere and ocean/sea-ice model are coupled through the OASIS (Ocean, Atmosphere, Sea Ice, Soil) coupler (Valcke et al., 2003).

The performance of the ocean component in EC-Earth is described in Sterl et al. (2012). Future projections of climate change and ocean heat transports in EC-Earth, focused specifically on the Arctic region, are analyzed in detail in Koenigk et al. (2013) and Koenigk and Brodeau (2014). 
Table 3.1 | Simulation name, $\mathrm{CO}_{2}$ concentration, the global equilibrium two-meter air temperature ( $\left.T_{\text {global }}\right)$, the equilibrium climate sensitivity (ECS), the Arctic equilibrium two-meter air temperature $\left(\mathrm{T}_{\text {arctic }}\right)$, and Arctic amplification $(A A)$. Here, ECS is computed with $\Delta \mathrm{T}_{\text {global }}=\mathrm{ECS} \ln \left(\mathrm{CO}_{2} / \mathrm{CO}_{2(\mathrm{t}=2000)}\right) / \ln (2)$ following Knutti (2008), and $\mathrm{AA}=\Delta \mathrm{T}_{\text {arctic }} / \Delta \mathrm{T}_{\text {global }}$, where $\Delta$ is the equilibrium change relative to the control climate, and the Arctic is defined as the region north of $70^{\circ} \mathrm{N}$.

\begin{tabular}{llllll}
\hline Simulation & $\mathrm{CO}_{2}[\mathrm{ppmv}]$ & $\mathrm{T}_{\text {global }}\left[{ }^{\circ} \mathrm{C}\right]$ & $\mathrm{ECS}\left[{ }^{\circ} \mathrm{C}\right]$ & $\mathrm{T}_{\text {arctic }}\left[{ }^{\circ} \mathrm{C}\right]$ & $\mathrm{AA}$ \\
\hline $1 / 4 \times \mathrm{CO}_{2}$ & 92.2 & 9.2 & 2.5 & -29.1 & 3.3 \\
$1 / 2 \times \mathrm{CO}_{2}$ & 184.4 & 11.7 & 2.6 & -20.9 & 3.3 \\
control & 368.9 & 14.3 & - & -12.2 & - \\
$2 \times \mathrm{CO}_{2}$ & 737.7 & 17.2 & 3.0 & -3.2 & 3.0 \\
$4 \times \mathrm{CO}_{2}$ & 1475.5 & 20.8 & 3.3 & 3.6 & 2.4 \\
\hline
\end{tabular}

\subsubsection{Simulations}

We study five simulations performed with EC-Earth with different atmospheric $\mathrm{CO}_{2}$ concentrations (Table 3.1). The first integration is the control climate which contains greenhouse gas concentrations, aerosol forcing, and land use scheme of the year 2000 (present-day). The initial state for the control run is obtained from a spin-up of about thousand years with preindustrial (1850) forcing and a subsequent integration over 44 years with present-day forcing. Thereafter the integration is continued over 550 years with constant present-day forcing, being the control simulation in this study. The other integrations all start from the initial state of the control climate. Their $\mathrm{CO}_{2}$ concentrations are instantaneously set at 1/4, 1/2, 2 and 4 times the present-day value and kept constant at that level for 550 years. After 450 years the upper ocean is in equilibrium. We use the final 100 years of the simulations in our analysis.

All changes or anomalies in the perturbed- $\mathrm{CO}_{2}$ climates are defined relative to the control climate state. Note that the climate change simulations analyzed here do not account for possible changes in land ice extent and elevation (Greenland, Antarctica), and for changes in land use or aerosols.

\subsection{Global characteristics}

The equilibrium climate sensitivity (ECS) in EC-Earth is $3.0 \mathrm{~K}$ (for $\mathrm{CO}_{2}$ doubling relative to present day), which is close to the median of global coupled mod- 

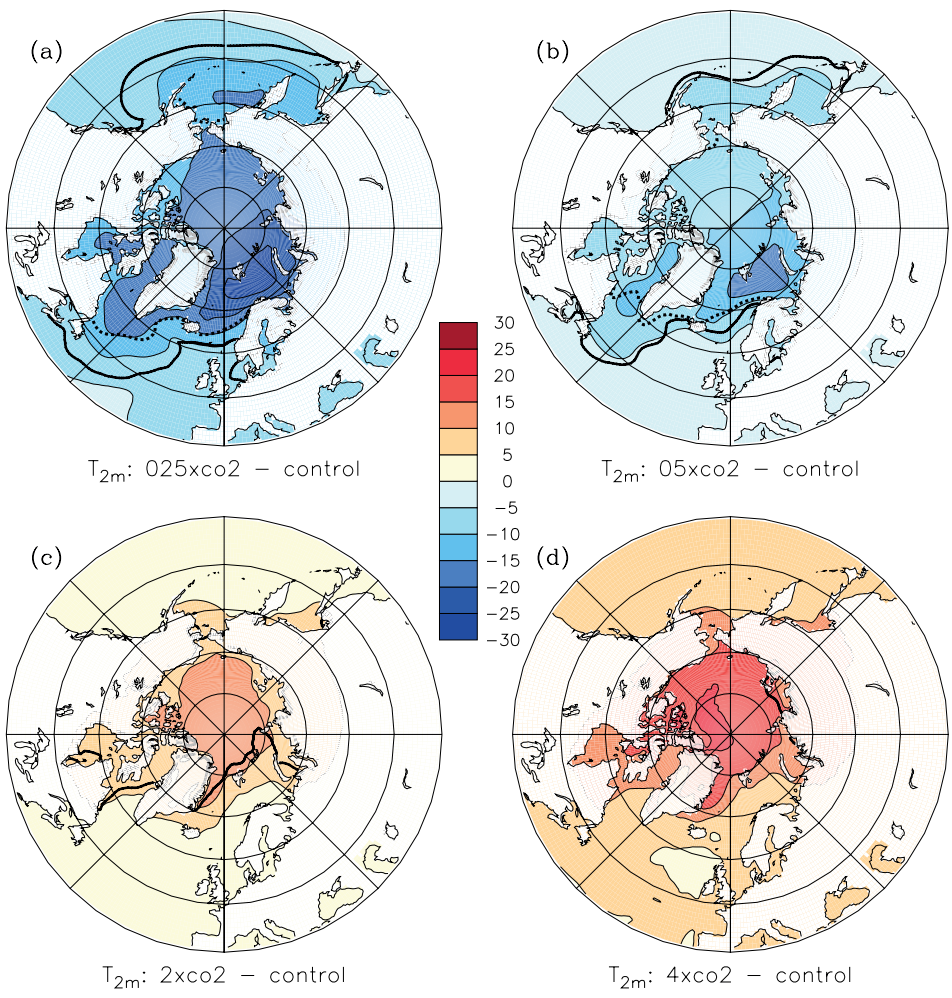

Figure 3.1 | The annual mean change in two-meter air temperature $(K)$ relative to the control climate at $40-90^{\circ} \mathrm{N}$. The thick black lines represent the sea ice edge in March (solid) and September (dashed), which is defined as the 15\% sea ice concentration isopleth.

els participating in CMIP5 (Knutti, 2008). The EC-Earth model shows a slight asymmetry in climate sensitivity with respect to atmospheric $\mathrm{CO}_{2}$ concentration: ECS is $2.5 \mathrm{~K}$ for $1 / 4 \times \mathrm{CO}_{2}$ and $3.3 \mathrm{~K}$ for $4 \times \mathrm{CO}_{2}$ (Table 3.1 ). This is consistent with other CMIP5-models that show an increasing ECS in warmer climates due to a strengthening of the water-vapor feedback (Meraner et al., 2013). There are also opposing results in which ECS is enhanced in cold climate states and reduced in warm ones (Kutzbach et al., 2013). The climate sensitivity to changing greenhouse gas concentrations is thus model-dependent. In any case, the changing ECS with climate states suggests that the simulated climate feedbacks change with the mean climate state.

Figure 3.1 shows the annual mean change in two-meter air temperature and 
sea ice edge in March and September for the different climate states in the Arctic region. The average two-meter temperature over $70-90^{\circ} \mathrm{N}$ varies from $3.6^{\circ} \mathrm{C}$ in $4 \times \mathrm{CO}_{2}$ to $-29.1^{\circ} \mathrm{C}$ in $1 / 4 \times \mathrm{CO}_{2}$ (Table 3.1). For each $\mathrm{CO}_{2}$ doubling the increase in global mean two-meter temperature becomes slightly larger, corresponding to the larger ECS in warmer climates. Also the increment in Arctic temperature increases with $\mathrm{CO}_{2}$ from $8.2 \mathrm{~K}$ for $1 / 4 \times \mathrm{CO}_{2}-1 / 2 \times \mathrm{CO}_{2}$ up to $9.0 \mathrm{~K}$ for control $-2 \times \mathrm{CO}_{2}$, but suddenly drops to $6.7 \mathrm{~K}$ for $2-4 \times \mathrm{CO}_{2}$. As a consequence the degree of Arctic amplification (AA) is smaller in the warmest climate state (Table 3.1), but still significant. On average, the Arctic temperature change is about three times larger than the global mean. This value is somewhat larger than that of the multimodel mean AA (2.6) for transient $\mathrm{CO}_{2}$ quadrupling in an ensemble of CMIP5 simulations, but similar to the transient value of AA in EC-Earth (Van der Linden et al., 2014). Arctic amplification thus occurs in both colder and warmer climates, as was also found for a broad range of summer paleoclimate data (Miller et al., 2010) as well as in LGM and future climate model simulations (Masson-Delmotte et al., 2006).

Many factors within the climate system, including changes in sea ice (Serreze et al., 2009; Screen and Simmonds, 2010), changes in clouds and water vapor content (Francis and Hunter, 2006; Graversen and Wang, 2009), and changes in meridional energy transports (Graversen et al., 2008; Chylek et al., 2009; Yang et al., 2010), have been shown to contribute to AA. In the following, we focus on quantifying and understanding the changes in poleward heat transport toward the Arctic, a prerequisite to quantify its impact on amplified Arctic temperature change.

\subsection{Meridional heat transport}

In this section we examine the deviations in meridional heat transport (MHT) toward the Arctic for modified $\mathrm{CO}_{2}$ concentrations. Here, the northward atmospheric heat transport (AHT) is approximated as:

$$
\frac{1}{a \cos \theta} \frac{\partial}{\partial \theta}(\cos \theta A H T)=\int_{0}^{2 \pi}\left(F_{s f c}-F_{t o a}\right) a \cos \theta d \phi
$$

where $\theta$ is latitude, $a$ is the radius of the earth, and $\phi$ is longitude. $F_{s f c}$ and $F_{\text {toa }}$ are the net surface and top-of-the-atmosphere fluxes, respectively, which are defined positive downward. In a similar manner, the oceanic heat transport $(\mathrm{OHT})$ is estimated as the residual of the surface fluxes and the ocean heat 
storage $(\mathrm{dE} / \mathrm{dt})$ :

$$
\frac{1}{a \cos \theta} \frac{\partial}{\partial \theta}(\cos \theta O H T)=\int_{0}^{2 \pi}\left(d E / d t-F_{s f c}\right) a \cos \theta d \phi
$$

First we compare the simulated transports to the observation-based estimates of meridional heat transports of Fasullo and Trenberth (2008) (hereinafter referred to as FT08). For each climate state, the total transport of about 5.3 PW peaks around $37^{\circ} \mathrm{N}$ (not shown), which is somewhat smaller than the estimate of $5.9 \mathrm{PW}$ at $35^{\circ} \mathrm{N}$ in FT08. Despite the large differences in $\mathrm{CO}_{2}$ levels, the total (ocean + atmosphere) poleward heat transport in the northern hemisphere is nearly identical in each climate state. This is due to the fact that the top-of-atmosphere radiation balance, which governs the total transport, hardly changes between climates. Figure 3.2 depicts the northern hemisphere oceanic and atmospheric heat transports. In the control climate, the ocean component dominates the total MHT in the deep tropics and peaks at $1.6 \mathrm{PW}$ at $19^{\circ} \mathrm{N}$, which is compatible with the observation-based estimate of $1.7 \mathrm{PW}$ at $15^{\circ} \mathrm{N}$ in FT08. The atmosphere dominates in the regions poleward of about $10^{\circ} \mathrm{N}$. Maximum atmospheric heat transport is about three times stronger (4.6 PW) than the peak OHT and is located more northerly (near $43^{\circ} \mathrm{N}$ ) compared to the $5.1 \mathrm{PW}$ at $41^{\circ} \mathrm{N}$ in FT08.

Clearly, the OHT into the Arctic increases for double and quadrupled $\mathrm{CO}_{2}$ levels. However, it becomes smaller in the subpolar latitudes in the warmer climates. In contrast, the OHT decreases at both subpolar and Arctic latitudes in colder climates in the Northern Hemisphere. This asymmetry reveals the nonlinear response of OHT to climate forcing. In this paper we will study the mechanisms related to these responses in more detail.

Although the total MHT is rather stable by virtue of the TOA radiation balance, the individual components are not. The zonal mean deviations in OHT and AHT relative to the control climate are almost equal in magnitude, but opposite in sign (Fig. 3.2). This compensation mechanism between oceanic and atmospheric heat transports is generally known as Bjerknes compensation (Bjerknes, 1964). To quantify the ocean-atmosphere compensation we compute the compensation rate as the residual of the ratio of the net MHT changes to the maximum changes in OHT and AHT following Van der Swaluw et al. (2007). The compensation mechanism is clearly operating at all latitudes for each $\mathrm{CO}_{2}$ concentration: the compensation rate is larger than $75 \%$ for all climate states and latitudes in the northern hemisphere, except for $2 \times \mathrm{CO}_{2}$ near the equator and 
(a)
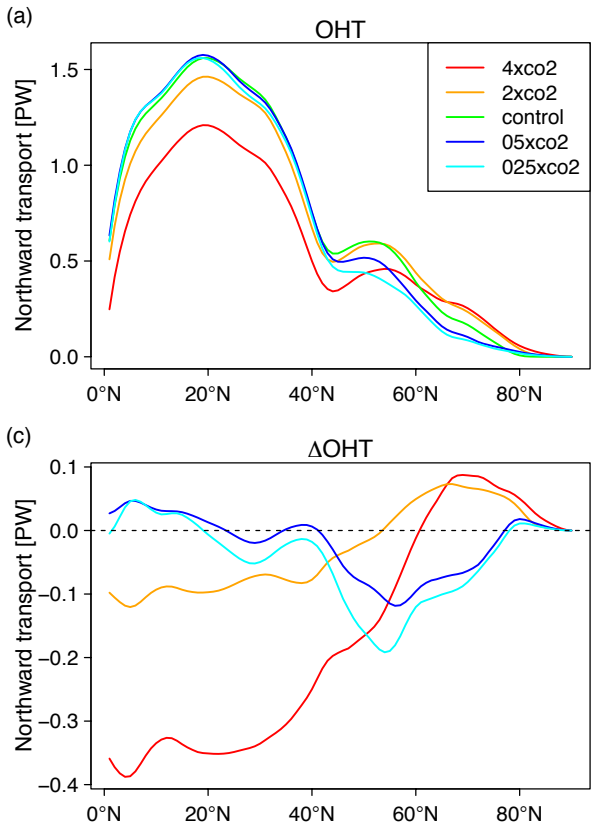

(b)

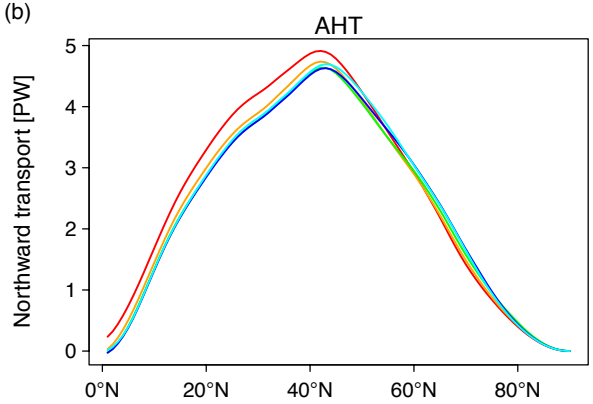

(d)

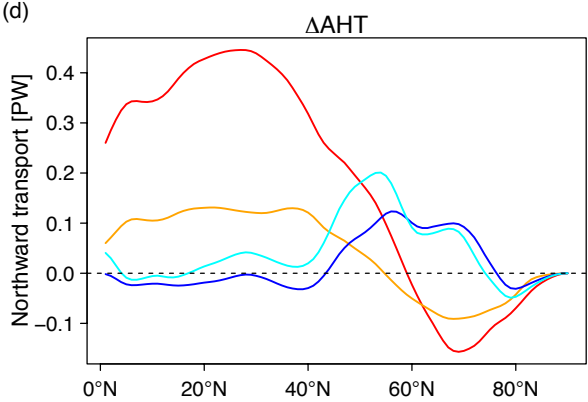

Figure 3.2 | Zonally averaged $\mathrm{OHT}(\mathrm{a})$ and $\mathrm{AHT}(\mathrm{b})$, and their respective changes relative to the control experiment $(c, d)$.

between 20 and $47^{\circ} \mathrm{N}$, although even there it still exceeds $60 \%$ (not shown). In earlier studies the effectiveness of Bjerknes compensation was already demonstrated for climate variations on decadal time scales (Shaffrey and Sutton, 2006; Van der Swaluw et al., 2007). Our results show that Bjerknes compensation for the North Atlantic and Arctic regions is applicable for equilibrium climate states as well.

At the entrance of the Arctic, the compensation rate between OHT and AHT is nearly complete with values between 79 and $93 \%$, as compared to a maximum compensation rate of $\sim 55 \%$ at $70^{\circ} \mathrm{N}$ on decadal time scales (Van der Swaluw et al., 2007). The poleward $\mathrm{OHT}$ at $70^{\circ} \mathrm{N}$ is stronger in warmer climates, and the atmosphere reacts to this by transporting less heat toward the Arctic in warmer climates owing mainly to a reduced meridional temperature gradient. The opposite is the case for the colder climate states. From now on we will focus on the OHT adjustment since at high latitudes this component is positively related to the temperature changes in the Arctic. 


\subsection{Atlantic ocean heat transport}

The Arctic Ocean is connected to the Atlantic Ocean via the Greenland-IcelandNorwegian Seas and the Canadian Archipelago, and to the Pacific Ocean through the Bering Strait. In EC-Earth, the projected twenty-first-century increase in OHT through the Barents Sea opening between Norway and Svalbard is one order of magnitude larger than that through the Bering Strait (Koenigk and Brodeau, 2014). In the following, we therefore concentrate our analysis on the Atlantic contribution to the total poleward heat transport. First, we examine two key mechanisms for the ocean heat transport in the North Atlantic Ocean: the Atlantic meridional overturning circulation (Section 3.5.1) and the Atlantic subpolar gyre (SPG; Section 3.5.2). Then we decompose the total Atlantic OHT into its overturning and gyre components and investigate how they relate to the strength of the AMOC and SPG, the ocean stratification, and other coupled atmosphere-ocean-sea ice mechanisms (Section 3.5.3).

\subsubsection{The Atlantic meridional overturning circulation}

We first examine the Atlantic meridional overturning circulation (Fig. 3.3), which constitutes the main conduit for OHT in the Atlantic Ocean (e.g., Kuhlbrodt et al., 2007). Its strength is related to convection processes in the Atlantic where North Atlantic Deep Water is formed. We can identify the main sources of this water mass by the location of the deepest mixed layer in its annual cycle in the Atlantic (Fig. 3.4). In the control experiment the AMOC operates in the upper $2.5 \mathrm{~km}$ of the ocean and has a maximum strength of $15.1 \mathrm{~Sv}$ at $29^{\circ} \mathrm{N}$ (Table 3.2), which is somewhat smaller than the present-day estimate on the basis of direct observations of $17.5 \mathrm{~Sv}$ at $26.5^{\circ} \mathrm{N}$ (Smeed et al., 2014). In warmer climates, the AMOC becomes shallower $(\sim 1.5 \mathrm{~km})$ and also weaker, a well-known feature in simulated warming climates in the twenty-first century (Cheng et al., 2013) and in the 'greenhouse' Eocene (Huber and Sloan, 2001). In the two cold climates the AMOC maximum depth $(\sim 3 \mathrm{~km})$ is enhanced, but the AMOC does not extend much further northward. The AMOC has a maximum strength in the second coldest climate $\left(1 / 2 \times \mathrm{CO}_{2}\right)$ when the mixed layer depth south of Greenland is also deepest ( $1800 \mathrm{~m})$. Moreover, in the central Arctic Ocean the maximum mixed layer depth increases in the colder climates. However, thick ice cover prevents mixing induced by the wind and surface buoyancy fluxes, and the well-mixed ocean is likely a result of diffusion processes rather than of deep water formation. Moreover, this Arctic water mass does not leave 


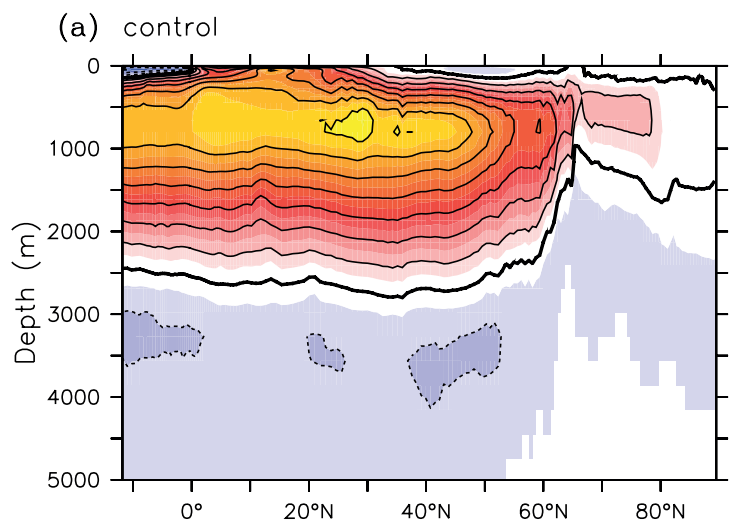

(b) $025 \times \mathrm{co} 2$
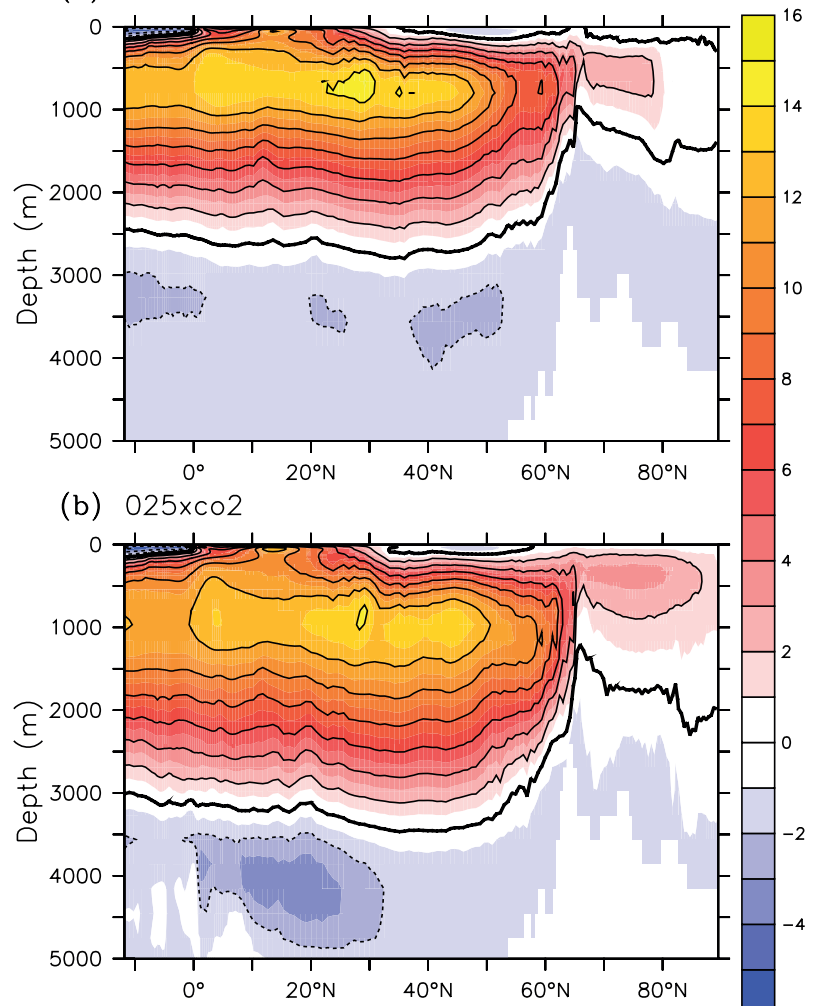

(c) $4 \times \mathrm{co} 2$

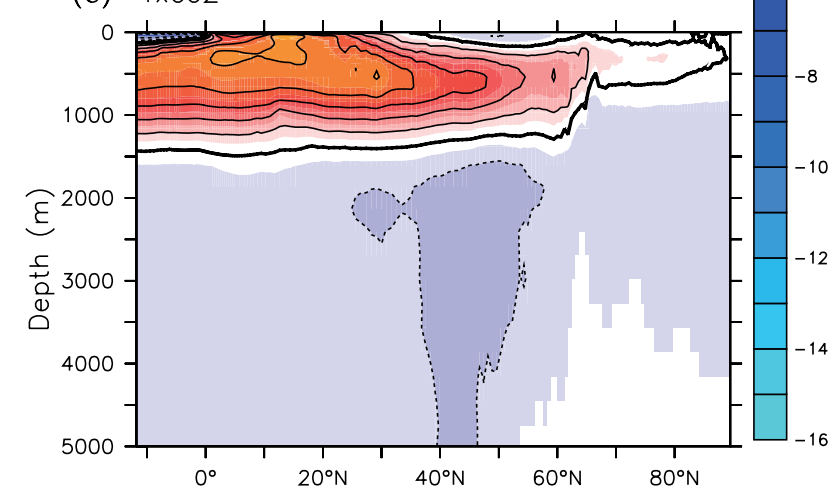

Figure 3.3 The annual mean streamfunction of the zonally integrated Atlantic volume transport in Sv $\left(1 \mathrm{~Sv}=10^{6} \mathrm{~m}^{3} \mathrm{~s}^{-1}\right)$ for the control (a), $1 / 4 \times \mathrm{CO}_{2}$ (b), and $4 \times \mathrm{CO}_{2}$ (c) climates, with positive values meaning clockwise circulation. 


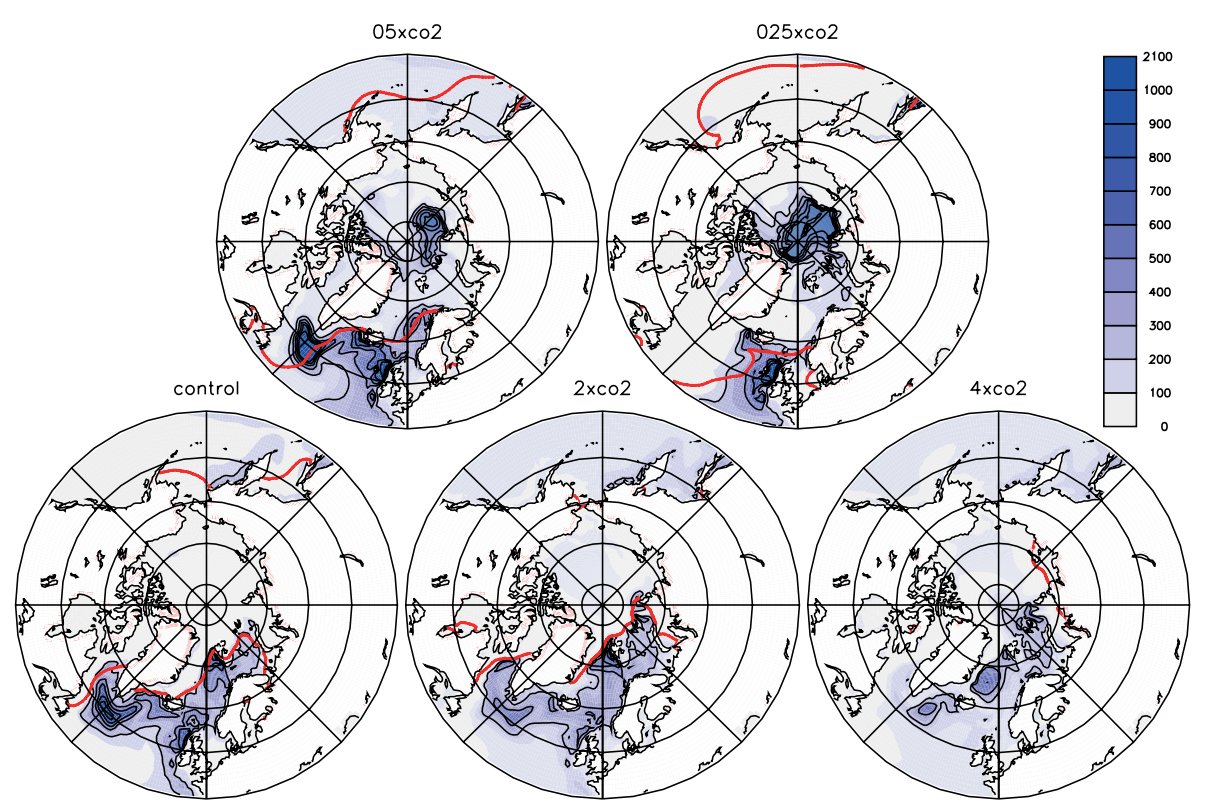

Figure 3.4 | Yearly maximum mixed layer depth ( $\mathrm{m}$; color scale) at $45-90^{\circ} \mathrm{N}$ and sea ice edge in March (red line). The sea ice edge is defined as the $15 \%$ isopleth.

the Arctic Ocean basin and therefore does not contribute to the OHT associated with the AMOC.

In the coldest climate the maximum strength of the AMOC is somewhat smaller than in the control climate, but its depth is similar as in $1 / 2 \times \mathrm{CO}_{2}$. Previous studies found that the mixed layer depth in the Labrador Sea is related to the AMOC strength on interdecadal time scales (Danabasoglu, 2008; Wouters et al., 2012). Our result suggests that the mixed layer depth in the Labrador Sea is also an indicator of the strength of the AMOC in equilibrium climate states, with the coldest climate being an exception. For this climate state $\left(1 / 4 \times \mathrm{CO}_{2}\right)$ the strength of the AMOC is only slightly smaller than in the control climate, even though the Labrador Sea convection is totally shut down. Instead, a convection region northwest of Scotland is active at the same latitude, with a similar mixed layer depth as in the control climate $(\sim 1200 \mathrm{~m})$, although in observations this region is not recognized as a deep water formation region in the current climate (Marshall and Schott, 1999). Nonetheless, our results clearly suggest that the simulated strength of the AMOC is tightly linked to the depth of the mixed layer and the associated production of deep water, but that the exact locations 
Table 3.2 | Total Atlantic meridional OHT, and its meridional and gyre components $\left(10^{14} \mathrm{~W}\right.$ at $\left.70^{\circ} \mathrm{N}\right)$, and the maximum value of the AMOC in Sv $\left(1 \mathrm{~Sv}=10^{6} \mathrm{~m}^{3} \mathrm{~s}^{-1}\right)$.

\begin{tabular}{lllll}
\hline Experiment & Atl. MOHT & Atl. Overturning & Atl. Gyre & Max. AMOC \\
\hline $1 / 4 \times \mathrm{CO}_{2}$ & 0.29 & 0.29 & -0.005 & 14.4 \\
$1 / 2 \times \mathrm{CO}_{2}$ & 0.52 & 0.10 & 0.42 & 15.8 \\
control & 1.88 & 0.20 & 1.66 & 15.1 \\
$2 \times \mathrm{CO}_{2}$ & 2.09 & 0.07 & 1.97 & 13.7 \\
$4 \times \mathrm{CO}_{2}$ & 2.05 & -0.52 & 2.55 & 11.9 \\
\hline
\end{tabular}

at which deep water formation occurs may vary with climate.

Considering the AMOC, we conclude that, in EC-Earth, there is no monotonic increase in the AMOC strength with climate cooling, with the maximum AMOC strength occurring in the second coldest climate state. Furthermore, the warming in high $\mathrm{CO}_{2}$ climates cannot (directly) be explained by the OHT changes associated with the AMOC since the overturning cell weakens while the climate warms. To understand the changes in the Atlantic OHT toward the Arctic and its contribution to Arctic amplification, we therefore need to look at other mechanisms.

\subsubsection{The Atlantic subpolar gyre}

The subpolar gyre (SPG) is a key factor for the OHT in the subpolar regions of the North Atlantic (Yang and Saenko, 2012; Born and Stocker, 2013). The strength of the SPG is largely controlled by wind forcing over the subpolar area, as well as by zonal gradients in upper-ocean densities between the gyre's center and its boundaries (Born and Stocker, 2013). On decadal and longer time scales the SPG strength is better correlated with the upper-ocean density gradient than with wind forcing (Moreno-Chamarro et al., 2016). A measure of the strength of the SPG is the barotropic streamfunction (Fig. 3.5), which demonstrates a non-linear response of the SPG to altered $\mathrm{CO}_{2}$ concentration. Its strength is largest in the control climate with a maximum value of $35 \mathrm{~Sv}$ in its center over the Labrador Sea. Interestingly, in both warmer and colder climates the SPG weakens.

In the following, we explore the dynamical processes that lead to a weaker SPG strength in both warm and cold climate states and explain why there is an optimum in its strength under the present-day climate conditions. Since the 


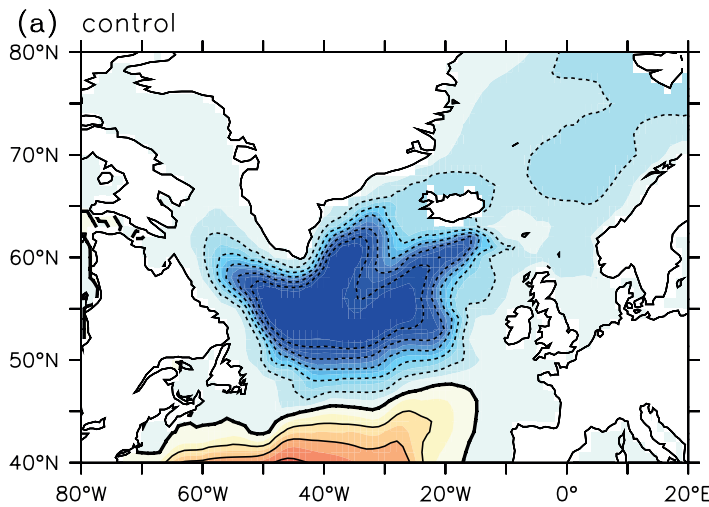

(b) $025 \times \mathrm{co} 2$

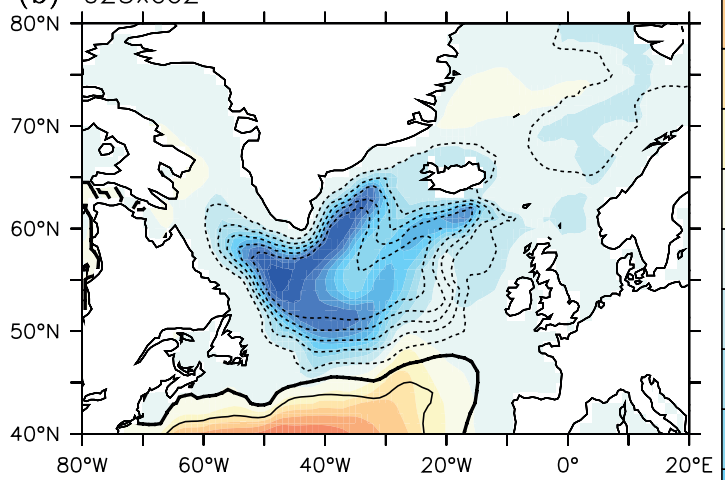

(c) $4 \times \mathrm{co} 2$

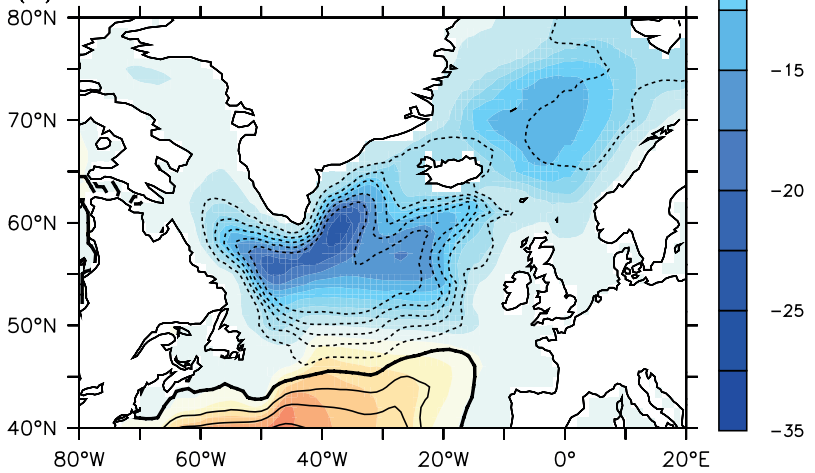

Figure 3.5 | The annual mean streamfunction in Sv $\left(1 \mathrm{~Sv}=10^{6} \mathrm{~m}^{3} \mathrm{~s}^{-1}\right)$ of the vertically integrated volume transport for the control (a), $1 / 4 \times \mathrm{CO}_{2}$ (b), and $4 \times \mathrm{CO}_{2}$ (c) climates, with a positive values meaning clockwise circulation. The contour lines (spacing: $5 \mathrm{~Sv}$ ) represent the streamfunction in the control climate. 


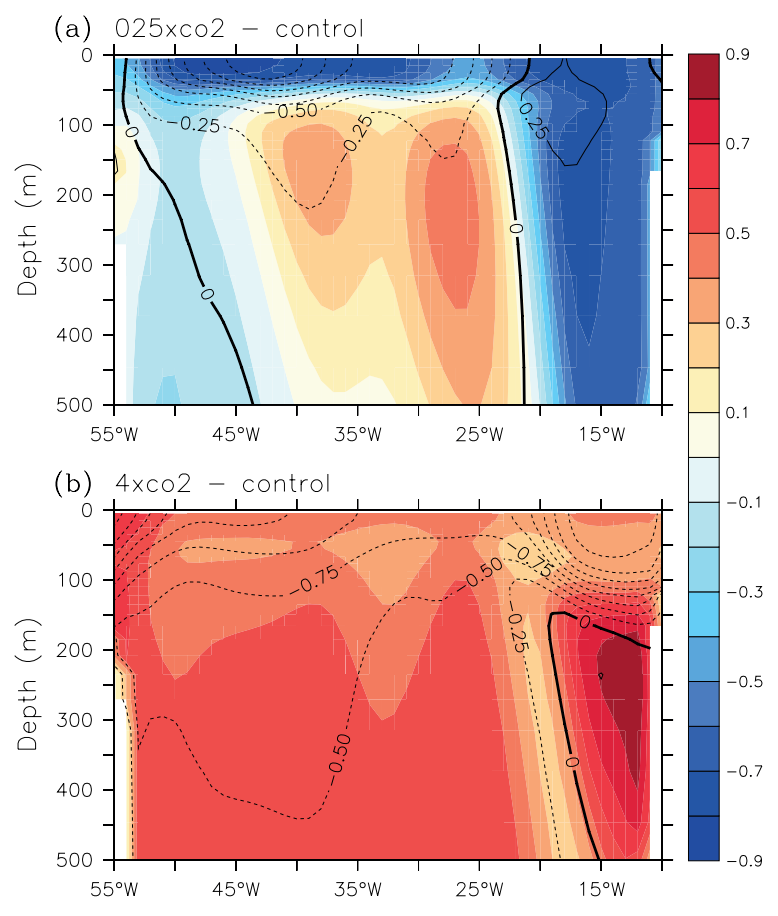

Figure 3.6 | Zonal section of ocean temperature expressed in equivalent density units ( $\mathrm{kg} \mathrm{m}^{-3}$; colors) and density ( $\mathrm{kg} \mathrm{m}^{-3}$; contour lines) anomalies relative to the control climate at $55^{\circ} \mathrm{N}$ in the North Atlantic for the $1 / 4 \times \mathrm{CO}_{2}$ (a) and $4 \times \mathrm{CO}_{2}$ (b) climates.

responsible mechanisms differ between the cold and warm climates, we discuss them separately.

\subsubsection{Cold climate mechanism}

The change in heat transport in the subpolar gyre and the Arctic can be decomposed into a component related to the stratification and a component related to the strength of the ocean transport. In the previous section we discussed the barotropic transports only. In this section we study the stratification and current changes in more detail.

For that reason, we examine the hydrographic structure over the subpolar region. The zonal section of the ocean temperature and salinity over the SPG region at $55^{\circ} \mathrm{N}$ shows that in the two cold climate states a relatively cold and fresh water layer sits on top of a saline and warm layer (Fig. 3.6, only shown for 
$\left.1 / 4 \times \mathrm{CO}_{2}\right)$. At the surface, the maximum temperature and salinity anomalies are located over the western part of the subpolar gyre (in the Labrador Sea), with a maximum drop in salinity of $3.5 \mathrm{psu}$ (not shown) and maximum cooling of $8.2 \mathrm{~K}$ for $1 / 4 \times \mathrm{CO}_{2}$. The upper-ocean freshening and cooling results from a stronger southward export of sea ice from the Nordic Seas and the Arctic Ocean into the Labrador Sea, where it partly melts and freshens the surface layer. The vertical density distribution shows that the effect of salinity on density dominates over the temperature effect (Fig. 3.6). The fresher, hence lighter, upper-ocean in the Labrador Sea contributes to the weakening of the SPG by reducing the zonal density gradient.

There is a relatively cold core of water at the eastern side of the basin where most northward transport takes place (see Fig. 3.7) and a warmer (and more saline) subsurface layer below the fresh and cold layer in the central part of the basin. The lack of vertical mixing and a reduced overturning results in a more stratified ocean.

Figure 3.7 shows the meridional component of the currents in the upper ocean. Most currents are weaker in the colder climate, consistent with the reduction in strength of the barotropic cyclonic circulation. There are indications of a westward shift of the North Atlantic Current. As a consequence, the relatively warm and saline subtropical water masses can be found below the fresh water masses in the center of the SPG. These water masses follow the North Atlantic Current poleward along the eastern boundary in the control climate but remain in the SPG in the cold climate (Fig. 3.8).

The weakening of the cyclonic circulation and the meridional currents are consistent with the changes in the density structure and in the wind stress curl. We find a positive anomaly in the wind stress curl at $55^{\circ} \mathrm{N}$ in the coldest climate (Fig. 3.9). This anomaly drives more warmer water towards the center of the gyre, rather than along the eastern boundary of the Atlantic basin.

In addition to the supply of fresh surface water, the insulating sea ice cover in the (western) SPG also plays a prominent role in modulating the surface heat fluxes and the impact of wind stresses on the ocean currents. In the cold climates, the sea ice cover is expanded over the Labrador and Barents-Norwegian Seas which significantly reduces the ocean heat losses (Fig. 3.10). This reduced surface heat loss increases the stability of the overlying atmosphere, inducing considerable positive anomalies in sea level pressure over the Labrador and Barents-Norwegian Seas (Fig. 3.11). This, in turn, causes an anticyclonic wind anomaly over the Nordic Seas with southwestward wind anomalies along the Norwegian coast and northward wind anomalies along the east coast of Green- 

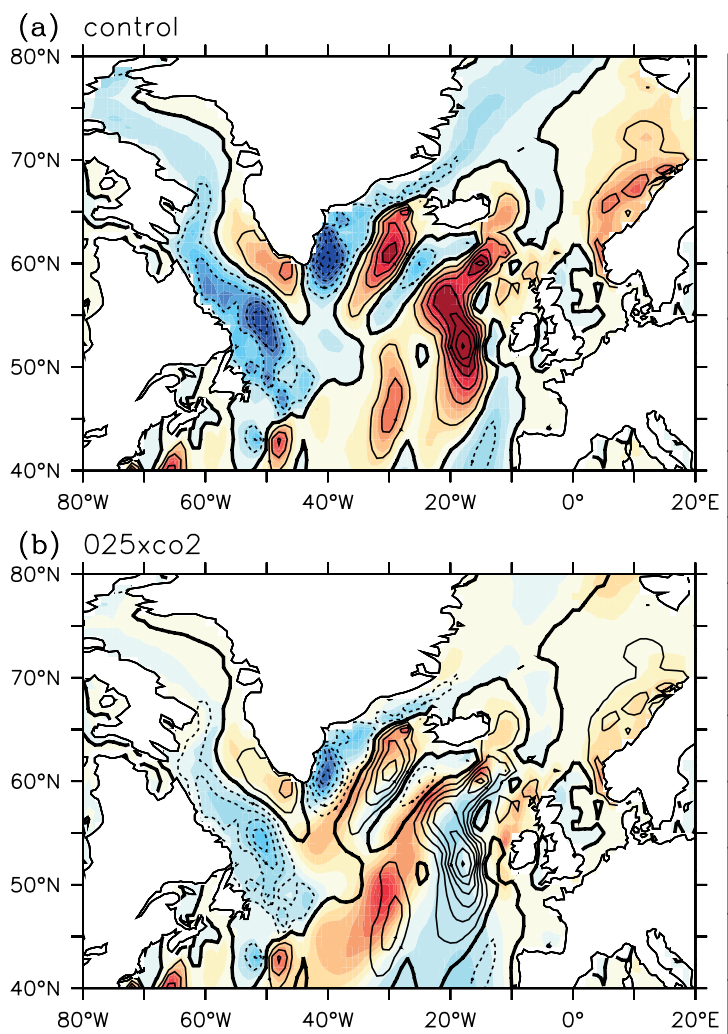

(c) $4 \times \mathrm{co} 2$

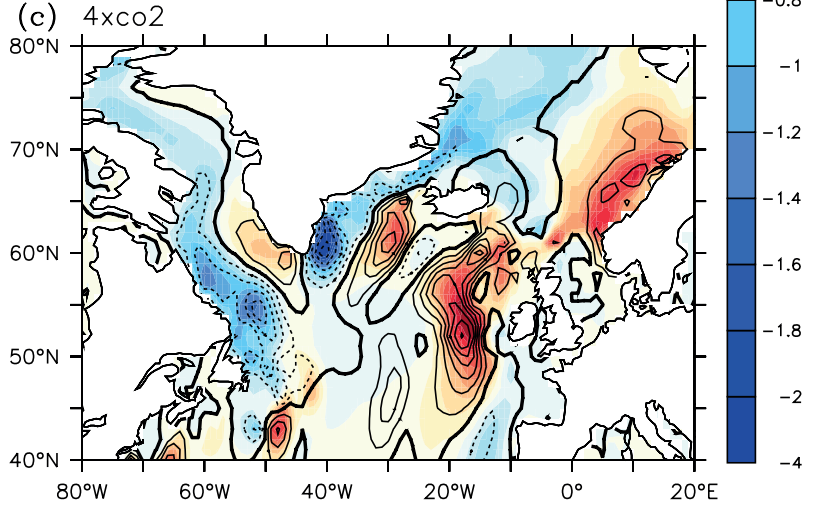

Figure 3.7 | Upper-ocean (0-400 m) meridional volume transport in Sv $\left(1 \mathrm{~Sv}=10^{6} \mathrm{~m}^{3}\right.$ $\mathrm{s}^{-1}$ ) in the North Atlantic for the control (a) $1 / 4 \times \mathrm{CO}_{2}$ (b), and $4 \times \mathrm{CO}_{2}$ (c) climates. The contour lines represent the transport in the control climate. 


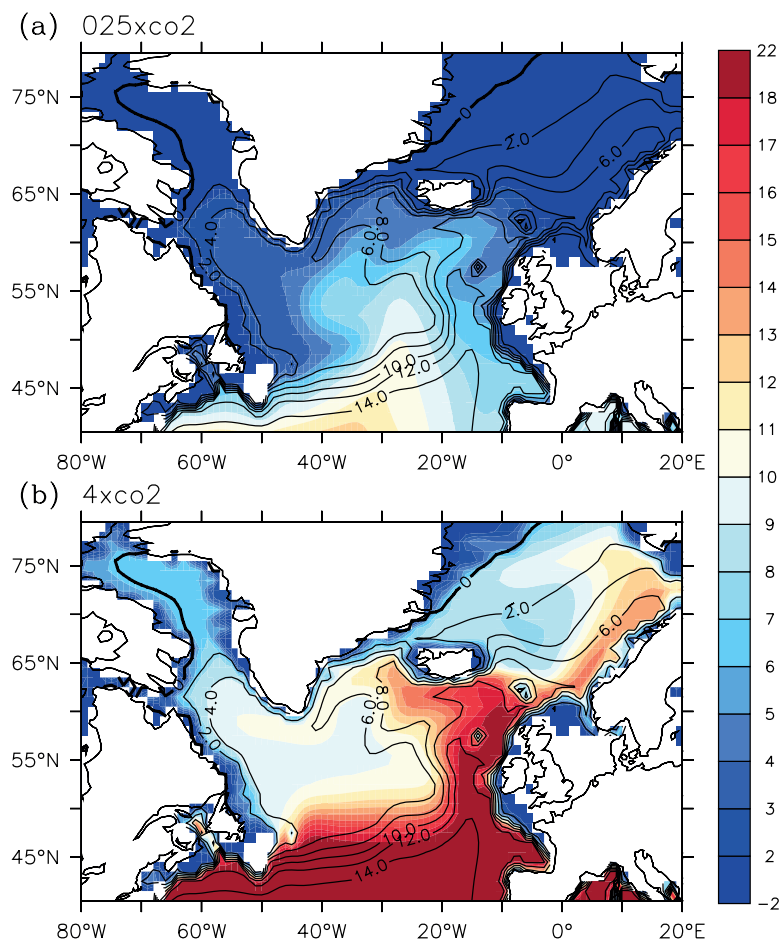

Figure 3.8 | Subsurface $(100-400 \mathrm{~m})$ ocean temperature $\left({ }^{\circ} \mathrm{C}\right)$ in the North Atlantic for the $1 / 4 \times \mathrm{CO}_{2}(\mathrm{a})$, and $4 \times \mathrm{CO}_{2}$ (b) climates. The contour lines represent the ocean temperature in the control climate.

land (Fig. 3.9). Furthermore, the expanded sea ice cover covering the SPG weakens the momentum flux towards the upper ocean and thereby slows down the underlying surface circulation. Hence, sea ice expansion plays an essential role in reducing poleward OHT. The sea ice change induces a two-folded response: it freshens the surface layer in the SPG due to seasonal melt and it reduces the friction acting on the surface ocean.

The sea ice cover also affects deep water formation. In the coldest climate the mixed layer depth over the Labrador sea is very shallow (Fig. 3.4). Here, sea ice strongly suppresses the heat fluxes at the surface, rendering it impossible to destabilize the underlying water column. Remarkably, in the second coldest climate state, the maximum mixed layer in the Labrador Sea is even deeper than in the control climate. A possible explanation is that in this climate state sea ice is not completely covering the ocean surface like in the $1 / 4 \times \mathrm{CO}_{2}$ climate. In 


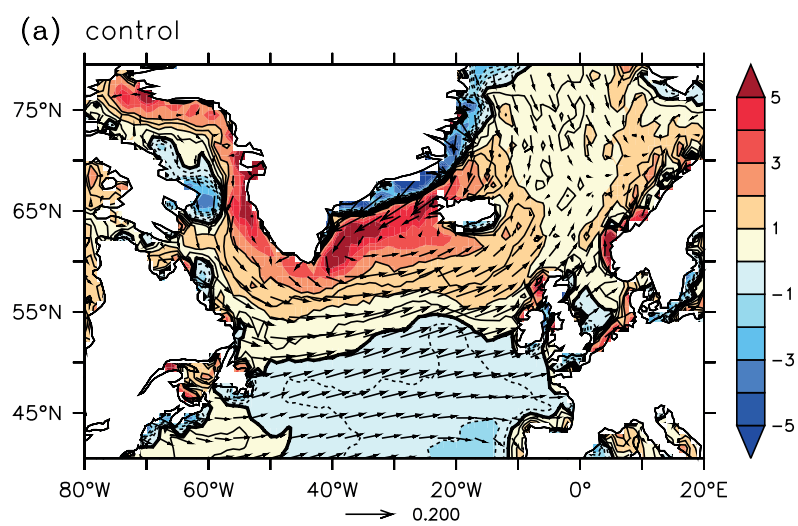

(b) $025 \times \mathrm{co} 2$ - control

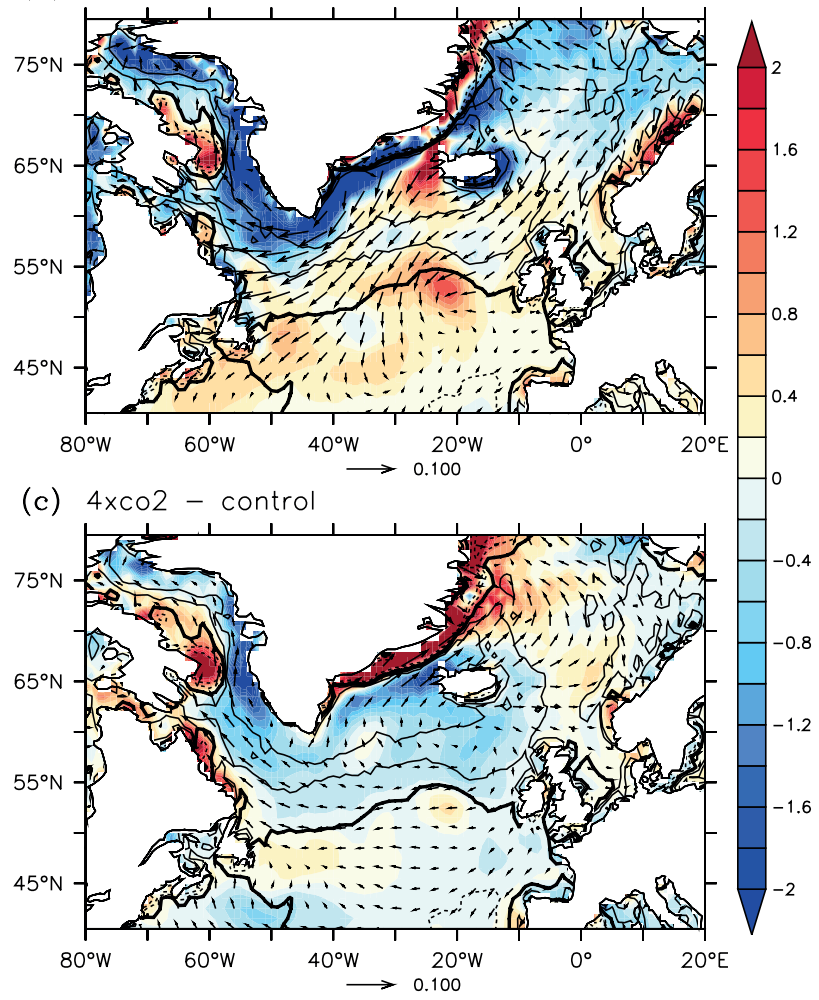

Figure 3.9 | Wind stress curl (colors; $10^{-7} \mathrm{~N} \mathrm{~m}^{-3}$ ) and wind stress (vectors; $\mathrm{N} \mathrm{m}^{-2}$ ) in the control climate (a), and changes relative to the control run in the $1 / 4 \times \mathrm{CO}_{2}$ (b), and $4 \times \mathrm{CO}_{2}$ (c) climates. The contour lines represent the wind stress curl in the control climate. 

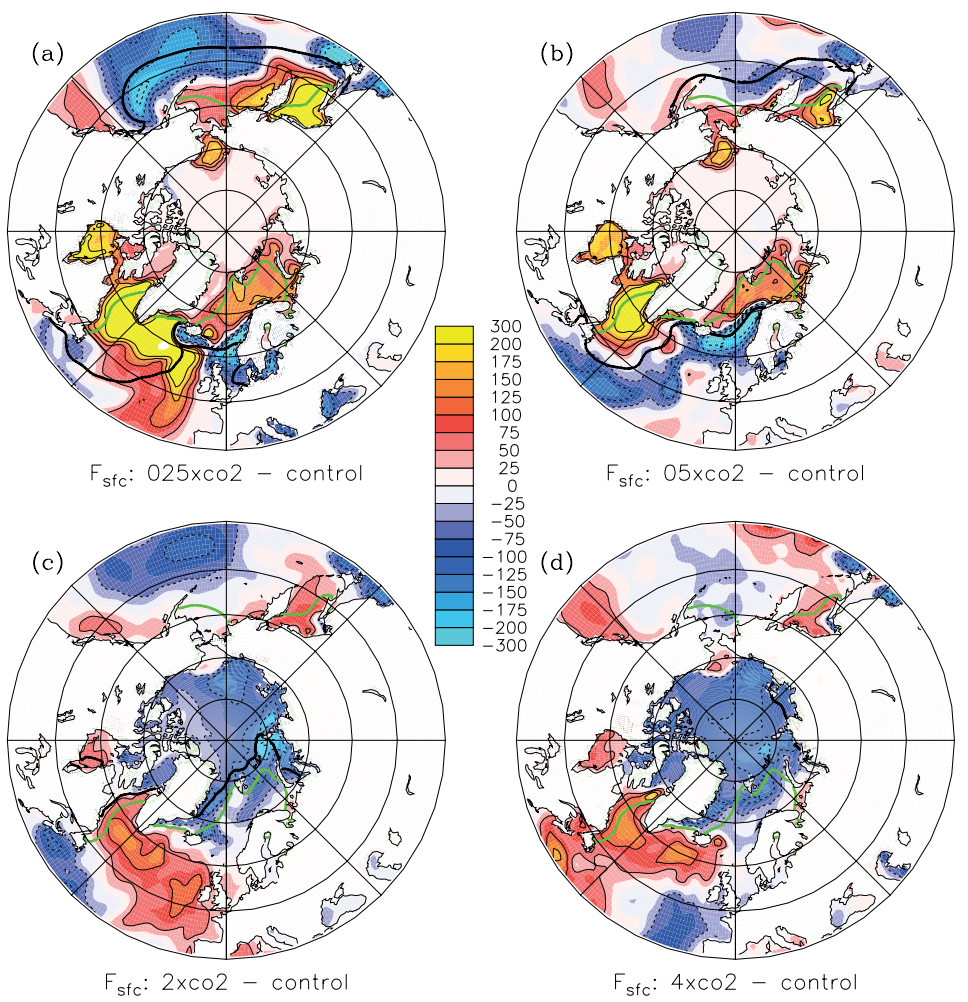

Figure 3.10 | Maps of surface heat flux anomalies $\left(\mathrm{W} \mathrm{m}^{-2}\right)$ with respect to the control climate at $40-90^{\circ} \mathrm{N}$. The thick lines represent the sea ice edge in March for the perturbed (black) and control (green) climate states, which is defined as the $15 \%$ sea ice concentration isoline.

$1 / 2 \times \mathrm{CO}_{2}$ the deepest mixed layer is located adjacent to the sea ice margin in March. Strong cold winds from the north (Fig. 3.9) then occasionally break up the relatively stable upper layer of the ocean and are able to cool the surface ocean by strong air-sea fluxes, enhancing deep water formation. The occurrence of deep water formation in the Labrador Sea is thus sensitive to the location and amount of sea ice, which is influenced in turn by the ocean heat transports.

\subsubsection{Warm climate mechanism}

In the warmer climate states, the surface buoyancy loss over the SPG region is reduced as the atmosphere warms owing to smaller air-sea temperature differences. Combined with enhanced precipitation (not shown) this causes rela- 
tively warm and fresh water to prevail in the top ocean layers, which lowers the upper-ocean density and enhances the vertical stability of the water column (Fig. 3.6). This, in turn, inhibits deep convection and weakens the strength of the AMOC (Fig. 3.3). The reduced deep water formation is apparent from the maximum mixed layer depth, which is much shallower in the warm climate states (Fig. 3.4) as compared to the current climate. The fresher and warmer top layer does not affect the strength of the subpolar gyre since the associated density changes do not modify the horizontal density gradient over the gyre. However, a low pressure anomaly develops over regions that are sea-ice covered in the control climate but ice-free in the warm climates, including the Greenland Sea (Fig. 3.11). In combination with a high pressure anomaly off the coast of Ireland this anomalous low pressure area induces a cyclonic wind stress anomaly over the Nordic Seas (Fig. 3.9). Moreover, the pressure anomaly reduces the wind stress curl over the SPG region, thereby weakening the SPG in the warm climates.

Despite the weaker AMOC, the barotropic SPG and the associated slower northward currents, the poleward OHT increases. This is primarily caused by the anomalous warming of the ocean so that more heat is transported by the currents. The cross section shown in Figure 3.6b clearly reveals the warm water mass at the eastern boundary. The northward propagation of this anomalous warm water along the Norwegian coast (see Fig. 3.8b) is enhanced by a windinduced strengthening of the cyclonic circulation north of $70^{\circ} \mathrm{N}$ (Figure $3.5 \mathrm{~b}$ and Figure 3.9c). Hence, the change in OHT in warmer climates is part of a coupled atmosphere-ocean-sea ice response to enhanced carbon dioxide concentrations.

\subsubsection{The overturning and gyre ocean heat transport}

In the previous section the changes in ocean currents as well as in the stratification in the North Atlantic were presented. In this section, we quantify the consequences of these changes for the OHT in the Atlantic.

We will investigate how the changes in the AMOC and the SPG contribute to the total Atlantic poleward ocean heat transport. For this purpose we compute the ocean heat flux directly from the threedimensional velocity $(v)$ and temperature $(T)$ fields:

$$
O H T=\rho_{0} c_{p} \int_{-H}^{0} \int_{\lambda_{1}(z)}^{\lambda_{2}(z)} v T \cos \phi a d \lambda d z
$$



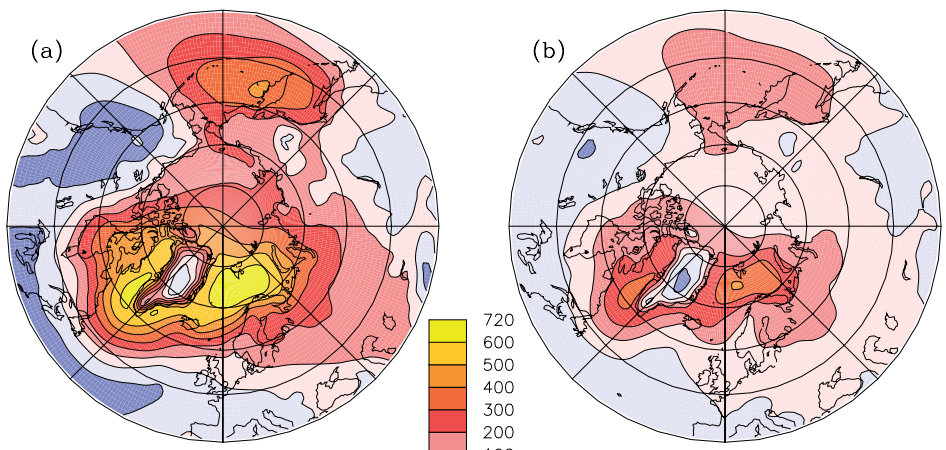

SLP: $025 \times c 02-$ control
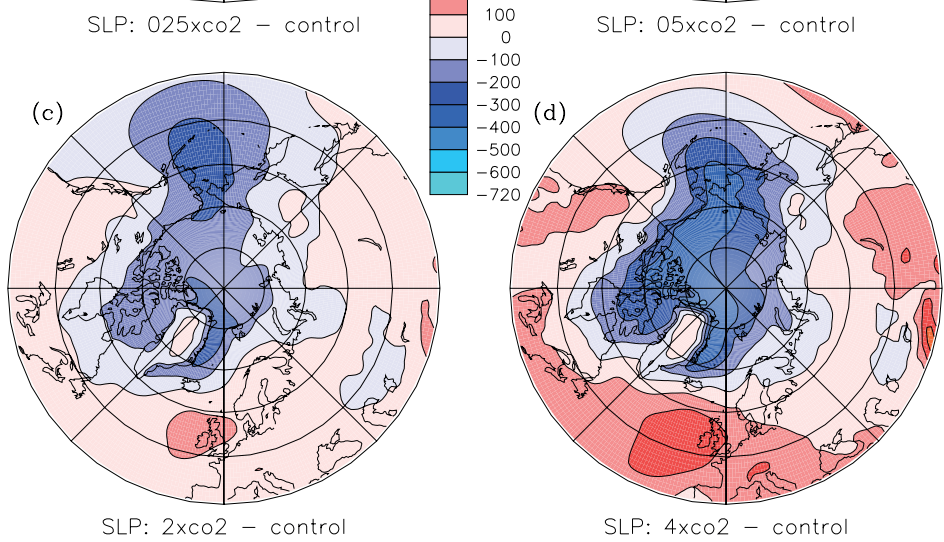

Figure 3.11 | Maps of mean sea level pressure anomalies $(\mathrm{Pa})$ with respect to the control climate at $40-90^{\circ} \mathrm{N}$.

where $\rho_{0}$ is the density of seawater, $c_{p}$ is the specific heat of seawater, $H$ is the depth of the basin, and $\lambda_{1}$ and $\lambda_{2}$ are the western and eastern boundaries, which are functions of ocean depth. The monthly mean values of $v$ and $T$ are used, where $v$ includes the eddy-induced component associated with mesoscale eddies (i.e. with length scales of $\sim 100 \mathrm{~km}$ ) represented by the Gent and McWilliams (1990) parameterization. The total OHT can be decomposed into contributions by the mean meridional overturning circulation and by horizontal gyre motions following Bryan (1982). The overturning heat transport is calculated as the integral of the product $\rho_{0} c_{p}\langle v\rangle\langle T\rangle$, where \langle\rangle denotes the zonal average. The gyre component is calculated as the integral of the product $\rho_{0} c_{p}\left\langle v^{*} T^{*}\right\rangle$, where ${ }^{*}$ denotes the departure from the zonal average. The overturning component is largely determined by the AMOC, while the SPG strength and ocean temperature distribution both contribute to the gyre component. 
(a) Total heat transport
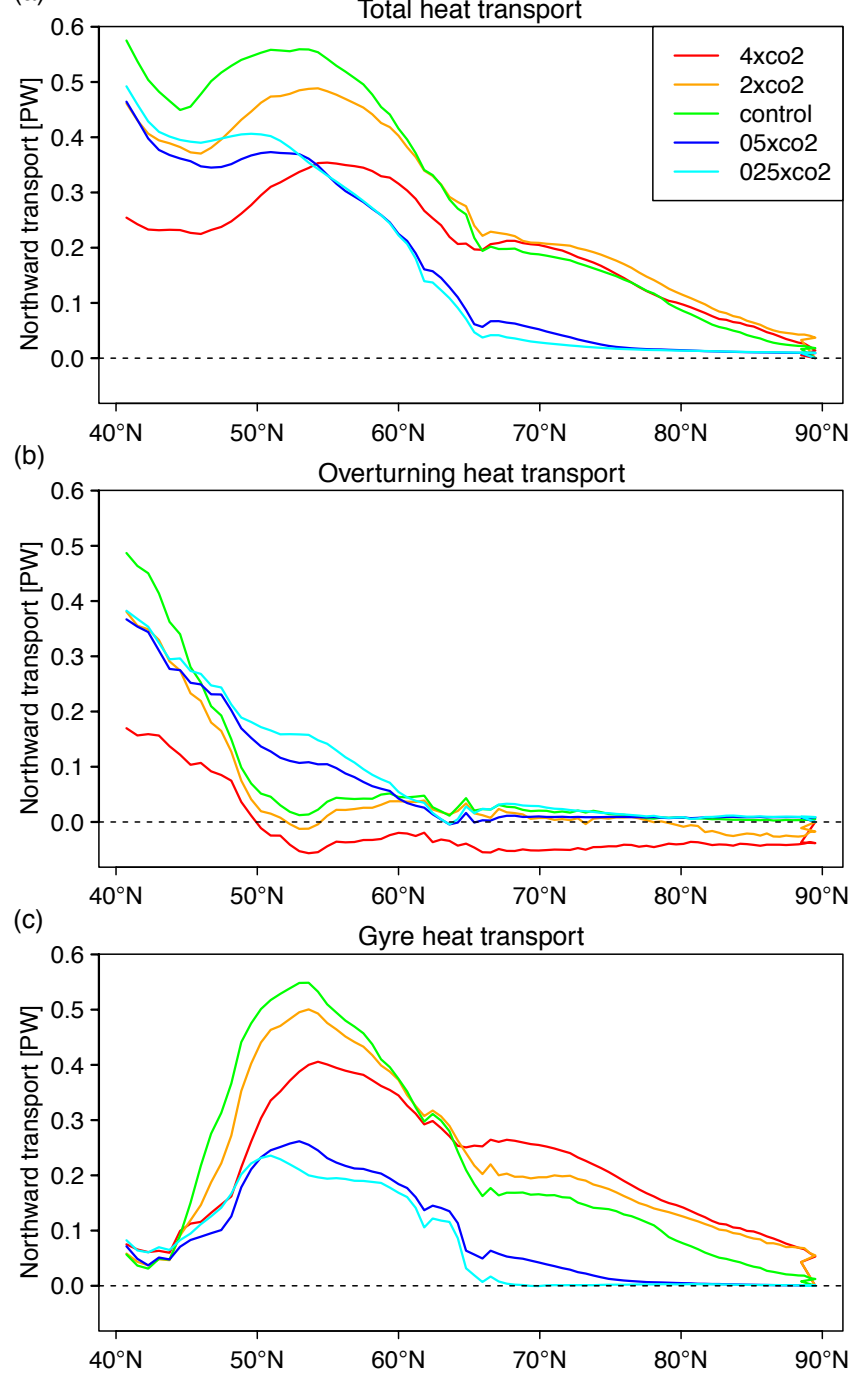

Figure 3.12 | Meridional profiles of the zonal- and vertical-mean northward heat transport in the Atlantic Ocean: the total heat transport (a), the stationary meridional overturning component (b), and the stationary eddy (gyre) component (c). 
Figure 3.12 shows the meridional profiles of the total northward heat transport in the Atlantic Ocean, as well as its overturning and gyre components. The overturning component dominates over low latitudes, but near $50^{\circ} \mathrm{N}$ there is a sudden increase in the Atlantic OHT, which is mainly due to the gyre component (Table 3.2).

Atlantic gyre heat transport in the subpolar region $\left(50-65^{\circ} \mathrm{N}\right)$ peaks in the control climate, and reduces towards both colder and warmer climate states. Similarly, the SPG weakens towards both warmer and colder climates (Section 3.5.2). The strength of the SPG thus governs the northward heat transport by gyres in subpolar latitudes. The contribution of the gyre component is clearly visible in the total Atlantic subpolar heat transport, especially in the warm climates.

In the polar region, between $65-90^{\circ} \mathrm{N}$, the Atlantic gyre heat transport is stronger for warmer climates and weaker for colder climates, both relative to present-day. The northward heat transport contributions of the overturning and gyre components at $70^{\circ} \mathrm{N}$ are listed in Table 3.2. The gyre contribution to the total northward heat transport at the Atlantic side of the Arctic increases for warmer climates from $0 \%$ in $1 / 4 \times \mathrm{CO}_{2}$ to more than $100 \%$ in $4 \times \mathrm{CO}_{2}$. Except for the coldest climate (in which the gyre component vanishes), the overturning contributes less than $20 \%$ for all climate states and becomes even negative for $4 \times \mathrm{CO}_{2}$. This negative overturning component is caused by strong southward export of 'warm' water (thus net outflow of heat) at about $800 \mathrm{~m}$ depth along the east coast of Greenland (not shown). Except for the coldest climate, we conclude that the gyre component governs the poleward ocean energy flux at $70^{\circ} \mathrm{N}$.

In the cold climates, the anticyclonic wind stress anomaly over the Nordic Seas (Section 3.5.2; Fig. 3.9) has little effect on the southward export of water near eastern Greenland, where the permanent sea ice cover reduces the momentum flux forcing on the upper ocean layer. In contrast, the wind stress anomaly likely contributes to reduce the northward inflow of warm water near the coast of Norway, where the sea ice cover in the coldest climate state is still seasonal. In this way the wind anomaly contributes to the decline in Arctic heat inflow on the Norwegian side of the Atlantic, which is most likely dominated by a deflection of the North Atlantic Current in the cold climate states (Section 3.5.2).

In the warm climates, wind anomalies can directly influence the ocean over the Nordic Seas because the sea ice cover disappeared over this region. The cyclonic wind stress anomaly over the Nordic Seas (Fig. 3.9c) enhances the Atlantic heat inflow by the gyre component. In addition, the rise in ocean temperatures with increasing $\mathrm{CO}_{2}$ concentration contributes to enhance the northward en- 
ergy flux (Fig. 3.6 and 3.8). The increased energy input into the Nordic Seas in the warm climates is thus a combination of both volume transport and temperature increase.

We note that the total poleward $\mathrm{OHT}$ at $70^{\circ} \mathrm{N}$ (Fig. 3.2) is clearly larger in the warm climates than in the control climate. This, however, is not the case for the Atlantic ocean heat transport at this latitude (Fig. 3.12), which has similar magnitudes in the control and in the warm climates. The poleward heat transport through the Bering Strait inflow must account for this difference and therefore increase towards the warmer climates ( $\sim 0.07 \mathrm{PW})$. However, such an increase seems to be on the high side for the fairly narrow passage of the Bering Strait. The meridional volume transports that are used to compute the meridional transports in the Atlantic basin have been confirmed to be conserved. Other processes that have been neglected in the computation may explain the large residual OHT in the Pacific. These include diffusive mixing, long-term deep ocean temperature drift, and sea surface height variations.

The quantitative OHT changes presented here corroborate the qualitative changes in ocean currents and density distribution discussed before. Sea ice changes play a primary role through the direct effect of insulation, the changes in ocean currents induced by those in density, and wind-stress changes due to variations in sea ice cover.

\subsection{Summary and conclusions}

In this study we investigate quasi-equilibrium changes in ocean heat transport toward the Arctic using the state-of-the-art coupled climate model EC-Earth. Our results are based on five model integrations with a wide range of atmospheric $\mathrm{CO}_{2}$ levels, varying from one-fourth to four times modern levels. At first sight, our results reveal that the climate system is quite robust under these extreme forcing conditions, as we find many similarities between the simulated climate states. For instance, even in climates with extreme warming, in which sea ice almost totally disappears, or extreme cooling, where it expands as far southward as $45^{\circ} \mathrm{N}$, the magnitudes of climate sensitivity and Arctic amplification do not change substantially.

Ocean heat transport (OHT) is a main contributor to Arctic warming. Hence, we focused on the OHT in the Atlantic Ocean, which in the current climate dominates the total OHT toward the Arctic. The AMOC, which strength peaks in the second-coldest climate state, is not directly involved in changing the Arctic 
energy inflow. In subpolar latitudes, however, the Atlantic subpolar gyre determines to a large extent the strength of the poleward ocean heat transport; intriguingly, both the SPG and OHT are strongest in the control climate at subpolar latitudes. This nonlinear response of the subpolar gyre to $\mathrm{CO}_{2}$ forcing is caused by mechanisms that are different for the warmer and colder climates, but for both changes in sea ice cover play a major role. In cold climates, seasonal melt causes freshening and reduction of surface density over the Labrador Sea. Moreover, expanding sea ice reduces the impact of wind stress on the surface ocean currents. Both effects reduce the SPG strength and the associated poleward OHT. In the warm climates, the disappearance of sea ice causes a lowpressure anomaly over the Greenland Sea, which reduces the wind stress curl over the northeastern SPG and thereby the strength of the SPG. However, the cyclonic circulation is strengthened in the Nordic seas and the waters that are transported northwards have warmed significantly compared to the control climate. This leads to an increase of OHT towards the Arctic. The net effect of these mechanisms is that the poleward OHT over the Nordic seas is enhanced (reduced) in warmer (colder) climate states.

Our results demonstrate that Bjerknes compensation (Bjerknes, 1964) - opposing changes in oceanic and atmospheric heat transports - is a governing mechanism in equilibrium climate states, with compensation rates between 79 and $93 \%$ at $70^{\circ} \mathrm{N}$. In earlier studies the importance of Bjerknes compensation was already demonstrated for climate variations on decadal time scales (Shaffrey and Sutton, 2006; Van der Swaluw et al., 2007); on interannual time scales the compensation mechanism was found to be negligible (Shaffrey and Sutton, 2004). This implies that the degree of compensation increases for longer time scales. Ocean heat transport acts to enhance Arctic amplification but is counteracted by the atmospheric response. Although the resulting anomalies in net northward heat transport are small, this compensation might still lead to changes in the Arctic climate system owing to differing responses to changes in oceanic and atmospheric heat transports. For instance, governing Arctic feedbacks such as the ice-albedo feedback may well interact differently with changes in OHT compared to AHT, in part due to the modulating effect of the sea ice cover.

An important issue is whether the nonlinear response of the subpolar gyre and AMOC also occurs in other coupled models, and whether these changes can or will be observed in past, present, and future climate change. Other coupled models also find a slowdown of the AMOC during climate warming (Cheng et al., 2013). Although the AMOC during climate warming is extensively stud- 
ied, its behavior during climate cooling is less understood (Otto-Bliesner et al., 2007). Our study shows that the AMOC strength does not monotonically increase in colder climates, which is useful information for paleoclimate studies concerning the LGM climate and the associated causes and mechanisms. Since in paleoclimate studies not only $\mathrm{CO}_{2}$ levels, but also insolation, continental ice sheets, coastlines, and vegetation are different than today, it is useful to isolate the role of $\mathrm{CO}_{2}$ and assess its effect on the paleoclimate system.

An asymmetric response of the SPG was also found for a persistent NAO-like forcing in Lohmann et al. (2009), suggesting that the North Atlantic Ocean responds in a nonlinear way to other atmospheric forcings as well. In this light, another interesting area of research is whether the anomalous pressure patterns can be detected in observations. We find a direct thermal response over former sea-ice-covered areas in warmer climates (e.g., the Greenland Sea) and over newly-formed sea-ice-covered areas in colder climates (the Norwegian-Barents Seas and the Labrador Sea). The high pressure in the eastern Atlantic is likely a response to tropical and midlatitude changes rather than to Arctic changes (Haarsma et al., 2015).

We must stress that our model, although state-of-the-art in resolution for a coupled model, has a relatively coarse ocean resolution. Details of the boundary current structure, important for accurately determining OHT, cannot be resolved at these resolutions. Hence, models with higher ocean resolution may exhibit a different OHT response. Nevertheless, this is the first systematic study of the effect of $\mathrm{CO}_{2}$ forcing in quasi-equilibrium climate states; as such our results point at important and intricate OHT sensitivity to changes in climate.

To conclude, we find distinctly different $\mathrm{CO}_{2}$-induced equilibrium changes in ocean heat transport toward the Arctic between warm and cold climates. Two important mechanisms for the North Atlantic OHT, the AMOC and the SPG, respond in an unforeseen way to $\mathrm{CO}_{2}$ forcing, with maximum strengths in the second coldest $\left(1 / 2 \times \mathrm{CO}_{2}\right)$ climate and control climate, respectively. We find that the ocean heat transport contributes to Arctic amplification through changes in (subpolar) gyre heat transport. It is clear that the net ocean heat transport toward the Arctic results from an interplay of various (remote) mechanisms that react in a nonlinear way to climate change. However, since this paper presents the results of only one coupled model, it remains to be seen how general these findings are. Further research on these mechanisms with other coupled models and observations is therefore necessary. 



\section{4}

\section{Low-frequency variability of surface air temperature over the Barents Sea: causes and mechanisms}

E. C. van der Linden, R. Bintanja, W. Hazeleger and R. G. Graversen

Climate Dynamics, 2016, 47 (3-4), 1247-1262

The predominant decadal to multidecadal variability in the Arctic region is a feature that is not yet well-understood. It is shown that the Barents Sea is a key region for Arctic-wide variability. This is an important topic because low-frequency changes in the ocean might lead to large variations in the sea ice cover, which then cause massive changes in the ocean-atmosphere heat exchanges. Here we describe the mechanism driving surface temperatures and heat fluxes in the Barents Sea based primarily on analyzes of one global coupled climate model. It is found that the ocean drives the low-frequency changes in surface temperature, whereas the atmosphere compensates the oceanic transport anomalies. The seasonal dependence and the role of individual components of the ocean-atmosphere energy budget are analyzed in detail, showing that seasonally-varying climate mechanisms play an important role. Herein, sea ice is governing the seasonal response, by acting as a lid that opens and closes during warm and cold periods, respectively, thereby modulating the surface heat fluxes. 


\subsection{Introduction}

Large low-frequency climate variations in the Arctic have been detected in observations during the last hundred years (Polyakov et al., 2003b). To distinguish anthropogenically forced temperature trends from decadal to multidecadal natural climate variability, it is important to obtain a better understanding of its many aspects and causes. The difference in simulated and observed trend patterns of Arctic near-surface temperature over land (1900-2008) is larger than would be expected based on the difference between individual model simulations in a multimodel ensemble (Gillett et al., 2008). This indicates that observed changes in Arctic temperature are not consistent with natural temperature variability alone. Decadal to multidecadal climate variability might sometimes enhance and at other times reduce long-term (anthropogenic) trends (Parker et al., 2007). This can also have implications for understanding the recent and early twentieth century warming trends in the Arctic as part of attributing Arctic climate change to human activities.

Arctic temperature fluctuations tend to exhibit larger amplitudes than global means on all time scales (Serreze and Barry, 2011). Observed surface air temperature (SAT) records show two Arctic warming periods (1910-1940 and 1970-present) and a cooling period (1940-1970), which might be (partly) attributable to long-term variability of the climate system. It is not clear whether this multidecadal variance in the 20th century is externally forced by aerosols or internally by mediation of the ocean circulation. Booth et al. (2012) showed that aerosol emissions and periods of volcanic activity explain 76 percent of the simulated multidecadal variance in detrended 1860-2005 North Atlantic sea surface temperatures in a state-of-the-art Earth system climate model. The multidecadal variance is, however, also highly correlated with the Atlantic Multidecadal Oscillation (AMO) (Chylek et al., 2009), suggesting that Arctic temperature variability on multidecadal timescales is linked to the Atlantic meridional overturning circulation (AMOC) (Delworth and Mann, 2000). In addition, observed freshwater anomalies in the Nordic Seas are primarily related to salinity changes in Atlantic inflow, suggesting that the AMOC is the driver of multidecadal freshening of the Nordic Seas (Glessmer et al., 2014). Associated with the Arctic SAT variability, the Atlantic water temperature record shows two warm periods, one in the 1930s-40s and one in recent decades, and two cold periods, one earlier in the century and one in the 1960s-70s, with a time scale of 50-80 yr (Polyakov et al., 2004).

Observed Arctic sea ice concentrations also show multidecadal (60-90 year) 
fluctuations that covary with the AMO and are most pronounced in the Greenland Sea (Miles et al., 2014). Unfortunately, the satellite-based sea ice record is not long enough to track more than one complete cycle. For the 19792011 period, observed retreat of Arctic September sea ice extent is about 70\% larger than the reduction simulated by the CMIP5 multimodel mean ensemble (Stroeve et al., 2012a). This difference in trends might be, at least partly, attributable to low-frequency natural variability in the climate system. Beitsch et al. (2014) studied a 3000-year unperturbed climate simulation and found 26 Arctic warming episodes caused by natural variability that are comparable with the early twentieth century warming. Also in model simulations it is thus not straightforward to separate anthropogenic trends from natural variability.

In model simulations most mechanisms that potentially influence Arctic climate variability have in common that they are related to changes in meridional heat and fresh water transports between the Arctic and North Atlantic. The heat transports can be related to the ocean, the atmosphere, or both. Given the long memory of the ocean, it is likely that low-frequency variability has its origin there. Using a 1000-year-long segment of a control simulation of the GFDL CM2.1 model, Mahajan et al. (2011) showed that simulated Arctic SAT is significantly correlated with the AMOC, with maximum correlation when the AMOC is leading by one year. In addition, Levitus et al. (2009) showed in observations a connection between ocean temperatures at 100-150 m depth of the Barents Sea (BS) - with a multidecadal variability on the order of $4 \mathrm{~K}$ - and the AMOC. The AMOC in the EC-Earth climate model has a dominant timescale of 50-60 years (Wouters et al., 2012), with associated positive anomalies of SAT in the BS. Weakening or strengthening of the AMOC can thus weaken or enhance Arctic warming by affecting the ocean heat transport and ocean heat uptake.

Besides ocean transports, atmospheric transports and local feedbacks are found to be related to the SAT variability over the Arctic. In the CCSM2 model the oceanic exchanges between the North Atlantic and Arctic and heat transport into the BS dominate Arctic SAT variability, but there is also a relation between SAT variability and the North Atlantic oscillation (NAO)/Arctic oscillation (AO) (Goosse and Holland, 2005). However, this relation is ambiguous since it is only significantly related to Arctic temperature variability over certain time periods. In the Hadley Centre and Max Planck coupled atmosphere-ocean models, ocean heat transport anomalies affect sea ice cover and surface heat fluxes mainly in the Barents Sea/Kara Sea region to which the atmosphere responds with a modified pressure field (Van der Swaluw et al., 2007; Jungclaus and Koenigk, 2010). As a result, variations in atmospheric and oceanic heat transports are 
strongly coupled and even compensate each other, a phenomenon that was diagnosed as Bjerknes compensation (Bjerknes, 1964). Another potential mechanism causing variability in the Arctic is the Arctic Ocean oscillation (AOO), a wind-driven oceanic motion in the Central Arctic that alternates every 5-7 yr between cyclonic and anticyclonic circulation regimes (Proshutinsky and Johnson, 1997). During the cyclonic regime, the SAT in the Arctic tends to be higher. Even though the relations between SAT variability and atmospheric circulation regimes are less pronounced than those related to ocean heat transport, changes in the ocean heat transport can be weakened or amplified as a result of those atmospheric processes.

Here we will address the multidecadal SAT variability over the Arctic. Since observational records in the Arctic are too short to track multiple multidecadal SAT cycles, we have to use model simulations to study this phenomenon. The focus of our study is the BS region, because it is clear that the BS region plays a key role in the processes that create variability in the entire Arctic system (Smedsrud et al., 2013). We will address the energy budget components in the BS, including their leads and lags as well as their seasonal cycle with respect to SAT. Although it is well-known that sea-ice related feedbacks influence atmosphere-ice-ocean interactions in the Barents and Kara Seas (Årthun and Schrum, 2010), these local mechanisms are not yet well-understood on multidecadal timescales. Therefore we will study in detail the local air-ice-ocean interactions that take place over multidecadal cycles.

\subsection{Data and methods}

We will focus on the pattern and timescale of low-frequency Arctic SAT variability in coupled models. For this purpose we use the preindustrial simulations of models in the Coupled Model Intercomparison Project phase 5 (CMIP5) (Taylor et al., 2012). Since we are interested in multidecadal variability, the length of the model experiment should be at least 500 years. In this way internal variability due to chaotic variations in the climate system can more accurately be distinguished from semi-oscillatory interannual to decadal variability. This leaves us with a subset of 18 climate models. Following Massonnet et al. (2012), we only select models that reasonably simulate the sea ice extent, including its seasonal cycle and trend over 1979-2010, and sea ice volume, which leaves only 5 models. For brevity, we will present results of only one of these models in detail, namely ACCESS1.3. Its smoothed time series of SAT over the BS is shown in Figure 4.1. 


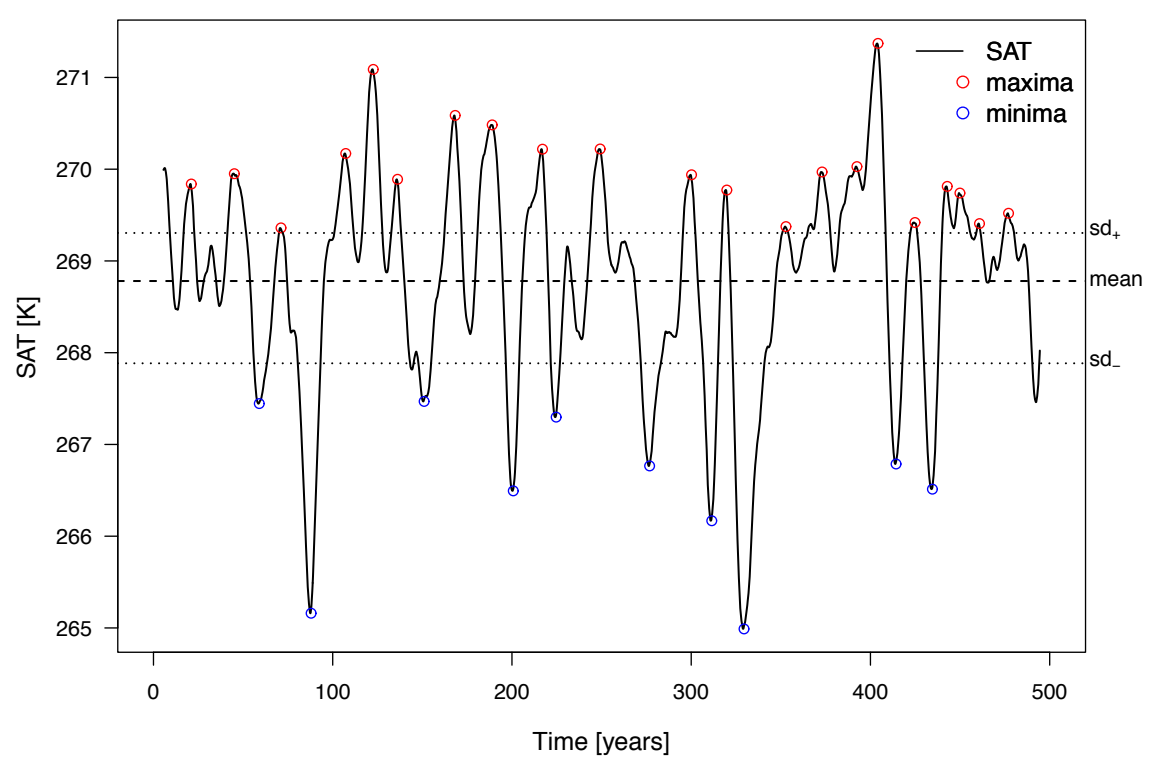

Figure 4.1 | Smoothed time series of surface air temperature over the Barents Sea. The red and blue dots represent the selected 11-year running local maxima and minima for the computation of the composites. We used two different standard deviations: $\mathrm{sd}_{+}$ $\left(s d_{-}\right)$is defined as the standard deviation of the warm (cold) phase. Only the values that are larger (smaller) than one positive (negative) standard deviation $\mathrm{sd}_{+}\left(\mathrm{sd}_{-}\right)$from the mean are considered as maxima (minima).

This model exhibits a reasonable and stable representation of key diagnostics of ocean climate performance in the preindustrial control simulations, including the meridional overturning circulation and poleward heat transport maximum (Marsland et al., 2013).

From observations we know that the dominant timescales of multidecadal variability in ocean temperatures in the North Atlantic have two main periods: the long (50-70 years) and the shorter period (20-30 years) (Frankcombe and Dijkstra, 2010). BS surface atmospheric temperatures in ACCESS1.3 show a 99\% significant peak at 26 years and a $95 \%$ significant peak at 62 years (Fig. 4.2), indicating that the time scales of its variability are close to observations. We compared the simulated pattern of annual mean Arctic decadal temperature variability (Fig. 4.3) with the early twentieth century warming (Bengtsson et al., 2004), which is thought to be dominated by internal climate variability. This comparison shows that both the observed and simulated variability exhibit a 


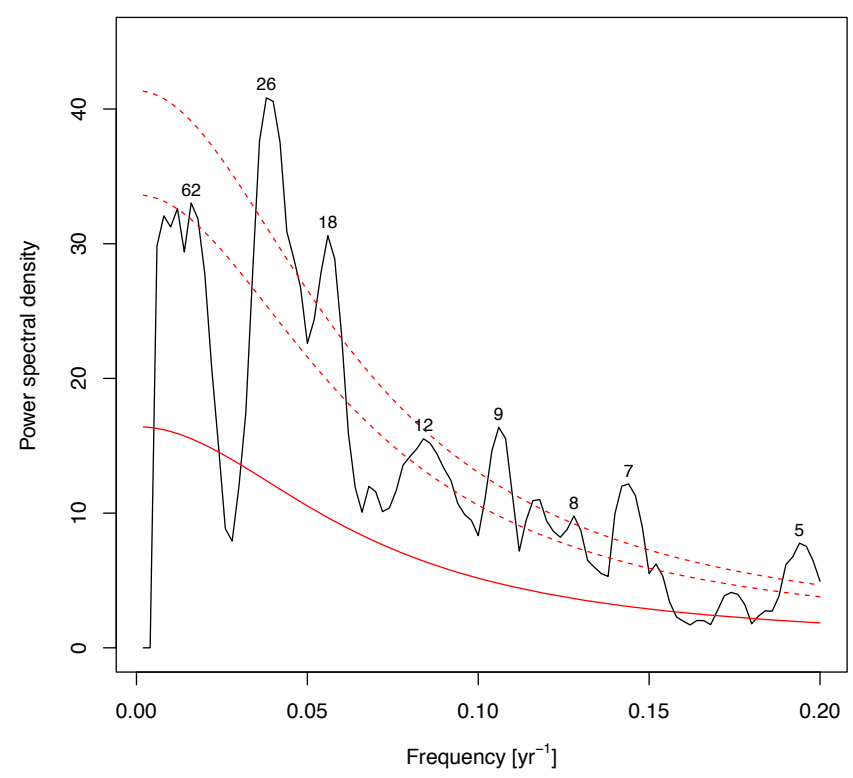

Figure 4.2 $\mid$ Spectrum of the annual mean surface air temperature over the Barents Sea (model ACCESS1.3). The two dashed red lines represent the 95 and $99 \%$ significance levels of the theoretical red noise spectrum (red line) with the autocorrelation and standard deviation of the time series. The numbers above the significant local maxima represent the periods that are associated with the local maxima in years.

dominant signal over the BS. The results presented here are likely representative for a broaden suite of CMIP5 models, since most models have qualitatively similar characteristics of simulated variability.

In our study, the BS is defined as the area between $20-70^{\circ} \mathrm{E}$ and $70-80^{\circ} \mathrm{N}$. All variables that will be shown and discussed have been detrended and deseasoned. To emphasize decadal time scales the time series are smoothed with an 11-year running Welch window, which was normalized to have an average power of unity.

\subsection{Barents Sea variability characteristics}

In this section we explore the low-frequency variability of SAT in the Arctic. The first empirical orthogonal function (EOF1) of Arctic SAT shows that annual mean Arctic SAT variability is dominated by variability over the BS region 


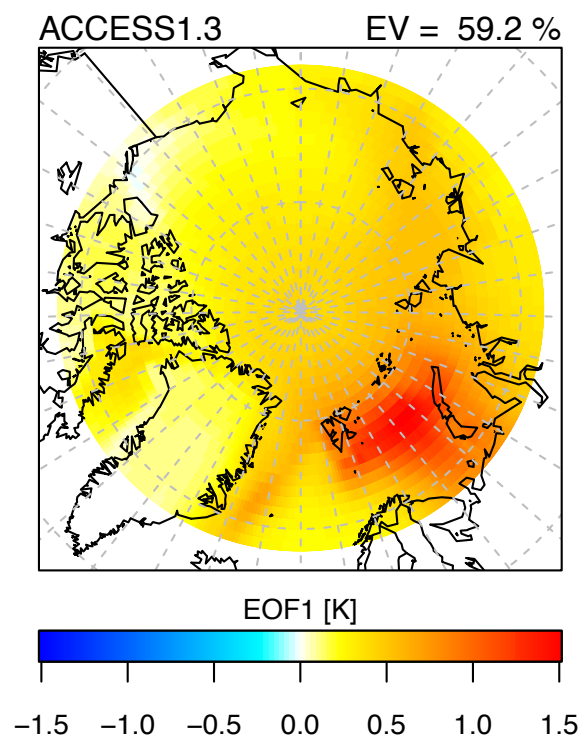

Figure 4.3 | First empirical orthogonal function (EOF1) of the surface air temperature over the Arctic in ACCESS1.3. The EOF represents the amplitude relative to one standard deviation of the associated principal components. EV is the percent variance explained by EOF1.

(Fig. 4.3). In ACCESS1.3, EOF1 explains 59 percent of the total variability in the Arctic. The temporal behaviour of the corresponding principal component of SAT in the Arctic is closely linked to the BS-averaged SAT, with a correlation of 0.90 . Both the time series of the first principal component and the time series of BS-averaged SAT exhibit a red spectrum, with enhanced power at low frequencies. The smoothed time series and spectrum of the annual mean SAT anomalies over the BS are presented in Figures 4.1 and 4.2, respectively. The principal component and SAT index time series both have a dominant periodicity of about 26 years. The smoothed SAT anomalies over the BS range from -3.8 to $2.6 \mathrm{~K}$, with a standard deviation of $1.1 \mathrm{~K}$. Periods with a positive SAT anomaly are defined as a warm phase, and periods with a negative SAT anomaly as a cold phase. The BS is in a warm phase for $60 \%$ of the time. This skewed behavior indicates that nonlinear processes likely play a role in the SAT variability. Despite this skewed behavior we will see later on that the feedbacks in the warm and cold phases are qualitatively similar, but opposite in sign. 


\subsection{Energy budget analysis of the Barents Sea}

To investigate what mechanisms are important during the multidecadal cycles of SAT variability, we analyze the flows of energy to and from the BS. The energy budget for the atmosphere in an enclosed region in the Arctic (Fig. 4.4) can be written as

$$
d E_{A} / d t=F_{T O A}-F_{S F C}-\nabla \cdot A H T \approx 0,
$$

where we assume that the atmosphere has zero heat storage $\left(\mathrm{dE}_{A} / \mathrm{dt} \approx 0\right)$. The net downward top-of-atmosphere radiation flux $\left(\mathrm{F}_{\mathrm{TOA}}\right)$ is obtained from differencing net absorbed shortwave radiation and outgoing longwave radiation. The total downward surface flux $\left(\mathrm{F}_{\mathrm{SFC}}\right)$ is computed as the sum of the net radiative flux (the net longwave and shortwave radiative fluxes), and the turbulent heat fluxes (sensible and latent). The convergence of atmospheric heat transport $\left(-\nabla \cdot\right.$ AHT) into the BS is approximated as the residual of $\mathrm{F}_{\mathrm{SFC}}$ and $\mathrm{F}_{\mathrm{TOA}}$. The ocean energy budget in an enclosed basin in the Arctic equals

$$
d E / d t=F_{S F C}-\nabla \cdot O H T .
$$

The convergence of ocean heat transport $(-\nabla \cdot$ OHT) into the basin is approximated as the residual of $\mathrm{F}_{\mathrm{SFC}}$ and ocean heat storage $(\mathrm{dE} / \mathrm{dt})$. The ocean heat content (E) is calculated as the volume integral of $\rho_{0} c_{p} \theta$ over the basin, where $\rho_{0}$ is the reference density for the Boussinesq approximation, $c_{p}$ is the specific heat capacity for seawater, and $\theta$ is the potential temperature. OHT and $\mathrm{dE} / \mathrm{dt}$ are divided by the surface area of the basin in order to compare them to the units of the other fluxes $\left(\mathrm{W} \mathrm{m}^{-2}\right)$.

To assess the realism of the simulated energy budget, the modelled Arctic energy budget (the region north of $70^{\circ} \mathrm{N}$ ) is compared with the energy budget using present-day observations (Serreze et al., 2007). The simulated total heat transport into the Arctic is slightly larger than in the observations, but the ratio of OHT to AHT is similar. Given that the heat budget is not closed in the realworld data, and that we use preindustrial climate conditions instead of presentday conditions, ACCESS 1.3 seems to simulate the Arctic heat budget sufficiently realistic.

In the mean preindustrial climate state, both OHT and AHT are directed towards the BS mainly due to the equator-to-pole temperature gradient (Fig. 4.4). The mean $\mathrm{F}_{\mathrm{SFC}}$ is directed upward, i.e. the ocean loses heat to the atmosphere. The net radiation at the top-of-atmosphere $\left(\mathrm{F}_{\mathrm{TOA}}\right)$ is outgoing. On average the atmosphere contributes $59 \%$ to the total energy transport into the BS region, 

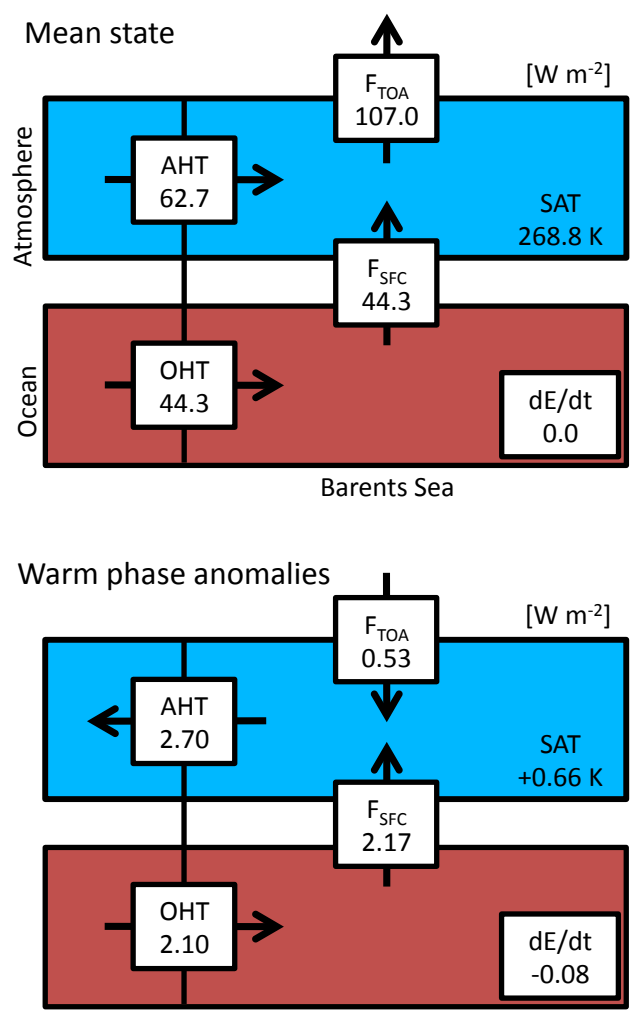

Barents Sea

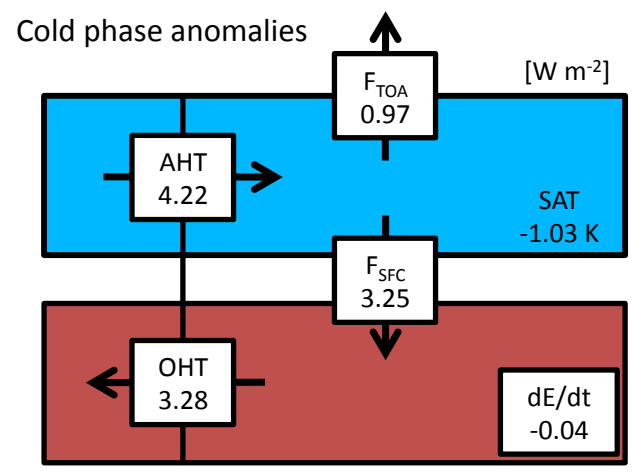

Barents Sea

Figure 4.4 | Energy budget components in the preindustrial climate of the Barents Sea in $\mathrm{W} \mathrm{m}^{-2}$. The top figure shows the energy flows in the mean climate state, and the middle and bottom figure the average anomalies in the warm and cold phase, respectively. The arrows point in the direction of the anomalies. 
and the ocean $41 \%$. Almost all the heat that enters the BS through OHT is used to either melt sea ice or heat the atmosphere through surface fluxes. The $\mathrm{dE} / \mathrm{dt}$ is very small, showing that the simulated preindustrial climate is close to equilibrium. All energy budget components exhibit a low-frequency variability with a timescale of 26 years. The mean energy budget anomalies of the BS averaged over the warm and cold phases are also shown in Figure 4.4. During warm phases, OHT, $\mathrm{F}_{\mathrm{SFC}}$, and $\mathrm{F}_{\mathrm{TOA}}$ enhance surface warming, whereas AHT dampens it. During cold phases, all anomalies are of opposite sign, and also slightly larger in magnitude than in the warm phases. This is related to the skewed behavior of the SAT time series, and for this reason warm phases last longer than cold phases. The magnitude of $\mathrm{dE} / \mathrm{dt}$ is small in both warm and cold phases, indicating that ocean heat storage is not in phase with fluctuations in SAT, but the ocean heat content itself is (i.e. little change at the peaks). Large amplitude variations of $\mathrm{AHT}$ and $\mathrm{OHT}$ are of opposite sign on multidecadal timescales, a characteristic that might be related to Bjerknes compensation. An explanation for this is that the atmospheric response to increased (decreased) surface fluxes is a decreased (increased) meridional temperature gradient, leading to a decreased (increased) heat transport by baroclinic eddies, and thus a weaker poleward transient atmospheric energy transport (Shaffrey and Sutton, 2006; Van der Swaluw et al., 2007). However, since we have no information on the direction of the atmospheric transport, we can only conclude that AHT is directed out of the BS when there is a gain of heat by ocean heat transport.

\subsubsection{Leads and lags}

To obtain a better understanding of the mechanisms behind BS variability on the multidecadal timescale we explore the lead-lag relationships between BSaveraged SAT and the energy budget components in the BS. To obtain more information about the causes and effects of the energy flow, we compute crosscorrelations between the energy budget variables and SAT over the BS. In accord with Bjerknes compensation, the smoothed OHT and AHT are strongly anticorrelated, with maximum anticorrelation $(-0.97)$ when OHT is leading AHT by 17 months (Fig. 4.5). The absolute correlation between OHT and SAT is maximum for OHT into the BS leading SAT by 15 months (not shown). AHT leaving the BS lags SAT by 6 months. From this it is clear that the atmosphere responds to SAT changes by compensating for the increased ocean heat transport. However, $\mathrm{F}_{\mathrm{SFC}}$ that can act to warm the atmosphere lags SAT by 7 months over the BS as a whole. In section 4.6 we will show that the spatial pattern of the $F_{S F C}$ anomalies 


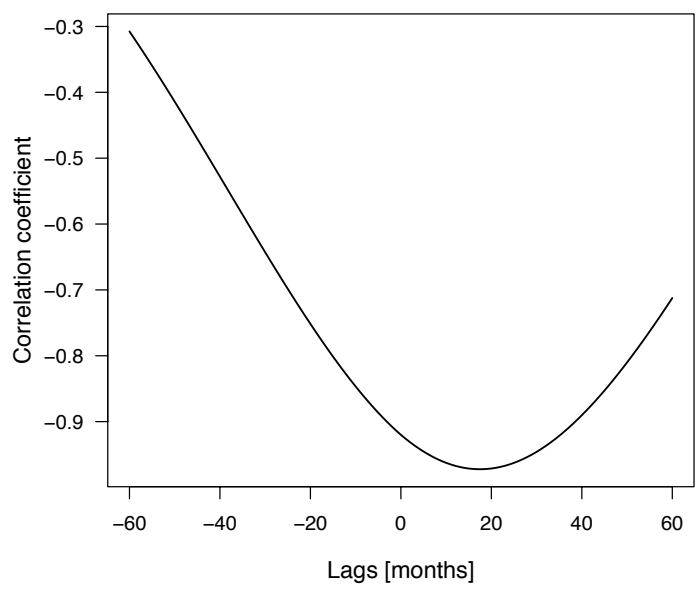

Figure 4.5 | The correlation of the ocean heat transport with the atmospheric heat transport into the BS. At positive lags $\mathrm{OHT}$ is leading.

over the BS reveals that it can be subdivided into an eastern and western part. The western part, where the sign of the response is negative, is leading changes in SAT, and the central/eastern part is lagging changes in SAT. This east-west difference in response time is likely linked to sea ice coverage.

In the cross correlation method the computed leads and lags take into account the entire period. To investigate the leads and lags that are active around the peak periods only we define two composites: a warm one and a cold one. The warm (cold) composite consists of the local SAT maxima (minima) of the smoothed time series that deviate more than one standard deviation from the mean (Fig. 4.1), in which 24 months before and after each peak are included in the composite. These SAT time indices for the warm and cold composites are used to make composites of other variables over the same time periods. Figure 4.6 shows the mean warm and cold composites of all energy budget components averaged over the BS. Before the mean was computed, all local SAT extremes were aligned on top of each other. The location of the energy budget component peaks relative to the SAT maxima provides a measure of their leads/lags. It seems clear, in this model, that the ocean drives the changes in the BS, and that the atmosphere is mostly responding to the ocean. We do not know, however, if the ocean drives the variability or that it only plays a mediating role. The question rises whether the OHT variability is due to variations in the strength of the ocean circulation (volume transport) or due to variations in 

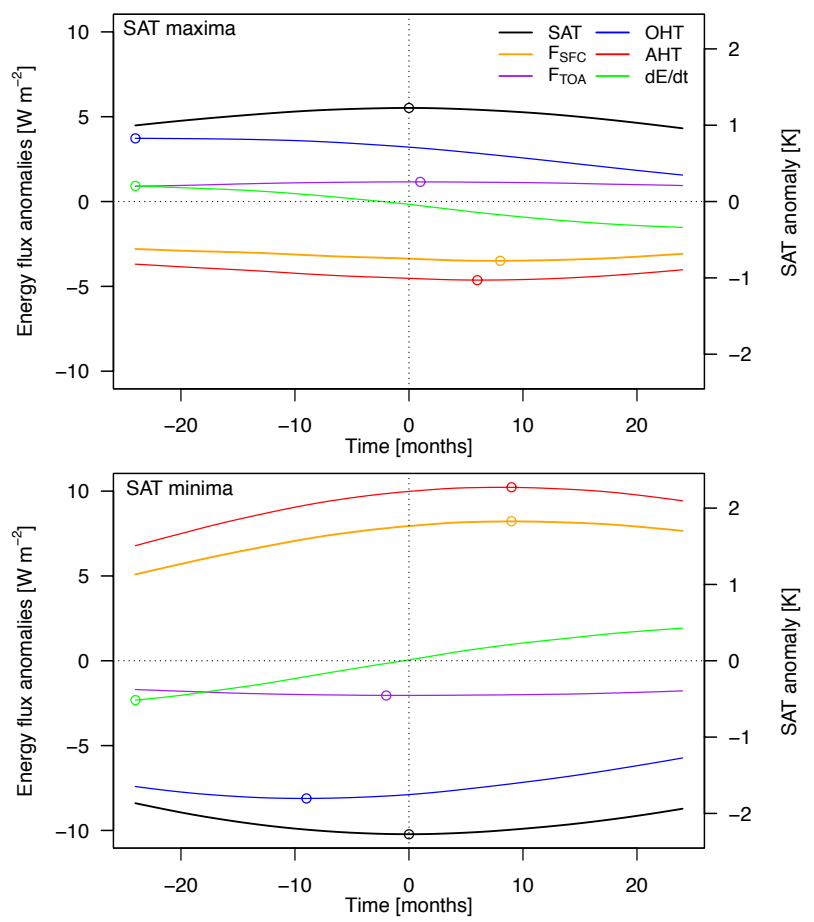

Figure 4.6 | Energy budget components of the Barents Sea in the warm (top) and cold (bottom) composites of the Barents Sea. The open circles represent the absolute maxima within each composite. Their relative position to the SAT maxima/minima gives an indication of their leads/lags.

the temperature stratification (inflow and outflow temperatures) of the ocean. To assess the variability of the strength of the circulation we study the time series of the AMOC index (Fig. 4.7). The correlation between OHT into the BS and the AMOC index is 0.40 , implying that about $16 \%$ of the low-frequency variability in OHT can be attributed to the AMOC strength. This value is similar to the value found by Mahajan et al. (2011). Note that at $60^{\circ} \mathrm{N}$, however, OHT is dominated by heat transport due to the sub-polar gyre (Beitsch et al., 2014). The gyre circulation might play an important role in the total heat transport into the Barents Sea in comparison with the AMOC-driven heat transports. The remaining variability can thus be explained by heat transport variations due to the sub-polar gyre and variations in temperature stratification. 


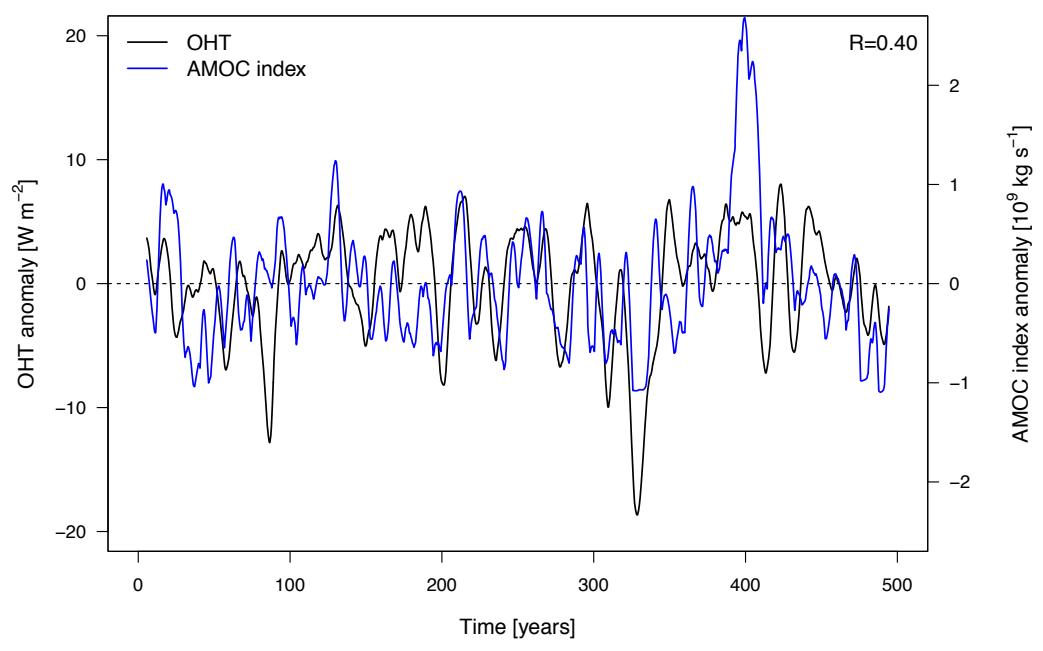

Figure 4.7 | Smoothed time series of OHT into the BS and the AMOC index. Here we define the $A M O C$ index as the maximum value of the meridional overturning mass stream function between 500 and $2000 \mathrm{~m}$ depth, and between 15 and $65^{\circ} \mathrm{N}$.

\subsection{Seasonal cycle in variability}

The multiyear variability in the BS-averaged SAT is not equally spread throughout the year (Fig. 4.8). Winter months exhibit four times larger multidecadal variability compared to the summer months. Synoptic eddy activity is strongest in winter and hence AHT exhibits most variations in winter. On the other hand, $\mathrm{F}_{\mathrm{TOA}}$ varies more in summer when there is a larger influx of solar radiation. OHT and $\mathrm{dE} / \mathrm{dt}$ show two periods of enhanced variability in summer and winter.

SST exhibits more decadal variability at the end of summer when SIC is low, and sea ice is not restricting the SST to melting point temperature. SIC variability is also lower at the end of summer, just because there is less sea ice to vary. When we look more closely at the variability of the surface energy balance fluxes (not shown), we infer that all components exhibit most variability in winter, except the SW fluxes. The SW fluxes are most variable in May-June, due to a combination of high SIC in late spring and high solar insolation in June.

Monthly EOFs of Arctic SAT show that the variability pattern has dominant variability over the BS, which is most pronounced in December-April and JulyAugust (Fig. 4.9). In winter, the amplitude of the variability is much larger than in summer. Therefore for summer months, the pattern is not clearly visible, since the EOFs are plotted on the same scale. In spring and autumn the 


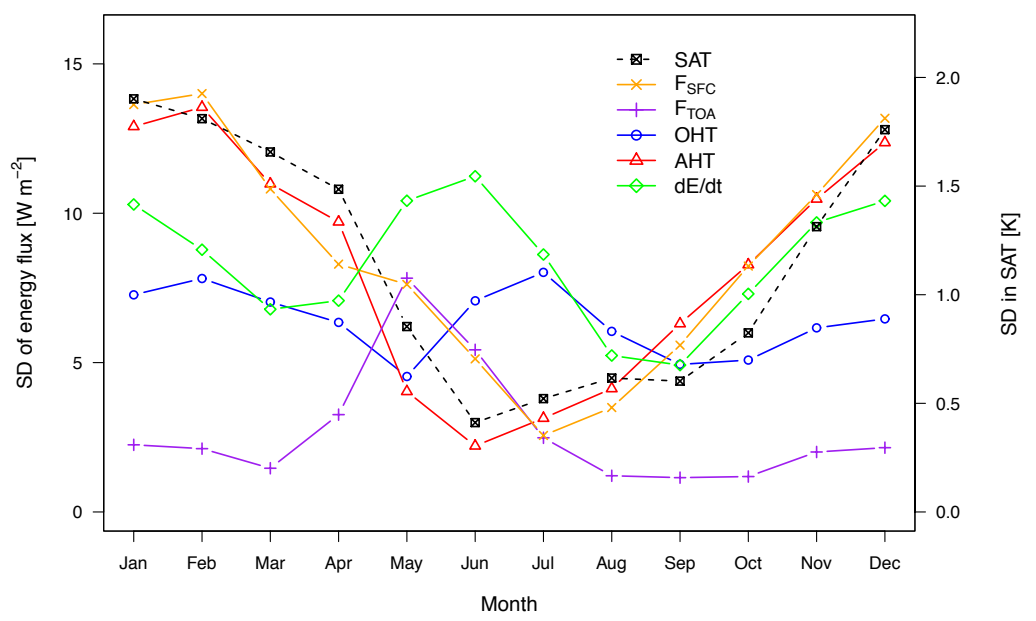

Figure 4.8 | Multiyear monthly standard deviation for the Barents Sea energy budget components and SAT.

dominant mode of temperature variability is more spatially uniform. The summer/winter versus spring/autumn division in the pattern of SAT variability is in agreement with variability in OHT, which likely drives variability in the BS region as shown before. In May-June and September-November dominant variability is less restricted to the BS. On multidecadal timescales the driver of the dominant variability is thus present throughout the year, but it is most enhanced during the winter months.

\subsection{Local characteristics}

In this section we investigate what variables covary with the regional average SAT over the BS to determine how the OHT influences SAT. For this purpose, linear regressions were computed between the time series of several local variables at each grid point in the Arctic versus the time series of the BS-averaged SAT (Fig. 4.10). Clearly, the Arctic response of all surface variables is strongest in the $\mathrm{BS}$ region. We use the difference between the mean of the cold and warm composites as a measure of the amplitude of the low-frequency variability. For SAT the largest differences between the composites are found over the central BS in December, with peaks up to $+9 \mathrm{~K}$ (Fig. 4.11). From January until April, SAT peaks are found slightly more to the west. From May until October, the SAT dif- 


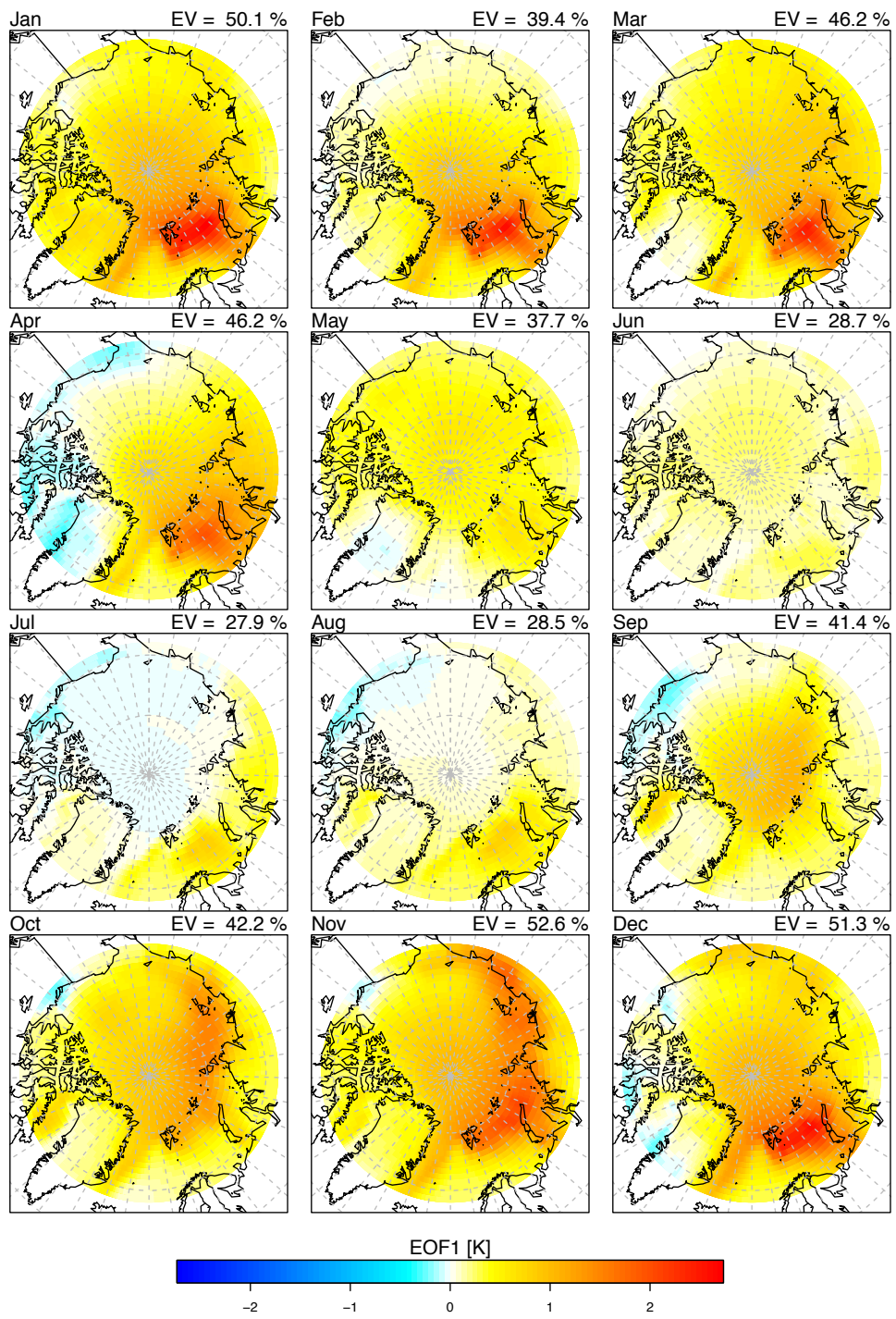

Figure 4.9 | Monthly EOF1 of smoothed surface air temperature over the Arctic. The EOF analysis is applied after smoothing the time series for each month. The EOFs represent the amplitude relative to one standard deviation of the associated principal components. EV is the percent variance explained by EOF1. 
ferences are smaller than $4 \mathrm{~K}$ over the whole BS. Since ice melts during warm periods, sea ice cover is reduced during the warm phase, and extended during the cold phase. The co-variability of sea ice concentration with BS-averaged SAT acts mainly local over the BS. In a warm phase, OHT is transporting energy to the BS, melting the sea ice at most locations and increasing SAT over the BS. The largest composite differences in sea ice concentration are found in the winter and spring months in the central BS, owing to retreat of the ice edge. When sea ice retreats, a clear atmospheric response is indicated by anomalous low pressure over the Greenland and Barents Seas (not shown). The differences between the warm and cold composites in SST are largest in the summer months, with maximum differences in June ( $+2 \mathrm{~K})$. Since the BS clearly dominates Arctic variability, the monthly surface energy balance components in the BS will be discussed in detail in the next subsection.

\subsubsection{Surface energy balance}

The variability in sea ice has huge consequences for $\mathrm{F}_{\mathrm{SFC}}$. BS-averaged $\mathrm{F}_{\mathrm{SFC}}$ is upwards (i.e. ocean to atmosphere) in the mean climate, and is enhanced during warm phases and reduced during cold phases (Fig. 4.10). The surface response, however, varies spatially owing to the sea ice variability in the central/eastern BS. During a warm phase, net $\mathrm{F}_{\mathrm{SFC}}$ is reduced in the western $\mathrm{BS}$ and over the central Arctic, whereas over the central/eastern BS the heat fluxes are enhanced. The amplitude of variability in surface heat fluxes is largest in winter (Fig. 4.8). In December the $\mathrm{F}_{\mathrm{SFC}}$ composite differences are largest in the western BS, where the surface fluxes are reduced by up to $84 \mathrm{~W} \mathrm{~m}^{-2}$ in the warm composite relative to the cold composite (Fig. 4.12). In January and February the surface heat flux differences are largest in the central BS, where in the warm composite they are enhanced by up to $146 \mathrm{~W} \mathrm{~m}^{-2}$. This shift in month and region is likely related to the eastward shift of the sea ice edge, and may be very model dependent, since the sea ice edge varies between models.

\subsubsection{Longwave radiation}

The net flux of longwave radiation in the mean climate is directed from ocean to atmosphere. LW $\uparrow$ and $\mathrm{LW} \downarrow$ fluxes are both enhanced when SAT is higher (Fig. 4.10), as there is a direct relation between LW radiation and temperature. $\mathrm{LW} \uparrow$ is governed by the surface temperature and thus sea ice, whereas LW $\downarrow$ is dictated by the temperature, humidity and cloudiness of the atmosphere aloft. 

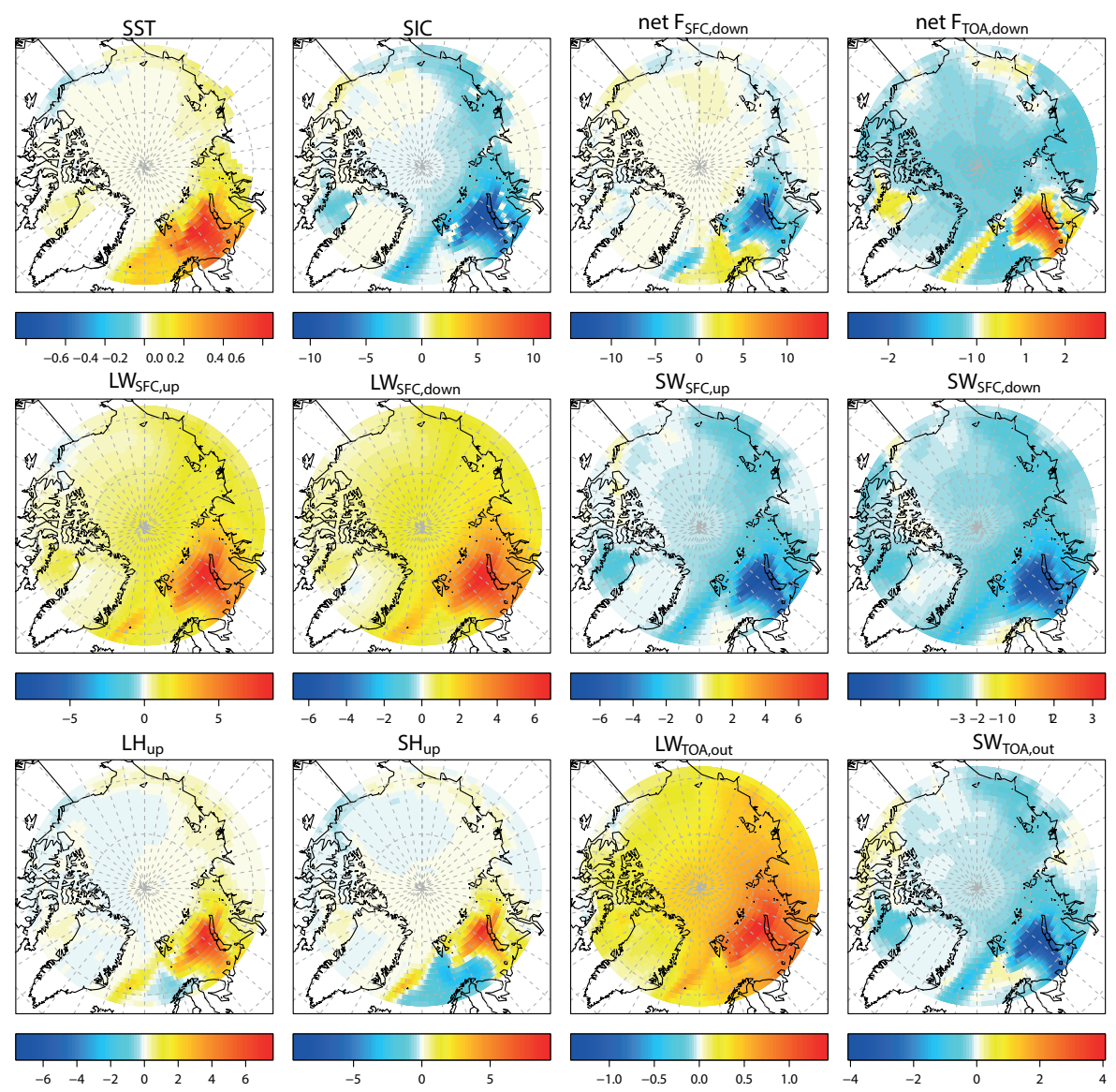

Figure 4.10 | Regression coefficient maps of surface and TOA variables on Barents Seaaveraged SAT. The subscripts behind the variable names refer to the sign of the reference state. Units are in $\mathrm{K} \mathrm{K}^{-1}$ for SST, $\% \mathrm{~K}^{-1}$ for SIC, and $\mathrm{W} \mathrm{m}^{-2} \mathrm{~K}^{-1}$ for the radiative and turbulent fluxes. 

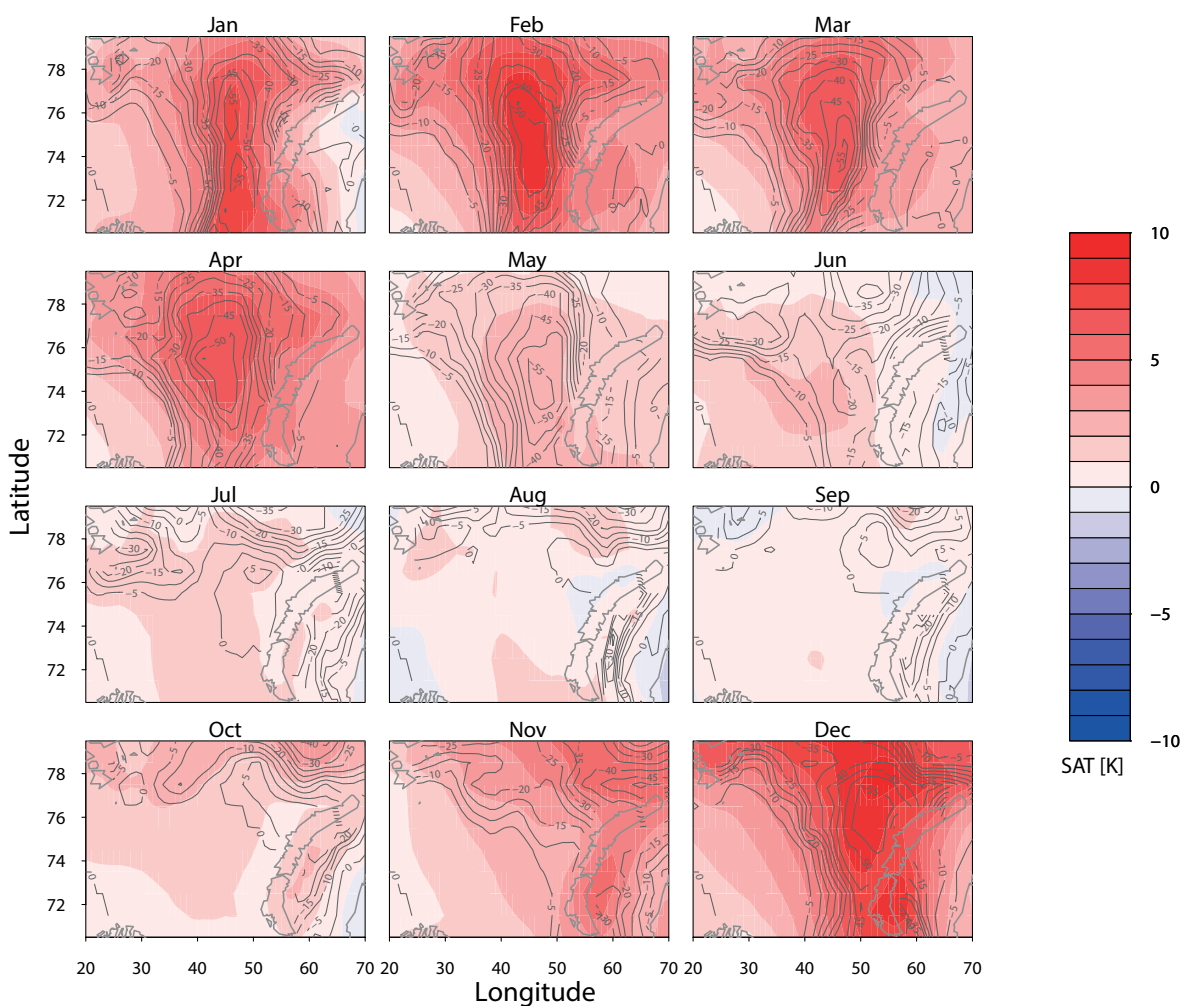

Figure 4.11 | Monthly composite differences of SAT (colorscale) and SIC (isolines, in \%) as function of latitude and longitude over the Barents Sea. The cold composites are subtracted from the warm composites.

Maximum $L W \downarrow$ variability is found over the central BS during the winter months (with composite differences up to $48 \mathrm{~W} \mathrm{~m}^{-2}$ in December). LW $\uparrow$ variability is maximum in the central BS in the winter months as well, but is concentrated later in the winter season in January/February (up to $48 \mathrm{~W} \mathrm{~m}^{-2}$ ). As a result, during warm phases the net longwave radiation flux is reduced over most of the BS in December, while in February the longwave radiation flux is enhanced over most of the BS (Fig. 4.13). In January, a dipole pattern is visible where net longwave radiation is reduced over the western BS, but enhanced over the eastern BS. 


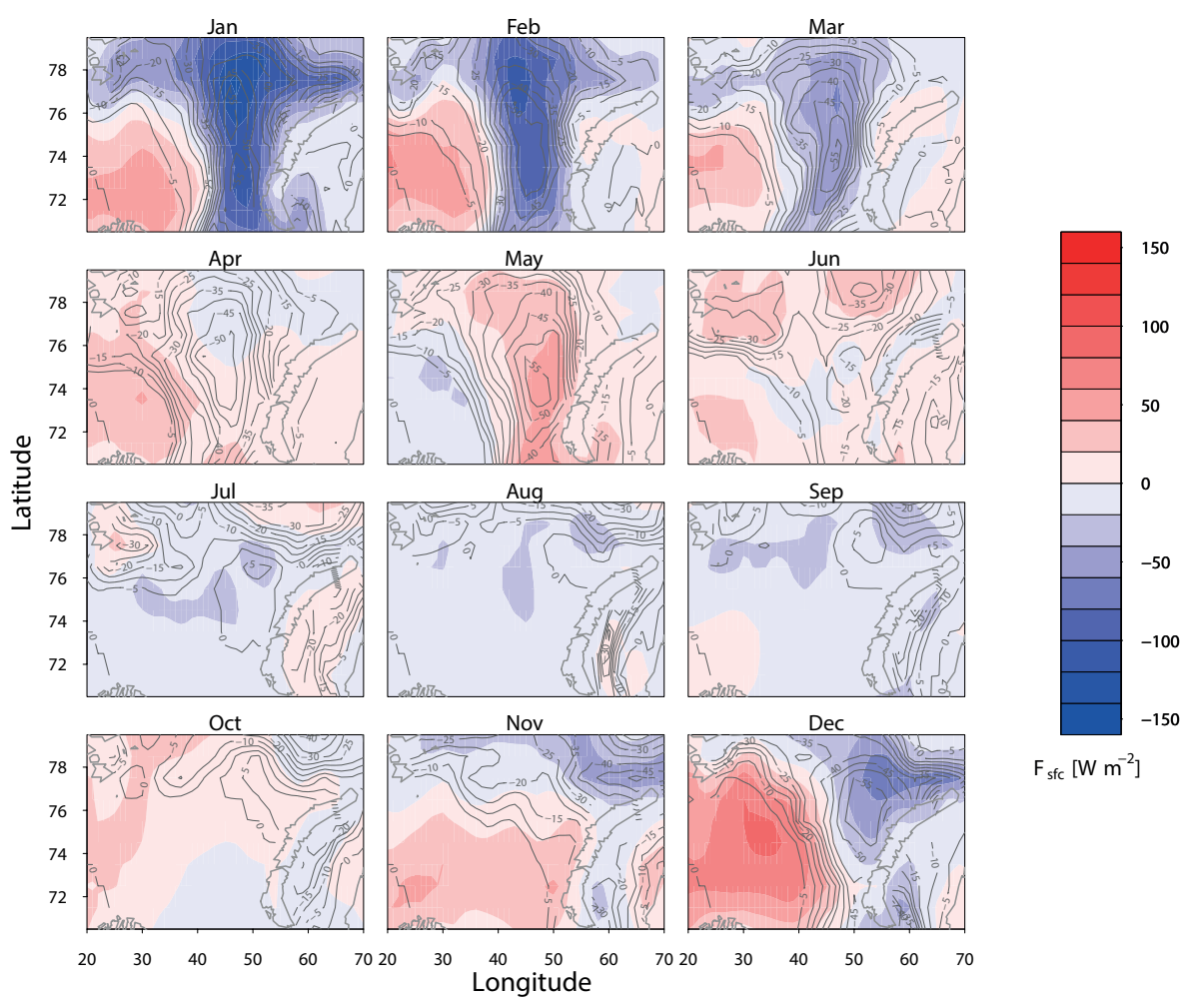

Figure 4.12 | Monthly composite differences (warm - cold) of net $F_{\mathrm{SFC}}$ (colorscale) and SIC (isolines, in \%) over the Barents Sea. $\mathrm{F}_{\mathrm{SFC}}$ is defined positive downward, which means that positive values (red) indicate a reduced upward heat flux and negative values (blue) indicate an enhanced upward heat flux.

\subsubsection{Shortwave radiation}

Both $\mathrm{SW} \uparrow$ and $\mathrm{SW} \downarrow$ are reduced during warm phases (Fig. 4.10). Since there is less sea ice, less SW radiation is reflected upward. The effect is clearly dominant in May, when the $S \mathrm{SW}$ in the central BS is reduced by up to about $115 \mathrm{~W} \mathrm{~m}^{-2}$ in the warm composite relative to the cold composite. At this time of the year sea ice concentration has decreased by up to $59 \%$ in the central BS and incoming solar radiation is close to its maximum. During warm phases, $\mathrm{SW} \downarrow$ is also smaller by up to about $45 \mathrm{~W} \mathrm{~m}^{-2}$ for the composite difference in May. This is likely caused by an increase in cloudiness in relation to reduced sea ice and enhanced surface evaporation. In addition, the back-scattering by the atmosphere (multiple reflection) also affects $S W \downarrow$. The increased absorption of SW radiation over 

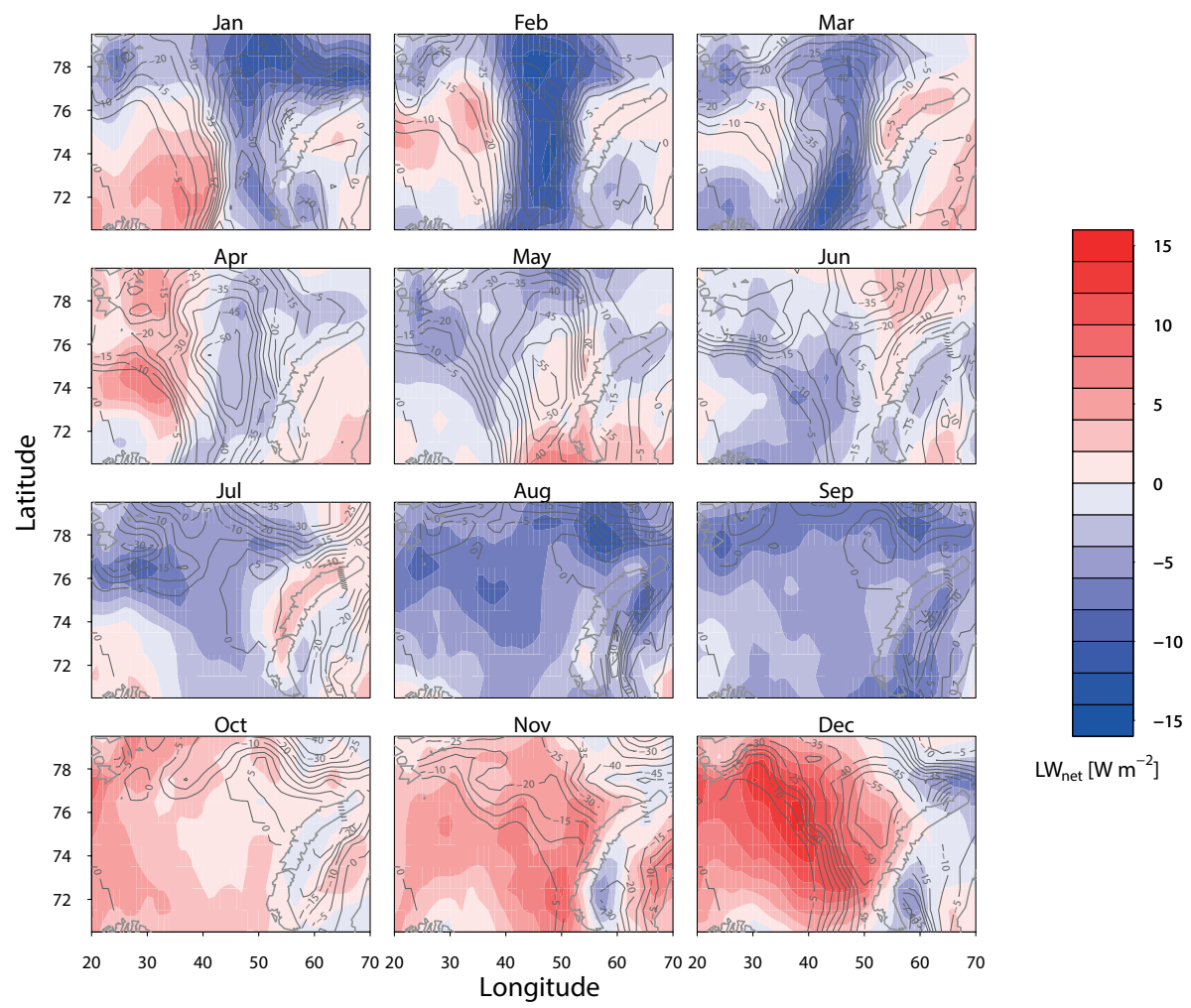

$\mathrm{LW}_{\text {net }}\left[\mathrm{W} \mathrm{m}^{-2}\right]$

Figure 4.13 | Monthly composite differences (warm - cold) of LW net radiation (LW $\downarrow-$ $\mathrm{LW} \uparrow$; colorscale) and SIC (isolines, in \%) over the Barents Sea. Positive values (red) indicate a reduced upward flux and negative values (blue) indicate an enhanced upward flux.

transition regions from sea ice to open water is dominant over the cloud and back-scattering effects, enhancing the net shortwave flux from the atmosphere to the ocean (Fig. 4.14).

\subsubsection{Latent and sensible heat fluxes}

The latent and sensible heat fluxes are directed upward in the mean climate, warming the atmosphere, especially in the western BS in winter. In the major part of the BS the upward turbulent fluxes are enhanced during the warm phases (Fig. 4.15), dampening ocean heating but warming the atmosphere. The increase in upward LH will likely enhance the cloudiness by adding more wa- 

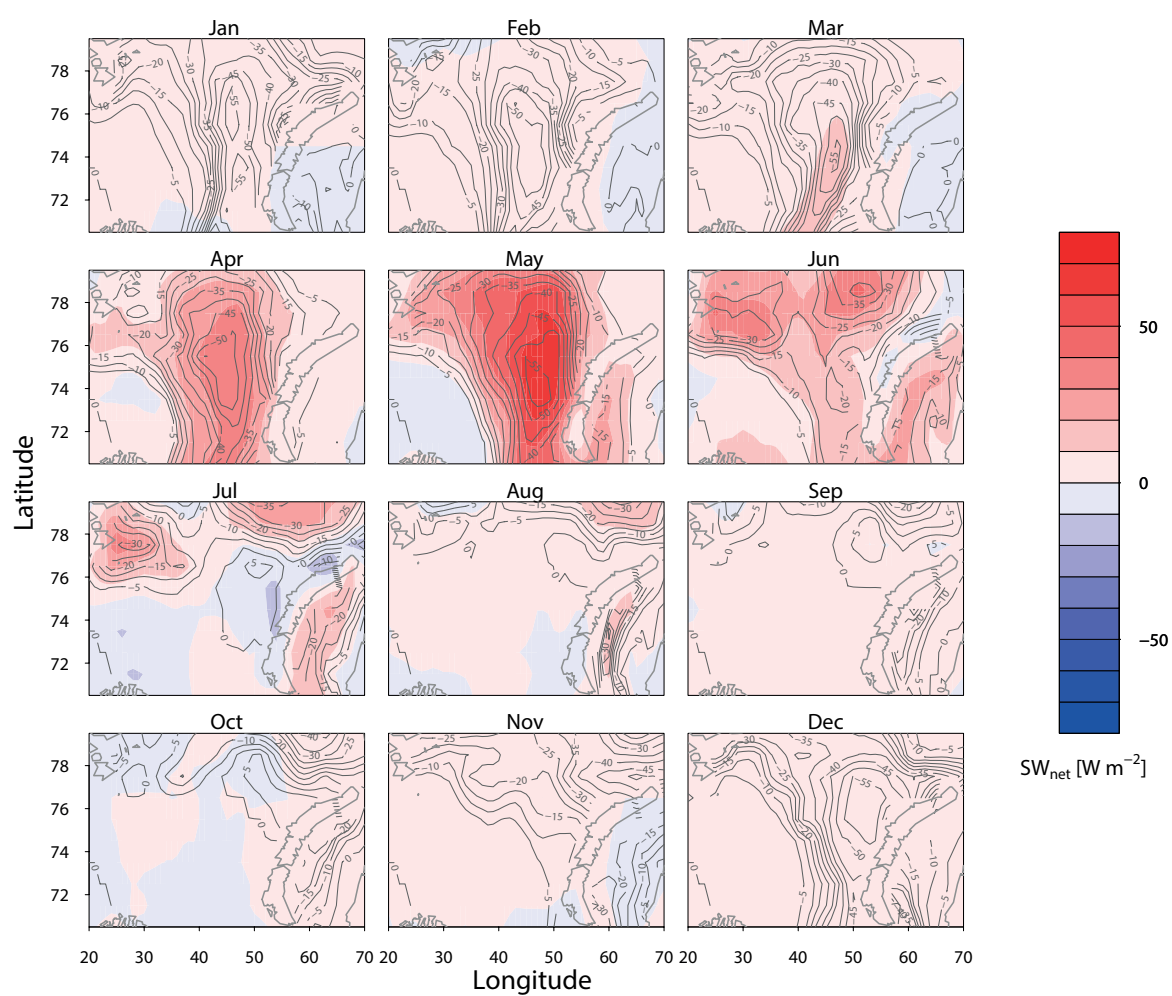

Figure 4.14 | Monthly composite differences (warm - cold) of SW net radiation (SW $\downarrow$ SW $\uparrow$; colorscale) and SIC (isolines, in \%) over the Barents Sea. Positive values (red) indicate a reduced upward flux and negative values (blue) indicate an enhanced upward flux.

ter vapour to the atmosphere, which in turn influences $\mathrm{LW} \downarrow$ and $\mathrm{SW} \downarrow$ radiation. The increases in turbulent fluxes are dominant in January and February and in the central BS. However, the western part of the BS and adjacent section of the Norwegian Sea exhibit turbulent fluxes that are reduced during warm phases, especially SH. This negative relation is dominant in December. A feature that can explain the differences between the west and central BS, is the presence of (seasonal) sea ice cover in the BS, compared to no sea ice in the Norwegian Sea. Sea ice insulates the ocean from the atmosphere. When sea ice is present (cold periods) the ocean-atmosphere heat fluxes are strongly reduced, whereas in warm periods, when the ice cover is absent, ocean-atmosphere fluxes are enhanced. On the other hand, to the west of the BS, sea ice cover is absent in 

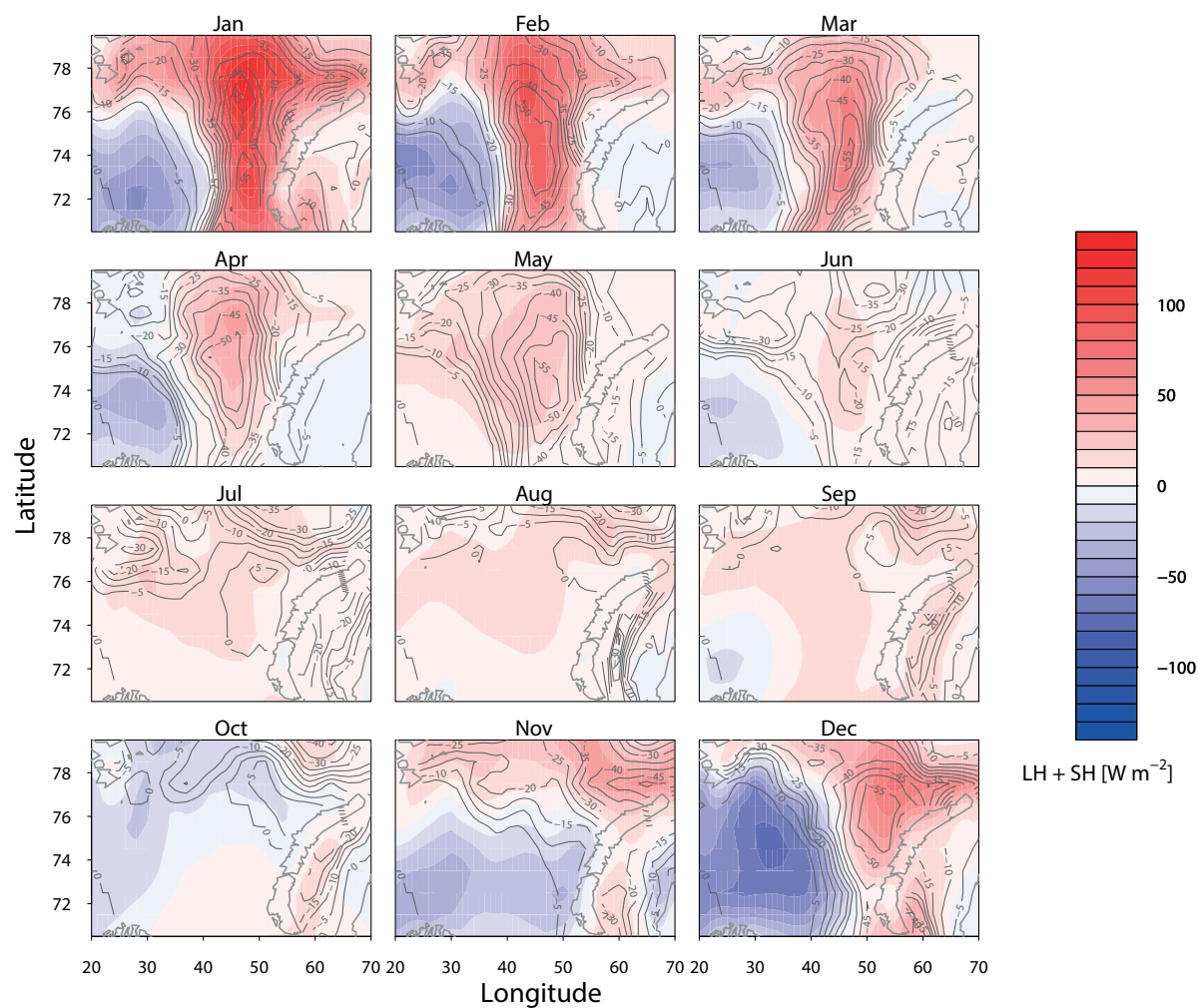

$\mathrm{LH}+\mathrm{SH}\left[\mathrm{W} \mathrm{m}^{-2}\right]$

Figure 4.15 | Monthly composite differences (warm - cold) of the net turbulent flux (LH + SH; colorscale) and SIC (isolines, in \%) over the Barents Sea. Positive values (red) indicate an enhanced upward flux and negative values (blue) indicate a reduced upward flux.

both warm and cold periods. In cold periods, the cold atmosphere over the open ocean takes up heat from the ocean, especially in winter, so that the heat flux is directed from ocean to atmosphere.

To summarize, the net surface energy fluxes over the central/eastern BS from the ocean towards the atmosphere are enhanced during warm phases, pointing towards the ocean as the driver of the BS SAT variability. During warm phases the advected heat input by the ocean is augmented by shortwave radiation and reduced through longwave radiation and latent and sensible heat loss. Sea ice plays a key role in this mechanism (Van der Swaluw et al., 2007). Sea ice separates the atmosphere from the ocean, creating large temperature gradients between them. When during a warm phase sea ice coverage changes to open 
water, surface fluxes are enhanced compared to regions that are permanently open water or sea-ice-covered in both warm and cold phases. This transition region is located in the central/eastern BS, where the ice edge is located in the preindustrial climate.

\subsection{Summary and conclusions}

The role of different energy budget components in low-frequency Arctic climate variability are examined in a 500-years simulation under preindustrial conditions of the ACCESS1.3 model. The multidecadal surface air temperature (SAT) variability in this model is qualitatively representative for other coupled climate models in terms of the spatial pattern of dominant variability. The dominant mode of Arctic variability in SAT features multidecadal fluctuations centered over the BS region. Locally in the BS, peak-to-peak differences in low-frequency SAT fluctuations are as large as $9 \mathrm{~K}$. This variability exhibits a periodicity with a dominant time scale of 26 years, which is similar compared to most other fully coupled climate models. The ocean heat transport leads SAT variability by more than one year, indicating that it drives Arctic SAT variability. Atmospheric heat transport is of opposite sign, and acts to counteract oceanic warming over the $\mathrm{BS}$. It thus compensates the warming that is due to ocean heat transport, a feature that is likely related to Bjerknes compensation (Bjerknes, 1964). The spatial pattern of dominant Arctic SAT variability over the BS is present in winter and summer, but not in spring and autumn. The months with a dominant BS variability pattern coincide with the season of maximum variability of OHT into the BS, further confirming that the ocean is indeed driving Arctic SAT variability. Our analysis of the ACCESS1.3 results are in agreement with earlier findings that ocean heat transport plays a dominant role in Arctic climate variability (Mahajan et al., 2011; Goosse and Holland, 2005). In turn, changes in OHT might be influenced by the Atlantic meridional overturning circulation (AMOC), which is found to be significantly related to OHT and explains $16 \%$ of the low-frequency variability. The remaining variability can be explained by heat transport variations due to the sub-polar gyre and variations in temperature stratification.

More information about local processes is obtained by studying warm and cold composites of the multidecadal cycles by month. We find that although ocean heat transport into the BS triggers the variability Arctic-wide, it is mostly amplified locally at the location of the sea ice edge in the BS. In areas where there is a transition from sea ice to open water during warm phases, the sur- 
face fluxes are enhanced in January and February. In areas with no sea ice in both warm and cold phases, the surface fluxes are reduced mainly in December. As a result, the surface fluxes are enhanced in the late winter season, and reduced during the early winter in warm phases compared to cold phases. This implies that sea ice growth takes place later in the year, and at higher latitudes in the warm phase. The location where the transition of sea ice to open water takes place determines the location of most variability in surface fluxes, and thus variability in SAT. Sea ice thus plays a key role in the transmission of heat from the ocean towards the atmosphere on multidecadal timescales, as was also suggested by Van der Swaluw et al. (2007).

The multidecadal variability in SAT has to be considered in assessments of Arctic warming and cooling trends, which can be enhanced or reduced by this type of variability. This also implies that differences between simulated and observed warming might be partly attributable to natural low-frequency variability. 


\title{
5
}

\section{Arctic decadal variability in a warming} world

\author{
E. C. van der Linden, R. Bintanja, and W. Hazeleger \\ Journal of Geophysical Research: Atmospheres, under review
}

Natural decadal variability of surface air temperature might obscure the recent Arctic warming trend induced by anthropogenic forcing. It is therefore imperative to know not only the characteristics of current variability but also how Arctic decadal variability (ADV) will change as the climate warms. In this study, we evaluate ADV characteristics in three equilibrium climate states of 400 years length with present-day, double and quadrupled atmospheric $\mathrm{CO}_{2}$ forcing. In all climates, ADV peaks in winter. The dominant region of variability, which is located over the Barents Sea and the Greenland Sea in the current climate, shifts to the central Arctic and Siberian regions as the climate warms. The relation between sea ice cover and surface air temperature remains strong in warmer climates, with maximum variability occurring in the $\mathrm{CO}_{2}$ doubling climate when sea ice becomes more vulnerable to melt over vast stretches of the Arctic. Furthermore, the links between dominant atmospheric circulation modes and Arctic climate characteristics vary strongly with climate change. For instance, a positive Arctic Oscillation (AO) index is associated with a colder Arctic region in warmer climates, instead of a warmer Arctic at present. Such changing relationships are partly related to the retreat of 
sea ice because altered wind patterns influence the sea ice distribution and hence the associated local surface fluxes. The atmospheric pressure distributions governing ADV also change with climate warming. The Aleutian and Icelandic Lows both play a key role in the changing mean state and the associated variability of the large-scale circulation. Whereas ocean heat transport is firmly associated with $\mathrm{ADV}$ in the current and $\mathrm{CO}_{2}$ doubling climate, the importance of the atmospheric heat transport increases in even warmer climates, suggesting that the large-scale dynamics associated with ADV change as well. The changing character of the ADV when climate warms shows that it is vital to consider ADV (and the changes therein) when addressing Arctic warming in climate model projections of the future climate.

\subsection{Introduction}

The Arctic is currently warming much faster than other parts of the world, and sea ice is rapidly diminishing. Superimposed on this warming trend is a strong decadal variability, which can reinforce or oppose the trend, depending on its phase. This renders interpreting Arctic changes in terms of anthropogenicallycaused forcing quite uncertain. The characteristics of this Arctic Decadal Variability (ADV) have been investigated using observations (Polyakov et al., 2003a) and climate models (e.g., Day et al., 2012; Van der Linden et al., 2016). There are strong indications that the ADV (expressed mainly in sea ice variability) exhibits links with other long-term modes of variability, such as the NAO (Holland, 2003), AMO (Li et al., 2013), and PDO (Day et al., 2012) - with a geographical imprint that seems to vary strongly between models - and with low-frequency variations in Arctic cyclone activity (Zhang et al., 2004). There also seems to exist a well-established connection with ocean-induced variability related to the Atlantic Meridional Overturning Circulation (AMOC) and related heat transports (Zhang and Wang, 2013), specifically in certain regions of the Arctic (the Barents Sea) (Goosse and Holland, 2005; Van der Linden et al., 2016).

Notwithstanding its causes and governing mechanisms, the ADV not only potentially obscures trends in Arctic climate, also the ADV itself might change with climate state. As with any mode of variability, the physics controlling the characteristics of the ADV are firmly rooted in the 'ambient' climate state, and if this state and the associated physics change (e.g. due to forced climate warming), the characteristics of the ADV will very likely change as well, possibly in conjunction with simultaneous fluctuations in the other modes of variability 
such as the Arctic Oscillation (AO) (Overland and Wang, 2005). For instance, Kay et al. (2011) find that the Arctic sea ice trend variability increases towards the end of the 21st century in an ensemble of forced scenario simulations, suggesting that the amplitude of the ADV will enhance with climate warming. Climate model simulations of warm paleoworlds demonstrate that ADV may be governed by high-latitude upper-ocean static stability, leading to increases in both the frequency and the magnitude of ADV in warmer climates (Poulsen and Zhou, 2013). To date, very little is known about the characteristics and possible causes of changing ADV towards warming climates.

In a transient climate, it is even more difficult to separate trends from internal climate variability since the climatology itself changes in time. This uncertainty impacts the timing of the Arctic Ocean to become ice-free for the first time; for instance, a strong negative trend combined with a large ADV may result in an ice-free state occurring much earlier than expected from forced trends alone (Swart et al., 2015). Furthermore, slowly changing feedbacks related to altered variability in sea ice and snow potentially modify tropospheric wave activity and the jet stream (Cohen et al., 2014). To obtain insight into the details of the ADV, and in particular the changes therein, a fruitful approach is to eliminate the complicating effects of a slowly varying background climate. In this study, we do so by specifically focusing on equilibrium climate states with little to no residual trend. We therefore use 550-yr integrations with the state-of-theart climate model EC-Earth in $1 \times \mathrm{CO}_{2}, 2 \times \mathrm{CO}_{2}$, and $4 \times \mathrm{CO}_{2}$ forcing simulations, for which we evaluate the characteristics of the ADV using the final 400 years of the simulations during which the respective climate states are in (quasi) equilibrium. We will focus on the large-scale climate mechanisms that are involved in atmosphere-ice-ocean interactions. By using a single climate model we can concentrate on process understanding, without having to deal with uncertainties related to structural differences in the model design (as in multimodel studies). Section 2 contains details of the model, the model simulations, and the analyses methodology. In Section 3 we describe the characteristics of the ADV for the 'warm' climates relative to the present-day climate. Changes in the atmospheric variability patterns are described in Section 4 . Links between ADV and various modes of climate variability as well as the responsible mechanisms are explored in Section 5. Conclusions and possible implications of our findings are discussed in Section 6. 


\subsection{Model and simulations}

\subsubsection{Model description}

The experiments in this study are performed with EC-Earth (Hazeleger et al., 2012). Here we use version 2.3, which has also contributed to the Coupled Model Intercomparison Project phase 5 (CMIP5) (Taylor et al., 2012). EC-Earth is a fully coupled atmosphere-ocean global climate model. The atmospheric component is the Integrated Forecast System (IFS) of the European Center for Medium-range Weather Forecasts (ECMWF). It runs at T159 spectral resolution with 62 vertical levels. The ocean component is the Nucleus for European Modelling of the Ocean (NEMO) model (Madec, 2008), developed by the Institute Pierre Simon Laplace (IPSL). NEMO uses a horizontal grid configuration which has a resolution of about 1 degree and 42 vertical levels. NEMO incorporates the Louvain la Neuve sea ice model version 2 (LIM2) (Fichefet and Morales Maqueda, 1997; Bouillon et al., 2009), which is a dynamic-thermodynamic sea ice model. The atmosphere and ocean/sea-ice model are coupled through the OASIS (Ocean, Atmosphere, Sea Ice, Soil) coupler (Valcke et al., 2003).

Future projections of climate change and ocean heat transports in EC-Earth, focused specifically on the Arctic region, are analyzed in detail in Koenigk et al. (2013) and Koenigk and Brodeau (2014).

\subsubsection{Simulations}

We study three simulations performed with EC-Earth forced with different carbon dioxide $\left(\mathrm{CO}_{2}\right)$ concentrations (Table 5.1). The first integration is the control climate (CTRL) which contains greenhouse gas concentrations, aerosol forcing, and a land use scheme of the year 2000 (present-day). The initial state for CTRL is obtained from a spin-up of about thousand years with preindustrial (1850) forcing and a subsequent integration over 44 years with present-day forcing. Thereafter the integration is continued over 550 years with constant presentday forcing, which in this study we refer to as the CTRL simulation. The other two integrations start from the initial state of CTRL. Their $\mathrm{CO}_{2}$ concentrations are instantaneously set at two $\left(2 \times \mathrm{CO}_{2}\right)$ and four $\left(4 \times \mathrm{CO}_{2}\right)$ times the present-day value and kept constant at that level for 550 years. After 150 years the upper ocean is close to equilibrium. We use the final 400 years in our analysis.

The variables that will be shown and discussed are detrended and deseasonalized prior to analysis. To focus on the decadal time scales, all time series are 
Table 5.1 | Simulation name, $\mathrm{CO}_{2}$ concentration (ppmv), the global equilibrium two meter air temperature $\left(T_{\text {global }}\right)$, the Arctic equilibrium two-meter air temperature in winter $\left(T_{D J F}\right)$ and summer $\left(T_{J J A}\right)$ in ${ }^{\circ} \mathrm{C}$, and the SIA maximum $\left(\mathrm{SI}_{\max }\right)$ and minimum $\left(\mathrm{SIA}_{\min }\right)$ in $10^{12} \mathrm{~m}^{2}$. Reanalysis data of the 10-member ERA-20CM ensemble averaged over the period 1990-2010 are included for comparison.

\begin{tabular}{lllllll}
\hline Simulation & $\mathrm{CO}_{2}$ & $\mathrm{~T}_{\text {global }}$ & $\mathrm{T}_{\text {DJF }}$ & $\mathrm{T}_{\text {JJA }}$ & SIA $_{\max }$ & SIA $_{\min }$ \\
\hline $\mathrm{CTRL}$ & 368.9 & 14.3 & -24.4 & 0.6 & 15.8 & 5.2 \\
$2 \times \mathrm{CO}_{2}$ & 737.7 & 17.2 & -9.5 & 4.1 & 10.8 & 0.15 \\
$4 \times \mathrm{CO}_{2}$ & 1475.5 & 20.8 & -1.0 & 9.3 & 0.63 & 0.13 \\
ERA-20CM & - & 13.7 & -24.6 & 0.3 & 15.1 & 6.0 \\
\hline
\end{tabular}

smoothed with an 11-year running Welch window, which consists of a single parabolic section. Note that the climate change simulations analyzed here do not account for possible changes in land ice extent and elevations (Greenland, Antarctica), and for changes in vegetation, in land use and aerosols.

\subsection{Temperature and sea ice}

\subsubsection{Mean state}

Sea ice plays a key role in the Arctic climate system and modulates the surface air temperature through various feedback processes. Table 5.1 summarizes the mean characteristics of sea ice area (SIA) and surface air temperature (SAT) for the three simulated climate states, and includes reanalysis data of ERA-20CM (Hersbach et al., 2015) for comparison. EC-Earth overestimates the seasonal cycle in sea ice area, with too high values in March and too low values in September, but captures Arctic surface air temperatures quite well. In the presentday Arctic climate, SIA and SAT are closely connected. In winter (DJF), when the temperature is on average about $-24^{\circ} \mathrm{C}$, SIA extends to 15.8 million $\mathrm{km}^{2}$, whereas in summer (JJA) SIA shrinks to approximately one-third of this area. It is also clear that in warmer climate states, the total Arctic SIA declines. Whereas in CTRL sea ice remains during the summer minimum, it is only seasonal in $2 \times \mathrm{CO}_{2}$, and almost completely absent throughout the year in $4 \times \mathrm{CO}_{2}$, with the global mean temperature increasing by $2.9^{\circ} \mathrm{C}$ and $6.5^{\circ} \mathrm{C}$, respectively. Using transient climate scenarios, Hezel et al. (2014) found that September sea ice disappears at a mean global temperature increase of $2.4^{\circ} \mathrm{C}$ and March sea ice 
(a)

control

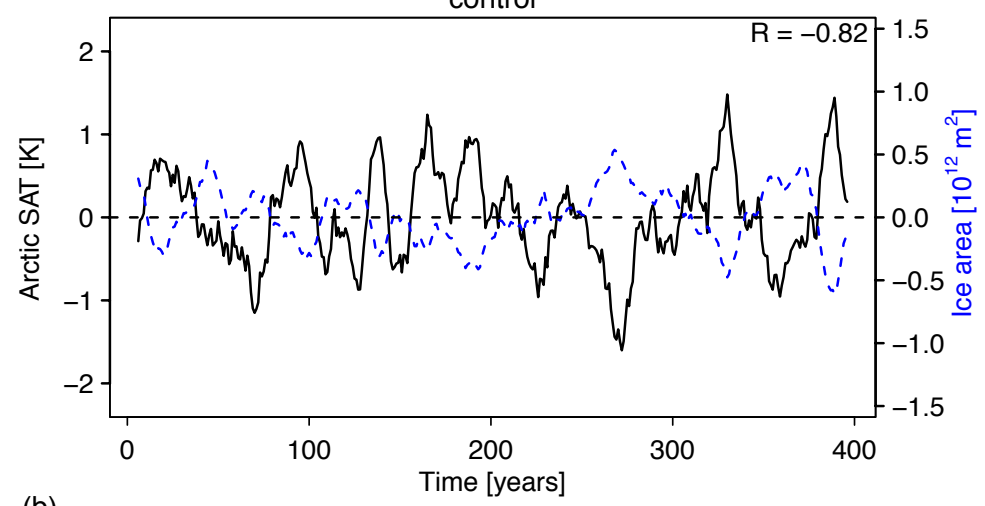

(b)

$2 x \operatorname{co} 2$

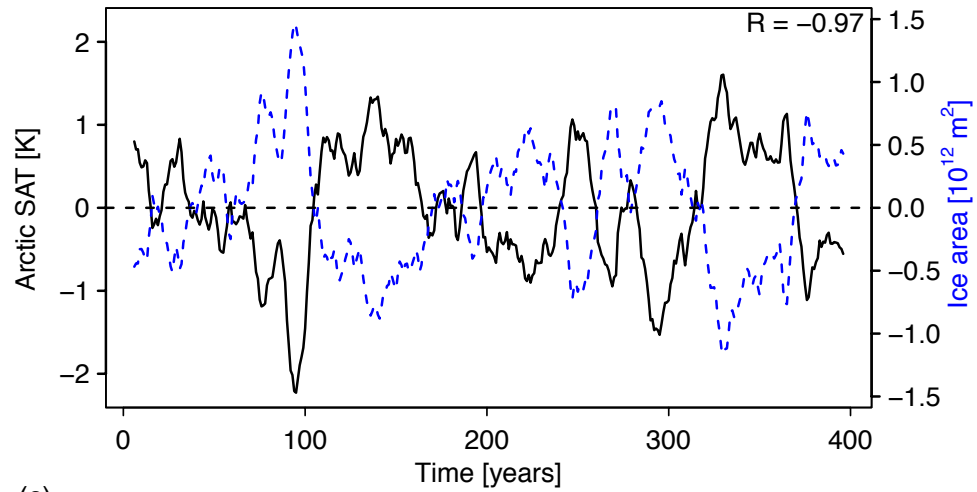

(c) $4 \mathrm{xcO} 2$

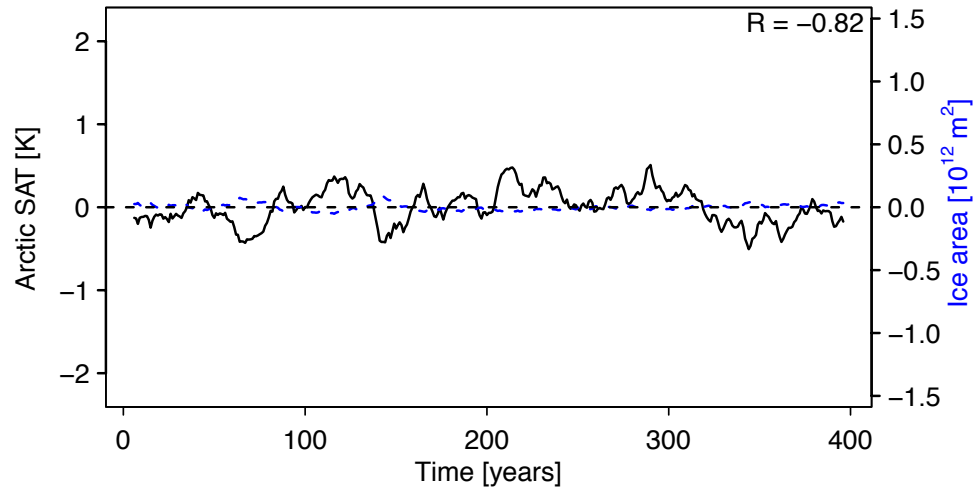

Figure 5.1 | Time series of winter (DJF) Arctic temperature anomalies (black line) and Arctic sea ice area anomalies (blue dashed line) for the CTRL (a), $2 \times \mathrm{CO}_{2}$ (b), and $4 \times \mathrm{CO}_{2}$ (c) climates. Time series are smoothed with an 11-yr running Welch window. The correlation coefficient between SAT and SIA is indicated. 
at a mean temperature increase of $8.2^{\circ} \mathrm{C}$. Although the mean winter and summer sea ice extent diminish when $\mathrm{CO}_{2}$ concentrations increase, it is important to analyze their long-term variability to separate longer term trends, caused by $\mathrm{CO}_{2}$ rise, from the shorter term variations due to natural fluctuations. In the following, we will investigate the variability of the SAT and sea ice in warmer climate states and evaluate how these compare to the current state.

\subsubsection{Variability}

Figures 5.1 and 5.2 show time series of two-meter Arctic air temperature anomalies and Arctic sea ice area anomalies for the three different climate states in winter and summer, respectively. Standard deviations of these time series and of the decadally smoothed ERA-20CM ensemble are listed in Table 5.2. We first assess if decadal variability has the potential to obscure forced trends. The ERA20CM data include a trend that is (partly) attributable to greenhouse gas forcing, which is not removed prior to analysis. The magnitude of decadal SAT variability in the CTRL climate corresponds to the ERA-20CM standard deviation in winter, and is somewhat smaller in summer, meaning that decadal SAT fluctuations in the Arctic can potentially obscure forced trends in temperature. Regarding SIA, the winter standard deviation is similar to the value in ERA-20CM, but the summer standard deviation in ERA-20CM is more than three times as large, and clearly falls outside the natural range of decadal variability. These results clearly illustrate the difficulty in separating forced trends from (unforced) decadal variability.

In the $4 \times \mathrm{CO}_{2}$ climate, the decadal variability (henceforth referred to as 'variability') of temperature and SIA is similar in winter and summer, corresponding to the relatively small differences in mean sea ice area between both seasons. However, for both CTRL and $2 \times \mathrm{CO}_{2}$ the summer temperature variability is much smaller than in winter. But while the SIA variability is much larger in winter in $2 \times \mathrm{CO}_{2}$ as compared to present-day, corresponding to the large winter temperature variability, the standard deviation of SIA in CTRL is the same for winter and summer. It seems as if the presence of significant sea ice determines to a considerable extent whether SAT variability is large or not, but SIA variability is additionally constrained by other factors.

In order to understand the reasons behind the dependence of the temperature and sea ice variability on the mean climate state, one has to analyze the associated patterns. To examine the spatial structure of 2-m air temperature variability we use the method of Empirical Orthogonal Function (EOF) analysis, 
(a)

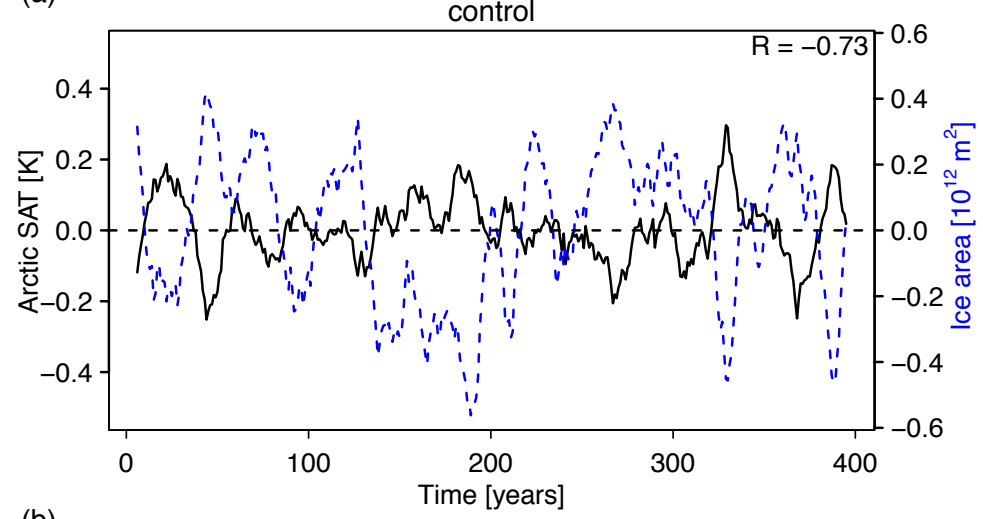

(b)

$2 x \operatorname{co} 2$

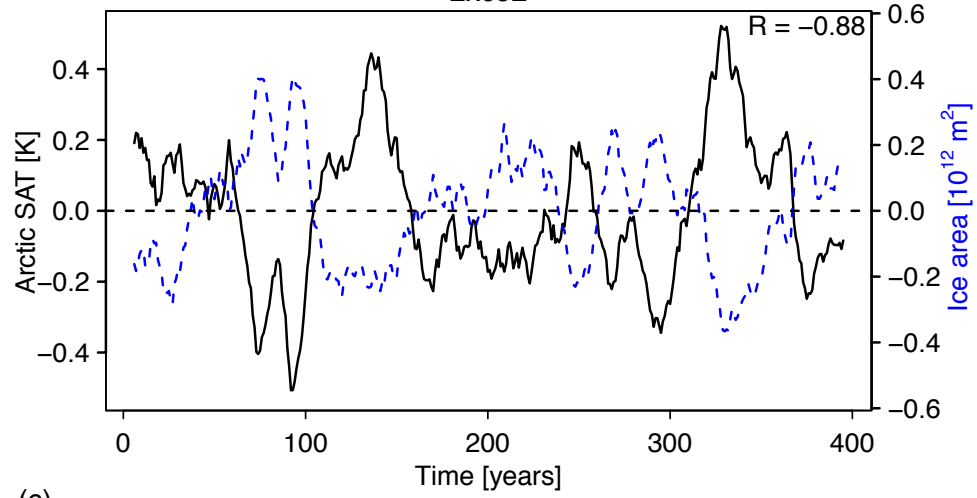

(c)

$4 \mathrm{xco} 2$

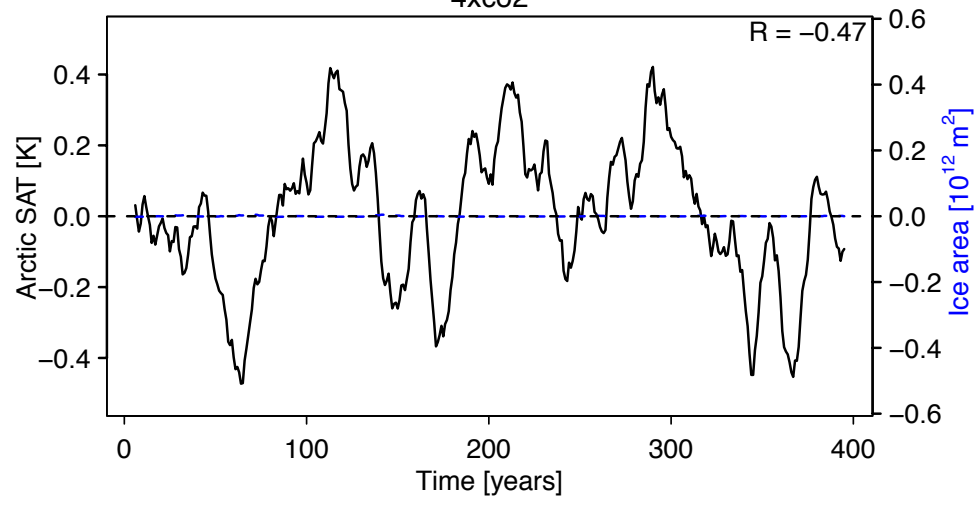

Figure 5.2 | Time series of summer (JJA) Arctic temperature anomalies (black line) and Arctic sea ice area anomalies (blue dashed line) for the CTRL (a), $2 \times \mathrm{CO}_{2}$ (b), and $4 \times \mathrm{CO}_{2}$ (c) climates. Time series are smoothed with an 11-yr running Welch window. The correlation coefficient between SAT and SIA is indicated. 

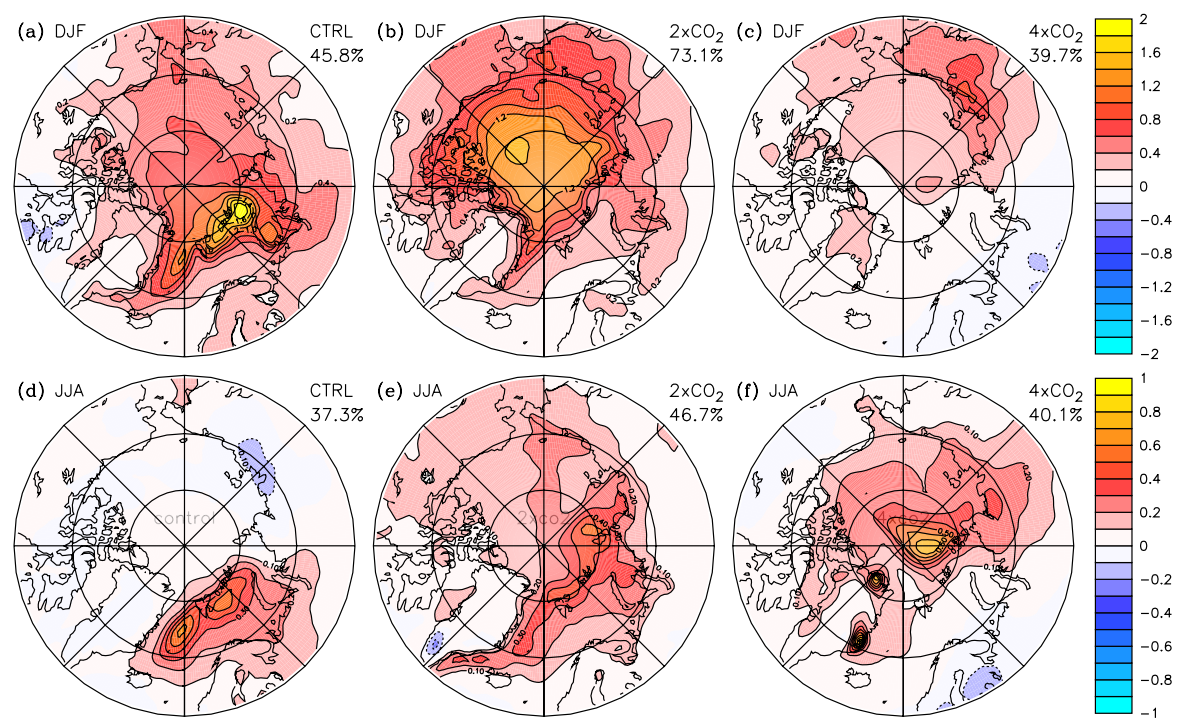

Figure 5.3 | Leading EOF of Northern Hemisphere (computed over $70-90^{\circ} \mathrm{N}$ ) SAT, represented as the regression of SAT $[\mathrm{K}]$ on the normalized principal component time series for the CTRL (a ,d), $2 \times \mathrm{CO}_{2}(\mathrm{~b}, \mathrm{e})$, and $4 \times \mathrm{CO}_{2}$ (c, f) climates, for winter and summer, respectively. The total variance explained by each pattern is indicated.

which (in our application) seeks spatial-temporal structures that explain most of the variability. In these analyses, EOFs are stationary fields by construction, while the principal component (PC) attached to each EOF represents the sign and amplitude of the EOF as a function of time. The leading EOFs (EOF1) of surface air temperature over the Arctic region $\left(70-90^{\circ} \mathrm{N}\right)$ are visualized in Figure 5.3, by the regressions of winter and summer SAT on the corresponding principal components (Fig. 5.4). These EOFs account for $37-73 \%$ of the explained variance, depending on climate state and season as indicated in Figure 5.3. The dominant region of variability, which in the current climate is located over the Barents Sea and the Greenland Sea, shifts more to the central Arctic and Siberia as the climate warms and follows the sea ice margin. Since the Arctic exhibits an outspoken seasonality in the mean climate and since also the variability depends strongly on the season, we analyze the variability in winter and summer separately. 
(a)

control

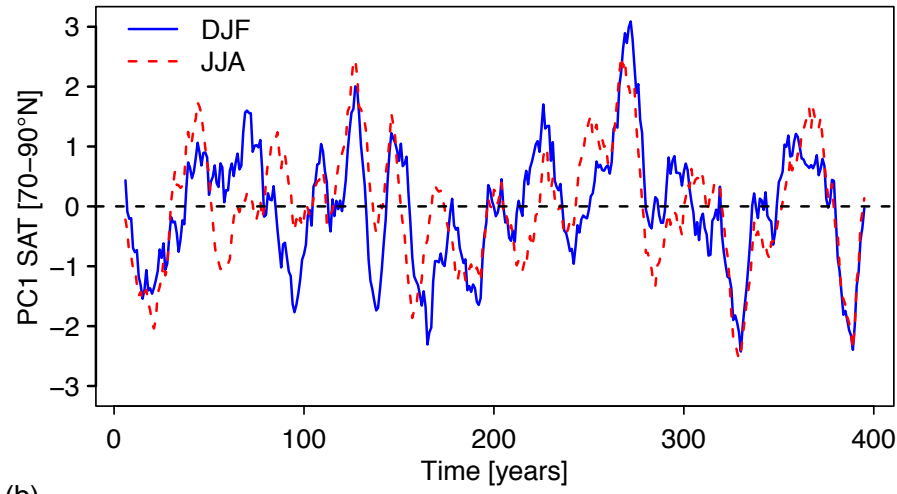

(b)

$2 x \operatorname{co} 2$

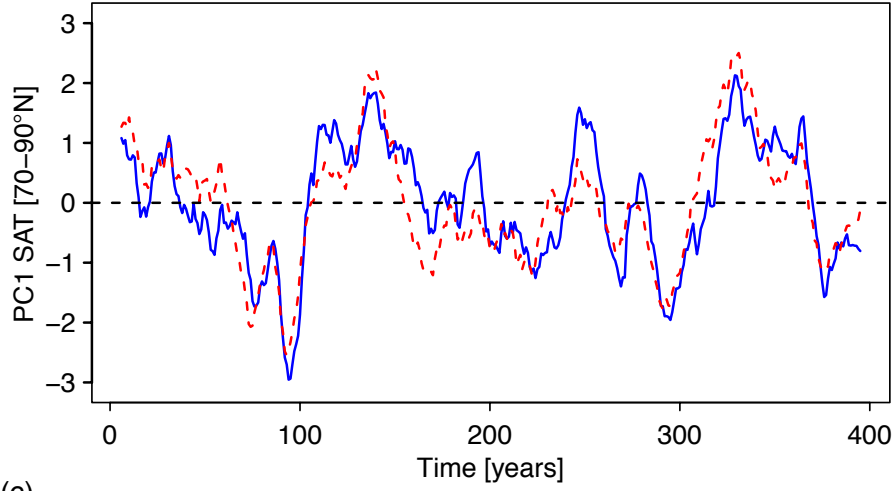

(c)

$4 \mathrm{xco} 2$

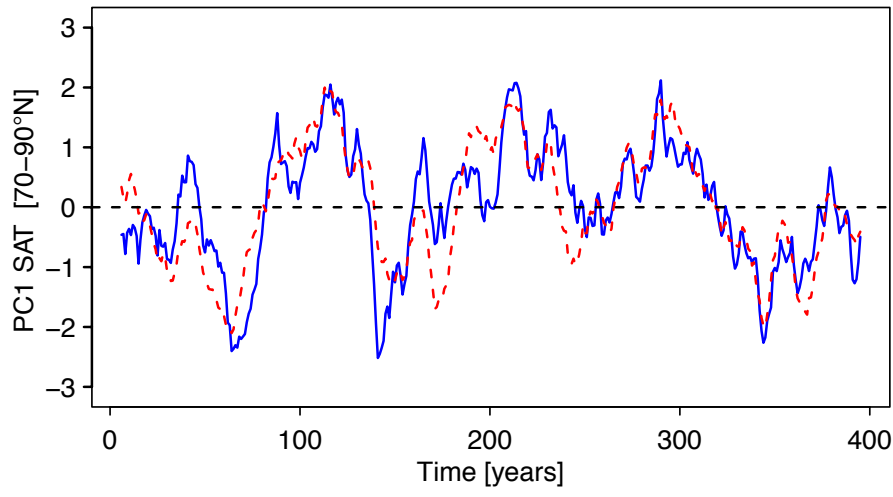

Figure 5.4 | Time series of principal components of the first EOF of $\operatorname{Arctic}\left(70-90^{\circ} \mathrm{N}\right)$ SAT, normalized by its standard deviation for the CTRL (a), $2 \times \mathrm{CO}_{2}$ (b), and $4 \times \mathrm{CO}_{2}$ (c) climates, for winter (blue) and summer (red dashed). The correlation coefficient between the PC1 of winter and PC1 of summer is indicated. 
Table 5.2 | The standard deviation of the Arctic mean two-meter air temperature (SAT, $\left.{ }^{\circ} \mathrm{C}\right)$, sea ice area $\left(\mathrm{SIA}, 10^{12} \mathrm{~m}^{2}\right)$, latent heat flux $\left(\mathrm{LH}, \mathrm{W} \mathrm{\textrm {m } ^ { - 2 }}\right)$, sensible heat flux (SH, $\mathrm{W} \mathrm{m}^{-2}$ ), net shortwave radiation $\left(\mathrm{SW}, \mathrm{W} \mathrm{m}^{-2}\right)$, and net longwave radiation $\left(\mathrm{LW}, \mathrm{W} \mathrm{m}^{-2}\right.$ ), for winter and summer, respectively. The radiation and heat fluxes are average values over the ocean. Reanalysis data of the 10-member ERA-20CM ensemble over the period 1900-2010 are included for comparison, but not detrended prior to analysis. All series are decadally smoothed prior to computing the standard deviation. In the $4 \times \mathrm{CO}_{2}$ climate some small localized areas near Greenland with high variability have a considerable influence on the average values of the radiative and turbulent fluxes.

\begin{tabular}{llllllll}
\hline Season & Climate & SAT & SIA & LH & SH & LW & SW \\
\hline DJF & CTRL & 0.57 & 0.23 & 0.59 & 0.66 & 0.51 & 0.01 \\
& $2 \times \mathrm{CO}_{2}$ & 0.73 & 0.51 & 0.98 & 0.64 & 0.96 & 0.02 \\
& $4 \times \mathrm{CO}_{2}$ & 0.21 & 0.03 & 0.78 & 0.57 & 0.78 & 0.02 \\
& ERA-20CM & 0.59 & 0.25 & & & & \\
\hline JJA & CTRL & 0.09 & 0.23 & 0.22 & 0.16 & 0.33 & 1.48 \\
& $2 \times \mathrm{CO}_{2}$ & 0.20 & 0.17 & 0.34 & 0.15 & 0.51 & 1.09 \\
& $4 \times \mathrm{CO}_{2}$ & 0.20 & $<0.01$ & 0.37 & 0.15 & 0.61 & 1.33 \\
& ERA-20CM & 0.17 & 0.84 & & & & \\
\hline
\end{tabular}

\subsubsection{Winter variability}

In winter, decadal variability of two-meter air temperature and SIA increases in $2 \times \mathrm{CO}_{2}$ as the ice cover shrinks compared to present-day conditions. In even warmer climates $\left(4 \times \mathrm{CO}_{2}\right)$, however, when winter ice extent decreases further, the variance of both temperature and SIA drops to lower values than in CTRL. Winter temperature and sea ice variability are thus nonlinearly related to the mean climate state. The correlations between Arctic winter temperature and SIA are high, ranging from -0.82 in CTRL and the $4 \times \mathrm{CO}_{2}$ climate to -0.97 in $2 \times \mathrm{CO}_{2}$, suggesting that the underlying mechanisms of the variability are similar. This temperature-sea-ice coupling operates mainly through enhanced variability of longwave radiation and latent heat fluxes over areas with most sea ice variability in CTRL and $2 \times \mathrm{CO}_{2}$ (not shown).

In CTRL, the dominant SAT variability is located on the Atlantic side of the Arctic, near the sea ice margin. In this location, the variability in sea ice concentration peaks as well. The local standard deviation of SAT reaches values of over $5^{\circ} \mathrm{C}$ over the Greenland Sea and the eastern Barents Sea (not shown). Over the central Arctic Ocean, however, CTRL sea ice is too thick for leads to form in 
relatively mild winters, explaining why the decadal temperature variability over the central Arctic in the current climate is relatively small (less than $1^{\circ} \mathrm{C}$ ). Note that the narrow region of relatively thin sea ice in the present-day climate is related to the geometry of the Arctic basin, which currently blocks the southward extension of (thin) sea ice (Eisenman, 2010).

In the $2 \times \mathrm{CO}_{2}$ climate, the temperature variability shifts northwards along with the sea ice edge, together with enhanced upward fluxes in latent heat and longwave radiation. However, the largest increase in variability is found more northerly over the central Arctic Ocean where variability is up to four times as large as in CTRL. In this warm climate, the central Arctic Ocean also experiences the strongest variability in the latent heat and longwave radiation fluxes (Table 5.2), as well as in sea ice concentration (not shown), confirming again the strong link between variability in temperature and sea ice concentration. Due to thinner sea ice in this warm climate, the sea ice pack is more fragile and vulnerable over basically the entire Arctic Ocean, resulting in enhanced fluctuations of its total area, and therefore stronger decadal variability. Related to this, Van der Linden et al. (2014) found that sea ice is most sensitive to temperature perturbations between 50 and $60 \%$ ice concentration, which equals the average sea ice concentration over the central Arctic basin in the $2 \times \mathrm{CO}_{2}$ climate. In $4 \times \mathrm{CO}_{2}$, the absence of sea ice causes reduced temperature variability over the entire Arctic region.

The variability of winter ice area and near-SAT is thus higher in moderately warmer climates compared to present-day values, which is related to an increased sea ice area that is vulnerable to melt. For stronger warming and further reductions in sea ice area, this effect vanishes and the variability drops off again. Goosse et al. (2009) find a similar dependency on the mean state for summer Arctic sea ice extent, which they explain by the shape of the Arctic basin that limits the sea ice area; currently, the most sensitive marginal ice-zone in the present-day climate would occur in regions where the continents bordering the Arctic Ocean are situated. Our simulations suggest that this mechanism is also effective in winter, but that it will become relevant only at a later stage of warming. When the climate becomes so warm that even winter sea ice disappears, the temperature variability is further diminished by strong damping of the ocean and lack of amplifying ice albedo feedbacks. 


\subsubsection{Summer variability}

In general, summer variability is much weaker than in winter, except in the $4 \times \mathrm{CO}_{2}$ climate. Summer variability of SAT becomes slightly larger in the warmer climates, whereas the variability of SIA drops off.

In the CTRL climate, the variance of summer SAT is much smaller than in winter, whereas the variance of SIA is the same in both seasons (Table 5.2). In this climate, sea ice survives during the summer (covering on average 7.3 million $\mathrm{km}^{2}$ ) meaning that summer SAT variability is bounded by the melting point temperature of sea ice and therefore smaller than in winter. The SIA variability itself is probably restricted by the presence of the surrounding continents. Goosse et al. (2009) found that the variance peaks for a mean September ice extent of around 3 million $\mathrm{km}^{2}$ (which is mainly due to geometrical restrictions), which in EC-Earth occurs somewhere between the CTRL and $2 \times \mathrm{CO}_{2}$ climate states. The coupling between SIA and SAT variability is quite strong $(\mathrm{R}=-0.73)$, and is primarily associated with variability in net shortwave radiation through the ice-albedo feedback (Table 5.2), which is active mainly over the marginal ice zone in the Atlantic sector of the Arctic.

In the $2 \times \mathrm{CO}_{2}$ climate, SIA and SAT variability are still strongly coupled $(\mathrm{R}=$ -0.88 ), even though the mean SIA in summer shrinks to only 1 million $\mathrm{km}^{2}$, and virtually disappears in September. The standard deviation of SIA obviously goes to zero when sea ice almost disappears in the $4 \mathrm{xCO} 2$ climate. In the (nearly) seaice-free summers of the warm climates, the magnitude of SAT variability is approximately twice as large as in the CTRL climate. The atmosphere-ocean interaction is enhanced through increased variability in the latent heat flux and net longwave radiation (Table 5.2), which averaged over the Arctic are almost twice as large in $4 \times \mathrm{CO}_{2}$ compared to the CTRL climate. The variability of shortwave radiation reduces as sea ice disappears, which is clearly visible in the $2 \times \mathrm{CO}_{2}$ climate.

In short, summer SIA variability in the CTRL climate is probably restricted by the surrounding continents, but in warmer climates the shrinking area becomes the limiting factor. Furthermore, melting sea ice restricts summer SAT variability, but in the absence of sea ice, summer SAT variability increases (partly) through enhanced surface fluxes. Locally, sea ice thus plays an important role for the decadal SAT variability. Sea ice cover itself is sensitive to meridional heat transfer variations into the Arctic through the large-scale circulation, which we will investigate in the next section. 


\subsection{Changes in the atmospheric circulation}

To improve our understanding of the feedback mechanisms and interactions of the Arctic ice-ocean-atmosphere coupled system involved in (changes in) ADV, we examine here how the atmospheric circulation changes with climate warming. We concentrate on atmospheric pressure patterns, which influence the large-scale atmospheric circulation, and thereby the atmospheric heat transports toward the Arctic region. Changes in the atmospheric circulation can have a large effect on oceanic transports to and from the Arctic Ocean through changes in wind patterns and associated ocean currents. Furthermore, the redistribution and transport of sea ice through changed atmospheric circulation patterns have been found to affect sea ice melt or growth (Kwok and Rothrock, 1999; Rigor et al., 2002; Zhang et al., 2000). Air-sea interaction is not a oneway process, however. Local temperature anomalies and related changes in sea ice can alter the atmospheric circulation through thermal forcing from below (Slonosky et al., 1997; Alexander et al., 2004; Dethloff et al., 2006; Budikova, 2009). In the following, we will briefly analyze the basic characteristics of the mean climatological distribution of SLP and how this changes as the climate warms. Thereafter, we will examine the spatial structure of the leading modes of SLP variability, and how this alters with climate warming.

\subsubsection{Mean state}

Figure 5.5 depicts the mean SLP pattern in the CTRL climate, as well as its changes relative to the CTRL for $2 \times \mathrm{CO}_{2}$ and $4 \times \mathrm{CO}_{2}$, for both winter and summer. The spatial patterns in the CTRL climate are virtually the same as those derived from the ERA-20CM reanalysis data (shown in contours). In winter, when the circulation is strongest, three well-known 'centers of action' dominate the pressure field: the Siberian High over east-central Asia, the Icelandic Low off the southeast coast of Greenland, and the Aleutian Low in the North Pacific Ocean. The winter Siberian High is driven largely by radiative cooling to space, with the location of its cold center being constrained by topography. The winter Icelandic and Aleutian Lows are partly due to thermal effects associated with the geographical distribution of the comparatively warm ocean, the cold contintents, and land ice. Surface pressures tend to be low over a warm surface as the overlying air will be milder and, therefore, less dense. Furthermore, both lows are located downstream of the large-scale stationary troughs in the mid-troposphere where cyclogenis favorably occurs, and are hence part of the 

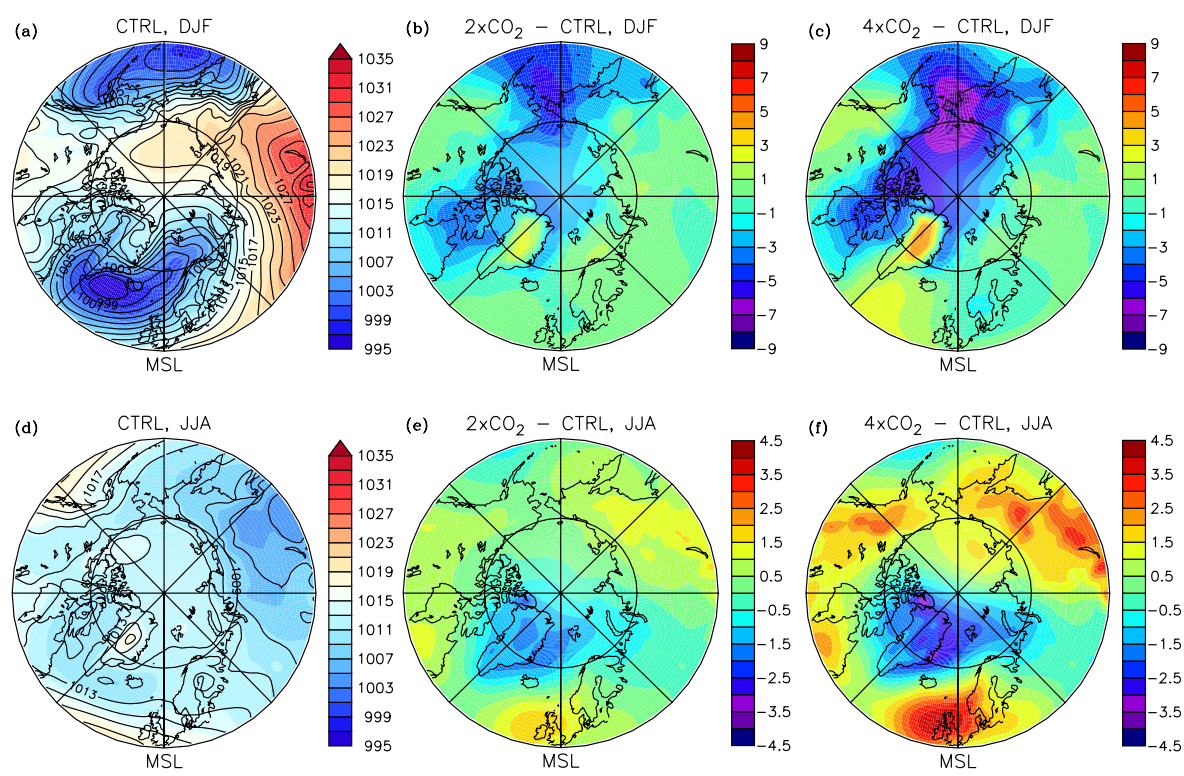

Figure 5.5 | Mean sea level pressure [hPa] at $50-90^{\circ} \mathrm{N}$ in the CTRL climate (a, c), and differences with respect to the CTRL in the $2 \times \mathrm{CO}_{2}(b, e)$ and $4 \times \mathrm{CO}_{2}(c, f)$ climates, for winter (top) and summer (bottom). The contour lines in the CTRL climate represent the average SLP of the 10-member ERA-20CM ensemble averaged over the period 19902010.

North Atlantic and North Pacific storm tracks. Also, strong horizontal temperature gradients (enhanced baroclinicity) along the sea ice margin and orographic effects induced by the Greenland Ice Sheet are associated with strong cyclone development processes. Compared to the mean winter SLP field in CTRL, especially the strengthening of the Aleutian Low in the warmer climates is quite remarkable. In warming climates, this low extends northeastward over the Bering Sea region, following the retreating sea ice margin and hence the region of favorable baroclinic conditions in terms of cyclogenesis. The changes in the mean pressure field might well stem from a northward shift of the Pacific storm track owing to the intensification of the westerly jet (Mizuta, 2012). This hypothesis is supported by the observed increase in the number and strength of cyclones entering the Arctic during the second half of the twentieth century (Graham and Diaz, 2001; Zhang et al., 2004).

In summer, the three centers of action are much weaker: the Aleutian Low has disappeared, the Icelandic Low is quite weak and extends over eastern 
Canada, and the Siberian High is replaced by a broad area of low pressure. This weakening can be attributed mainly to the reduced meridional gradient of solar heating, which reduces the strength of the atmospheric circulation and the jet stream as well as the 'depth' of the low-pressure centers. The weak low pressure over Siberia is a thermal response to increased solar heating and loss of snow cover. In warmer climates, the Icelandic Low deepens and extends northward over the Greenland Sea, while the northern flank of the Azores High strengthens as well. The northward extension of the Icelandic Low might be related to the strong temperature gradients over the sea ice edge, which migrate northwards in warmer climates, and the related cyclogenesis (Inoue et al., 2012). Furthermore, the very strong temperature gradient between the Greenland Ice Sheet (which in the model is essentially represented as a white mountain) and adjacent milder ocean might enhance baroclinic conditions in this region as well. The high-pressure anomaly over the British Isles is part of an atmospheric response to the decelerating Atlantic meridional overturning circulation (Haarsma et al., 2015). The similarity of this anomaly pattern (in geographical distribution) to the North Atlantic Oscillation (NAO) suggests that it induces increased westerlies through an enhanced north-south pressure gradient.

In a warming climate, we thus find that the Aleutian Low intensifies in winter and that the Icelandic Low becomes stronger in summer. Both centers of low pressure also migrate northward, which is consistent with the warming-related poleward migration of the jet stream in climate model simulations (Barnes and Polvani, 2013), although the full effect of Arctic warming on the jet stream might well be more complicated (Barnes and Screen, 2015).

\subsubsection{Leading modes of SLP and associated temperature changes}

Climate warming-related changes in the mean state of the large-scale atmospheric circulation are more extensively studied than changes in its variability. To gain insight into the signature of changes in SLP variability, and how this relates to temperature and sea ice variations, we use EOF analysis. As a first step, we compare the leading EOF modes of SLP variability and related patterns of SAT anomalies between the various climate states. For each mode, we only discuss the winter patterns, since these are stronger and more distinct than their summer equivalents.

The leading EOF of winter SLP over $20-90^{\circ} \mathrm{N}$, which explains $27.4-32.6 \%$ of the variance, is characterized by a prominent pressure anomaly over the central 

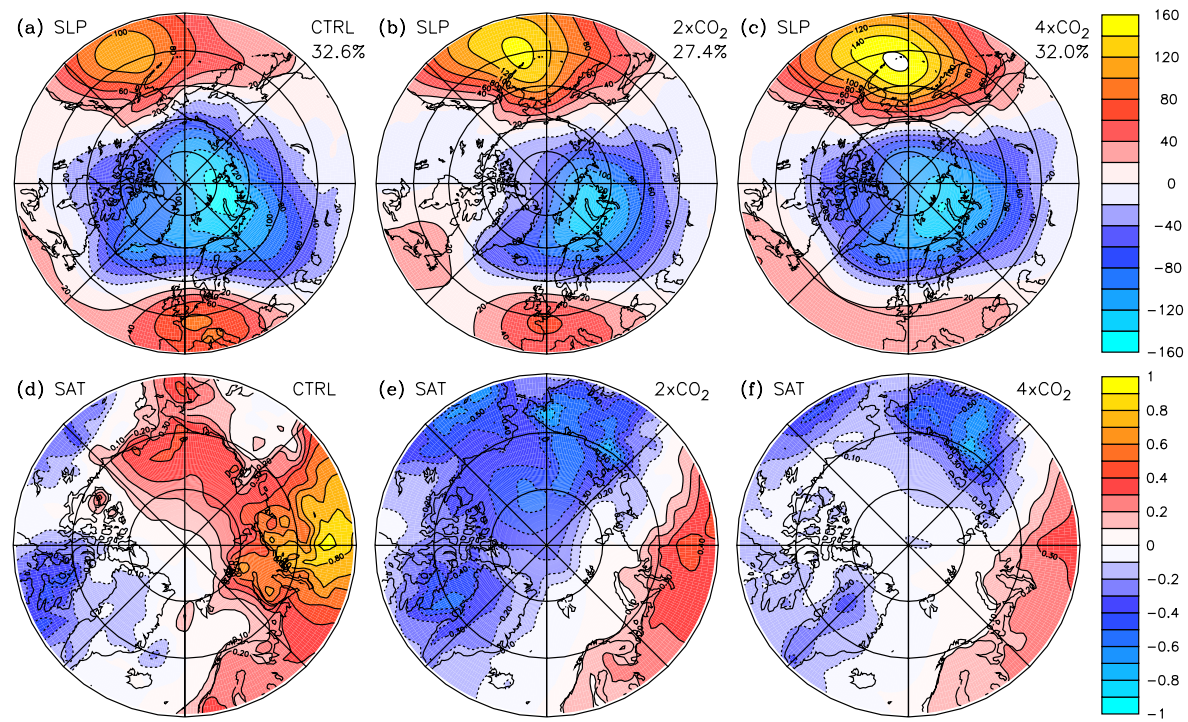

Figure 5.6 | (Top) First EOF of Northern Hemisphere (computed over $20-90^{\circ} \mathrm{N}$ ) winter (DJF) sea level pressure anomalies [Pa] for filtered time series, represented as the regression of SLP on the normalized principal component time series for the CTRL (a), $2 \times \mathrm{CO}_{2}$ (b), and $4 \times \mathrm{CO}_{2}$ (c) experiments. The total variance explained by each pattern is indicated. (Bottom) Regression of winter two-meter temperature $[\mathrm{K}]$ on the first EOF of sea level pressure (PC1) for the control (d), $2 \times \mathrm{CO}_{2}$ (e), and $4 \times \mathrm{CO}_{2}$ (f) experiments.

Arctic basin, and two pressure anomalies of opposite sign over the North Pacific and North Atlantic basins (Fig. 5.6). This mode is generally known as the Arctic Oscillation (AO) (Thompson and Wallace, 1998) or Northern Annular Mode (NAM), which is the hemispheric expression of the more regional NAO. This simulated EOF1 resembles the leading mode derived from observations (e.g., Holland, 2003), although the simulated amplitude is obviously smaller owing to the decadal smoothing. The principal component time series of EOF1 is a measure of the strength of the $\mathrm{AO}$ as a function of time: the $\mathrm{AO}$ index. In winter, the leading EOF of SLP splits the Arctic into two regions, based on the related pattern of temperature variability (Fig. 5.6). Even though the SAT index is only weakly linked to the AO index $(\mathrm{R}=0.29)$ owing mainly to the dipole-like nature of the SAT signature, it affects the regional pattern of SAT anomalies in the present-day climate, agreeing with results of Graversen (2006). During positive phases of the AO/NAM (low pressure over the central Arctic) the European/Siberian continent is relatively mild and the Canadian continent cold. 

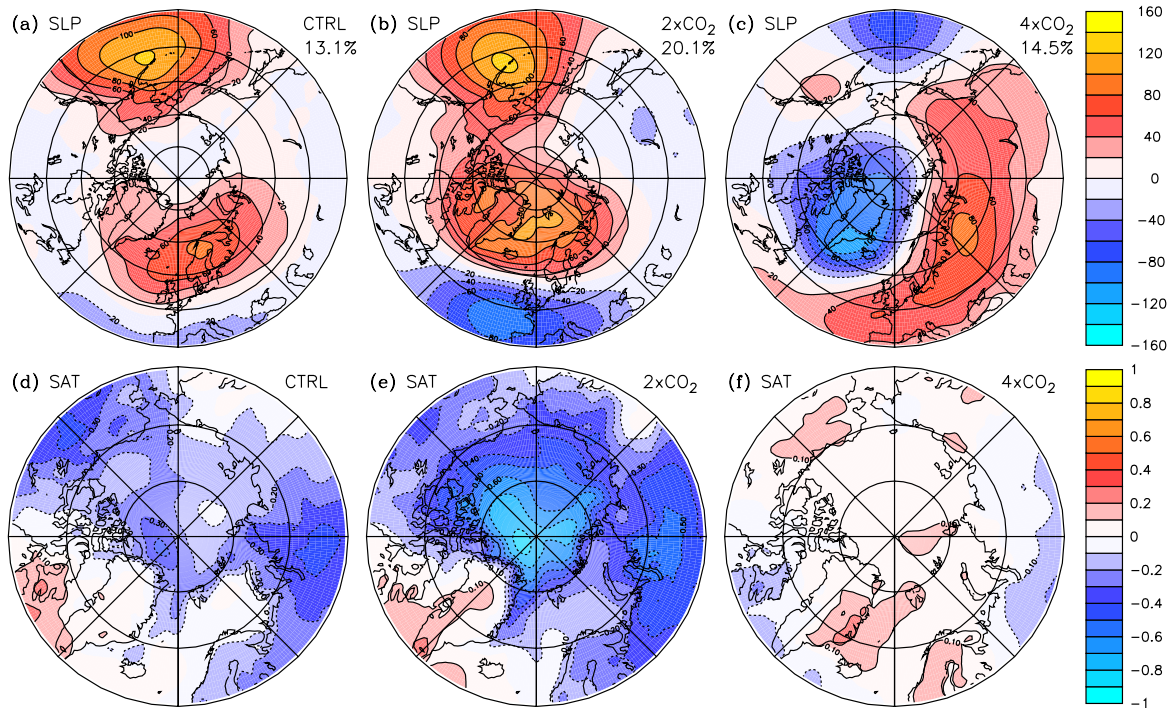

Figure 5.7 | (Top) Second EOF of Northern Hemisphere (computed over 20-90 $\mathrm{N}$ ) winter (DJF) sea level pressure anomalies [Pa] for filtered time series, represented as the regression of SLP on the normalized principal component time series for the control (a), $2 \times \mathrm{CO}_{2}$ (b), and $4 \times \mathrm{CO}_{2}$ (c) experiments. The total variance explained by each pattern is indicated. (Bottom) Regression of winter two-meter temperature $[\mathrm{K}]$ on the second EOF of sea level pressure (PC2) for the control (d), $2 \times \mathrm{CO}_{2}$ (e), and $4 \times \mathrm{CO}_{2}$ (f) experiments.

Related to these SAT patterns, sea ice reduces over most of the Arctic Ocean (not shown). In warmer climates during winter, positive temperature anomalies associated with a positive $\mathrm{AO}$ index reach less far into the Arctic region and remain mostly over the western Eurasian continent. The negative temperature anomalies on the Canadian side of the Arctic occupy a much larger region, including east Siberia and the Pacific sector of the central Arctic Ocean. As a result, a positive AO index relates to cold anomalies and extended sea ice in warmer climates whereas it coincides with warm anomalies and reduced sea ice in the present-day climate. Remarkably, our model simulations thus indicate that the SAT signature associated with a positive mode of the AO changes with climate warming.

The AO-related shift in the temperature response is likely associated with the strengths and locations of the centers of action. The influence of the Pacific center becomes stronger and shifts northwestward in milder climates, while 

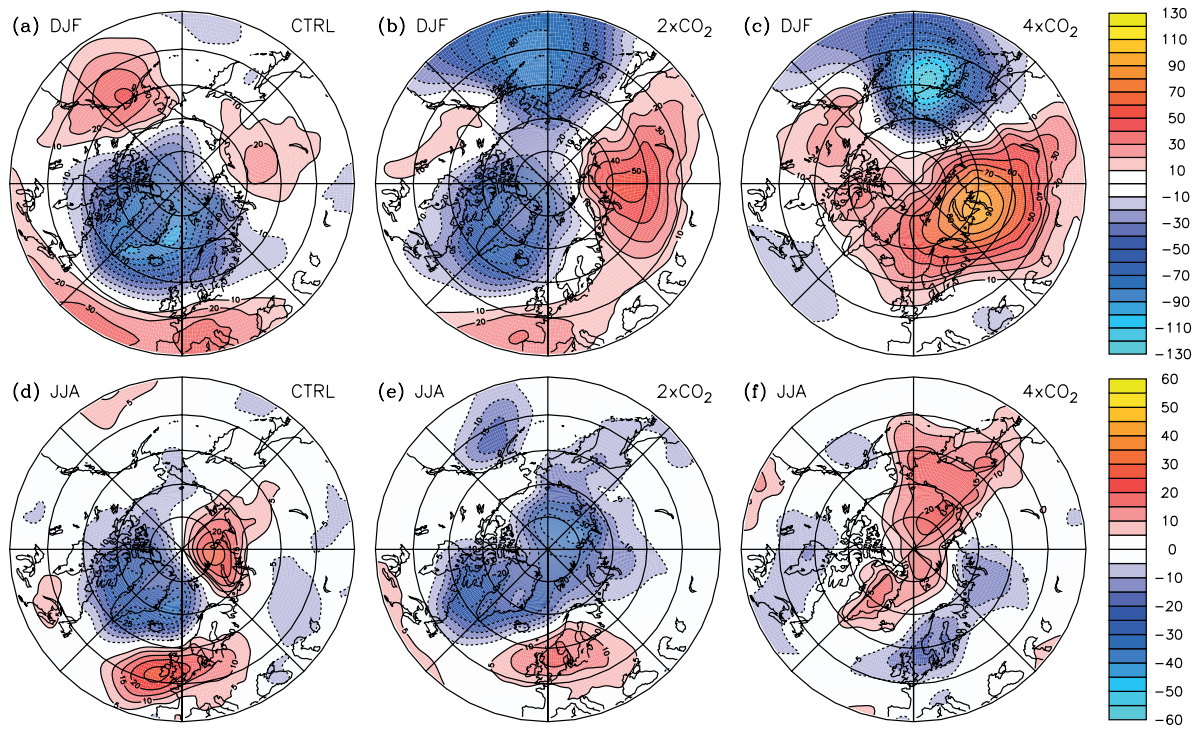

Figure 5.8 | Regression of SLP anomalies on the normalized time series of PC1 of SAT for the CTRL (a ,d), $2 \times \mathrm{CO}_{2}(b, e)$, and $4 \times \mathrm{CO}_{2}$ (c, f) climates, for winter and summer, respectively.

the influence of the Atlantic center weakens substantially, consistent with Choi et al. (2010). On the Atlantic side of the Arctic, a higher AO index is associated with stronger zonal winds in the midlatitudes and eastward advection of heat from the Atlantic Ocean to Eurasia. This effect is most pronounced in the control climate and weakens in warmer climate states. On the Pacific side, a stronger $\mathrm{AO}$ is associated with reduced advection of warm southerly air masses toward the Arctic region, and thus a cooler Arctic.

The second leading mode of SLP variability (EOF2), which explains 13.1$20.1 \%$ of the decadal variability, also affects temperature and sea ice over the Arctic region (Fig. 5.7). In winter, this second mode is associated with the strength of the Aleutian Low in CTRL and $2 \times \mathrm{CO}_{2}$, which links to the Pacific Decadal Oscillation (PDO) (Mantua et al., 1997). A stronger Aleutian Low (positive PDO) has been associated with transport of warm, moist air over Alaska into the Arctic (Hartmann and Wendler, 2005). Furthermore, the associated SLP pattern has characteristics of the NAO, with opposing pressure anomalies over the Atlantic between high and mid latitudes. This has been linked to an increase in the amount and temperature of the Atlantic water inflow to the Arctic Ocean 

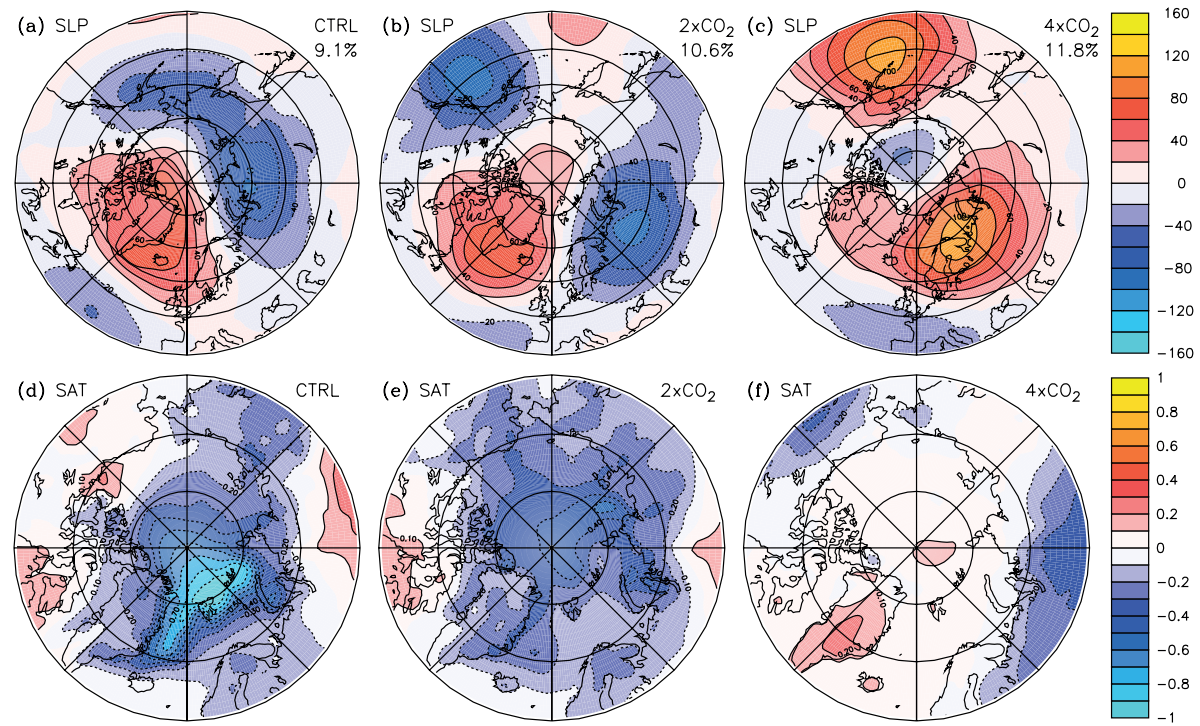

Figure 5.9 | (Top) Third EOF of Northern Hemisphere (computed over $20-90^{\circ} \mathrm{N}$ ) winter (DJF) sea level pressure anomalies for filtered time series, represented as the regression of SLP on the normalized principal component time series for the control (a), $2 \times \mathrm{CO}_{2}(\mathrm{~b})$, and $4 \times \mathrm{CO}_{2}$ (c) experiments. The total variance explained by each pattern is indicated. (Bottom) Regression of winter two-meter temperature $[\mathrm{K}]$ on the third EOF of sea level pressure (PC3) for the control (d), $2 \times \mathrm{CO}_{2}(\mathrm{e})$, and $4 \times \mathrm{CO}_{2}(\mathrm{f})$ experiments.

(e.g., Dickson et al., 2000). Both mechanisms likely contribute to the simulated SAT signature. The regression of SAT temperature on PC2 shows that, in winter, deeper Aleutian and Icelandic Lows are associated with higher temperature anomalies and sea ice decline over most of the Arctic, and lower temperatures over the east Canadian Arctic (Fig. 5.8). The SAT response to EOF2 is concentrated over the central Arctic, compared to the subpolar response in EOF1, and is especially large in $2 \times \mathrm{CO}_{2}$, where fluctuations in sea ice concentration govern the total climate variability.

Finally, the third EOF of winter sea level pressure in CTRL and $2 \times \mathrm{CO}_{2}$ is characterized by a dipole of opposite surface pressures across the Arctic (Fig. 5.9). This mode is often referred to as the Arctic Dipole Anomaly (DA) (Wu et al., 2006) and is associated with a strong meridional component in the surface wind anomaly and related sea ice motion (Watanabe et al., 2006). A low-pressure area over Greenland and high pressure over Siberia are linked to higher SAT in the Arctic region. In the reanalysis, this 'negative' phase of the DA is associated 
with a strengthened Beaufort gyre, and with reduced sea ice over the Barents and the Greenland Seas (Wu et al., 2006). EC-Earth exhibits similar DA-related sea ice characteristics in the CTRL climate. In regions where sea ice diverges, open water and/or thin sea ice appears and the heat flux from the ocean can directly influence the local air temperature. Arctic SAT changes related to the DA are especially large over regions with high sea ice variability (not shown). Surface winds associated with the DA seem to be of crucial importance for sea ice motion, and thereby significantly affect the surface air temperature distribution. For $4 \times \mathrm{CO}_{2}$, the third mode of SLP variability resembles the second mode of CTRL and $2 \times \mathrm{CO}_{2}$, and likewise, the second mode resembles the third mode (DA), but the associated temperature changes are fairly small. It thus seems that EOF2 and EOF3 affect SAT variability mainly through sea ice-related feedbacks.

Although the leading modes of SLP variability change with climate warming, the dominant characteristics of the EOFs remain largely similar among the climate states that were simulated since they are, at least partially, constrained by the geography of the Arctic region (continental boundaries and orography). Nonetheless, the differences in the corresponding SAT anomalies between the various climate states are much larger than expected from the changes in the leading modes of SLP alone, with an important role for sea ice.

\subsection{Patterns of temperature variability and heat trans- ports}

In the previous section, we have found that the variability of SLP changes towards warmer climates, which thereby affects SAT. In this section, we reverse this analysis by examining what changes in SLP anomalies are related to the dominant changes in SAT variability. We also assess to what extent the total oceanic (OHT) and atmospheric (AHT) heat transport toward the Arctic are involved.

We use the first principal component of SAT north of $70^{\circ} \mathrm{N}$ (SAT index; Fig. 5.4) for spatial regressions of SLP, thereby implicitly including regions outside the Arctic where SAT varies in phase with temperatures in the Arctic (Fig. 5.3). For the linkages with OHT and AHT, we use the averaged SAT over $70-90^{\circ} \mathrm{N}$, since these boundaries are also used to compute both heat transport terms. Furthermore, we perform spatial regressions of SLP and SAT on OHT and 
AHT at $70^{\circ} \mathrm{N}$ to assess the dominant pressure patterns associated with meridional heat transfer in the ocean and the atmosphere.

OHT is evaluated as the residual of net surface fluxes and ocean heat storage, while AHT is calculated from the net surface and top-of-the-atmosphere fluxes. Here we will discuss winter and summer variability separately.

\subsubsection{Winter patterns}

Figure 5.8 shows regressions of the SLP anomalies on the SAT index. The winter atmospheric SLP pattern associated with the SAT index changes gradually from the CTRL climate towards warmer climate states. In the present-day climate, high Arctic temperature anomalies are associated with a strong low-pressure area centered over the Greenland Sea that extends well into the Arctic basin, and high-pressure anomalies over the Gulf of Alaska and east Siberia. These spatial structures extend upward into the troposphere, where the associated patterns in geopotential height at 850,500 , and $200 \mathrm{hPa}$ exhibit similar characteristics (not shown), indicating an equivalent-barotropic structure with little variation in the wind patterns with height. The intense low-pressure anomaly over the Greenland Sea, which is clearly associated with poleward advection of warm air in the present climate, becomes less important for SAT variability towards warmer climate states. In contrast, the importance of the low-pressure anomaly over the Aleutian Islands and the high-pressure anomaly over Siberia increases with climate warming.

In the CTRL climate, the atmospheric pressure signature that is related to decadal variability (Fig. 5.8a) is quite firmly connected to the third EOF of SLP (Fig. 5.9a), being the DA pattern. The related SAT pattern (Fig. 5.9d) exhibits a rather large SAT response over the regions where the largest SAT variability occurs (Fig. 5.3a). The prominent role of the DA pattern in terms of Arctic SAT variability in the current climate is further emphasized by the relatively strong correlation between the SAT index and PC3 of SLP $(R=0.54)$, whereas the other PCs are only weakly correlated.

We also find a relatively strong relation between ocean heat transport and Arctic SAT variability during winter, which is strongest when SAT leads by 3 years $(\mathrm{R}=-0.51)$, suggesting that in winter months the ocean responds to Arctic temperature changes. During warm events, OHT anomalies reduce the climatological mean $\mathrm{OHT}$ at $70^{\circ} \mathrm{N}$, which in winter is directed northward. To gain further insight into the role of the ocean on SAT variability, we regressed both SLP and SAT anomalies on the OHT anomalies at $70^{\circ} \mathrm{N}$ (Fig. 5.10a and 5.11a). 

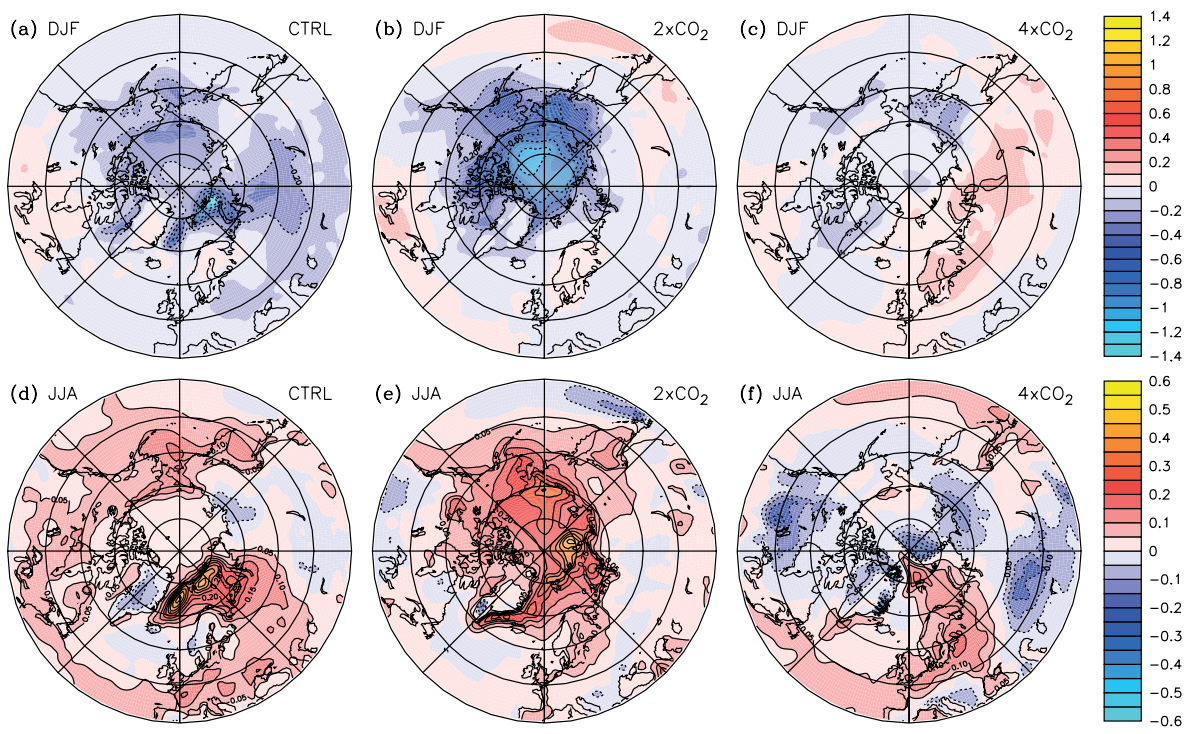

Figure 5.10 | Regression of SAT anomalies on the normalized time series of oceanic heat transport across $70^{\circ} \mathrm{N}$ for the CTRL (a , d), $2 \times \mathrm{CO}_{2}(\mathrm{~b}, \mathrm{e})$, and $4 \times \mathrm{CO}_{2}(\mathrm{c}, \mathrm{f})$ climates, for winter and summer, respectively.

Consistently, the regression of SAT on OHT at $70^{\circ} \mathrm{N}$ (Fig. 5.10a) indicates that the ocean tends to dampen Arctic warm anomalies.

In $2 \times \mathrm{CO}_{2}$, anomalous Arctic warming is characterized by a deep lowpressure area over the Aleutian Islands and a high-pressure anomaly over Siberia (Fig. 5.8b). This pattern strikingly resembles the second EOF of SLP (Fig. 5.7b), except for the high-pressure anomaly over Siberia. Moreover, the SAT signature associated with EOF2 (Fig. 5.7e) depicts the strongest SAT response over the central Arctic. This coincides with the region of dominant SAT variability in this warm climate (Fig. 5.3b), meaning that EOF2 contributes significantly to Arctic SAT variability. The strong link between the second EOF of SLP and SAT variability is confirmed by the fact that PC2 is significantly correlated with the SAT index $(\mathrm{R}=0.52)$, whereas the other PCs are not.

The regression of SLP on OHT (Fig. 5.11b) clearly emphasizes the importance of the Aleutian Low. A weaker (i.e. more positive) pressure anomaly over the Aleutian Islands relates to a stronger OHT towards the Arctic, and vice versa. The reason for this link is hard to identify without investigating the processes behind the OHT in more detail, which is outside the scope of this paper. One 

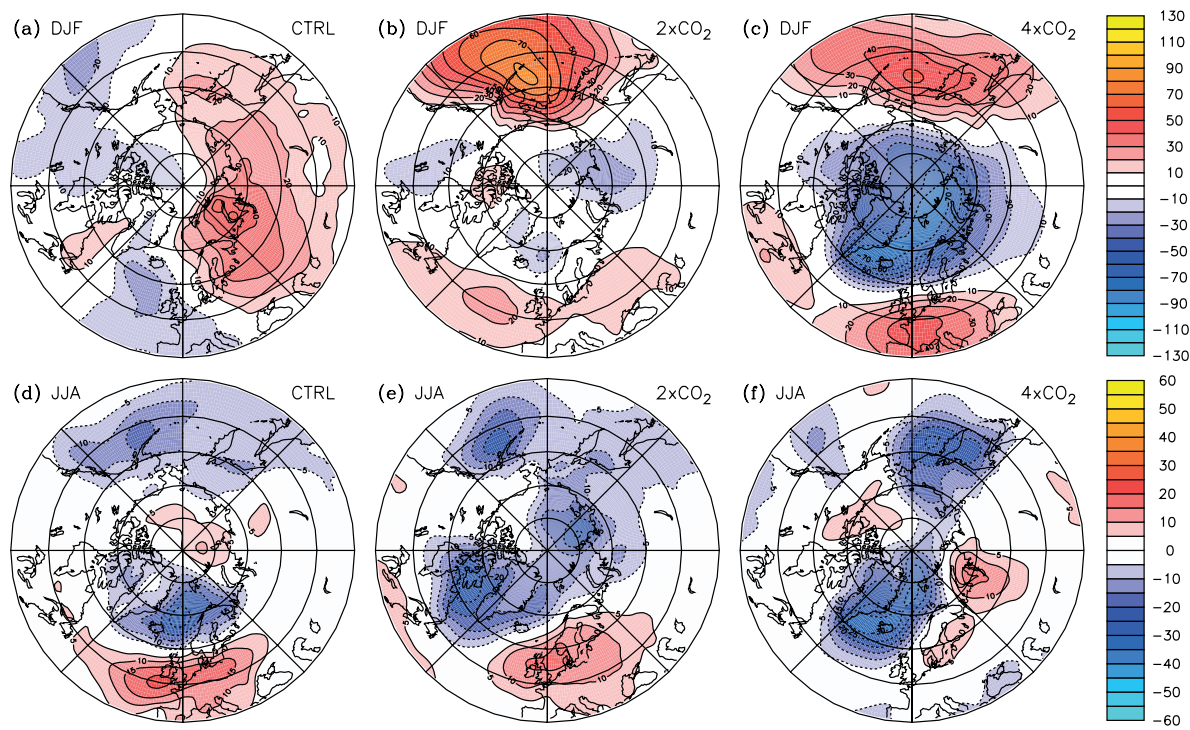

Figure 5.11 | Regression of SLP anomalies on the normalized time series of oceanic heat transport across $70^{\circ} \mathrm{N}$ for the CTRL (a ,d), $2 \times \mathrm{CO}_{2}(\mathrm{~b}, \mathrm{e})$, and $4 \times \mathrm{CO}_{2}(\mathrm{c}, \mathrm{f})$ climates, for winter and summer, respectively.

possibility is that the decadal-scale variability of the heat inflow through Bering Strait increases in warm climates. However, it is unclear to what extent this fairly narrow passage is able to affect the total heat transport because the total mass transport is quite limited. Another possible explanation is a remote forcing to the Atlantic side through an atmospheric teleconnection. At the same time, somewhat counter-intuitively, stronger (winter) northward ocean heat transports are related to colder Arctic winters (Fig. 5.10b). Given the fact that the Aleutian Low is connected to both OHT and Arctic temperature variability, some relation between these variables can be expected. An anomalous outflow of ocean heat is indeed strongly related to Arctic warming $(\mathrm{R}=0.66)$. This correlation is even (slightly) stronger when SAT leads by 1 year, implying that winter OHT responds to the corresponding SAT changes. In both CTRL and $2 \times \mathrm{CO}_{2}$, reduced northward OHT during winter is thus mainly associated with a warmer Arctic in the previous winter.

In the warmest climate state, the influence of the Siberian High and Aleutian Low on SAT variability becomes even stronger than in $2 \times \mathrm{CO}_{2}$, whereas the influence of the Icelandic Low vanishes (Fig. 5.8c). This pattern exhibits striking 

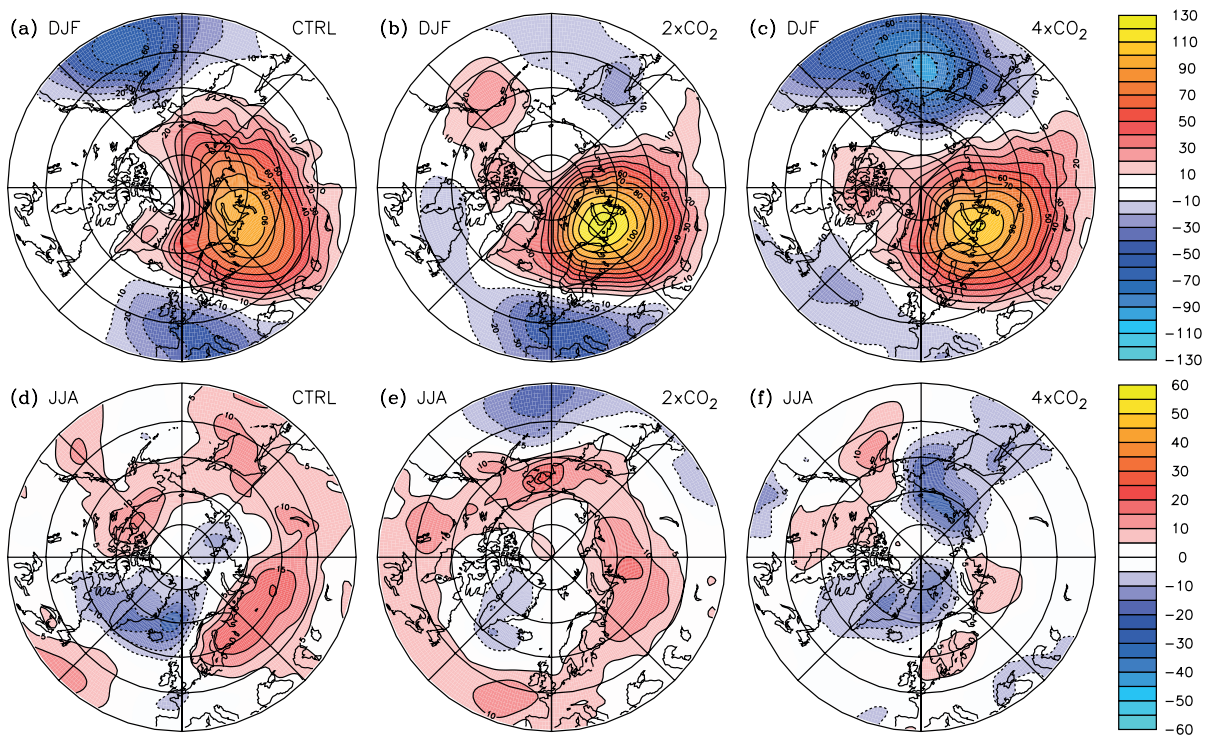

Figure 5.12 | Regression of SLP anomalies on the normalized time series of atmospheric heat transport across $70^{\circ} \mathrm{N}$ for the CTRL (a ,d), $2 \times \mathrm{CO}_{2}$ (b, e), and $4 \times \mathrm{CO}_{2}$ (c, f) climates, for winter and summer, respectively.

similarities with the AO-like EOF1-pattern of SLP (Fig. 5.6c), which is confirmed by the rather firm correlation between PC1 of SLP and the SAT index $(R=0.49)$, while the correlations with the other PCs are rather weak.

The spatial structure of SLP associated with Arctic warm phases in $4 \times \mathrm{CO}_{2}$ strongly resembles the atmospheric pattern of SLP related to enhanced atmospheric heat transport into the Arctic (Fig. 5.12c), pointing to a dominant role of AHT in Arctic decadal variability in the $4 \times \mathrm{CO}_{2}$ climate. The relation between AHT and Arctic temperature variability is moderately positive ( $\mathrm{R}=0.37$ ).

To summarize, winter SLP patterns associated with SAT variability change considerably as the climate warms. Different SLP modes are firmly linked to SAT variability during the various stages of warming: the DA-like EOF3 pattern for CTRL, the PDO-like EOF2 for $2 \times \mathrm{CO}_{2}$, and the AO-like EOF1 for $4 \times \mathrm{CO}_{2}$, suggesting that the dominant circulation mode associated with decadal variability is likely to change with future warming. When the climate warms, the wintertime Aleutian Low considerably deepens in the climatological mean state and also plays a more prominent role in winter SAT variability. The Aleutian Low is associated with OHT variability in $2 \times \mathrm{CO}_{2}$, for which it lags SAT fluctuations, 

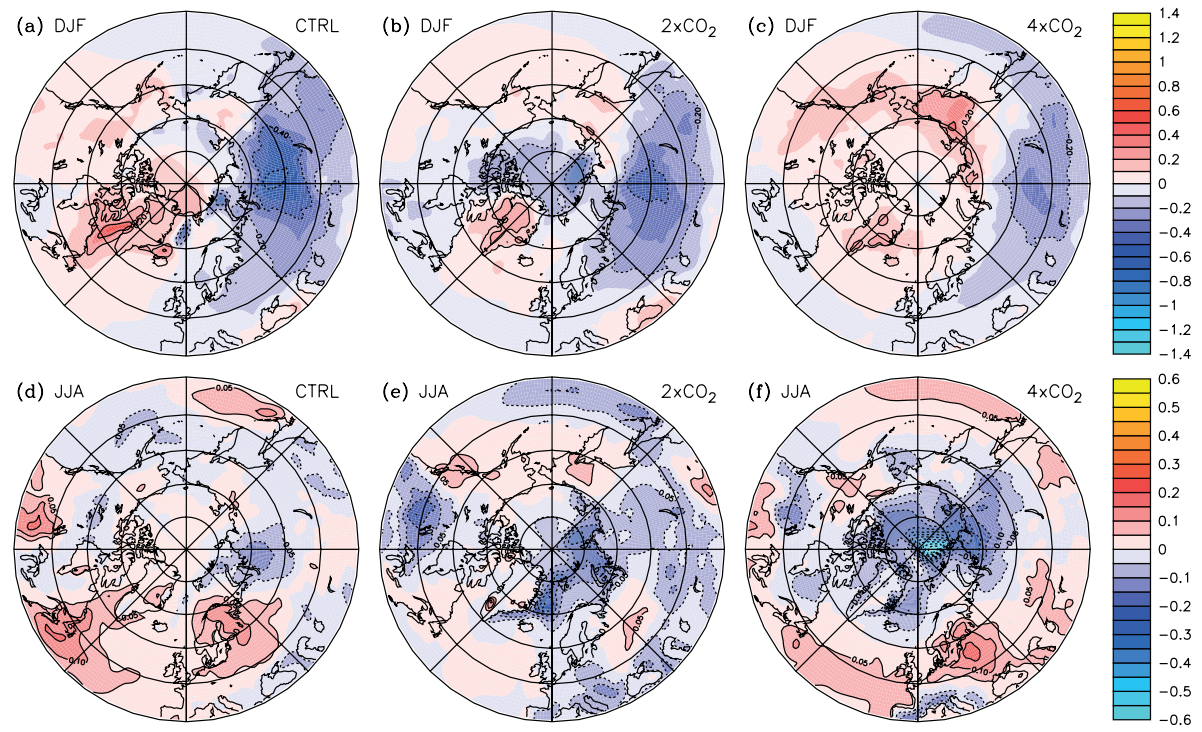

Figure 5.13 | Regression of SAT anomalies on the normalized time series of atmospheric heat transport across $70^{\circ} \mathrm{N}$ for the CTRL (a ,d), $2 \times \mathrm{CO}_{2}$ (b, e), and $4 \times \mathrm{CO}_{2}$ (c, f) climates, for winter and summer, respectively.

and AHT variability in $4 \times \mathrm{CO}_{2}$.

\subsubsection{Summer patterns}

In summer, SLP patterns related to SAT variability are more regional and more diverse among the three climate states compared to winter. In CTRL, the warm phase of decadal variability is associated with a regional atmospheric pattern characterized by a low-pressure anomaly over Greenland, which forms a tripole of surface pressure with high-pressure anomalies over the eastern Arctic basin and off the coast of Ireland (Fig. 5.8d). This pattern bears some resemblance to the NAO, a dipole between mid- and high latitudes, but then with northward shifted high- and low-pressure centers, as well as to the DA, a dipole of opposite pressure anomalies across the Arctic Ocean. The pressure pattern indicates a southwesterly flow near the Barents Sea entrance. This circulation pattern is accompanied by an anomalous northward inflow of ocean heat transport, which is confirmed by a strong relation between total $\mathrm{OHT}$ at $70^{\circ} \mathrm{N}$ and Arctic SAT $(\mathrm{R}=0.79)$. This relation is highlighted by the regression of SLP on OHT at $70^{\circ} \mathrm{N}$ 
(Fig. 5.11d), which strongly resembles the regression map of SLP on the SAT index (Fig. 5.8d). This implies that the net climatological ocean heat transport at $70^{\circ} \mathrm{N}$, which in summer is directed southward, is reduced during warm phases of decadal variability. In combination with the reduced northward OHT in winter, this shows that during anomalously warm periods the heat transport by the ocean reinforces Arctic warming throughout the year. Hence, ocean heat transport amplifies Arctic temperature variability.

In the summer of the $2 \times \mathrm{CO}_{2}$ climate, the influence of the high-pressure center over the eastern Arctic on the SAT variability vanishes (Fig. 5.8e). Instead, warm Arctic summers relate to the anomalous low-pressure system over Greenland, which in this climate state merges with a newly formed low-pressure anomaly over the central Arctic. In summer, there is also a strong link between northward OHT and Arctic SAT $(\mathrm{R}=0.93)$ in this mild climate. This strong relation is confirmed by the regression of SLP on OHT at $70^{\circ} \mathrm{N}$ (Fig. 5.11e), which strikingly resembles the regression map of SLP on the SAT index (Fig. 5.8e). The reduced seasonal cycle of OHT during warm periods in the CTRL climate, is thus also present in the $2 \times \mathrm{CO}_{2}$ climate and amplifies Arctic warming.

Finally, in the $4 \times \mathrm{CO}_{2}$ climate, the summer SLP distribution associated with mild Arctic summers is completely different compared to the two other climate states (Fig. 5.8f). In this climate, a high-pressure anomaly centered over the Arctic Ocean with extensions over Greenland and east Siberia, and a lowpressure anomaly over the North Sea are related to Arctic warm phases. In contrast to the other two climates, the relation between total northward OHT and Arctic temperatures is negligible $(\mathrm{R}=-0.09)$, with AHT seemingly taking over the prominent role of OHT. The correlation between northward atmospheric heat transport and Arctic warming in summer is quite strong and negative $(\mathrm{R}=-0.61)$, implying that the net northward $\mathrm{AHT}$ at $70^{\circ} \mathrm{N}$ in summer is reduced during warm phases and reduces Arctic temperature variability.

\subsubsection{Seasonal cycle}

Since summer changes might impact winter processes, and vice versa, we combine and summarize the previous results into a seasonal picture in which we highlight the roles of OHT and AHT. In the CTRL and $2 \times \mathrm{CO}_{2}$ climate, OHT plays a major role in Arctic decadal variability. During warm periods of decadal variability, the seasonal cycle in $\mathrm{OHT}$ at $70^{\circ} \mathrm{N}$ is reduced, with smaller northward (southward) heat transport in winter (summer). A regression of SAT on OHT in winter and summer confirms this: in winter, positive OHT anomalies are related 
to a colder Arctic region, while in summer, positive OHT anomalies are linked to a warmer Arctic (Fig. 5.10). We also find that winter warming is strongly and positively linked to summer OHT ( $\mathrm{R}=0.74$ for CTRL and $\mathrm{R}=0.88$ for $2 \times \mathrm{CO}_{2}$ ), meaning that a decrease in southward OHT in summer, possibly through the ice-albedo feedback and ocean heat storage, contributes to increased winter warming. Moreover, the wintertime OHT lags the variability in SAT by $1-3$ years, suggesting that OHT fluctuations dampen SAT anomalies, whereas in summer, there is no lag between OHT and Arctic SAT. These results suggest that enhanced northward heat transport anomalies in summer (that is, reduced export of heat out of the Arctic) lead the temperature changes in the Arctic region. These, in turn, might be initiated through atmospheric pressure anomalies in summer (Fig. 5.11d and 5.11e): a NAO-like pressure gradient between mid- and high latitudes over the North Atlantic and a low-pressure anomaly over the Gulf of Alaska. However, the details of the mechanisms determining the decadal variability in the large-scale ocean circulation are beyond the scope of this paper.

For $4 \times \mathrm{CO}_{2}$, the prominent role of OHT on Arctic SAT variability vanishes. Instead, atmospheric heat transport becomes more important. During warm anomalies, the net AHT at $70^{\circ} \mathrm{N}$, which is directed northward throughout the year, is enhanced in winter, and reduced in summer. This means that AHT tends to reduce the amplitude of temperature variability in summer. In winter, however, strong AHT is associated with the intensified Aleutian Low and Siberian High (Fig. 5.12), through which warm air is advected northwards over the Bering Strait region, and deep into the Arctic region over the Siberian shelf seas (Fig. 5.13). This mechanism also operates in the other two climate states, given the roughly similar SLP and SAT fields that are related to AHT. However, in the coldest two climates the SAT changes associated with AHT are about two times as small compared to the SAT signature determined by the OHT variability, particularly in winter (Fig. 5.10).

\subsection{Summary and conclusions}

In this study, we investigate how Arctic decadal variability in SAT changes as the climate warms. For this purpose three 550-yr long simulations with the stateof-the-art climate model EC-Earth using present-day, double, and quadrupled $\mathrm{CO}_{2}$ forcing have been carried out. The final 400 years of these simulations have been evaluated, meaning that the climate states studied here are in (quasi) 
equilibrium. Our approach concentrates on the large-scale atmospheric circulation patterns in the Northern Hemisphere, how these contribute to ADV in the present climate, and how (much) these change warmer climate states. To obtain a comprehensive picture of ADV, we chose not to focus on a specific atmospheric mode or a particular region. In contrast to previous studies, we assess three dominant atmospheric modes north of $20^{\circ} \mathrm{N}$ and include the entire Arctic and surrounding areas in our analysis. In an effort to elucidate the driving mechanisms of ADV, the zonal mean OHT and AHT across $70^{\circ} \mathrm{N}$ are integrated into our approach. Finally, seasonal variability is taken into account by considering winter and summer conditions separately.

First of all, a comparison of ERA-20CM reanalysis data with decadal-scale variability in our present-day equilibrium simulation clearly shows that this variability has the potential to obscure forced trends in surface air temperature, as well as in (winter) sea ice area. Decadal variability (and changes therein) should thus be taken into account when analyzing climate trends in the Arctic region. The difficulty in separating forced trends from (unforced) decadal variability in observations is related to the data having either too scattered temporal coverage or too low temporal resolution (e.g. in proxy data) to accurately capture decadal variability. Model simulations are therefore an appropriate and indispensable tool to study this type of variability, notwithstanding the caveats associated with climate models, especially when using only one model (e.g. model-dependent physics).

It is found that the relationship between sea ice and temperature variability changes nonlinearly when the climate warms. SAT and SIA variability are strongest in $2 \times \mathrm{CO}_{2}$ in winter, when the average sea ice concentration north of $70^{\circ} \mathrm{N}$ is about $55 \%$. A broken sea ice cover with intermittent leads at a coverage around $50 \%$ is indeed most vulnerable to temperature changes, as shown by Van der Linden et al. (2014). Moreover, Goosse et al. (2009) found an increased variability of Arctic summer ice extent when the climate warms, which confirms our finding. This suggests that in the near-future, Arctic variability will very likely become stronger. When Arctic warming continues and sea ice melts away almost completely, SAT variability over the Arctic region will strongly diminish, since all ice-related feedbacks will disappear as well. These include a more intense turbulent heat release to the atmosphere in winter when sea ice is reduced and a reduced reflection of solar radiation in summer due to a lower surface albedo. In a paleoclimate study of even more extreme climate states, Poulsen and Zhou (2013) also found that ADV is highly dependent on the mean climate state. In their study, variability increases with a rise in $\mathrm{CO}_{2}$ levels (ten 
times present-day) and is driven by mass transport and salinity advection into the Arctic.

The increase in variability in $2 \times \mathrm{CO}_{2}$ is especially relevant because this is the climate state where the current trajectory of radiative forcing is directed to. Since climate warming and retreating sea ice are associated with stronger ADV, it is vitally important to consider ADV changes when assessing trends in Arctic warming from model simulations/projections.

In warmer climates the mean large-scale atmospheric circulation changes, with intensified Aleutian (winter) and Icelandic Lows (summer). Moreover, the variability of the atmospheric circulation changes as well, and also its impact on surface air temperature anomalies. Several earlier studies have assessed the link between the $\mathrm{AO} / \mathrm{NAO}$ and Arctic warming or sea ice decline (e.g., Holland, 2003; Goosse and Holland, 2005), finding mostly a positive but relatively weak relation. In our model, a positive AO index is indeed associated with a warmer Arctic in the current climate. This is consistent with observations in the late 1980s through early 1990s, when a decline in summer ice concentration in the eastern Arctic Ocean and the Barents and Nordic Seas was associated with a positive trend in the AO. However, this relationship does not hold for more recent observations. Since the mid-1990s, the AO is in a near-neutral or negative state, yet sea ice decline is ongoing, and likely even accelerating - a feature termed the Arctic Climate Paradox by Overland and Wang (2005). Our results suggest that this paradox might be (at least partly) attributed to changes in the $\mathrm{AO}$ and the associated SAT pattern. In our simulations of warmer-than-present climates, there is still a difference in temperature response between the Eurasian and Canadian sectors of the Arctic region, but the transition region between positive and negative temperature anomalies associated with the AO shifts towards Siberia. This suggests that the ADV-contribution of the various atmospheric modes is thus dependent on the mean climate state.

We find that the Arctic Dipole Anomaly, the Aleutian Low, and the AO govern the winter SAT response to the large-scale atmospheric circulation variability in the CTRL, the $2 \times \mathrm{CO}_{2}$, and the $4 \times \mathrm{CO}_{2}$ climate states, respectively. Different atmospheric modes dominate circulation-related ADV during subsequent stages of climate warming. Hence, links between atmospheric circulation modes and Arctic climate variability are not necessarily constant as the climate warms, meaning that transitions between circulation types determining Arctic variability might be expected when the climate system continues to warm.

Changes in the variability of the atmospheric circulation are associated with oceanic and atmospheric heat transport anomalies. There are strong indica- 
tions that the summer OHT is leading ADV in the current and the $2 \times \mathrm{CO}_{2}$ climates, in agreement with results of Goosse and Holland (2005), Van der Linden et al. (2016), and Zhang (2015), whereas the winter AHT plays a more important role in the $4 \times \mathrm{CO}_{2}$ climate. Finer details of the changes in the large-scale circulation in the ocean and the atmosphere should be the topic of subsequent research.

All results presented here are based on one particular climate model. The obvious disadvantage of this approach is that the results may depend (partially) on model physics/parameterizations. Similar analyses using other climate models is therefore necessary to infer if our conclusions are robust. Nonetheless, this study provides valuable new insights into how Arctic decadal variability might change with climate warming. 



\section{6}

\section{Synthesis and outlook}

\subsection{Overview of the present research}

The primary aim of this thesis is to understand how anthropogenic forcing by greenhouse gases and aerosols and natural decadal to multidecadal variability affect the Arctic climate system, in order to improve our understanding of observed Arctic climate changes and to better forecast future Arctic climate changes.

The findings in each chapter of this thesis contribute to the general research questions that were formulated at the beginning of this thesis. This final part reflects upon all chapters and puts the results in a broader perspective. In order to do so, Chapter 2 to 5 were subdivided into two general topics. Section 6.2 summarizes our main insights concerning changes in the mean Arctic climate from Chapter 2 (intermodel spread) and Chapter 3 (changes in ocean heat transport). In Section 6.3, aspects of low-frequency natural climate variability are addressed as presented in Chapter 4 (governing mechanisms) and Chapter 5 (changes in variability). In all sections, we use as a guideline the general research questions that were presented at the beginning of this thesis (Chapter 1). We synthesize our key findings and highlight some important connections between the various chapters, and also between our findings and adjacent areas of research. Finally, in Section 6.4, we provide recommendations for future research. 


\subsection{Changes in the Arctic mean climate state}

This section summarizes and discusses the key findings concerning changes in the Arctic mean climate state as presented in Chapter 2 and 3.

Q1 What causes the intermodel spread in future climate model simulations of Arctic warming?

In climate research, climate models are the primary tool to advance our understanding of the Arctic climate system. The climate models have become more and more complex as our understanding of the climate system improved over time, leading to better parameterizations of the various processes and feedback mechanisms, and thereby to a more realistic representation of the actual climate system (Flato et al., 2013). Nevertheless, multimodel analyses demonstrate that even current climate models diverge, as shown by the intermodel differences in century-scale climate projections (see Fig. 1.10), which peak in the Arctic region. This suggests that the uncertainty in the simulated Arctic climate is substantial and larger than in other parts of the globe.

We examined the mean state of Arctic sea ice and its effect on the intermodel spread in century-scale projections of Arctic warming. For that purpose, we used idealized simulations of an ensemble of 33 state-of-the-art global climate models that contributed to the Coupled Model Intercomparison Project Phase 5 (CMIP5) (Taylor et al., 2012), in which the atmospheric $\mathrm{CO}_{2}$ concentration was uniformly increased by $1 \%$ per year.

Our results reveal that the mean state of sea ice varies considerably among the various models. We also found that on the Arctic mean spatial scale, the intermodel spread in temperature trends is only weakly related to the initial sea ice volume or area. However, the pattern of simulated Arctic warming is associated with the spatial distribution of initial sea ice. We therefore recommend to consider regional patterns of (winter) sea ice distributions in climate model validation, because it was found that these could be used to constrain projected Arctic warming.

Besides being beneficial for simulations of long-term temperature trends, a realistic spatial distribution of sea ice will likely help to obtain a better representation of related physical processes. For instance, state-of-the-art global climate models were generally unable to correctly simulate the recent strong sea ice retreat in the Arctic (Rampal et al., 2011; Stroeve et al., 2012a). However, 
a recent study showed that the minimum extent of Arctic sea ice (in September) could be accurately predicted from the melt pond area in spring (Schröder et al., 2014). The implementation of more complex parameterizations of the physics involved in the formation of melt ponds (e.g., Hunke et al., 2013) might, therefore, also improve projections of sea ice area trends in the longer term, due to a better representation of the ice-albedo feedback. Bitz et al. (2012) demonstrates that the two models that best capture the observed sea ice trends employ the most advanced sea ice dynamics. For this reason, a too simplistic sea ice representation can be a justified reason to downweight the Arctic climate change projection of a specific model (Räisänen, 2007). Furthermore, a number of studies show that sea ice anomalies affect the local and large-scale atmospheric circulation (Magnusdottir et al., 2004; Alexander et al., 2004), suggesting that the impact of improving sea ice dynamical processes extends well beyond the Arctic.

Q2 What feedback mechanisms contribute to Arctic amplification, and to what extent?

Processes behind the intermodel spread are not necessarily the same physical mechanisms that contribute primarily to Arctic warming, but there might be considerable overlap. The same feedbacks that amplify Arctic climate change might account for a part of the differences in climate model projections of Arctic temperature trends. In the following, we therefore concentrate on physical processes that reinforce Arctic warming.

One of the mechanisms potentially contributing to Arctic warming concerns enhanced ocean heat transport into the Arctic. Most climate models project an increase in oceanic energy transport towards higher latitudes in future climate projections, but the physical mechanisms involved are not yet fully understood (Hwang et al., 2011). To obtain a more fundamental understanding of the processes that cause the ocean heat transport to increase, we carried out a set of sensitivity experiments with a coupled atmosphere-ocean general circulation model (AOGCM) (Chapter 3). Within these experiments, atmospheric $\mathrm{CO}_{2}$ levels are instantaneously set to one-fourth to four times current values, resulting in considerable differences in surface air temperature between the resulting quasi-equilibrium climate states. Our results reveal that poleward ocean heat transport in the Atlantic sector of the Arctic at $70^{\circ} \mathrm{N}$ increases from $0.03 \mathrm{PW}$ (petawatt) in the coldest climate to $0.2 \mathrm{PW}$ in the warmest climate. This in- 
crease is caused primarily by changes in sea ice cover, in the horizontal ocean currents owing to anomalous surface winds in response to sea ice changes, and in ocean advection of thermal anomalies. Hence, the Atlantic heat inflow becomes larger because the temperature of the water is higher, but also because the volume transport increases. This combination of effects has also been found in an ensemble of future scenario simulations by Koenigk and Brodeau (2014).

Even though ocean heat transport increases in warmer climates, the magnitude of Arctic amplification does not vary substantially among the various simulations. This can be attributed, at least partly, to a reduced atmospheric heat transport in warmer climates, counteracting the enhanced poleward oceanic heat transport. Even though the differences in net (atmosphere + ocean) northward heat transport between the various quasi-equilibrium climates are small, the enhanced ocean heat transport still affects Arctic changes, mainly because the Arctic climate system responds differently to changes in ocean heat transport compared to those in the atmosphere. For instance, enhanced oceanic heat inflow likely triggers substantial and direct changes in sea ice and the associated feedback mechanisms that amplify Arctic warming. The dynamical coupling between the energy transports in the atmosphere and the ocean, in conjunction with their differential effects on regional Arctic feedback processes, should therefore be taken into account when assessing the causes behind Arctic amplification.

To better understand the effects of changes in ocean circulation on the Arctic climate system, the analysis can be extended by exploring the seasonality of the response (and the associated mechanisms). This is shown to be a vital aspect concerning the decadal variability of Arctic amplification (Chapter 5), and might even be important for equilibrium climate changes.

At subpolar latitudes, the North Atlantic subpolar gyre is found to weaken toward both the warmer and the colder climates, relative to the current climate. This nonlinear response is due to a complex interplay between seasonal sea ice melt, the near-surface wind response to sea ice changes, and changes in the density-driven circulation.

The response of the subpolar gyre to climate change and its effect on ocean heat transport at $70^{\circ} \mathrm{N}$ is, however, likely model dependent. For instance, Jungclaus et al. (2014) found a strengthening subpolar gyre as a result of 20th-century warming, which they identified as the (downstream) driving mechanism for the warming of Atlantic waters flowing toward the Arctic. In contrast, our results depict a weakening of the subpolar gyre with climate 
warming, which shows that the subpolar gyre response to climate warming is fundamentally different between models. Moreover, our results show an increased ocean heat transport into the Arctic despite a weaker subpolar gyre, and a weaker ocean heat transport at subpolar latitudes. This means that the subpolar gyre does not govern the simulated ocean heat transport into the Arctic basin.

The Atlantic Meridional Overturning Circulation (AMOC) and its associated heat transport even oppose the total ocean heat transport into the Arctic in the warmest climate. Going from warm to cold climates, or from high to low $\mathrm{CO}_{2}$ concentrations, the strength of the AMOC initially increases. The AMOC strength peaks in the second-coldest ( $50 \%$ of present-day $\mathrm{CO}_{2}$ concentration) climate state, but then declines toward the coldest climate, implying a nonlinear AMOC-response to $\mathrm{CO}_{2}$-induced climate change.

A slowdown of the AMOC is a common feature in 21st-century climate model projections (Cheng et al., 2013), and has been shown in a paleoclimate context for the high greenhouse Eocene climate as well (Huber and Sloan, 2001). Although an AMOC slowdown is generally associated with reduced northward heat transport and consequent cooling in the high northern latitudes (Cheng et al., 2007), our results clearly show that the AMOC is of minor importance for $\mathrm{CO}_{2}$-induced changes in the total ocean heat transport toward the Arctic region.

Under Last Glacial Maximum (LGM)-like $\mathrm{CO}_{2}$ forcing, without adjusting other boundary conditions, the modeled AMOC strengthens compared to the current climate. This finding contrasts with proxy data that indicate a (slight) AMOC decline during glacial maxima (Lynch-Stieglitz et al., 2007; Hesse et al., 2011), although a glacial overturning circulation at least as strong as today was derived from studying a different paleoclimate proxy (Böhm et al., 2015). The most recent Paleoclimate Model Intercomparison Project (PMIP3) simulations, which include glacial boundary conditions, also consistently exhibit a stronger and deeper Atlantic overturning cell (Muglia and Schmittner, 2015), in agreement with our model results. Since the LGM climate is considered an important test case for fully coupled AOGCMs used to make climate projections, it is vital to understand the discrepancy between models and observations in the oceanic response to climate change. The strengthened AMOC in our model simulation with reduced $\mathrm{CO}_{2}$ levels indicates that a stronger AMOC in LGM simulations is likely not only caused by glacial boundary conditions but by $\mathrm{CO}_{2}$ forcing as well. However, this contradicts the results of Klockmann et al. (2016), which show a decrease in the AMOC following a reduction in greenhouse gas forcing, point- 
ing to differences between models and model physics as a possible cause for this discrepancy. This clearly illustrates the importance of comparing multiple climate models to test the robustness of modeling results.

\subsection{Low-frequency Arctic climate variability}

This section summarizes and discusses the key findings concerning decadalscale Arctic natural climate variability as presented in Chapters 4 and 5.

Q3 What are the causes and governing mechanisms of Arctic low-frequency climate variability?

On all time scales, surface temperature changes tend to be larger in the Arctic than anywhere else on Earth (Serreze and Barry, 2011). This applies to equilibrium changes, but also to changes that are related to low-frequency variability on decadal to multidecadal timescales. The driving mechanisms behind natural decadal variability in the Arctic region are, however, not yet fully understood. Multicentury climate model simulations are required to assess the influence of low-frequency variability (Stott et al., 2010).

In Chapter 4, we investigate the processes that contribute to Arctic decadal natural variability in a 500-yr long simulation. The associated spatial pattern reveals that this type of variability peaks over the Barents Sea region. We show that the ocean leads the changes in surface air temperature by transporting heat northward prior to the warm phase. Seasonally-dependent heat and radiative surface fluxes transfer excess heat toward the atmosphere, reducing the meridional temperature gradient, and thereby the poleward atmospheric heat transport. Remarkably, the Atlantic meridional overturning explains only $16 \%$ of the decadal variability, implying that gyre transport and/or vertical temperature stratification are likely more important in explaining the ocean heat transport anomalies.

Chapter 5 clearly shows that ocean heat transport is firmly associated with Arctic decadal variability, and reveals that the seasonal cycle in ocean heat transport is crucial. Summertime ocean heat transport toward the Arctic leads the changes in decadal variability, whereas the winter transport lags the variations in the Arctic temperature and is of opposite sign. The simulations do not reveal, however, whether the ocean is the driving force behind Arctic decadal 
variability since it is also possible that the ocean only modulates the response. The summertime ocean heat transport appears to be driven partly by variations in atmospheric forcing that exhibit a North Atlantic Oscillation (NAO)like structure, which is generally related to the temperature and volume of the Atlantic water inflow into the Arctic Ocean (e.g., Dickson et al., 2000).

Sea ice governs the seasonal response by acting as a lid that opens and closes during warm and cold periods, respectively, thereby strongly modulating the surface fluxes between the ocean and the atmosphere. Although the ocean seems to determine the timing of variability, sea ice acts as a signal amplifier and thereby largely controls the location of maximum variability. The spatial distribution of Arctic climate variability is strongly model dependent, especially since the location of the sea ice edge varies widely among climate models. This result once again highlights that an accurate simulation of the spatial distribution of sea ice is important, not only for long-term temperature trends (Chapter 2) but also in terms of decadal variability.

We thus recommend exploring in more detail the processes behind ocean heat transport toward the Arctic during decadal cycles of variability, similar to the analyses in Chapter 3 with regard to changes in the mean climate state. This can be achieved by focusing on the longitudinally dependent heat transport at the entrances of the Arctic, and by separating the respective contributions of volume flux and temperature stratification. Additionally, vertical profiles of temperature and salinity can provide more insight into the spatial mechanisms. Further downstream, it would be interesting to assess the effect of the subpolar gyre (spatial distribution, magnitude) on the northward ocean heat transport into the Arctic over decadal cycles.

\section{Q4 How does Arctic low-frequency climate variability change in a warming world?}

So far, we studied mechanisms underlying natural climate variability in the pre-industrial climate state. However, the Arctic is warming at a fast rate, and the amount of sea ice is rapidly retreating and thinning. This means that the background climate on which the natural variability is superimposed is changing, which raises the question whether the low-frequency variability will also change. In other words, are the natural climate variations in the Arctic climate dependent?

Our climate model sensitivity simulations show that the relationship between sea ice and temperature variability changes nonlinearly when the climate 
warms. Temperature and ice area variability increase in winter in a simulation where the atmospheric $\mathrm{CO}_{2}$ concentration is doubled with respect to today. The dominant region of variability, currently located over the Barents Sea and the Greenland Sea, shifts to the central Arctic and Siberian regions towards warmer climates, along with the sea ice margin. Currently, ice area fractions over the central Arctic range from $\sim 85 \%$ in late summer to $~ 99 \%$ in winter. Continued thinning will render the sea ice cover more vulnerable to warm episodes, meaning that vast stretches can melt more easily, leading to substantial sea ice area fluctuations. In turn, the receding sea ice cover causes an amplification of the temperature changes owing to the ice-albedo feedback. In the simulation where the climate becomes so warm that all sea ice has disappeared the temperature variability over the Arctic region is strongly diminished, as all the icerelated feedback mechanisms cease to exist. Related to this, Goosse et al. (2009) found an increased variability of the Arctic summer ice extent when the climate warms. They found that the distance between the ice edge and the coastline is an important contributor to the increased variability. Under current climate conditions, the most sensitive sea ice concentration regions would hypothetically be located over the continents (if there were sea), but in warmer climates with reduced sea ice cover, the potential for decadal variations in sea ice extent to govern climate variability is considerably larger (Eisenman, 2010). The decadal variability first increases in summer, and in even warmer climates, for which the sea ice retreats even further, winter variability is enhanced as well.

The increase in ice extent variability toward warmer climates is especially relevant because this is the climate state where the current trajectory in radiative forcing is directed to. For instance, the rapidly shrinking sea ice cover in the Arctic (Stroeve et al., 2012b) might be due to anthropogenic change reinforced by an intensified internal variability. However, it is hard to separate anthropogenic (forced) trends from (unforced) decadal internal variability, since observation-based estimates either are too short or have a too low temporal resolution (especially proxy data) to capture decadal variability fully. Model simulations are therefore an appropriate and indispensable tool to study Arctic variability, its governing mechanisms, and its relation to trends. Depending on the phase of the low-frequency fluctuations, they can either enhance or suppress long-term trends in the Arctic climate system, which is relevant for the attribution studies concerning Arctic climate change and human-activities-induced climate forcing. Since climate warming and retreating sea ice are associated with increased decadal variability (and also shifts in the peak regions), it is of vital importance to consider (changes in) 
decadal variability when quantifying trends in Arctic warming using model simulations or observations.

Simulations suggest that the mean large-scale atmospheric circulation will change toward warmer climates, with intensified Aleutian (winter) and Icelandic Lows (summer). Moreover, the variability of the atmospheric circulation changes as well, and also its impact on surface air temperature anomalies. The dominant mode of atmospheric variability in the Arctic is the Arctic Oscillation (AO) (Thompson and Wallace, 1998). In the AOGCM EC-Earth, a positive AO index is associated with a warmer Arctic and reduced sea ice in the current climate, consistent with earlier studies (e.g., Holland, 2003; Goosse and Holland, 2005). In our simulations of warmer-than-present climates, the difference in temperature response between the Eurasian and Canadian sectors of the Arctic region remains, but the transition region between positive and negative temperature anomalies associated with the AO shifts toward Siberia. This suggests that the contribution to Arctic decadal variability of the various modes of atmospheric surface pressure depends on the background climate state. These differing contributions are likely related to the strength and location of the centers of action over the Pacific and Atlantic Oceans. In warmer climates, the Pacific center intensifies and shifts northwestward, whereas the influence of the Atlantic center reduces considerably, showing that the variability associated with the atmospheric circulation varies with the background climate.

Moreover, different atmospheric modes (the Arctic Dipole Anomaly, the Aleutian Low, and the AO) govern the variability in winter surface air temperature associated with subsequent stages of warming. Also, links between atmospheric circulation modes and Arctic climate variability may change as the climate warms, meaning that transitions between stationary circulation types determining Arctic variability can be expected when the climate system continues to warm. Changes in the variability of the atmospheric circulation are associated with oceanic and atmospheric poleward heat transport anomalies. There are strong indications that the summer oceanic heat transport leads Arctic decadal variability in the current and $\mathrm{CO}_{2}$ doubling climates, in agreement with results of Goosse and Holland (2005) and Zhang (2015), whereas the winter atmospheric heat transport plays a more important role in the $\mathrm{CO}_{2}$-quadrupling climate. Subsequent research could be focused on understanding the finer details of the ocean (which we previously discussed) and atmospheric heat transports toward the Arctic during the various phases of decadal climate variability. 
An important research topic related to simulated changes in the atmospheric modes concerns the impact of Arctic warming on midlatitudes. Of particular interest are extreme weather events, such as winter cold spells and summer droughts and heatwaves, since these can have severe societal and economic consequences in the midlatitudes, including Western Europe. In recent years, several atmospheric connections between Arctic warming and extreme events in midlatitudes have been investigated, such as those concerning changes in storm tracks, in the jet stream, and in planetary waves (Cohen et al., 2014). These connections remain, however, still controversial and highly uncertain (Barnes and Polvani, 2015). The results of Chapter 5 clearly demonstrate that future Arctic climate variability is associated with changes in the large-scale atmospheric circulation. Future progress could be made by improving process understanding of the simulated changes, and by assessing their impact on the midlatitude climate.

\subsection{Outlook}

Arctic amplification is one of the outstanding features of ongoing and projected climate change. Throughout this thesis, Arctic amplification is assessed in equilibrium (Chapter 3) and transient (Chapter 2) climate settings, as well as in the framework of decadal-scale internal variability (Chapter 4 and 5). Furthermore, we have examined Arctic amplification in simulations of warm and cold climates. By analyzing these simulations, we focused on the role of coupled oceansea-ice-atmosphere processes on the long-term trends and decadal variability of the Arctic climate system. Important mechanisms linked to the location of the sea ice margin and ocean heat transports into the Arctic have been identified and were shown to have a substantial effect on the Arctic's response to climate change. However, we also identified some interesting physical processes and links that could be explored further. Based on these findings we will provide recommendations for future research.

First, in Chapters 3 and 5, only one AOGCM is used in specific sensitivity simulations. By using only one climate model we could concentrate on process understanding, without having to deal with uncertainties related to structural differences in climate model design. The obvious disadvantage of this approach is that the results may be (partially) dependent on the specific physics and parameterizations in the model that was used. Further research with other cou- 
pled climate models into these mechanisms is, therefore, necessary to corroborate the results.

Although it is clear that the Arctic region undergoes rapid changes, it is as of yet unclear what causes behind these changes are. Attribution studies seek to determine what external drivers affect climate change, and to what extent natural climate fluctuations affect the changes. The attribution of regional Arctic climate change is generally hampered by a comparatively large natural climate variability, with the paucity of observations in most of the Arctic adding to the incomplete understanding of its contribution (Hegerl and Stott, 2014). Therefore, the magnitude of natural variability has to be estimated using climate model simulations (Stott et al., 2010). In the standard approach of these attribution studies, such estimates are made using the current state of the climate system. However, the climate system is changing rapidly, especially in the Arctic. We therefore believe that the standard attribution methods should be refined by quantifying natural variability in future climate states and taking into account changes in the pattern and magnitude of natural climate variability. This, in turn, will likely lead to more accurate projections of future climate change. For example, the results in Chapter 5 reveal that the amplitude of Arctic decadal variability will initially increase in a warming climate, which thus might to a larger extent contribute to a certain trend compared to natural variability in the current climate state. Separating natural from human-induced effects in future climates is vital information for policymakers who are faced with issues surrounding mitigation of climate change.

Changes in ocean heat transport toward the Arctic have been found to trigger decadal variability in surface air temperature and sea ice (Chapters 4 and 5), suggesting the possibility that knowledge of the ocean state might provide predictive power concerning Arctic changes (Solomon et al., 2011). The idea behind decadal prediction is that if climate models can somehow capture the slow natural fluctuations of the climate system, an initialization using ocean observations might result in accurate near-term decadal forecasts (Meehl et al., 2007). For instance, such a decadal prediction approach might provide clues concerning the rate at which Arctic sea ice will decline in response to ocean processes. However, decadal prediction studies are still in their infancy. Even on seasonal timescales, for which prediction techniques have been more commonly applied, predictions are still riddled with considerable uncertainty (Krikken et al., 2016). In further research, other predictors should be investigated as well, such as those related to relevant aspects of the large-scale atmospheric circulation. Predicting changes in sea ice conditions is valuable for a vast array of economic activi- 
ties in the Arctic, such as the fishing industry, the offshore extraction of oil and gas, shipping, and tourism, because the variability of Arctic sea ice invokes substantial uncertainties and risks in operation planning (Stephenson et al., 2013).

Aside from the connection between the mean state in sea ice and temperature trends we also addressed the linear relationships between the mean state and trends in some other climatic variables. Our results suggest that, at least in the Arctic, the ability of a climate model to accurately simulate present-day temperature is not a sufficient constraint on its ability to correctly simulate future temperature trends. However, Räisänen et al. (2010) shows that the January mean surface temperature in the high-latitude North Atlantic and North Pacific oceans significantly correlates with January 21st-century temperature changes over those regions, which can likely be attributed to sea-ice-related feedbacks. This finding suggests that regional variables might be more suitable predictors in terms of Arctic climate change than their large-scale mean counterparts. On the other hand, we found it is necessary to reduce the spread in simulated sea ice volume in the present-day climate in order to improve long-term projections of sea ice volume loss. These examples clearly illustrate that the relation between the simulated mean state and projected trends of certain quantities strongly depend on the selected predictor and response variables. This raises the question whether global tuning of climate models will yield reliable projections. Perhaps tuning on regional variables would be more effective. Subsequent research should, therefore, focus on the sensitivity of the climate system to the selection of tuning targets. This might reduce the number of constraints for reliable climate projections, or it might mean that other (e.g. regional) variables will give better results.

Climate models become more and more advanced over time. State-of-theart Earth System Models (ESMs) include interactive carbon cycle feedbacks, and are driven by $\mathrm{CO}_{2}$ emissions rather than prescribed atmospheric $\mathrm{CO}_{2}$ concentrations (Friedlingstein et al., 2014). The complexity of the simulated carbon cycle in different models is strongly varying, in particular with respect to ocean biogeochemistry and land surface processes (Simmons et al., 2016). Furthermore, several ESMs have the possibility to simulate interactions with additional components, such as dynamic vegetation, a nitrogen cycle, and/or interactive ice sheets. This development opens up new opportunities for studying other types of feedbacks in the Arctic climate system. Using ESMs, it could be of interest to examine the effect of vegetation changes on Arctic warming (Swann et al., 2010; Pearson et al., 2013). For example, if higher temperatures lengthen the (subpolar) growing season, more vegetation might be able to survive and take 
up more carbon dioxide from the air. On the other hand, vegetation changes also alter the reflectivity of the surface, e.g. tundra being replaced by forest, which would be a positive feedback because the albedo of trees is relatively low. An additional effect of vegetation is the increased evapotranspiration of water vapor which would reinforce the greenhouse effect, as atmospheric water vapor absorbs infrared radiation. Also, the geophysical feedback concerning various pigments in phytoplankton absorbing solar radiation differently may alter sea surface temperatures and affect sea ice changes (Park et al., 2015). Furthermore, ESMs enable one to study the permafrost carbon feedback (Schuur et al., 2015). Thawing permafrost may accelerate the microbial conversion of organic carbon into greenhouse gases (carbon dioxide and methane), which in turn accelerate climate warming, which is thus a positive climate feedback. The addition of an ice sheet component to AOGCMs provides the possibility to assess the effects of Arctic warming on melting of the Greenland ice sheet and smaller Arctic ice caps and glaciers, including their impact on eustatic sea level rise (Huybrechts et al., 2011; Vizcaíno et al., 2014). On longer, multicentury timescales this will introduce additional dynamical feedback mechanisms since the Greenland ice sheet affects the large-scale atmospheric circulation owing to its high surface elevation, and the ocean circulation through altered runoff and freshwater input (Stammer, 2008). Also, parameterizations in AOGCMs improve further, for example by including more realistic schemes for polar clouds, which would ultimately lead to a better understanding of the Arctic cloud feedback. Recent developments that led to a better representation of low-level Arctic clouds include a formula that accounts for freeze-drying, and improved parameterizations of cloud microphysics and boundary layer turbulence (Barton et al., 2012). Additionally, the incorporation of more advanced sea ice dynamics likely leads to a better model performance in the Arctic region (Bitz et al., 2012).

Furthermore, computing power increases, which provides opportunities for running climate models at finer resolutions. Recent simulations have shown that high-resolution simulations warm more rapidly in response to increasing $\mathrm{CO}_{2}$ levels than low-resolution simulations, with the differences peaking in the Arctic region (Kirtman et al., 2012; Delworth et al., 2012). Apparently, models that run on finer grids more accurately resolve physical processes relevant for the Arctic climate. For instance, high-resolution simulations improve the ocean circulation concerning currents through narrow straits, such as the Bering Strait and Fram Strait. Furthermore, sea ice dynamics, the transport of sea ice within the Arctic and exports through Fram Strait, as well as deformation processes of sea ice, are considerably better represented using finer model grids (Gent et al., 
2010). Also, possible influences of Arctic climate change on the midlatitude atmospheric circulation can be better resolved in high-resolution AOGCMs.

The paucity of observations in the Arctic region, particularly over the Arctic Ocean, is another important (limiting) aspect in Arctic climate research. Improving the number and quality of observations would significantly advance our understanding of the Arctic climate system, and would also yield better constraints for climate model validation. Sustained observations will improve our knowledge of natural decadal variability, simply because the length of the time series increases and more decadal cycles can be captured. Furthermore, additional measurements of 'new' climatic variables might provide novel insights into the Arctic climate system. As an example, Arctic-wide observations of sea ice thickness since 2003 have revealed a rapid thinning of the total Arctic sea ice cover (Kwok and Rothrock, 2009). Since these measurements include the entire Arctic region, they provide valuable insight into the total volume loss of sea ice, which is important with respect to changes in the Arctic energy balance. Finally, more and better observations of surface air temperature over the fast-warming and sea-ice-covered Arctic Ocean would constitute a significant step forward.

This research helped to improve our understanding of observed Arctic changes and to better constrain climate model projections for the Arctic, which may be used by policymakers to make decisions concerning the adaptation to and mitigation of climate change, both in the Arctic region and globally. Increasing computing power, improving quality of AOGCMs, and better observations will ultimately lead to a more accurate assessment of the drivers of Arctic amplification. Ongoing changes in the Arctic will undoubtedly keep this remote region in the spotlight of climate science for decades to come. 



\section{Bibliography}

Aagaard, K., L. K. Coachman, and E. Carmack (1981). On the halocline of the Arctic Ocean, Deep Sea Research Part A, Oceanographic Research Papers, 28 (6), 529-545.

Aagaard, K., J. H. Swift, and E. C. Carmack (1985). Thermohaline circulation in the Arctic Mediterranean Seas, Journal of Geophysical Research, 90 (C3), 4833-4846.

ACIA (2005). Arctic Climate Impact Assessment, Cambridge University Press.

Alexander, M. A., U. S. Bhatt, J. E. Walsh, M. S. Timlin, J. S. Miller, and J. D. Scott (2004). The atmospheric response to realistic Arctic sea ice anomalies in an AGCM during winter, Journal of Climate, 17 (5), 890-905.

AMAP (1998). Assessment Report: Arctic Pollution Issues, Tech. rep., Arctic Monitoring and Assessment Programme (AMAP), Oslo, Norway.

Anklin, M., J. Schwander, B. Stauffer, J. Tschumi, A. Fuchs, J. M. Barnola, and D. Raynaud (1997). $\mathrm{CO}_{2}$ record between 40 and $8 \mathrm{kyr}$ B.P. from the Greenland Ice Core Project ice core, Journal of Geophysical Research, 102 (C12), 26539-26545.

Arrhenius, S. (1896). On the influence of carbonic acid in the air upon the temperature of the ground, Philosophical Magazine and Journal of Science, 41, 237-279.

Årthun, M. and C. Schrum (2010). Ocean surface heat flux variability in the Barents Sea, Journal of Marine Systems, 83 (1-2), 88-98.

Arzel, O., T. Fichefet, and H. Goosse (2006). Sea ice evolution over the 20th and 21st centuries as simulated by current AOGCMs, Ocean Modelling, 12 (3-4), 401-415.

Ayarzagüena, B. and J. A. Screen (2016). Future Arctic sea ice loss reduces severity of cold air outbreaks in midlatitudes, Geophysical Research Letters, 43, 2801-2809.

Barnes, E. A. and L. Polvani (2013). Response of the midlatitude jets, and of their variability, to increased greenhouse gases in the CMIP5 models, Journal of Climate, 26 (18), 7117-7135.

Barnes, E. A. and L. M. Polvani (2015). CMIP5 projections of Arctic amplification, of the North American/North Atlantic circulation, and of their relationship, Journal of Climate, 28 (13), 5254-5271. 
Barnes, E. A. and J. A. Screen (2015). The impact of Arctic warming on the midlatitude jet-stream: Can it? Has it? Will it?, Wiley Interdisciplinary Reviews: Climate Change, 6 (3), 277-286.

Barnhart, K. R., I. Overeem, and R. S. Anderson (2014). The effect of changing sea ice on the physical vulnerability of Arctic coasts, Cryosphere, 8 (5), 1777-1799.

Barton, N. P., S. A. Klein, J. S. Boyle, and Y. Y. Zhang (2012). Arctic synoptic regimes: Comparing domain-wide Arctic cloud observations with CAM4 and CAM5 during similar dynamics, Journal of Geophysical Research, 117, D15205.

Beerling, D. J. and D. L. Royer (2011). Convergent Cenozoic $\mathrm{CO}_{2}$ history, Nature Geoscience, 4 (7), 418-420.

Beitsch, A., J. H. Jungclaus, and D. Zanchettin (2014). Patterns of decadal-scale Arctic warming events in simulated climate, Climate Dynamics, 43, 1773-1789.

Bekryaev, R. V., I. V. Polyakov, and V. A. Alexeev (2010). Role of polar amplification in long-term surface air temperature variations and modern Arctic warming, Journal of Climate, 23 (14), 3888-3906.

Bengtsson, L., V. A. Semenov, and O. M. Johannessen (2004). The early twentiethcentury warming in the Arctic - A possible mechanism, Journal of Climate, 17 (20), 4045-4057.

Bindoff, N., P. Stott, K. AchutaRao, M. Allen, N. Gillett, D. Gutzler, K. Hansingo, G. Hegerl, Y. Hu, S. Jain, I. Mokhov, J. Overland, J. Perlwitz, R. Sebbari, and X. Zhang (2013). Detection and Attribution of Climate Change: from Global to Regional, in T. Stocker, D. Qin, G.-K. Plattner, M. Tignor, S. Allen, J. Boschung, A. Nauels, Y. Xia, V. Bex, and P. Midgley, eds., Climate Change 2013: The Physical Science Basis. Contribution of Working Group I to the Fifth Assessment Report of the Intergovernmental Panel on Climate Change, Cambridge University Press, Cambridge, United Kingdom and New York, NY, USA, pp. 867-952.

Bintanja, R., R. G. Graversen, and W. Hazeleger (2011). Arctic winter warming amplified by the thermal inversion and consequent low infrared cooling to space, Nature Geoscience, 4 (11), 758-761.

Bintanja, R. and F. M. Selten (2014). Future increases in Arctic precipitation linked to local evaporation and sea-ice retreat, Nature, 509 (7501), 479-482.

Bintanja, R. and E. C. van der Linden (2013). The changing seasonal climate in the Arctic, Scientific Reports, 3 (1556).

Bitz, C. (2008). Some aspects of uncertainty in predicting sea ice thinning, in E. DeWeaver, C. M. Bitz, and B. Tremblay, eds., AGU Geophysical Monograph Series, American Geophysical Union, pp. 63-76.

Bitz, C., J. Ridley, and M. Holland (2012). Global climate models and 20th and 21st century Arctic climate change, in P. Lemke and H. W. Jacobi, eds., Arctic Climate Change: The ACSYS Decade and Beyond, chap. 11, Springer, Dordrecht and New York, pp. 405436. 
Bitz, C. M., P. R. Gent, R. A. Woodgate, M. M. Holland, and R. Lindsay (2006). The influence of sea ice on ocean heat uptake in response to increasing $\mathrm{CO}_{2}$, Journal of Climate, 19 (11), 2437-2450.

Bitz, C. M., M. M. Holland, E. C. Hunke, and R. E. Moritz (2005). Maintenance of the sea-ice edge, Journal of Climate, 18 (15), 2903-2921.

Bitz, C. M. and G. H. Roe (2004). A mechanism for the high rate of sea ice thinning in the Arctic Ocean, J. Climate, 17, 3623-3632.

Bjerknes, J. (1964). Atlantic air-sea interaction, Advances in geophysics, 10, 1-82.

Blanchard-Wrigglesworth, E., K. C. Armour, C. M. Bitz, and E. DeWeaver (2011). Persistence and inherent predictability of Arctic sea ice in a GCM ensemble and observations, Journal of Climate, 24 (1), 231-250.

Blunden, M. (2012). Geopolitics and the Northern Sea Route, International Affairs, 88 (1), 115-129.

Boé, J., A. Hall, and X. Qu (2009). Current GCMs' unrealistic negative feedback in the Arctic, Journal of Climate, 22 (17), 4682-4695.

Böhm, E., J. Lippold, M. Gutjahr, M. Frank, P. Blaser, B. Antz, J. Fohlmeister, N. Frank, M. B. Andersen, and M. Deininger (2015). Strong and deep Atlantic meridional overturning circulation during the last glacial cycle, Nature, 517 (7534), 73-76.

Boisvert, L. N. and J. C. Stroeve (2015). The Arctic is becoming warmer and wetter as revealed by the Atmospheric Infrared Sounder, Geophysical Research Letters, 42 (11), 4439-4446.

Booth, B. B. B., N. J. Dunstone, P. R. Halloran, T. Andrews, and N. Bellouin (2012). Aerosols implicated as a prime driver of twentieth-century North Atlantic climate variability, Nature, 484 (7393), 228-232.

Born, A. and T. F. Stocker (2013). Two stable equilibria of the Atlantic subpolar gyre, Journal of Physical Oceanography, 44 (1), 246-264.

Bouillon, S., M. A. Morales Maqueda, V. Legat, and T. Fichefet (2009). An elastic-viscousplastic sea ice model formulated on Arakawa B and C grids, Ocean Modelling, 27 (3-4), 174-184.

Bowen, G. J., T. J. Bralower, M. L. Delaney, G. R. Dickens, D. C. Kelly, P. L. Koch, L. R. Kump, J. Meng, L. C. Sloan, E. Thomas, S. L. Wing, and J. C. Zachos (2006). Eocene hyperthermal event offers insight into greenhouse warming, Eos, Transactions American Geophysical Union, 87 (17), 165-169.

Braconnot, P., S. P. Harrison, M. Kageyama, P. J. Bartlein, V. Masson-Delmotte, A. AbeOuchi, B. Otto-Bliesner, and Y. Zhao (2012). Evaluation of climate models using palaeoclimatic data, Nature Climate Change, 2 (6), 417-424.

Brigham-Grette, J. (2009). Contemporary Arctic change: a paleoclimate déjà vu?, Proceedings of the National Academy of Sciences, 106 (44), 18431-18432.

Bryan, K. (1982). Poleward heat transport by the ocean: observations and models, Annual Review of Earth and Planetary Sciences, 10, 15-38. 
Budikova, D. (2009). Role of Arctic sea ice in global atmospheric circulation: A review, Global and Planetary Change, 68 (3), 149-163.

Cai, M. (2006). Dynamical greenhouse-plus feedback and polar warming amplification. Part I: A dry radiative-transportive climate model, Climate Dynamics, 26 (7-8), 661 675.

Caldeira, K. and N. P. Myhrvold (2013). Projections of the pace of warming following an abrupt increase in atmospheric carbon dioxide concentration, Environmental Research Letters, 8 (3), 034039.

Carmack, E., I. Polyakov, L. Padman, I. Fer, E. Hunke, J. Hutchings, J. Jackson, D. Kelley, R. Kwok, C. Layton, H. Melling, D. Perovich, O. Persson, B. Ruddick, M. L. Timmermans, J. Toole, T. Ross, S. Vavrus, and P. Winsor (2015). Toward quantifying the increasing role of oceanic heat in sea ice loss in the new Arctic, Bulletin of the American Meteorological Society, 96 (12), 2079-2105.

Carmack, E. C., M. Yamamoto-Kawai, T. W. N. Haine, S. Bacon, B. A. Bluhm, C. Lique, H. Melling, I. V. Polyakov, F. Straneo, M.-L. Timmermans, and W. J. Williams (2016). Freshwater and its role in the Arctic Marine System: Sources, disposition, storage, export, and physical and biogeochemical consequences in the Arctic and global oceans, Journal of Geophysical Research: Biogeosciences, 121 (3), 675-717.

Cavalieri, D. J. and C. L. Parkinson (2012). Arctic sea ice variability and trends, 19792010, Cryosphere, 6 (4), 881-889.

Cheng, W., C. M. Bitz, and J. C. H. Chiang (2007). Adjustment of the global climate to an abrupt slowdown of the Atlantic meridional overturning circulation, in A. Schmittner, J. C. H. Chiang, and S. R. Hemming, eds., AGU Geophysical Monograph Series, American Geophysical Union, pp. 295-313.

Cheng, W., J. C. H. Chiang, and D. Zhang (2013). Atlantic meridional overturning circulation (AMOC) in CMIP5 Models: RCP and historical simulations, Journal of Climate, 26 (18), 7187-7197.

Chevallier, M. and D. Salas-Mélia (2012). The role of sea ice thickness distribution in the Arctic sea ice potential predictability: A diagnostic approach with a coupled GCM, Journal of Climate, 25 (8), 3025-3038.

Choi, D. H., J. S. Kug, W. T. Kwon, F. F. Jin, H. J. Baek, and S. K. Min (2010). Arctic Oscillation responses to greenhouse warming and role of synoptic eddy feedback, Journal of Geophysical Research, 115, D17103.

Chylek, P., C. K. Folland, G. Lesins, M. K. Dubey, and M. Wang (2009). Arctic air temperature change amplification and the Atlantic Multidecadal Oscillation, Geophysical Research Letters, 36 (14), 2-6.

Clark, P. U., N. G. Pisias, T. F. Stocker, and A. J. Weaver (2002). The role of the thermohaline circulation in abrupt climate change, Nature, 415 (6874), 863-869.

Cohen, J., J. a. Screen, J. C. Furtado, M. Barlow, D. Whittleston, D. Coumou, J. Francis, K. Dethloff, D. Entekhabi, J. Overland, and J. Jones (2014). Recent Arctic amplification and extreme mid-latitude weather, Nature Geoscience, 7 (August), 627-637. 
Collins, M., R. Knutti, J. Arblaster, J.-L. Dufresne, T. Fichefet, P. Friedlingstein, X. Gao, W. J. Gutowski, T. Johns, G. Krinner, M. Shongwe, C. Tebaldi, A. J. Weaver, and M. Wehner (2013). Long-term Climate Change: Projections, Commitments and Irreversibility, in T. Stocker, D. Qin, G.-K. Plattner, M. Tignor, S. Allen, J. Boschung, A. Nauels, Y. Xia, V. Bex, and P. Midgley, eds., Climate Change 2013: The Physical Science Basis. Contribution of Working Group I to the Fifth Assessment Report of the Intergovernmental Panel on Climate Change, Cambridge University Press, Cambridge, United Kingdom and New York, NY, USA, pp. 1029-1136.

Comiso, J. C. (2003). Warming trends in the Arctic from clear sky satellite observations, Journal of Climate, 16 (21), 3498-3510.

Comiso, J. C. and D. K. Hall (2014). Climate trends in the Arctic as observed from space, Wiley Interdisciplinary Reviews: Climate Change, 5 (3), 389-409.

Comiso, J. C. and F. Nishio (2008). Trends in the sea ice cover using enhanced and compatible AMSR-E, SSM/I, and SMMR data, Journal of Geophysical Research: Oceans, 113, C02S07.

Coumou, D., V. Petoukhov, S. Rahmstorf, S. Petri, and H. J. Schellnhuber (2014). Quasiresonant circulation regimes and hemispheric synchronization of extreme weather in boreal summer, Proceedings of the National Academy of Sciences, 111 (34), 1233112336.

Cowtan, K. and R. G. Way (2014). Coverage bias in the HadCRUT4 temperature series and its impact on recent temperature trends, Quarterly Journal of the Royal Meteorological Society, 140 (683), 1935-1944.

Crook, J. A., P. M. Forster, and N. Stuber (2011). Spatial patterns of modeled climate feedback and contributions to temperature response and polar amplification, Journal of Climate, 24 (14), 3575-3592.

Curry, J. a., J. L. Schramm, and E. E. Ebert (1995). Sea-Ice Albedo Climate Feedback Mechanism.

Curry, W. B. and D. W. Oppo (1997). Synchronous, high-frequency oscillations in tropical sea surface temperatures and North Atlantic Deep Water production during the last glacial cycle, Paleoceanography, 12 (1), 1-14.

Dahl-Jensen, D., K. Mosegaard, N. Gundestrup, G. D. Clow, S. J. Johnsen, A. W. Hansen, and N. Balling (1998). Past Temperatures Directly from the Greenland Ice Sheet, Science, 282, 268-271.

Danabasoglu, G. (2008). On multidecadal variability of the Atlantic meridional overturning circulation in the community climate system model version 3, Journal of Climate, 21 (21), 5524-5544.

Dansgaard, W., S. J. Johnsen, H. B. Clausen, D. Dahl-Jensen, N. S. Gundestrup, C. U. Hammer, C. S. Hvidberg, J. P. Steffensen, Á. E. Sveinbjörnsdóttir, J. Jouzel, and G. C. Bond (1993). Evidence for general instability of past climate from a 250-kyr ice-core record, Nature, 364 (6434), 218-220. 
Day, J. J., J. C. Hargreaves, J. D. Annan, and A. Abe-Ouchi (2012). Sources of multi-decadal variability in Arctic sea ice extent, Environmental Research Letters, 7 (3), 034011.

Dee, D. P., S. M. Uppala, A. J. Simmons, P. Berrisford, P. Poli, S. Kobayashi, U. Andrae, M. A. Balmaseda, G. Balsamo, P. Bauer, P. Bechtold, A. C. M. Beljaars, L. van de Berg, J. Bidlot, N. Bormann, C. Delsol, R. Dragani, M. Fuentes, A. J. Geer, L. Haimberger, S. B. Healy, H. Hersbach, E. V. Hólm, L. Isaksen, P. Kållberg, M. Köhler, M. Matricardi, A. P. Mcnally, B. M. Monge-Sanz, J. J. Morcrette, B. K. Park, C. Peubey, P. de Rosnay, C. Tavolato, J. N. Thépaut, and F. Vitart (2011). The ERA-Interim reanalysis: Configuration and performance of the data assimilation system, Quarterly Journal of the Royal Meteorological Society, 137 (656), 553-597.

Delworth, T. and M. E. Mann (2000). Observed and simulated multidecadal variability in the Northern Hemisphere, Climate Dynamics, 16, 661-676.

Delworth, T. L., A. Rosati, W. Anderson, A. J. Adcroft, V. Balaji, R. Benson, K. Dixon, S. M. Griffies, H. C. Lee, R. C. Pacanowski, G. A. Vecchi, A. T. Wittenberg, F. Zeng, and R. Zhang (2012). Simulated climate and climate change in the GFDL CM2.5 highresolution coupled climate model, Journal of Climate, 25 (8), 2755-2781.

Delworth, T. L., F. Zeng, G. A. Vecchi, X. Yang, L. Zhang, and R. Zhang (2016). The North Atlantic Oscillation as a driver of rapid climate change in the Northern Hemisphere, Nature Geoscience, 9 (7), 509-512.

Deser, C., R. Knutti, S. Solomon, and A. S. Phillips (2012). Communication of the role of natural variability in future North American climate, Nature Climate Change, 2 (11), 775-779.

Dethloff, K., A. Rinke, A. Benkel, M. Køltzow, E. Sokolova, S. Kumar Saha, D. Handorf, W. Dorn, B. Rockel, H. von Storch, J. E. Haugen, L. P. Røed, E. Roeckner, J. H. Christensen, and M. Stendel (2006). A dynamical link between the Arctic and the global climate system, Geophysical Research Letters, 33, L03703.

Dickson, R. R., T. J. Osborn, J. W. Hurrell, J. Meinke, J. Blindheim, B. Adlandsvik, T. Vinje, G. Alekseev, and W. Maslowski (2000). The Arctic Ocean response to the North Atlantic Oscillation, Journal of Climate, 13 (15), 2671-2696.

Dokken, T. M., K. H. Nisancioglu, C. Li, D. S. Battisti, and C. Kissel (2013). DansgaardOeschger cycles: Interactions between ocean and sea ice intrinsic to the Nordic seas, Paleoceanography, 28 (3), 491-502.

Eisenman, I. (2010). Geographic muting of changes in the Arctic sea ice cover, Geophysical Research Letters, 37, L16501.

Fasullo, J. T. and K. E. Trenberth (2008). The annual cycle of the energy budget. Part II: Meridional structures and poleward transports, Journal of Climate, 21 (10), 23132325.

Fetterer, F., K. Knowles, W. Meier, and M. Savoie (2016). Sea Ice Index Version 2.

Fichefet, T. and M. A. Morales Maqueda (1997). Sensitivity of a global sea ice model to the treatment of ice thermodynamics and dynamics, Journal of Geophysical Research, 102 (C6), 12609-12646. 
Flato, G., J. Marotzke, B. Abiodun, P. Braconnot, S. Chou, W. Collins, P. Cox, F. Driouech, S. Emori, V. Eyring, C. Forest, P. Gleckler, E. Guilyardi, C. Jakob, V. Kattsov, C. Reason, and M. Rummukainen (2013). Evaluation of Climate Models, in T. Stocker, D. Qin, G.-K. Plattner, M. Tignor, S. Allen, J. Boschung, A. Nauels, Y. Xia, V. Bex, and P. Midgley, eds., Climate Change 2013: The Physical Science Basis. Contribution of Working Group I to the Fifth Assessment Report of the Intergovernmental Panel on Climate Change, Cambridge University Press, Cambridge, United Kingdom and New York, NY, USA, pp. 741-866.

Flato, G. M. (2004). Sea-ice and its response to $\mathrm{CO}_{2}$ forcing as simulated by global climate models, Climate Dynamics, 23 (3-4), 229-241.

Flato, G. M. (2011). Earth system models: An overview, Wiley Interdisciplinary Reviews: Climate Change, 2 (6), 783-800.

Forbes, D. L., G. S. Parkes, G. K. Manson, and L. A. Ketch (2004). Storms and shoreline retreat in the southern Gulf of St. Lawrence, Marine Geology, 210 (1-4), 169-204.

Ford, J. D. (2009). Dangerous climate change and the importance of adaptation for the Arctic's Inuit population, Environmental Research Letters, 4 (2), 024006.

Francis, J. A. and E. Hunter (2006). New insight into the disappearing Arctic sea ice, Eos, Transactions American Geophysical Union, 87 (46), 509-511.

Francis, J. A. and S. J. Vavrus (2012). Evidence linking Arctic amplification to extreme weather in mid-latitudes, Geophysical Research Letters, 39, L06801.

Frankcombe, L. M. and H. A. Dijkstra (2010). Internal modes of multidecadal variability in the Arctic Ocean, Journal of Physical Oceanography, 40 (11), 2496-2510.

Friedlingstein, P., M. Meinshausen, V. K. Arora, C. D. Jones, A. Anav, S. K. Liddicoat, and R. Knutti (2014). Uncertainties in CMIP5 climate projections due to carbon cycle feedbacks, Journal of Climate, 27 (2), 511-526.

Ganopolski, A. and R. Calov (2011). The role of orbital forcing, carbon dioxide and regolith in 100 kyr glacial cycles, Climate of the Past, 7 (4), 1415-1425.

Gent, P. R. and J. C. McWilliams (1990). Isopycnal mixing in ocean circulation models, Journal of Physical Oceanography, 20 (1), 150-155.

Gent, P. R., S. G. Yeager, R. B. Neale, S. Levis, and D. A. Bailey (2010). Improvements in a half degree atmosphere/land version of the CCSM, Climate Dynamics, 34 (6), 819-833.

Giles, K. A., S. W. Laxon, A. L. Ridout, D. J. Wingham, and S. Bacon (2012). Western Arctic Ocean freshwater storage increased by wind-driven spin-up of the Beaufort Gyre, Nature Geoscience, 5 (3), 194-197.

Gillett, N. P., D. A. Stone, P. A. Stott, T. Nozawa, A. Y. Karpechko, G. C. Hegerl, M. F. Wehner, and P. D. Jones (2008). Attribution of polar warming to human influence, Nature Geoscience, 1 (11), 750-754.

Gleckler, P. J., K. E. Taylor, and C. Doutriaux (2008). Performance metrics for climate models, Journal of Geophysical Research, 113, D06104.

Glessmer, M. S., T. Eldevik, K. Våge, J. E. Øie Nilsen, and E. Behrens (2014). Atlantic origin of observed and modelled freshwater anomalies in the Nordic Seas, Nature Geo- 
science, 7 (11), 801-805.

Gloersen, P., W. J. Campbell, D. J. Cavalieri, J. C. Comiso, C. L. Parkinson, and H. J. Zwally (1993). Satellite passive microwave observations and analysis of Arctic and Antarctic sea ice, 1978-1987, Annals of Glaciology, 17, 149-154.

Goosse, H., O. Arzel, C. M. Bitz, A. de Montety, and M. Vancoppenolle (2009). Increased variability of the Arctic summer ice extent in a warmer climate, Geophysical Research Letters, 36 (23), L23702.

Goosse, H. and M. M. Holland (2005). Mechanisms of decadal Arctic climate variability in the Community Climate System Model, Version 2 (CCSM2), Journal of Climate, 18 (17), 3552-3570.

Graham, N. E. and H. F. Diaz (2001). Evidence for intensification of North Pacific winter cyclones since 1948, Bulletin of the American Meteorological Society, 82 (9), 18691893.

Graversen, R. G. (2006). Do changes in the midlatitude circulation have any impact on the Arctic surface air temperature trend?, Journal of Climate, 19 (20), 5422-5438.

Graversen, R. G., T. Mauritsen, M. Tjernström, E. Källén, and G. Svensson (2008). Vertical structure of recent Arctic warming, Nature, 451 (7174), 53-56.

Graversen, R. G. and M. Wang (2009). Polar amplification in a coupled climate model with locked albedo, Climate Dynamics, 33 (5), 629-643.

Gregory, J. M., P. A. Stott, D. J. Cresswell, N. A. Rayner, C. Gordon, and D. M. H. Sexton (2002). Recent and future changes in Arctic sea ice simulated by the HadCM3 AOGCM, Geophysical Research Letters, 29 (24), 2175.

Haarsma, R. J., W. Hazeleger, C. Severijns, H. de Vries, A. Sterl, R. Bintanja, G. J. van Oldenborgh, and H. W. van den Brink (2013). More hurricanes to hit western Europe due to global warming, Geophysical Research Letters, 40 (9), 1783-1788.

Haarsma, R. J., F. M. Selten, and S. S. Drijfhout (2015). Decelerating Atlantic meridional overturning circulation main cause of future west European summer atmospheric circulation changes, Environmental Research Letters, 10 (9), 094007.

Hall, A. (2004). The role of surface albedo feedback in climate, Journal of Climate, 17 (7), 1550-1568.

Hansen, J., M. Sato, and R. Ruedy (1997). Radiative forcing and climate response, Journal of Geophysical Research, 102 (D6), 6831-6864.

Hartmann, B. and G. Wendler (2005). The significance of the 1976 Pacific climate shift in the climatology of Alaska, Journal of Climate, 18 (22), 4824-4839.

Hátún, H., A. B. Sandø, H. Drange, B. Hansen, and H. Valdimarsson (2005). Influence of the Atlantic subpolar gyre on the thermohaline circulation, Science, 309 (5742), 1841-1844.

Hawkins, E. and R. Sutton (2009). The potential to narrow uncertainty in regional climate predictions, Bulletin of the American Meteorological Society, 90 (8), 1095-1107.

Hays, J. D., J. Imbrie, and N. J. Shackleton (1976). Variations in the Earth's orbit: Pacemaker of the Ice Ages, Science, 194 (4270), 1121-1132. 
Hazeleger, W., X. Wang, C. Severijns, S. Stefanescu, R. Bintanja, A. Sterl, K. Wyser, T. Semmler, S. Yang, B. van den Hurk, T. van Noije, E. van der Linden, and K. van der Wiel (2012). EC-Earth V2.2: Description and validation of a new seamless Earth system prediction model, Climate Dynamics, 39 (11), 2611-2629.

Hegerl, G. and P. Stott (2014). From past to future warming, Science, 343 (6173), 844845.

Hersbach, H., C. Peubey, A. Simmons, P. Berrisford, P. Poli, and D. Dee (2015). ERA-20CM: A twentieth-century atmospheric model ensemble, Quarterly Journal of the Royal Meteorological Society, 141 (691), 2350-2375.

Hesse, T., M. Butzin, T. Bickert, and G. Lohmann (2011). A model-data comparison of $\delta^{13} \mathrm{C}$ in the glacial Atlantic Ocean, Paleoceanography, 26, PA3220.

Hezel, P. J., T. Fichefet, and F. Massonnet (2014). Modeled Arctic sea ice evolution through 2300 in CMIP5 extended RCPs, Cryosphere, 8 (4), 1195-1204.

Holland, M. M. (2003). The North Atlantic Oscillation-Arctic oscillation in the CCSM2 and its influence on Arctic climate variability, Journal of Climate, 16 (16), 2767-2781.

Holland, M. M. and C. M. Bitz (2003). Polar amplification of climate change in coupled models, Climate Dynamics, 21 (3-4), 221-232.

Hollowed, A. B., M. Barange, R. J. Beamish, K. Brander, K. Cochrane, K. Drinkwater, M. G. G. Foreman, J. A. Hare, J. Holt, S.-i. Ito, S. Kim, J. R. King, H. Loeng, B. R. MacKenzie, F. J. Mueter, T. A. Okey, M. A. Peck, V. I. Radchenko, J. C. Rice, M. J. Schirripa, A. Yatsu, and Y. Yamanaka (2013). Projected impacts of climate change on marine fish and fisheries, ICES Journal of Marine Science, 70 (5), 1023-1037.

Hu, C., S. Yang, Q. Wu, Z. Li, J. Chen, K. Deng, T. Zhang, and C. Zhang (2016). Shifting El Niño inhibits summer Arctic warming and Arctic sea-ice melting over the Canada Basin, Nature Communications, 7, 11721.

Huber, C., M. Leuenberger, R. Spahni, J. Flückiger, J. Schwander, T. F. Stocker, S. Johnsen, A. Landais, and J. Jouzel (2006). Isotope calibrated Greenland temperature record over Marine Isotope Stage 3 and its relation to $\mathrm{CH} 4$, Earth and Planetary Science Letters, 243 (3-4), 504-519.

Huber, M. and L. C. Sloan (2001). Heat transport, deep waters, and thermal gradients: Coupled simulation of an Eocene Greenhouse Climate, Geophysical Research Letters, 28 (18), 3481-3484.

Hunke, E. C., D. A. Hebert, and O. Lecomte (2013). Level-ice melt ponds in the Los Alamos sea ice model, CICE, Ocean Modelling, 71, 26-42.

Hunke, E. C., W. H. Lipscomb, and A. K. Turner (2011). Sea-ice models for climate study: Retrospective and new directions, Journal of Glaciology, 56 (200), 1162-1172.

Huybrechts, P., H. Goelzer, I. Janssens, E. Driesschaert, T. Fichefet, H. Goosse, and M. F. Loutre (2011). Response of the Greenland and Antarctic Ice Sheets to multi-millennial greenhouse warming in the Earth system model of intermediate complexity LOVECLIM, Surveys in Geophysics, 32 (4-5), 397-416. 
Hwang, Y. T., D. M. W. Frierson, and J. E. Kay (2011). Coupling between Arctic feedbacks and changes in poleward energy transport, Geophysical Research Letters, 38, L17704.

Inoue, J., M. E. Hori, and K. Takaya (2012). The role of Barents sea ice in the wintertime cyclone track and emergence of a warm-Arctic cold-Siberian anomaly, Journal of Climate, 25 (7), 2561-2569.

Jacob, T., J. Wahr, W. T. Pfeffer, and S. Swenson (2012). Recent contributions of glaciers and ice caps to sea level rise, Nature, 482 (7386), 514-518.

Jakobsson, M., L. Mayer, B. Coakley, J. A. Dowdeswell, S. Forbes, B. Fridman, H. Hodnesdal, R. Noormets, R. Pedersen, M. Rebesco, H. W. Schenke, Y. Zarayskaya, D. Accettella, A. Armstrong, R. M. Anderson, P. Bienhoff, A. Camerlenghi, I. Church, M. Edwards, J. V. Gardner, J. K. Hall, B. Hell, O. Hestvik, Y. Kristoffersen, C. Marcussen, R. Mohammad, D. Mosher, S. V. Nghiem, M. T. Pedrosa, P. G. Travaglini, and P. Weatherall (2012). The International Bathymetric Chart of the Arctic Ocean (IBCAO) Version 3.0, Geophysical Research Letters, 39, L12609.

Johannessen, O. M., L. Bengtsson, M. W. Miles, S. I. Kuzmina, V. A. Semenov, G. V. Alekseev, A. P. Nagurnyi, V. F. Zakharov, L. P. Bobylev, L. H. Pettersson, K. Hasselmann, and H. P. Cattle (2004). Arctic climate change: Observed and modelled temperature and sea-ice variability, Tellus, Series A: Dynamic Meteorology and Oceanography, 56A (4), 328-341.

Johannessen, O. M., S. I. Kuzmina, P. Leonid, L. Bengtsson, and M. W. Miles (2016). Surface air temperature variability and trends in the Arctic, Tellus, Series A: Dynamic Meteorology and Oceanographys, 68, 28234.

Jones, P. D. and A. Moberg (2003). Hemispheric and large-scale surface air temperature variations: An extensive revision and an update to 2001, Journal of Climate, 16 (2), 206-224.

Jungclaus, J. H. and T. Koenigk (2010). Low-frequency variability of the Arctic climate: The role of oceanic and atmospheric heat transport variations, Climate Dynamics, 34 (2), 265-279.

Jungclaus, J. H., K. Lohmann, and D. Zanchettin (2014). Enhanced 20th-century heat transfer to the Arctic simulated in the context of climate variations over the last millennium, Climate of the Past, 10 (6), 2201-2213.

Kattsov, V., V. E. Ryabinin, J. E. Overland, M. C. Serreze, M. Visbeck, J. E. Walsh, W. Meier, and X. Zhang (2010). Arctic sea-ice changes: a grand challenge of climate science, Journal of Glaciology, 56 (200), 1115-1121.

Kay, J. E., M. M. Holland, C. M. Bitz, E. Blanchard-Wrigglesworth, A. Gettelman, A. Conley, and D. Bailey (2012). The influence of local feedbacks and northward heat transport on the equilibrium Arctic climate response to increased greenhouse gas forcing, Journal of Climate, 25 (16), 5433-5450.

Kay, J. E., M. M. Holland, and A. Jahn (2011). Inter-annual to multi-decadal Arctic sea ice extent trends in a warming world, Geophysical Research Letters, 38, L15708.

Kay, J. E. and T. L'Ecuyer (2013). Observational constraints on Arctic Ocean clouds and 
radiative fluxes during the early 21st century, Journal of Geophysical Research: Atmospheres, 118 (13), 7219-7236.

Kidston, J., A. A. Scaife, S. C. Hardiman, D. M. Mitchell, N. Butchart, M. P. Baldwin, and L. J. Gray (2015). Stratospheric influence on tropospheric jet streams, storm tracks and surface weather, Nature Geoscience, 8 (6), 433-440.

Kim, B.-M., S.-W. Son, S.-K. Min, J.-H. Jeong, S.-J. Kim, X. Zhang, T. Shim, and J.-H. Yoon (2014). Weakening of the stratospheric polar vortex by Arctic sea-ice loss, Nature communications, 5, 4646.

Kirtman, B. P., C. Bitz, F. Bryan, W. Collins, J. Dennis, N. Hearn, J. L. Kinter, R. Loft, C. Rousset, L. Siqueira, C. Stan, R. Tomas, and M. Vertenstein (2012). Impact of ocean model resolution on CCSM climate simulations, Climate Dynamics, 39 (6), 1303-1328.

Klein Tank, A., J. Beersma, J. Bessembinder, B. van den Hurk, and G. Lenderink (2015). KNMI'14-klimaatscenario's voor Nederland; Leidraad voor professionals in klimaatadaptatie, Tech. rep., KNMI, De Bilt.

Klockmann, M., U. Mikolajewicz, and J. Marotzke (2016). The effect of greenhouse gas concentrations and ice sheets on the glacial AMOC in a coupled climate model, Climate of the Past Discussions, 12, 1829-1846.

Knutti, R. (2008). Why are climate models reproducing the observed global surface warming so well?, Geophysical Research Letters, 35, L18704.

Knutti, R. and J. Sedláček (2012). Robustness and uncertainties in the new CMIP5 climate model projections, Nature Climate Change, 3 (4), 369-373.

Koenigk, T. and L. Brodeau (2014). Ocean heat transport into the Arctic in the twentieth and twenty-first century in EC-Earth, Climate Dynamics, 42 (11-12), 3101-3120.

Koenigk, T., L. Brodeau, R. G. Graversen, J. Karlsson, G. Svensson, M. Tjernström, U. Willén, and K. Wyser (2013). Arctic climate change in 21st century CMIP5 simulations with EC-Earth, Climate Dynamics, 40 (11-12), 2719-2743.

Krikken, F., M. Schmeits, W. Vlot, V. Guemas, and W. Hazeleger (2016). Skill improvement of dynamical seasonal Arctic sea ice forecasts, Geophysical Research Letters, 43 (10), 5124-5132.

Kuhlbrodt, T., A. Griesel, M. Montoya, A. Levermann, M. Hofmann, and S. Rahmstorf (2007). On the driving processes of the Atlantic meridional overturning circulation, Reviews of Geophysics, 45 (2004), RG2001.

Kumar, A., J. Perlwitz, J. Eischeid, X. Quan, T. Xu, T. Zhang, M. Hoerling, B. Jha, and W. Wang (2010). Contribution of sea ice loss to Arctic amplification, Geophysical Research Letters, 37 (21), L21701.

Kutzbach, J. E., F. He, S. J. Vavrus, and W. F. Ruddiman (2013). The dependence of equilibrium climate sensitivity on climate state: Applications to studies of climates colder than present, Geophysical Research Letters, 40 (14), 3721-3726.

Kwok, R. and D. A. Rothrock (1999). Variability of Fram Strait ice flux and North Atlantic Oscillation, Journal of Geophysical Research, 104 (1998), 5177-5189. 
Kwok, R. and D. A. Rothrock (2009). Decline in Arctic sea ice thickness from submarine and ICESat records: 1958-2008, Geophysical Research Letters, 36, L15501.

Kwok, R. and N. Untersteiner (2011). The thinning of Arctic sea ice, Physics Today, 64 (4), 36-41.

Laidre, K. L., I. Stirling, L. F. Lowry, Ø. Wiig, M. P. Heide-Jørgensen, and S. H. Ferguson (2008). Quantifying the sensitivity of Arctic marine mammals to climate-induced habitat change, Ecological Applications, 18 (2), S97-S125.

Lang, C. (1999). $16^{\circ} \mathrm{C}$ Rapid temperature variation in central Greenland 70,000 years ago, Science, 286 (5441), 934-937.

Levitus, S., G. Matishov, D. Seidov, and I. Smolyar (2009). Barents Sea multidecadal variability, Geophysical Research Letters, 36, L19604.

Li, C., J. S. von Storch, and J. Marotzke (2013). Deep-ocean heat uptake and equilibrium climate response, Climate Dynamics, 40 (5-6), 1071-1086.

Lindsay, R. and A. Schweiger (2015). Arctic sea ice thickness loss determined using subsurface, aircraft, and satellite observations, Cryosphere, 9 (1), 269-283.

Lindsay, R. W., J. Zhang, A. Schweiger, M. Steele, and H. Stern (2009). Arctic sea ice retreat in 2007 follows thinning trend, Journal of Climate, 22 (1), 165-176.

Lohmann, K., H. Drange, and M. Bentsen (2009). Response of the North Atlantic subpolar gyre to persistent North Atlantic oscillation like forcing, Climate Dynamics, 32 (2-3), 273-285.

Lowenstein, T. K. and R. V. Demicco (2006). Elevated Eocene atmospheric $\mathrm{CO}_{2}$ and its subsequent decline, Science, 313 (5795), 1928.

Lynch, A. H., M. C. Serreze, E. N. Cassano, A. D. Crawford, and J. Stroeve (2016). Linkages between Arctic summer circulation regimes and regional sea ice anomalies, Journal of Geophysical Research: Atmospheres, 121 (13), 7868-7880.

Lynch-Stieglitz, J., J. F. Adkins, W. B. Curry, T. Dokken, I. R. Hall, J. C. Herguera, J. J.M. Hirschi, E. V. Ivanova, C. Kissel, O. Marchal, T. M. Marchitto, I. N. McCave, J. F. McManus, S. Mulitza, U. Ninnemann, F. Peeters, E.-F. Yu, and R. Zahn (2007). Atlantic meridional overturning circulation during the Last Glacial Maximum., Science, 316 (5821), 66-69.

Madec, G. (2008). NEMO ocean engine, Tech. rep., Institut Pierre-Simon Laplace (IPSL), France.

Magnusdottir, G., C. Deser, and R. Saravanan (2004). The effects of North Atlantic SST and sea ice anomalies on the winter circulation in CCM3. Part I: Main features and storm track characteristics of the response, Journal of Climate, 17 (5), 857-876.

Mahajan, S., R. Zhang, and T. L. Delworth (2011). Impact of the Atlantic meridional overturning circulation (AMOC) on Arctic surface air temperature and sea ice variability, Journal of Climate, 24 (24), 6573-6581.

Mahlstein, I. and R. Knutti (2011). Ocean heat transport as a cause for model uncertainty in projected Arctic warming, Journal of Climate, 24 (5), 1451-1460.

Mahlstein, I. and R. Knutti (2012). September Arctic sea ice predicted to disappear near 
$2{ }^{\circ} \mathrm{C}$ global warming above present, Journal of Geophysical Research: Atmospheres, 117 (6), 1-11.

Manabe, S. and R. J. Stouffer (1980). Sensitivity of a global climate model to an increase of $\mathrm{CO}_{2}$ concentration in the atmosphere, Journal of Geophysical Research, 85 (80), 5529-5554.

Mann, M. E., Z. Zhang, S. Rutherford, R. S. Bradley, M. K. Hughes, D. Shindell, C. Ammann, G. Faluvegi, and F. Ni (2009). Global signatures and dynamical origins of the Little Ice Age and Medieval Climate Anomaly, Science, 326, 1256-1260.

Manney, G. L., M. L. Santee, M. Rex, N. J. Livesey, M. C. Pitts, P. Veefkind, E. R. Nash, I. Wohltmann, R. Lehmann, L. Froidevaux, L. R. Poole, M. R. Schoeberl, D. P. Haffner, J. Davies, V. Dorokhov, H. Gernandt, B. Johnson, R. Kivi, E. Kyrö, N. Larsen, P. F. Levelt, A. Makshtas, C. T. McElroy, H. Nakajima, M. C. Parrondo, D. W. Tarasick, P. von der Gathen, K. A. Walker, and N. S. Zinoviev (2011). Unprecedented Arctic ozone loss in 2011, Nature, 478 (7370), 469-475.

Mantua, N. J., S. R. Hare, Y. Zhang, J. M. Wallace, and R. C. Francis (1997). A Pacific interdecadal climate oscillation with impacts on salmon production, Bulletin of the American Meteorological Society, 78 (6), 1069-1079.

Marsland, S. J., D. Bi, P. Uotila, R. Fiedler, S. M. Griffies, K. Lorbacher, S. O’Farrell, A. Sullivan, P. Uhe, X. Zhou, and A. C. Hirst (2013). Evaluation of ACCESS climate model ocean diagnostics in CMIP5 simulations, Australian Meteorological and Oceanographic Journal, 63 (1), 101-119.

Martin, S., E. Munoz, and R. Drucker (1997). Recent observations of a spring-summer surface warming over the Arctic Ocean, Geophysical Research Letters, 24 (10), 12591262.

Marvel, K., G. A. Schmidt, K. Tsigaridis, and B. I. Cook (2015). Sensitivity to factors underlying the hiatus, U.S. CLIVAR Variations, 13 (3), 25-29.

Masson-Delmotte, V., M. Kageyama, P. Braconnot, S. Charbit, G. Krinner, C. Ritz, E. Guilyardi, J. Jouzel, A. Abe-Ouchi, M. Crucifix, R. M. Gladstone, C. D. Hewitt, A. Kitoh, A. N. LeGrande, O. Marti, U. Merkel, T. Motoi, R. Ohgaito, B. Otto-Bliesner, W. R. Peltier, I. Ross, P. J. Valdes, G. Vettoretti, S. L. Weber, F. Wolk, and Y. Yu (2006). Past and future polar amplification of climate change: Climate model intercomparisons and ice-core constraints, Climate Dynamics, 26 (5), 513-529.

Masson-Delmotte, V., M. Schulz, A. Abe-Ouchi, J. Beer, A. Ganopolski, J. F. González Rouco, E. Jansen, K. Lambeck, J. Luterbacher, T. Naish, T. Osborn, B. Otto-Bliesner, T. Quinn, R. Ramesh, M. Rojas, X. Shao, A. Timmermann, and J. F. G. Rouco (2013). Information from Paleoclimate Archives, in T. Stocker, D. Qin, G.-K. Plattner, M. Tignor, S. Allen, J. Boschung, A. Nauels, Y. Xia, V. Bex, and P. Midgley, eds., Climate Change 2013: The Physical Science Basis. Contribution of Working Group I to the Fifth Assessment Report of the Intergovernmental Panel on Climate Change, Cambridge University Press, Cambridge, United Kingdom and New York, NY, USA, pp. 383-464. 
Massonnet, F., T. Fichefet, H. Goosse, C. M. Bitz, G. Philippon-Berthier, M. M. Holland, and P. Y. Barriat (2012). Constraining projections of summer Arctic sea ice, Cryosphere, 6 (6), 1383-1394.

Mauritsen, T., R. G. Graversen, D. Klocke, P. L. Langen, B. Stevens, and L. Tomassini (2013). Climate feedback efficiency and synergy, Climate Dynamics, 41 (9-10), 25392554 .

Mauritzen, C. (2012). Oceanography: Arctic freshwater, Nature Geoscience, 5 (3), 162164.

Maykut, G. A. (1978). Energy exchange over young sea ice in the central Arctic, Journal of Geophysical Research, 83 (C7), 3646.

Meehl, G. A., C. Covey, T. Delworth, M. Latif, B. McAvaney, J. F. B. Mitchell, R. J. Stouffer, and K. E. Taylor (2007). The WCRP CMIP3 multimodel dataset: A new era in climatic change research, Bulletin of the American Meteorological Society, 88 (9), 1383-1394.

Meincke, J. (1997). The Arctic Ocean-Nordic Seas thermohaline system, ICES Journal of Marine Science, 54, 283-299.

Meraner, K., T. Mauritsen, and A. Voigt (2013). Robust increase in equilibrium climate sensitivity under global warming, Geophysical Research Letters, 40 (22), 5944-5948.

Miles, M. W., D. V. Divine, T. Furevik, E. Jansen, M. Moros, and A. E. J. Ogilvie (2014). A signal of persistent Atlantic multidecadal variability in Arctic sea ice, Geophysical Research Letters, 41 (2), 463-469.

Miller, G. H., R. B. Alley, J. Brigham-Grette, J. J. Fitzpatrick, L. Polyak, M. C. Serreze, and J. W. C. White (2010). Arctic amplification: Can the past constrain the future?, Quaternary Science Reviews, 29 (15-16), 1779-1790.

Min, S.-K., X. Zhang, and F. Zwiers (2008a). Human-induced Arctic moistening, Science, 320 (5875), 518-520.

Min, S.-K., X. Zhang, F. W. Zwiers, and T. Agnew (2008b). Human influence on Arctic sea ice detectable from early 1990s onwards, Geophysical Research Letters, 35 (21), L21701.

Mizuta, R. (2012). Intensification of extratropical cyclones associated with the polar jet change in the CMIP5 global warming projections, Geophysical Research Letters, 39, L19707.

Moreno-Chamarro, E., D. Zanchettin, K. Lohmann, and J. H. Jungclaus (2016). An abrupt weakening of the subpolar gyre as trigger of Little Ice Age-type episodes, Climate Dynamics.

Morice, C. P., J. J. Kennedy, N. A. Rayner, and P. D. Jones (2012). Quantifying uncertainties in global and regional temperature change using an ensemble of observational estimates: The HadCRUT4 data set, Journal of Geophysical Research: Atmospheres, 117, D08101.

Morison, J., R. Kwok, C. Peralta-Ferriz, M. Alkire, I. Rigor, R. Andersen, and M. Steele (2012). Changing Arctic Ocean freshwater pathways, Nature, 481 (7379), 66-70. 
Muglia, J. and A. Schmittner (2015). Glacial Atlantic overturning increased by wind stress in climate models, Geophysical Research Letters, 42 (22), 9862-9869.

Myhre, G., D. Shindell, F.-M. Bréon, W. Collins, J. Fuglestvedt, J. Huang, D. Koch, J.-F. Lamarque, D. Lee, B. Mendoza, T. Nakajima, A. Robock, G. Stephens, T. Takemura, and H. Zhang (2013). Anthropogenic and Natural Radiative Forcing, in T. Stocker, D. Qin, G.-K. Plattner, M. Tignor, S. Allen, J. Boschung, A. Nauels, Y. Xia, V. Bex, and P. Midgley, eds., Climate Change 2013: The Physical Science Basis. Contribution of Working Group I to the Fifth Assessment Report of the Intergovernmental Panel on Climate Change, Cambridge University Press, Cambridge, United Kingdom and New York, NY, USA, pp. 659-740.

Najafi, M. R., F. W. Zwiers, and N. P. Gillett (2015). Attribution of Arctic temperature change to greenhouse-gas and aerosol influences, Nature Climate Change, 5 (3), 246249.

Nelson, F. E., O. A. Anisimov, and N. I. Shiklomanov (2001). Subsidence risk from thawing permafrost, Nature, 410 (6831), 889-890.

Notz, D. and J. Marotzke (2012). Observations reveal external driver for Arctic sea-ice retreat, Geophysical Research Letters, 39 (8), L08502.

Ogi, B. M., Y. Tachibana, F. Nishio, and M. A. Dachenkov (2001). Does the fresh water supply from the Amur river flowing into the Sea of Okhotsk affect sea ice formation?, Journal of the Meteorological Society of Japan, 79 (1), 123-129.

Otto-Bliesner, B. L., E. C. Brady, R. Tomas, S. Levis, and Z. Kothavala (2006). Last Glacial Maximum and Holocene climate in CCSM3, Journal of Climate, 19 (11), 2526-2544.

Otto-Bliesner, B. L., C. D. Hewitt, T. M. Marchitto, E. Brady, A. Abe-Ouchi, M. Crucifix, S. Murakami, and S. L. Weber (2007). Last Glacial Maximum ocean thermohaline circulation: PMIP2 model intercomparisons and data constraints, Geophysical Research Letters, 34, L12706.

Overeem, I., R. S. Anderson, C. W. Wobus, G. D. Clow, F. E. Urban, and N. Matell (2011). Sea ice loss enhances wave action at the Arctic coast, Geophysical Research Letters, 38, L17503.

Overland, J. E. and M. Wang (2005). The Arctic climate paradox: The recent decrease of the Arctic Oscillation, Geophysical Research Letters, 32 (6), L06701.

Overpeck, J., K. Hughen, D. Hardy, R. Bradley, R. Case, M. Douglas, B. Finney, K. Gajewski, G. Jacoby, A. Jennings, S. Lamoureux, A. Lasca, G. MacDonald, J. Moore, M. Retelle, S. Smith, A. Wolfe, and G. Zielinski (1997). Arctic environmental change of the last four centuries, Science, 278 (5341), 1251-1256.

Palm, S. P., S. T. Strey, J. Spinhirne, and T. Markus (2010). Influence of Arctic sea ice extent on polar cloud fraction and vertical structure and implications for regional climate, Journal of Geophysical Research, 115 (D21), D21209.

Park, J.-Y., J.-S. Kug, J. Bader, R. Rolph, and M. Kwon (2015). Amplified Arctic warming by phytoplankton under greenhouse warming, Proceedings of the National Academy of Sciences, 112 (19), 5921-5926. 
Parker, D., C. Folland, A. Scaife, J. Knight, A. Colman, P. Baines, and B. Dong (2007). Decadal to multidecadal variability and the climate change background, Journal of Geophysical Research, 112, D18115.

Parkinson, C. L. and J. C. Comiso (2013). On the 2012 record low Arctic sea ice cover: Combined impact of preconditioning and an August storm, Geophysical Research Letters, 40 (7), 1356-1361.

Pavelsky, T. M., J. Boé, A. Hall, and E. J. Fetzer (2011). Atmospheric inversion strength over polar oceans in winter regulated by sea ice, Climate Dynamics, 36 (5-6), 945-955.

Pearson, R. G., S. J. Phillips, M. M. Loranty, P. S. A. Beck, T. Damoulas, S. J. Knight, and S. J. Goetz (2013). Shifts in Arctic vegetation and associated feedbacks under climate change, Nature Climate Change, 3 (7), 673-677.

Peltier, W. R. and G. Vettoretti (2014). Dansgaard-Oeschger oscillations predicted in a comprehensive model of glacial climate: A "kicked" salt oscillator in the Atlantic, Geophysical Research Letters, 41 (20), 7306-7313.

Perovich, D. K. and C. Polashenski (2012). Albedo evolution of seasonal Arctic sea ice, Geophysical Research Letters, 39, L08501.

Perovich, D. K. and J. A. Richter-Menge (2009). Loss of sea ice in the Arctic, Annual Review of Marine Science, 1 (1), 417-441.

Petersen, S. V., D. P. Schrag, and P. U. Clark (2013). A new mechanism for DansgaardOeschger cycles, Paleoceanography, 28 (1), 24-30.

Pierrehumbert, R. T. (2011). Infrared radiative and planetary temperature, Physics Today, (January), 33-38.

Pincus, R., C. P. Batstone, R. J. Patrick Hofmann, K. E. Taylor, and P. J. Glecker (2008). Evaluating the present-day simulation of clouds, precipitation, and radiation in climate models, Journal of Geophysical Research, 113, D14209.

Pithan, F. and T. Mauritsen (2014). Arctic amplification dominated by temperature feedbacks in contemporary climate models, Nature Geoscience, 7 (3), 181-184.

Poli, P., H. Hersbach, D. Tan, D. Dee, J.-N. Thépaut, A. Simmons, C. Peubey, P. Laloyaux, T. Komori, P. Berrisford, and R. Dragani (2013). The data assimilation system and initial performance evaluation of the ECMWF pilot reanalysis of the 20th-century assimilating surface observations only (ERA-20C), ERA report series, 14, 59.

Polyakov, I. V., G. V. Alekseev, R. V. Bekryaev, U. S. Bhatt, R. Colony, M. A. Johnson, V. P. Karklin, D. Walsh, and A. V. Yulin (2003a). Long-term ice variability in Arctic marginal seas, Journal of Climate, 16 (12), 2078-2085.

Polyakov, I. V., G. V. Alekseev, L. A. Timokhov, U. S. Bhatt, R. L. Colony, H. L. Simmons, D. Walsh, J. E. Walsh, and V. F. Zakharov (2004). Variability of the intermediate Atlantic water of the Arctic Ocean over the last 100 years, Journal of Climate, 17 (23), 44854497.

Polyakov, I. V., R. V. Bekryaev, G. V. Alekseev, U. S. Bhatt, R. L. Colony, M. A. Johnson, A. P. Maskshtas, and D. Walsh (2003b). Variability and trends of air temperature and pressure in the maritime Arctic, 1875-2000, Journal of Climate, 16 (12), 2067-2077. 
Post, E., U. S. Bhatt, C. M. Bitz, J. F. Brodie, T. L. Fulton, M. Hebblewhite, J. Kerby, S. J. Kutz, I. Stirling, and D. A. Walker (2013). Ecological consequences of sea-ice decline, Science, 341 (6145), 519-524.

Poulsen, C. J. and J. Zhou (2013). Sensitivity of Arctic climate variability to mean state: Insights from the Cretaceous, Journal of Climate, 26 (18), 7003-7022.

Proshutinsky, A. Y. and M. A. Johnson (1997). Two circulation regimes of the wind-driven Arctic Ocean, Journal of Geophysical Research, 102 (C6), 12493-12514.

Räisänen, J. (2007). How reliable are climate models?, Tellus, Series A: Dynamic Meteorology and Oceanography, 59A (1), 2-29.

Räisänen, J., L. Ruokolainen, and J. Ylhäisi (2010). Weighting of model results for improving best estimates of climate change, Climate Dynamics, 35 (2), 407-422.

Rampal, P., J. Weiss, C. Dubois, and J.-M. Campin (2011). IPCC climate models do not capture Arctic sea ice drift acceleration: Consequences in terms of projected sea ice thinning and decline, Journal of Geophysical Research, 116 (9), C00D07.

Reichler, T. and J. Kim (2008). How well do coupled models simulate today's climate?, Bulletin of the American Meteorological Society, 89 (3), 303-311.

Renssen, H., A. Mairesse, H. Goosse, P. Mathiot, O. Heiri, D. M. Roche, K. H. Nisancioglu, and P. J. Valdes (2015). Multiple causes of the Younger Dryas cold period, Nature Geoscience, 8 (12), 946-949.

Renssen, H., H. Seppä, X. Crosta, H. Goosse, and D. Roche (2012). Global characterization of the Holocene Thermal Maximum, Quaternary Science Reviews, 48, 7-19.

Ridley, J., J. Lowe, C. Brierley, and G. Harris (2007). Uncertainty in the sensitivity of Arctic sea ice to global warming in a perturbed parameter climate model ensemble, Geophysical Research Letters, 34, L19704.

Rigor, I. G., R. L. Colony, and S. Martin (2000). Variations in surface air temperature observations in the Arctic, 1979-97, Journal of Climate, 13 (5), 896-914.

Rigor, I. G., J. M. Wallace, and R. L. Colony (2002). Response of sea ice to the Arctic Oscillation, Journal of Climate, 15 (18), 2648-2663.

Rind, D., R. Healy, C. Parkinson, and D. Martinson (1995). The role of sea ice in $2 \times \mathrm{CO}_{2}$ climate model sensitivity. Part I: The total influence of sea ice thickness and extent, Journal of Climate, 8 (3), 449-463.

Rind, D., R. Healy, C. Parkinson, and D. Martinson (1997). The role of sea ice in $2 \times \mathrm{CO}_{2}$ climate model sensitivity: Part II: Hemispheric dependencies, Geophysical Research Letters, 24 (12), 1491-1494.

Röhl, U., T. Westerhold, T. J. Bralower, and J. C. Zachos (2007). On the duration of the Paleocene-Eocene thermal maximum (PETM), Geochemistry, Geophysics, Geosystems, 8 (12).

Sand, M., T. K. Berntsen, J. E. Kay, J. F. Lamarque, Ø. Seland, and A. Kirkeväg (2013). The Arctic response to remote and local forcing of black carbon, Atmospheric Chemistry and Physics, 13 (1), 211-224. 
Schröder, D., D. L. Feltham, D. Flocco, and M. Tsamados (2014). September Arctic seaice minimum predicted by spring melt-pond fraction, Nature Climate Change, 4 (5), 353-357.

Schuur, E. A. G., A. D. McGuire, C. Schädel, G. Grosse, J. W. Harden, D. J. Hayes, G. Hugelius, C. D. Koven, P. Kuhry, D. M. Lawrence, S. M. Natali, D. Olefeldt, V. E. Romanovsky, K. Schaefer, M. R. Turetsky, C. C. Treat, and J. E. Vonk (2015). Climate change and the permafrost carbon feedback, Nature, 520 (7546), 171-179.

Screen, J. A. and I. Simmonds (2010). The central role of diminishing sea ice in recent Arctic temperature amplification, Nature, 464 (7293), 1334-1337.

Screen, J. A. and I. Simmonds (2011). Erroneous Arctic temperature trends in the ERA-40 reanalysis: A closer look, Journal of Climate, 24 (10), 2620-2627.

Semenov, V. A. and L. Bengtsson (2003). Modes of the wintertime Arctic temperature variability, Geophysical Research Letters, 30 (15), 1781.

Serreze, M. C., A. P. Barrett, J. C. Stroeve, D. N. Kindig, and M. M. Holland (2009). The emergence of surface-based Arctic amplification, The Cryosphere, 3 (1), 11-19.

Serreze, M. C. and R. G. Barry (2011). Processes and impacts of Arctic amplification: A research synthesis, Global and Planetary Change, 77 (1-2), 85-96.

Serreze, M. C., M. M. Holland, and J. Stroeve (2007). Perspectives on the Arctic's shrinking sea-ice cover, Science, 315 (5818), 1533-1536.

Shaffrey, L. and R. Sutton (2004). The interannual variability of energy transports within and over the Atlantic Ocean in a coupled climate model, Journal of Climate, 17 (7), 1433-1448.

Shaffrey, L. C. and R. Sutton (2006). Bjerknes compensation and the decadal variability of the energy transports in a coupled climate model, Journal of Climate, 19 (7), 11671181.

Shupe, M. D. and J. M. Intrieri (2004). Cloud radiative forcing of the Arctic surface: The influence of cloud properties, surface albedo, and solar zenith angle, Journal of Climate, 17 (3), 616-628.

Simmons, A., J. L. Fellous, V. Ramaswamy, K. Trenberth, G. Asrar, M. Balmaseda, J. P. Burrows, P. Ciais, M. Drinkwater, P. Friedlingstein, N. Gobron, E. Guilyardi, D. Halpern, M. Heimann, J. Johannessen, P. F. Levelt, E. Lopez-Baeza, J. Penner, R. Scholes, and T. Shepherd (2016). Observation and integrated Earth-system science: A roadmap for 2016-2025, Advances in Space Research, 57 (10), 2037-2103.

Simmons, A. J. and P. Poli (2015). Arctic warming in ERA-Interim and other analyses, Quarterly Journal of the Royal Meteorological Society, 141 (689), 1147-1162.

Slonosky, V. C., L. A. Mysak, and J. Derome (1997). Linking Arctic sea-ice and atmospheric circulation anomalies on interannual and decadal timescales, AtmosphereOcean, 35 (3), 333-366.

Sluijs, A., S. Schouten, M. Pagani, M. Woltering, H. Brinkhuis, J. S. Sinninghe Damsté, G. R. Dickens, M. Huber, G.-J. Reichart, R. Stein, J. Matthiessen, L. J. Lourens, N. Pedentchouk, J. Backman, K. Moran, and the Expedition 302 Scientists (2006). Subtropi- 
cal Arctic Ocean temperatures during the Palaeocene/Eocene thermal maximum, Nature, 441 (7093), 610-613.

Smedsrud, L. H., I. Esau, R. B. Ingvaldsen, T. Eldevik, P. M. Haugan, C. Li, V. S. Lien, A. Olsen, A. M. Omar, O. H. Otterå, B. Risebrobakken, A. B. Sandø, V. A. Semenov, and S. A. Sorokina (2013). The role of the Barents Sea in the Arctic climate system, Reviews of Geophysics, 5 (2012), 415-449.

Smeed, D. A., G. D. McCarthy, S. A. Cunningham, E. Frajka-Williams, D. Rayner, W. E. Johns, C. S. Meinen, M. O. Baringer, B. I. Moat, A. Duchez, and H. L. Bryden (2014). Observed decline of the Atlantic meridional overturning circulation 2004-2012, Ocean Science, 10 (1), 29-38.

Solomon, A., L. Goddard, A. Kumar, J. Carton, C. Deser, I. Fukumori, A. M. Greene, G. Hegerl, B. Kirtman, Y. Kushnir, M. Newman, D. Smith, D. Vimont, T. Delworth, G. A. Meehl, and T. Stockdale (2011). Distinguishing the roles of natural and anthropogenically forced decadal climate variability: Implications for prediction, Bulletin of the American Meteorological Society, 92 (2), 141-156.

Spielhagen, R. F., K. Werner, S. A. Sørensen, K. Zamelczyk, E. Kandiano, G. Budeus, K. Husum, T. M. Marchitto, and M. Hald (2011). Enhanced modern heat transfer to the Arctic by warm Atlantic Water, Science, 331 (6016), 450-453.

Stammer, D. (2008). Response of the global ocean to Greenland and Antarctic ice melting, Journal of Geophysical Research, 113, C06022.

Steele, M., J. Zhang, and W. Ermold (2010). Mechanisms of summertime upper Arctic Ocean warming and the effect on sea ice melt, Journal of Geophysical Research, 115, C11004.

Stephenson, S. R., L. C. Smith, L. W. Brigham, and J. A. Agnew (2013). Projected 21stcentury changes to Arctic marine access, Climatic Change, 118 (3-4), 885-899.

Sterl, A., R. Bintanja, L. Brodeau, E. Gleeson, T. Koenigk, T. Schmith, T. Semmler, C. Severijns, K. Wyser, and S. Yang (2012). A look at the ocean in the EC-Earth climate model, Climate Dynamics, 39 (11), 2631-2657.

Stommel, H. and A. Arons (1959). On the abyssal circulation of the world ocean - I. Stationary planetary flow patterns on a sphere, Deep Sea Research (1953), 6 (February), $140-154$.

Stott, P. A., N. P. Gillett, G. C. Hegerl, D. J. Karoly, D. A. Stone, X. Zhang, and F. Zwiers (2010). Detection and attribution of climate change: A regional perspective, Wiley Interdisciplinary Reviews: Climate Change, 1 (2), 192-211.

Stroeve, J., M. M. Holland, W. Meier, T. Scambos, and M. Serreze (2007). Arctic sea ice decline: Faster than forecast, Geophysical Research Letters, 34, L09501.

Stroeve, J. C., V. Kattsov, A. Barrett, M. Serreze, T. Pavlova, M. Holland, and W. N. Meier (2012a). Trends in Arctic sea ice extent from CMIP5, CMIP3 and observations, Geophysical Research Letters, 39, L16502.

Stroeve, J. C., M. C. Serreze, M. M. Holland, J. E. Kay, J. Malanik, and A. P. Barrett (2012b). The Arctic's rapidly shrinking sea ice cover: a research synthesis, Climatic Change, 
$110(3-4), 1005-1027$.

Swann, A. L., I. Y. Fung, S. Levis, G. B. Bonan, and S. C. Doney (2010). Changes in Arctic vegetation amplify high-latitude warming through the greenhouse effect, Proceedings of the National Academy of Sciences, 107 (4), 1295-1300.

Swart, N. C., J. C. Fyfe, E. Hawkins, J. E. Kay, and A. Jahn (2015). Influence of internal variability on Arctic sea-ice trends, Nature Climate Change, 5 (2), 86-89.

Tang, Q., X. Zhang, X. Yang, and J. A. Francis (2013). Cold winter extremes in northern continents linked to Arctic sea ice loss, Environmental Research Letters, 8 (1), 014036.

Taylor, K. E., R. J. Stouffer, and G. A. Meehl (2012). An overview of CMIP5 and the experiment design, Bulletin of the American Meteorological Society, 93 (4), 485-498.

Tebaldi, C., J. M. Arblaster, and R. Knutti (2011). Mapping model agreement on future climate projections, Geophysical Research Letters, 38, L23701.

Thompson, D. W. J. and J. M. Wallace (1998). The Arctic Oscillation signature in the wintertime geopotential height and temperature fields, Geophysical Research Letters, 25 (9), 1297-1300.

Thomson, J. and W. E. Rogers (2014). Swell and sea in the emerging Arctic Ocean, Geophysical Research Letters, 41 (9), 3136-3140.

Toohey, M., K. Krüger, M. Bittner, C. Timmreck, and H. Schmidt (2014). The impact of volcanic aerosol on the Northern Hemisphere stratospheric polar vortex: mechanisms and sensitivity to forcing structure, Atmospheric Chemistry and Physics, 14 (23), 13063-13079.

Trenberth, K. E. and D. P. Stepaniak (2003). Seamless poleward atmospheric energy transports and implications for the Hadley circulation, Journal of Climate, 16 (22), 3706-3722.

Valcke, S., A. Caubel, D. Declat, and L. Terray (2003). OASIS3 ocean atmosphere sea ice soil user's guide, Prisim project report, 2.

Van der Linden, E. C., R. Bintanja, W. Hazeleger, and R. G. Graversen (2016). Lowfrequency variability of surface air temperature over the Barents Sea: causes and mechanisms, Climate Dynamics, 47 (3-4), 1247-1262.

Van der Linden, E. C., R. Bintanja, W. Hazeleger, and C. A. Katsman (2014). The role of the mean state of Arctic sea ice on near-surface temperature trends, Journal of Climate, 27 (8), 2819-2841.

Van der Swaluw, E., S. S. Drijfhout, and W. Hazeleger (2007). Bjerknes compensation at high northern latitudes: The ocean forcing the atmosphere, Journal of Climate, 20 (24), 6023-6032.

Vaughan, D. G., J. C. Comiso, I. Allison, J. Crrasco, R. Kaser, R. Kwok, P. Mote, T. Murray, F. Paul, J. Ren, E. Rignot, O. Solomina, K. Steffen, and T. Zhang (2013). Observations: Cryosphere, in T. Stocker, D. Qin, G.-K. Plattner, M. Tignor, S. Allen, J. Boschung, A. Nauels, Y. Xia, V. Bex, and P. Midgley, eds., Climate Change 2013: The Physical Science Basis. Contribution of Working Group I to the Fifth Assessment Report of the Intergovernmental Panel on Climate Change, Cambridge University Press, Cambridge, 
United Kingdom and New York, NY, USA, pp. 317-382.

Vavrus, S., D. Waliser, A. Schweiger, and J. Francis (2009). Simulations of 20th and 21st century Arctic cloud amount in the global climate models assessed in the IPCC AR4, Climate Dynamics, 33 (7-8), 1099-1115.

Vinnikov, K. Y., A. Robock, R. J. Stouffer, J. E. Walsh, C. L. Parkinson, D. J. Cavalieri, J. F. B. Mitchell, D. Garrett, and V. F. Zakharov (1999). Global warming and Northern Hemisphere sea ice extent, Science, 286 (5446), 1934-1937.

Vizcaíno, M., W. H. Lipscomb, W. J. Sacks, and M. van den Broeke (2014). Greenland surface mass balance as simulated by the Community Earth System Model. Part II: Twenty-first-century changes, Journal of Climate, 27 (1), 215-226.

Watanabe, E., J. Wang, A. Sumi, and H. Hasumi (2006). Arctic dipole anomaly and its contribution to sea ice export from the Arctic Ocean in the 20th century, Geophysical Research Letters, 33, L23703.

Weaver, A., C. Bitz, A. Fanning, and M. Holland (1999). Thermohaline circulation: Highlatitude phenomena and the difference between the Pacific and Atlantic, Annual Review of Earth and Planetary Sciences, 27 (1), 231-285.

Weijers, J. W. H., S. Schouten, A. Sluijs, H. Brinkhuis, and J. S. Sinninghe Damsté (2007). Warm Arctic continents during the Palaeocene-Eocene thermal maximum, Earth and Planetary Science Letters, 261 (1-2), 230-238.

Wild, M., D. Folini, C. Schär, N. Loeb, E. G. Dutton, and G. König-Langlo (2013). The global energy balance from a surface perspective, Climate Dynamics, 40 (11-12), 3107-3134.

Winguth, A. M. E., E. Thomas, and C. Winguth (2012). Global decline in ocean ventilation, oxygenation, and productivity during the Paleocene-Eocene Thermal Maximum: Implications for the benthic extinction, Geology, 40 (3), 263-266.

Winton, M. (2006a). Amplified Arctic climate change: What does surface albedo feedback have to do with it?, Geophysical Research Letters, 33, L03701.

Winton, M. (2006b). Surface albedo feedback estimates for the AR4 climate models, Journal of Climate, 19 (3), 359-365.

Winton, M. (2011). Do climate models underestimate the sensitivity of Northern Hemisphere sea ice cover?, Journal of Climate, 24 (15), 3924-3934.

Wood, K. R. and J. E. Overland (2010). Early 20th century Arctic warming in retrospect, International Journal of Climatology, 30 (9), 1269-1279.

Wouters, B., S. Drijfhout, and W. Hazeleger (2012). Interdecadal North-Atlantic meridional overturning circulation variability in EC-EARTH, Climate Dynamics, 39 (11), 2695-2712.

Wu, B., J. Wang, and J. E. Walsh (2006). Dipole anomaly in the winter Arctic atmosphere and its association with sea ice motion, Journal of Climate, 19 (2), 210-225.

Wyser, K., C. G. Jones, P. Du, E. Girard, U. Willén, J. Cassano, J. H. Christensen, J. A. Curry, K. Dethloff, J. E. Haugen, D. Jacob, M. Køltzow, R. Laprise, A. Lynch, S. Pfeifer, A. Rinke, M. Serreze, M. J. Shaw, M. Tjernström, and M. Zagar (2008). An evaluation of 
Arctic cloud and radiation processes during the SHEBA year: Simulation results from eight Arctic regional climate models, Climate Dynamics, 30 (2-3), 203-223.

Yamanouchi, T. (2011). Early 20th century warming in the Arctic: A review, Polar Science, 5 (1), 53-71.

Yang, D. and O. A. Saenko (2012). Ocean heat transport and its projected change in CanESM2, Journal of Climate, 25 (23), 8148-8163.

Yang, Q., T. H. Dixon, P. G. Myers, J. Bonin, D. Chambers, and M. R. van den Broeke (2016). Recent increases in Arctic freshwater flux affects Labrador Sea convection and Atlantic overturning circulation, Nature Communications, 7, 10525.

Yang, X. Y., J. C. Fyfe, and G. M. Flato (2010). The role of poleward energy transport in Arctic temperature evolution, Geophysical Research Letters, 37, L14803.

Zachos, J. C., U. Röhl, S. A. Schellenberg, A. Sluijs, D. A. Hodell, D. C. Kelly, E. Thomas, M. Nicolo, I. Raffi, L. J. Lourens, H. McCarren, and D. Kroon (2005). Rapid acidification of the ocean during the Paleocene-Eocene thermal maximum., Science, 308 (5728), 1611-1615.

Zhang, J., D. Rothrock, and M. Steele (2000). Recent changes in Arctic sea ice: The interplay between ice dynamics and thermodynamics, Journal of Climate, 13 (17), 30993114.

Zhang, L. and C. Wang (2013). Multidecadal North Atlantic sea surface temperature and Atlantic meridional overturning circulation variability in CMIP5 historical simulations, Journal of Geophysical Research: Oceans, 118 (10), 5772-5791.

Zhang, R. (2015). Mechanisms for low-frequency variability of summer Arctic sea ice extent, Proceedings of the National Academy of Sciences, 112 (15), 4570-4575.

Zhang, X., J. E. Walsh, J. Zhang, U. S. Bhatt, and M. Ikeda (2004). Climatology and interannual variability of Arctic cyclone activity: 1948-2002, Journal of Climate, 17 (12), 2300-2317. 


\section{Dankwoord}

Dit dankwoord is voor iedereen die mij gedurende mijn promotietraject heeft gesteund, geïnspireerd en geholpen, in welke vorm dan ook.

In de eerste plaats wil ik mijn promotor Wilco en co-promotor Richard hartelijk bedanken voor de begeleiding en goede adviezen. Richard, ik waardeer je positieve en nuchtere instelling en vond het fijn dat ons contact altijd laagdrempelig was. Bedankt ook voor je vertrouwen, geduld en je altijd snelle respons op de stukken die ik stuurde. Jouw taal-technische tips en suggesties hebben de tekst in deze thesis op veel plaatsen een stuk toegankelijker gemaakt. Wilco, ik ben je dankbaar voor je begrip, geduld en het vertrouwen dat je in me stelde. Jij dacht vaak ver vooruit over mijn onderzoek en jouw inzichten kwamen altijd goed van pas. Ik vond het heel prettig om met jou samen te werken en had meestal weer nieuwe ideeën en energie na onze meetings. Bedankt voor de inspiratie en voor alles wat je me geleerd hebt.

Verder wil ik graag alle (oud)collega's van de RDWK-afdeling bedanken voor de prettige werksfeer in de groep waar ik me echt thuis heb gevoeld. Bedankt voor jullie interesse en gesprekken over mijn onderzoek, en voor de gezelligheid tijdens de koffie-, thee- en lunchpauzes. Frank, bedankt voor je geduldige uitleg en de technische ondersteuning bij de modelruns, maar ook voor je bereidheid altijd mee te denken over allerlei andere kwesties. Caroline, jou wil ik graag als co-auteur bedanken voor je praktische hulp bij het afronden van mijn eerste paper. Ook de collega's uit Wageningen van het QUASI-project, Marina, Bert en Gert-Jan, bedankt voor jullie belangstelling in mijn onderzoek en de leuke meetings. Daarnaast wil ik graag mijn (oud)kamergenoten Marco, Renske, Lucinda en Jonathan bedanken voor hun plezierige gezelschap door de jaren heen. In het bijzonder wil ik hier Jessica en Anna noemen, die in de laatste, drukke periode 
mijn kamergenoten waren en mijn paranimfen zijn. Bedankt voor jullie steun en begrip, maar ook voor alle gezelligheid, want dat was minstens zo belangrijk. Jessica, het afgelopen jaar was jij zelfs op weekenddagen mijn 'partner in crime', fijn dat we altijd konden sparren en ervaringen konden uitwisselen. Bovendien enorm bedankt voor het mooie ontwerp van de omslag van mijn thesis! Joyce, al even geen collega meer, maar sinds we elkaar tegenkwamen tijdens onze studie kon ik met jou ook altijd alles bespreken. Dankjewel voor alle belangstelling en gezelligheid tijdens je tijd op het KNMI, maar zeker ook daarbuiten.

During my PhD I had the opportunity to visit MISU at Stockholm University for a couple of months and to meet many nice people over there. Thank you Rune, for your inspiring ideas, insightful discussions, and for making me feel very welcome. Also many thanks to the other MISU people for your interest in my research and for introducing me to svamp jakt, innebandy, fika, and other typical Swedish habits.

Support heb ik niet allleen gehad van directe collega's, maar ook van mijn ouders, zus, vrienden en (schoon)familie. Ik wil jullie daarom ook graag bedanken voor alle belangstelling en steun tijdens de afgelopen jaren. Jullie zorgden voor de welkome afleiding en ontspanning in de vorm van etentjes, gesprekken, muziek, wandelingen en vele andere activiteiten. Marjolein, bovendien bedankt dat ik een beroep op jou kon doen voor het proeflezen van delen van mijn thesis.

Tot slot, lieve Harm Jan, bedankt voor jouw hulp bij het maken van mooie plaatjes en voor het proeflezen. Maar bovenal, bedankt dat je er altijd voor me bent!

Eveline 


\section{About the author}

Eveline van der Linden was born on 28 November 1986 in Papendrecht, the Netherlands. She attended secondary school at the Willem de Zwijger College in Papendrecht from which she obtained her vwo diploma in 2005. She went on to study at the TU Delft and Utrecht University, from which she graduated with a BSc degree in Physics and Astronomy in 2008. Eveline continued to study at the Institute for Marine and Atmospheric research Utrecht (IMAU) and graduated from Utrecht University with an MSc in Meteorology, Physical Oceanography, and Climate (cum laude) in 2011. As part of her MSc degree, she completed a one-year research project on modeling the interaction between ice sheets and the solid Earth during which she spent two months at the University of Urbino in Italy. In the same year Eveline started her $\mathrm{PhD}$ research on Arctic climate change and decadal variability at the Royal Netherlands Meteorological Institute (KNMI), which resulted in this thesis. During her $\mathrm{PhD}$ she spent three months at the Department of Meteorology (MISU) at Stockholm University. Starting in 2015 Eveline has worked as a science communicator at SRON Netherlands Institute for Space Research. In 2016, she returned to KNMI where she could combine her interests in climate research and science communication in a postdoc position on climate risk assessment and user engagement. This position is part of the European Union project PRIMAVERA, in which the new generation of advanced high-resolution global climate models is used. 



\section{List of journal publications}

Van der Linden, E. C., R. Bintanja, and W. Hazeleger. Arctic decadal variability in a warming world, under review for publication in Journal of Geophysical Research: Atmospheres (Chapter 5).

Van der Linden, E. C., R. Bintanja, and W. Hazeleger. Ocean heat transport towards the Arctic under high and low $\mathrm{CO}_{2}$ forcing, under review for publication in Climate Dynamics (Chapter 3).

Van der Linden, E. C., R. Bintanja, W. Hazeleger, and R. G. Graversen (2016). Low-frequency variability of surface air temperature over the Barents Sea: causes and mechanisms, Climate Dynamics, 47 (3-4), 1247-1262 (Chapter 4).

Van der Linden, E. C., R. Bintanja, W. Hazeleger, and C. A. Katsman (2014). The role of the mean state of Arctic sea ice on near-surface temperature trends, Journal of Climate, 27 (8), 2819-2841 (Chapter 2).

Bintanja, R, and E. C. van der Linden (2013). The changing seasonal climate in the Arctic, Scientific Reports, 3 (1556).

Bintanja, R, E. C. van der Linden, and W. Hazeleger (2012). Boundary layer stability and Arctic climate change: A feedback study using EC-Earth, Climate Dynamics, 39 (11), 2659-2673.

Hazeleger, W., X. Wang, C. Severijns, S. Stefanescu, R. Bintanja, A. Sterl, K. Wyser, T. Semmler, S. Yang, B. van den Hurk, T. van Noije, E. C. van der Linden, and K. van der Wiel (2012). EC-Earth V2.2: Description and validation of a new seamless earth system prediction model, Climate Dynamics, 39 (11), 2611-2629. 

Graduate school certificate 


\section{SENSE}

Netherlands Research School for the

Socio-Economic and Natural Sciences of the Environment

\section{I P L O M A}

For specialised PhD training

The Netherlands Research School for the

Socio-Economic and Natural Sciences of the Environment

(SENSE) declares that

\section{Eveline Cornelia van der Linden}

born on 28 November 1986 in Papendrecht, the Netherlands

has successfully fulfilled all requirements of the

Educational Programme of SENSE.

Wageningen, 21 December 2016

the Chairman of the SENSE board

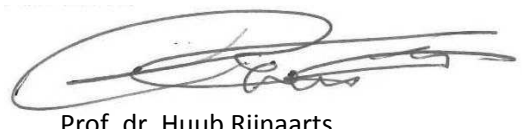

Prof. dr. Huub Rijnaarts the SENSE Director of Education

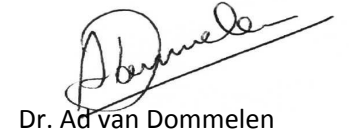

The SENSE Research School has been accredited by the Royal Netherlands Academy of Arts and Sciences (KNAW)

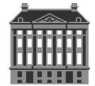

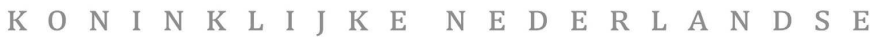

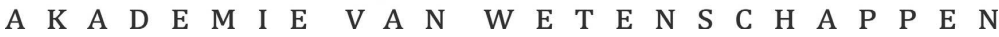




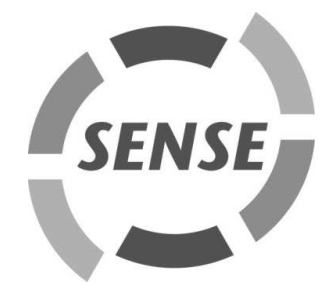

The SENSE Research School declares that Ms Eveline van der Linden has successfully fulfilled all requirements of the Educational PhD Programme of SENSE with a workload of $45.5 \mathrm{EC}$, including the following activities:

\section{SENSE PhD Courses}

- Environmental research in context (2012)

- Research in context activity: 'Designing and teaching lessons and a debating challenge for high school students on the physics and impacts of climate change' (2012)

o Dealing with uncertainties in research for climate change adaptation (2012)

\section{Other PhD and Advanced MSc Courses}

- Summer school on Arctic climate, Bolin Centre for Climate Research, Sweden (2011)

- Project and time management, Wageningen University (2011)

- Techniques for writing and presenting a scientific paper, Wageningen University (2011)

- Didactic and communication skills, Wageningen University (2012)

- Second European Earth system and climate modeling school, Barcelona Supercomputing Center, Spain (2014)

- Career coaching, Topselect Groep (2015)

External training at a foreign research institute

o Visiting scientist, Department of Meteorology (MISU), Stockholm University (2014)

\section{Management and Didactic Skills Training}

- Assisting in MSc course 'Earth System Modeling' (2012)

\section{Selection of Oral Presentations}

- Arctic climate change and its governing feedbacks. National Polar Symposium 'Exploring Polar Regions: 100 years since Amundsen', 14 December 2011, Utrecht, the Netherlands

- Effects of sea ice on Arctic amplification and climate sensitivity. European Geosciences Union General Assembly, 23-27 April 2012, Vienna, Austria

- The role of the mean state of Arctic sea ice on near-surface temperature trends. International Symposium on Sea Ice in a Changing Climate of the International Glaciological Society, 10-14 March 2014, Hobart, Australia

- Near-surface temperature variability over the Barents Sea on multidecadal timescales. Arctic workshop, Stockholm University, 4 November 2014, Stockholm, Sweden

\section{SENSE Coordinator PhD Education}


Cover design Jessica Loriaux

Printing DigiForce, Vianen

This work is part of the research programme Feedbacks in the Climate System with project number 829.09.004, which is financed by the Netherlands Organisation for Scientific Research (NWO).

Financial support from Wageningen University and the Royal Netherlands Meteorological Institute (KNMI) for printing this thesis is gratefully acknowledged. 